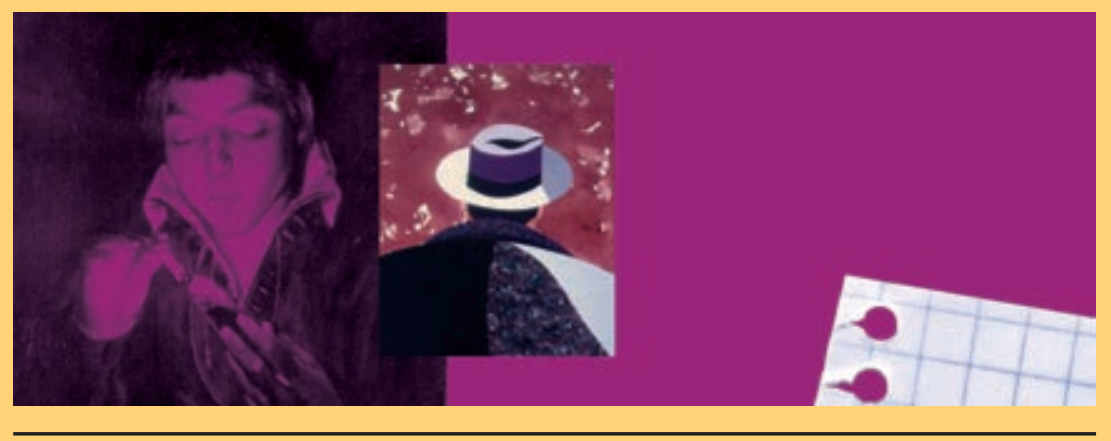

La pintura española

en los museos y colecciones de Génova y Liguria (Italia)

Mónica Vázquez Astorga

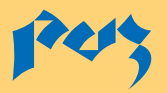

Prensas Universitarias de Zaragoza 

LA PINTURA ESPAÑOLA

EN LOS MUSEOS Y COLECCIONES

DE GENOVA Y LIGURIA (ITALIA) 



\section{LA PINTURA ESPAÑOLA EN LOS MUSEOS Y COLECCIONES DE GENNOVA Y LIGURIA (ITALIA)}

Mónica Vázquez Astorga 


\section{FICHA CATALOGRÁFICA}

\section{VÁZQUEZ ASTORGA, Mónica}

La pintura española en los museos y colecciones de Génova y Liguria (Italia) / Mónica Vázquez Astorga. —Zaragoza : Prensas Universitarias de Zaragoza, 2008 270 p. : il. col. y n. ; $22 \mathrm{~cm}$. — (Humanidades ; 70)

ISBN 978-84-92521-57-9

1. Pintura española-Colecciones-Liguria. I. Prensas Universitarias de Zaragoza. II. Título. IV. Serie: Humanidades (Prensas Universitarias de Zaragoza) ; 70 75(460):069.5(450.42)

Cualquier forma de reproducción, distribución, comunicación pública o transformación de esta obra solo puede ser realizada con la autorización de sus titulares, salvo excepción prevista por la ley. Diríjase a CEDRO (Centro Español de Derechos Reprográficos, www.cedro.org) si necesita fotocopiar o escanear algún fragmento de esta obra.

(C) Mónica Vázquez Astorga

(C) De la presente edición, Prensas Universitarias de Zaragoza $1 .^{a}$ edición, 2008

Las ilustraciones se reproducen con autorización de sus propietarios: Comune di Genova, Archivio Fotografico; Mse. Marcello Cattaneo Adorno; Ministero per i Beni e le Attività Culturali, Soprintendenza per il Patrimonio Storico, Artistico e Etnoantropologico della Liguria; Musei di Strada Nuova; Museo dell'Accademia Ligustica di Belle Arti; Museo di Palazzo Reale (todos ellos de Génova); y Museo Civico Amedeo Lia (La Spezia).

Ilustración de la cubierta: José Luis Cano

Colección Humanidades, n. ${ }^{\circ} 70$

Director de la colección: José Ángel Blesa Lalinde

Prensas Universitarias de Zaragoza. Edificio de Ciencias Geológicas, c/ Pedro Cerbuna, 12 50009 Zaragoza, España. Tel.: 976761 330. Fax: 976761063

puz@unizar.es http://puz.unizar.es

Prensas Universitarias de Zaragoza es la editorial de la Universidad de Zaragoza, que edita e imprime libros desde su fundación en 1542.

Impreso en España

Imprime: INO Reproducciones, S. A.

D.L.: Z-27-2009 
A todos los que han hecho posible este libro 



\section{PREÁMBULO}

Este trabajo es el resultado de una estancia de investigación de dos años en Génova (Italia). Durante la estancia en esta ciudad (1996-1998), tuve la oportunidad de descubrir y conocer su patrimonio cultural y artístico a través de las visitas a los distintos museos e iglesias, sorprendiéndome la cantidad de obras de pintura española que conservan. De este modo, bajo la dirección de la Dra. María Isabel Álvaro Zamora, decidí elaborar dicho estudio, que presenté como memoria de licenciatura en la Universidad de Zaragoza en diciembre de 1998. En concreto, los fondos pictóricos comprenden obras datadas entre los siglos XV y XX, y la mayoría de ellos se conservan en museos y colecciones genovesas. En un principio, se procedió al inventario y catalogación de las obras de pintura española existentes en Génova, pero con el tiempo se fueron descubriendo muchos más fondos pictóricos en el resto del territorio ligur, que fueron también objeto de estudio.

Los objetivos que se persiguieron en la realización de la memoria de licenciatura fueron los siguientes: recuperar parte del patrimonio español que, por diferentes motivos, se encuentra fuera de Espańa; realizar su catalogación e inventario; determinar las vías de llegada de estas obras de pintura espańola a Liguria; y estudiarlas monográficamente para valorar su interés en el contexto general de la pintura espańola y en el concreto de sus posibles influencias en la pintura italiana, particularmente en la pintura ligur.

Antes de pasar al estudio en cuestión, es preciso realizar una serie de anotaciones. De este modo, hay que señalar que para llevarlo a cabo se siguió la siguiente metodología de trabajo: 
1. Localización de las diferentes obras, dispersas en las colecciones y museos públicos, tanto expuestas como depositadas en sus almacenes, y en las colecciones privadas de Génova y de Liguria. ${ }^{1}$ En cuanto a los museos de Génova, cabe mencionar: Galleria di Palazzo Bianco, Galleria di Palazzo Reale, Galleria Nazionale di Palazzo Spinola, Palazzo Durazzo Pallavicini, Museo dell'Accademia Ligustica di Belle Arti, Galleria d'Arte Moderna y Museo Luxoro. Entre las colecciones privadas se encuentran la de L. Masini, Alessandro Pernecco, T. Pelizza, V. E. Rota, I. Mazzola, Vitaliano Rocchiero y algunas otras más cuyos propietarios desean mantenerse en el anonimato. En el contexto genovés, se debe incluir la pintura espańola conservada en la iglesia de San Giorgio. En cuanto al resto de Liguria, se revisaron las otras tres provincias que, junto con Génova, constituyen esta región, incluyendo así en este trabajo: Museo Civico Amedeo Lia de La Spezia, Pinacoteca Civica de Imperia, la iglesia de Santo Stefano de Chiusanico (Imperia) y el oratorio dei Rossi de Gavi Ligure, y las colecciones privadas de G. Robaldo y D. Tiscione de Albisola (Savona), de Roberto Debenedetti y Silvia Bottaro, y diferentes colecciones privadas de Savona.

Las dificultades que se encontraron en la realización del trabajo fueron grandes, tanto para obtener los correspondientes permisos de entrada a los museos, algunos cerrados en ese momento al público (Galleria d'Arte Moderna de Génova), como para localizar los archivos familiares, que se presentan de modo fragmentario en el caso de las obras del siglo XVII, y a los coleccionistas privados, en especial de la obra de Serafín Avendaño y de la pintura contemporánea, muy remisos en general a dejar estudiar dichas obras debido a las leyes sobre patrimonio vigentes en Italia (Ley de la Privacidad n. ${ }^{\circ}$ 675/96). Respecto a las obras que se encuentran fuera de Génova (La Spezia, Imperia y Savona), se visitaron cada una de estas ciudades para estudiar las telas, que, en ciertos casos, tales como el de la iglesia de Santo Stefano de Chiusanico (Imperia), solo se pueden ver determinados días de la semana.

2. Consulta de archivos de museos, galerías y colecciones privadas, que incluyen inventarios de obras y material fotográfico.

1 Dentro de este contexto, es preciso decir que Liguria es una región de Italia que linda con el golfo de Génova y comprende las provincias de Imperia, Savona, Génova y La Spezia. 
3. Realización de entrevistas a los directores de los museos, a los coleccionistas, que aparecen citados en el primer punto, y a los profesores del Departamento de Historia del Arte de la Universidad de Génova, en concreto a los doctores Sborgi y Magnani, que proporcionaron numerosos datos, contribuyendo notablemente al conocimiento de la historia de las pinturas (adquisición, momento de llegada, etc.).

4. Búsqueda, recopilación, consulta y lectura sistemática de la bibliografía relativa a cada una de las obras localizadas. Para acometer esta labor se consultaron fondos de bibliotecas italianas y espańolas, en la mayoría de las ocasiones pertenecientes a los museos antes citados.

5. Elaboración del inventario completo de la pintura española conservada en Liguria, aportando un total de setenta obras ordenadas según un criterio cronológico. La mayoría son óleos sobre lienzo; se registran también ocho óleos sobre tabla y uno sobre cartón, un pastel sobre cartulina, una acuarela sobre cartón y tres pinturas al temple. Se recogieron como datos básicos de la ficha catalográfica los siguientes: autor-atribución, título de la obra, cronología, material y técnica, dimensiones, elementos autógrafos, localización y procedencia, descripción, historia de la pieza-estado de conservación, noticias documentales inéditas, participación en exposiciones, catálogos, bibliografía específica y realización o adquisición de la correspondiente reproducción fotográfica.

A partir de todo esto, se redactó el correspondiente estudio, que se estructura de la siguiente manera:

1. Introducción, que incluye el estado de la cuestión, en el que se reúnen las aportaciones bibliográficas existentes sobre este tema, valorando su aportación.

2. Estudio global de la pintura española, que consta de dos partes: «I.La pintura española en Génova» y «II. La pintura española en el resto de Liguria». Cada uno de estos apartados está integrado por tres capítulos.

En el capítulo 1 de la primera parte se estudian las obras de pintura española del siglo XVII, que son las más antiguas conservadas en galerías y museos; el capítulo 2 trata de la cultura ilustrada, concretada en la personalidad de Gerolamo Grimaldi, y del estudio de las obras de pintura del siglo XVIII; el capítulo 3 se centra en la pintura del siglo XIX. La mayoría de las obras catalogadas en este capítulo corresponden a la producción 
artística del pintor vigués Serafín Avendaño (1837-1916), tratándose del único caso documentado de la estancia de un pintor español, por un período prolongado (1866-1896), en tierras genovesas.

En la segunda parte se ofrece una visión más global de las obras de pintura española existentes en el resto de Liguria (Imperia, Savona y La Spezia), y se atiende igualmente a una ordenación cronológica. El tema comprende tres capítulos: el capítulo 1 estudia las obras de pintura espańola correspondientes a los siglos XV-XVIII; el capítulo 2 se ocupa principalmente de la producción artística de Serafín Avendaño, siglo XIX; el capítulo 3 se dedica a las obras pertenecientes al siglo XX.

Además, se analizan las vías de llegada de la pintura española conservada en Liguria, que son diferentes según sea esta pintura del siglo XVII o de los siglos siguientes, tal como se verá en el apartado dedicado a las conclusiones.

3. Conclusión. Se recogen las conclusiones más importantes del trabajo relativas a las vías de llegada de esta pintura, a su importancia global dentro de la pintura espańola y a su influencia en el ambiente artístico ligur.

4. Catálogo sistemático de todos los fondos pictóricos localizados en Liguria. Como el estudio global, consta de dos partes: «I. La pintura española en Génova» y "II. La pintura española en el resto de Liguria». Se trata de un extenso conjunto formado por setenta obras. La mayoría de estas se encuentran en Génova (otras dispersas por el resto del territorio ligur), fueron realizadas en distintos soportes y técnicas, y, en general, son desconocidas. Se incluyen las obras catalogadas como de escuela española, pero también aquellas que han sido atribuidas en algún momento a maestros españoles, incluso cuando las investigaciones recientes les atribuyen otra autoría. Cada obra catalogada va acompañada de su correspondiente ficha técnica, que atiende a un orden cronológico, desde el siglo XV al XX: en el caso de Génova se inicia en el siglo XVII, momento al que pertenecen las pinturas más antiguas, y finaliza en el XIX, mientras que en el resto de Liguria arranca del siglo XV y concluye en el XX.

5. Bibliografía, presentada por orden alfabético.

Antes de concluir este preámbulo quisiera expresar mi agradecimiento a todas las personas e instituciones que me ayudaron en la realización de este trabajo, y de un modo muy especial: 
A los profesores del Departamento de Historia del Arte de la Universidad de Zaragoza, en particular a la Dra. María Isabel Álvaro Zamora, directora de este estudio de investigación, que es la primera persona a quien debo mi gratitud en la consecución del mismo.

A la Dra. Maria Flora Giubilei, quien muy amablemente me permitió visitar la Galleria d'Arte Moderna y me puso en contacto con otros historiadores del arte italianos.

Al Dr. Clario di Fabio, que me mostró la Galleria di Palazzo Bianco de Génova, facilitándome la información necesaria.

Al Dr. Gianfranco Bruno, quien me dio a conocer la existencia de la obra de Serafín Avendaño conservada en las diferentes colecciones privadas de Liguria y me puso en contacto con sus propietarios.

Al profesor Vitaliano Rocchiero, coleccionista de arte, autor de la mayoría de las publicaciones sobre la pintura ligur del último tercio del siglo XIX y gran estudioso de Serafín Avendaño. Rocchiero me proporcionó información sobre este pintor y me dio a conocer su colección de pintura, que incluye una obra de este artista. A él le debo también algunas de las fotografías sobre obras de Avendaño que aquí se presentan.

Al Dr. Franco Boggero y al Dr. Alessandro Giacobbe, gracias a los cuales pude visitar la iglesia de Santo Stefano de Chiusanico (Imperia) y entrar en contacto con otros historiadores del arte italianos.

A Roberto Debenedetti y Silvia Bottaro, coleccionistas de arte, quienes muy amablemente me enseñaron su colección de pintura contemporánea, en la que se incluyen las obras de García Segura, Tàpies, Eduardo Arroyo y José Ortega. 



\section{INTRODUCCIÓN. ESTADO DE LA CUESTIÓN}

Hasta la fecha no existía ningún estudio completo y conjunto en el que se examinase la presencia de pintura española en Génova y en el resto del territorio ligur, tal como se plantea en este trabajo, como tampoco existía ninguno en el que se aluda directamente a cuáles fueron las vías de llegada. Sí que hay, por el contrario, trabajos que, de manera general, tratan de este patrimonio al referirse a la presencia de la pintura española fuera de España, otros que se ocupan de ciertas obras o artistas, y algunos que se centran monográficamente en un pintor. Estas investigaciones fueron realizadas, esencialmente, por historiadores del arte italianos, siendo menos los estudios españoles publicados sobre el tema.

En relación con lo expuesto, el estado de la cuestión se divide en tres bloques sucesivos: en primer lugar, se comentan las obras de carácter general; en segundo lugar, las referencias más concretas aparecidas en catálogos o referidas a determinadas obras; $y$, en tercer lugar, los estudios monográficos sobre alguno de los pintores españoles presentes en los museos y colecciones ligures.

1. Dentro del apartado de estudios generales sobre el tema en cuestión destacan tres publicaciones:

J. A. GaYa NuÑo, La pintura española fuera de España (1958). Gaya Nuño ha sido el historiador del arte español que más se ha aproximado al tema tratado, elaborando un estado de la cuestión sobre el patrimonio espańol existente fuera de Espańa, analizando las causas de la salida de la pintura española fuera de sus fronteras y realizando también un inventa- 
rio de esta pintura dispersa en los diferentes museos y colecciones mundiales, que incluye en su libro como apéndice final. En cuanto a Génova, se citan tan solo algunas de las obras conservadas de pintura española en la zona, aunque se debe señalar que este libro ha sido fundamental para la realización del presente trabajo.

O. Grosso, «L'Arte spagnuola a Genova», en la revista Vell i Nou (1920). Fue director de la Oficina de Bellas Artes de las Galerías y de los Museos Municipales de Génova. Este autor señala la riqueza de las antiguas colecciones de arte genovesas en obras de artistas españoles, y se interesa por conocer cuáles eran aquellas obras para poder deducir su influencia sobre los artistas locales, para lo cual estudia exclusivamente la pintura española del siglo XVII en la capital ligur. De este modo, a través del artículo se puede conocer qué sucedió con algunas de las obras que fueron compradas por los duques de Galliera en las subastas parisinas. En esta línea, cabe mencionar que Orlando Grosso informa que la pintura dedicada a san Francisco de Asís (atribuida a Murillo) fue retirada de la colección del Palazzo Bianco en torno al año 1900 y vendida en el extranjero. Es preciso decir que, aunque trata únicamente la pintura espańola del sigloXVII, es una obra esencial para el tema en cuestión.

P. Boccardo, J. L. Colomer y C. Di Fabio (dirs.), España y Génova. Obras, artistas y coleccionistas (2004). Reciente publicación en la que se analizan las relaciones culturales y artísticas entre Génova y Espańa entre los siglos XII y XX, ejemplificadas en la presencia de pintores genoveses en España o de españoles en Génova, como es el caso de Serafín Avendaño.

2. En este apartado se incluyen los estudios y referencias más concretas relativas a determinadas obras. Se divide en diferentes subapartados, en función de la orientación de las publicaciones.

2.1. En este punto se recogen las descripciones y guías artísticas de la ciudad de Génova, escritas por historiadores del arte genoveses entre los siglos XVIII y XIX, que citan las obras de pintura que podían verse en aquel entonces en la ciudad. En este caso, es necesario remitir a las publicaciones de los siguientes historiadores:

C. G. RATTI, Istruzione di quanto può vedersi di più bello in Genova in Pittura, Scultura ed Architettura (1780, 2. ${ }^{\text {a }}$ edición). Este autor menciona 
todo lo que en aquel momento existía de más «bello» en arquitectura, escultura y pintura en Génova. La obra es una fuente fundamental, pues en ella aparecen citados los palacios y museos genoveses con sus obras de arte, y, a través de su consulta, se puede conocer la gran cantidad de obras de pintura del siglo XVII que fueron atribuidas por Ratti a maestros españoles. A este respecto, cabe señalar que muchas de estas atribuciones han sido modificadas en las últimas décadas.

F. Poleggi, Descrizione della città di Genova da un anonimo del 1818, ricerca iconografica e note, obra anónima de 1818 publicada en 1969. En ella se describe la ciudad de Génova, haciendo referencia a todas las obras de pintura existentes en aquella época en los palacios e iglesias genoveses. Su aportación es relevante para comprobar, en relación con la obra antes citada de Ratti, si había aparecido o desaparecido alguna de las pinturas o si alguno de los cuadros de pintura española del Siglo de Oro había recibido una atribución diferente a la dada inicialmente por dicho investigador italiano.

Otra fuente tradicional de gran interés es F. Alizeri, quien escribe la Guida artistica per la città di Genova (1846-1847) y la Guida illustrativa del cittadino e del forastiero per la città di Genova e sue adiacenze (1875). En estas dos guías se encuentran las obras de arte conservadas en el siglo XIX en los palacios, galerías y colecciones genoveses, entre las que figuran obras de pintura española. El historiador realiza sus aportaciones personales, de forma que, como se verá después, algunas de las obras atribuidas por Ratti a maestros españoles con Alizeri reciben una diferente clasificación. De hecho, cabe destacar que, para estudiar la pintura española del Siglo de Oro existente en Génova, deben revisarse conjuntamente las obras de estos dos historiadores. Según la opinión de los estudiosos del arte contemporáneos es la obra de Ratti la que, desde el punto de vista histórico, merece más prestigio.

2.2. En este punto se incluyen los catálogos que fueron redactados con motivo de la venta de las colecciones de arte pertenecientes al mariscal Nicolas Soult y al marqués de las Marismas del Guadalquivir, denominado en la documentación "Mr. Aguado», que comprendían obras de pintura española del siglo XVII y que fueron adquiridas en París por nobles genoveses deseosos de revalorizar sus moradas de acuerdo con su posición social. Se recogen también los catálogos correspondientes a colecciones 
familiares, que permiten conocer las obras que integraban estas colecciones desde sus orígenes. Dichos catálogos son los siguientes:

En 1843 se redacta el catálogo de la colección de pintura del marqués de las Marismas, "Mr. Aguado», con motivo de su venta en París. En esta subasta fue adquirido por el duque de Galliera el cuadro San Francisco recibe del ángel los siete privilegios de la Regla, considerado entonces obra de Murillo, que actualmente se encuentra en la Galleria di Palazzo Bianco de Génova.

En 1852 se publica el catálogo de la venta de las obras de pintura de la gran colección del mariscal Soult, constituida por más de tres mil obras. El catálogo revela la procedencia de las obras de pintura española del siglo XVII que ahora se hallan en la Galleria di Palazzo Bianco de Génova, que fueron sacadas de España a principios del siglo XIX por dicho mariscal y posteriormente adquiridas en la capital francesa por los duques de Galliera.

En 1984 D. PuncuH, tras la organización de los archivos de la familia Durazzo, elabora una reseña que permite saber cuándo y por quién fueron compradas las obras de pintura española del siglo XVII y cómo llegaron hasta donde actualmente se localizan.

2.3. Existen numerosas publicaciones sobre museos y colecciones genoveses en las que se procede a una descripción de las obras existentes. Estos trabajos se consultaron para aquellas obras de pintura española conservadas en alguno de estos museos. Los estudios son los que siguen:

2.3.1. Estudios sobre la Galleria di Palazzo Bianco de Génova:

O. Grosso, Le Gallerie d'Arte del Comune di Genova (1932). Este autor se ocupa de las obras existentes en las galerías de arte de Génova, dedicando una parte del libro al estudio de las colecciones de los duques de Galliera conservadas en sus residencias, Palazzo Rosso y Palazzo Bianco. Grosso procede a la descripción de estos palacios, sala por sala, incluyendo todas las obras expuestas en aquel entonces, entre las cuales se encuentran las correspondientes a la pintura española del siglo XVII. En la misma línea, cabe citar el capítulo de L. TAGLIAFERRO sobre «I musei della Duchessa», incluido en el libro colectivo I Duchi di Galliera (1991). La consulta de estas obras es necesaria porque permite conocer a qué pintor eran atribuidas las telas a principios del siglo XX. 
L. Tagliaferro y C. Di Fabio realizaron en 1991 una guía de la Galleria di Palazzo Bianco, en la que se describen las obras correspondientes a los maestros españoles. Un año después, este trabajo se complementó con la guía de Di FABIO de la misma galería, cuyo estudio es importante para el análisis de la pintura española del siglo XVII conservada en el palacio (Ribera, Zurbarán, Murillo y Alonso Cano). Di Fabio ha llevado también a cabo investigaciones centradas en el Viático de san Buenaventura, atribuido a Zurbarán, y en el San Juan de la Cruz, perteneciente al ámbito del pintor Antonio Puga.

E. Papone, Il passato e il presente. I Musei del Comune di Genova (1991). Esta obra ofrece un recorrido histórico por todos los museos genoveses, analizando las obras localizadas en ellos y destacando su aportación con respecto a las obras de Zurbarán y Murillo conservadas en la Galleria di Palazzo Bianco de Génova.

2.3.2. Estudios sobre la Galleria di Palazzo Reale de Génova:

P. TORRITI publica un estudio sobre Il Palazzo Reale di Genova e la sua quadreria en 1963, proporcionando nuevos datos sobre las obras consideradas españolas que se conservan en este palacio. De hecho, es Torriti quien, siguiendo la opinión de Orlando Grosso, considera La dama con el perrito y El retrato de Felipe IV de escuela española. Los estudios sobre estas obras son confusos, debido a que no se conservan los archivos del palacio. Recientemente, la historiadora del arte Leticia Lodi ha situado ambas obras fuera del ámbito español.

2.3.3. Estudios sobre la Galleria Nazionale di Palazzo Spinola de Génova:

El estudio de P. Rotondi La Galleria Nazionale di Palazzo Spinola a Genova (1967) es la aportación más reciente realizada sobre este palacio y su pinacoteca, en la que figuran obras atribuidas a maestros españoles. De hecho, P. Rotondi, frente a las fuentes tradicionales (Ratti, Alizeri), relaciona el Martirio de san Lorenzo y el San Jerónimo oyendo la trompeta, conservados en la galería del palacio, con el ámbito artístico de Ribera. En cambio, con respecto a la tercera obra, La Sagrada Familia, que algunos autores atribuyen a Francisco de Zurbarán, Torriti considera que se trata de una obra de escuela. 
2.3.4. Estudios sobre el Palazzo Durazzo Pallavicini de Génova:

P. TORriti, en su estudio sobre La Galleria del Palazzo Durazzo Pallavicini a Genova (1967), además de realizar un análisis de las obras de pintura conservadas en esta galería, elabora una interesante crítica sobre los tres filósofos atribuidos a Ribera por Mayer (1923a), y pone en duda su atribución a este maestro. Esta misma opinión será defendida por N. SPINOSA (1995a), historiador del arte que también se ha ocupado del tema. Ambos autores mantienen la autoría riberesca en el caso del Santiago apóstol. Los dos estudios constituyen las últimas aportaciones sobre este punto y renuevan la visión ofrecida por las fuentes tradicionales.

2.3.5. Estudios sobre la iglesia de San Giorgio de Génova:

En este contexto destaca la obra de L. De SimOni Le chiese di Genova (1948), quien elabora una descripción de todas las iglesias de Génova. Se trata del primer estudio sobre el tema, y su consulta es importante para intentar definir la personalidad artística que realizó La Piedad de la iglesia de San Giorgio. De Simoni atribuye la obra a Claudio Coello, y así aparece también en el libro de L. BAlestreri y W. Piastra, Storia della chiesa di San Giorgio in Genova (1973). La atribución reciente de esta obra a Alonso Sánchez Coello se debe a Franco Boggero, quien publicó una guía sobre la iglesia en 1979, fecha desde la cual no se ha llevado a cabo ningún estudio sobre el tema.

2.3.6. Estudios sobre el Museo dell'Accademia Ligustica di Belle Arti de Génova:

Para el análisis de la obra del pintor madrileño Francisco Javier Ramos conservada en la Accademia es fundamental la consulta de la obra de P. TORRITI La quadreria dell'Accademia Ligustica di Belle Arti (1963). Es preciso señalar que esta publicación ha sido superada con la edición del catálogo de E. BACCHESCHI, sobre el Museo dell'Accademia Ligustica (1983, 1988), quien ha realizado novedosas aportaciones sobre la obra de F. Javier Ramos y sobre la otra obra española conservada en el museo de la Accademia correspondiente a Serafín Avendaño, que será analizada a continuación.

2.3.7. Estudios sobre la Galleria d'Arte Moderna de Génova:

Con el fin de estudiar y analizar las tres obras de Serafín Avendaño conservadas en esta galería se consultaron dos publicaciones de M. ${ }^{a}$ F. 
GiUbilei, La Pittura di paesaggio in Liguria tra Otto e Novecento. Collezionismo pubblico e privato nelle raccolte della Galleria d'Arte Moderna di Genova (1990) y "Serafín Avendaño (1837-1916). Un español en Génova», en España y Génova. Obras, artistas y coleccionistas (2004, pp. 259266), que constituyen las últimas aportaciones sobre dichas obras.

2.3.8. Estudios sobre las colecciones Frugone de Génova:

M. ${ }^{a}$ F. GiUbiLeI, en «Ferruccio Stefani, un collezionista-mercante di buon gusto e di buona volontà al servizio dei fratelli Frugone», Bollettino dei Musei Civici Genovesi (1994), recoge las colecciones de arte de los hermanos Frugone (1993) y cita las obras de Sorolla que actualmente se encuentran en el Museo Luxoro, procedentes de dicha colección.

2.3.9. Estudios sobre el Museo Civico Amedeo Lia de La Spezia (Liguria):

Los historiadores del arte F. ZERI y A. G. De MARCHI son los autores del catálogo del Museo Lia, que fue fundado por Amedeo Lia y comprende las obras donadas por este. En el museo existe una tabla y dos lienzos atribuidos por ambos historiadores a un anónimo español.

2.3.10. Estudios sobre el oratorio dei Rossi de Gavi Ligure:

G. Meriana, Le valli del Lemme dello Stura e dell'Olba (1975). Este autor realiza un estudio sobre los valles del Lemme, del Stura y del Olba, dando a conocer la existencia, en un oratorio localizado en estos valles, de un lienzo atribuido a un anónimo español. Los estudios sobre la obra en cuestión no han tenido continuación, por lo que constituye el único documento al respecto.

2.3.11. Estudios sobre la iglesia de Santo Stefano de Chiusanico (Liguria):

En el Congreso celebrado en Chiusanico en agosto de 1991, el historiador del arte A. GiACOBBE, con «La parrocchiale di Santo Stefano, centro aggregante del borgo, e la sua quadreria spagnola», realiza una intervención sobre los cuadros existentes en la parroquia de Chiusanico, hasta ese momento desconocidos, considerándolos de procedencia española.

En el mismo congreso interviene también el historiador del arte L. Calzamiglia, que se centra en el estudio de dos telas dedicadas a la 
Virgen de Guadalupe, y realiza un profundo análisis de ambas, considerándolas copias devocionales de la imagen mexicana de la Virgen de Guadalupe y defendiendo su procedencia española. Para el estudio de la imagen mexicana de la Virgen de Guadalupe es recomendable la consulta, entre otras, de las siguientes obras: C. PerfetTI, Guadalupe. La tilma de la Morenita (1987) y S. SeBASTIÁN, El barroco iberoamericano: mensaje iconográfico (1990).

A. GiACOBBE retoma el estudio de la parroquia de Chiusanico elaborando una ficha de catalogación del cuadro Alegoría de la muerte, que se encuentra recogida en F. BOGGERO y B. CILIENTO (eds.), Restauri in provincia di Imperia, 1986-1993 (1995), en la que el historiador defiende su posible relación con la figura de Juan de Ries (véase, entre otras publicaciones, E. VAlDIVIESO, Historia de la pintura sevillana, 1986).

2.4. En este punto se incluyen los estudios sobre la pintura ligur de finales del siglo XIX e inicios del XX que recogen el ambiente artístico del que participó Serafín Avendaño durante los treinta años que residió en Quarto dei Mille (Génova). Para el tema en cuestión hay que remitirse a las siguientes obras:

M. LABÓ, en el catálogo que realiza para la muestra sobre la Pittura Ligure dell'Ottocento, celebrada en Génova en 1926, define por primera vez la personalidad artística de Avendaño y valora su contribución a la pintura de paisaje ligur.

O. Grosso, en su catálogo sobre la exposición celebrada en Génova en 1938 sobre Pittori ligure dell'Ottocento, recoge las obras de Serafín Avendańo que se expusieron con motivo de la muestra, y cita el nombre de sus compradores. La consulta de los catálogos de exposiciones en las que participaron obras de Avendaño es esencial para conocer cómo algunas obras de este pintor pasaron de unos propietarios a otros.

V. ROCCHIERO, profesor y gran estudioso del tema, dedica varias publicaciones a la pintura ligur del período, en las cuales aparece citado Avendaño. En este contexto, cabe destacar: Scuola grigia genovese ed altri valori ottocenteschi (1963), donde se definen los principios de la Escuela Gris de paisaje genovesa, de la que Serafín Avendaño fue uno de sus fundadores, incluyendo como apéndice final un inventario de obras de pintores pertenecientes a esta escuela, que recoge tres pertenecientes a Avendaño; y Scuole, gruppi, pittori 
dell'Ottocento ligure (1981), donde se alude a otras escuelas de paisaje coetáneas a la genovesa como, por ejemplo, la de Rivara, de la que también formó parte Serafín Avendaño, y que se caracterizó igualmente por la superación del Romanticismo para abrazar la poética naturalista.

F. SBORGI realiza un estudio sobre «La pittura dell'Ottocento in Liguria», en La Pittura in Italia. L'Ottocento (1990), que, aunque no trata propiamente de obras españolas, es básico para comprender el contexto artístico en el que participó Serafín Avendaño.

G. BRUNO es uno de los grandes estudiosos de la pintura ligur de los siglos XIX y XX, tal como se constata en su obras: Immagine e paesaggio. Liguria 1850-1970 (1979) y La pittura in Liguria dal 1850 al Divisionismo (1981), donde ofrece la evolución pictórica que se produce en la concepción del paisaje ligur, en la que participará de modo activo el pintor vigués Avendaño; L'alba del vero: Pittura del secondo '800 in Liguria (1993), donde estudia el panorama pictórico ligur y adjunta un catálogo de las obras más representativas de los pintores de este período, entre las que destacan las obras de Serafín Avendaño conservadas en colecciones privadas. Se debe señalar que la consulta de este catálogo reveló la existencia de pinturas de Avendaño en algunas colecciones privadas.

En este contexto, hay que citar el estudio que G. BRUNO realizó, junto con L. PerissinotTi, sobre La Scuola Grigia a Carcare (1989), que se centra en la nueva pintura de paisaje y dedica un capítulo a la Escuela Gris y a sus manifestaciones artísticas.

3. Otros trabajos tienen un carácter monográfico y se dedican a estudiar un pintor y su producción.

3.1. Existen diversos estudios monográficos sobre el Greco, Ribera, Zurbarán, Murillo, Alonso Cano, Claudio Coello y Sorolla; muchos de ellos no se tratan en este apartado porque no atañen directamente al tema en cuestión. Los estudios relevantes son los que siguen:

El historiador alemán A. L. MAYER dedica un estudio crítico a Ribera, Jusepe de Ribera, "Lo Spagnoletto" (1923a), y otro a Murillo, titulado Murillo (1923b); ambos son fundamentales a la hora de atribuir ciertas obras a un maestro u otro, como sucede en el caso del cuadro San Francisco recibe del ángel los siete privilegios de la Regla de la Galleria di Palazzo Bianco de Génova. 
D. ANGUlo IÑígueZ realiza un catálogo crítico de la obra de Murillo, Murillo. Catálogo crítico (1981), comprendiendo aquellas obras que se consideran del maestro o atribuidas a él. Este catálogo es de gran utilidad cuando el historiador del arte se enfrenta a obras cuya atribución es dudosa, como sucede en el caso de San Francisco recibe del ángel los siete privilegios de la Regla de la Galleria di Palazzo Bianco de Génova.

H. E. WeTHEY, en su estudio monográfico sobre Alonso Cano, Alonso Cano. Pintor, escultor y arquitecto (1983), incluye como apéndice final un catálogo de la producción de este pintor, que recoge el cuadro San Juan Evangelista da la comunión a la Virgen de la Galleria di Palazzo Bianco de Génova.

3.2. En este apartado se tratan los estudios sobre Serafín Avendaño, pintor vigués que residió durante treinta años (1866-1896) en Quarto dei Mille (Génova) y cuya pintura, a su regreso a España, queda dispersa tanto en Liguria como en otra ciudades italianas. Entre estos estudios destacan:

V. RocCHIERo dedica en 1960 un artículo a Serafín Avendaño en la revista Liguria, titulado «Ottocento pittorico genovese. Serafino De Avendaño», en el que señala las características de esta personalidad artística y destaca su papel de renovador dentro del ambiente pictórico ligur.

Junto a los historiadores de arte genoveses, cabe señalar el catálogo que R. E. CAAMAÑO, historiadora del arte y profesora universitaria española, publica sobre Serafin Avendaño, 1837-1916, en Vigo (1991), en colaboración con otros historiadores del arte españoles, como Rafael Úbeda, e italianos, como Vitaliano Rocchiero. El catálogo en cuestión incluye un estudio preliminar de la figura de Avendańo y como apéndice se adjunta un catálogo de su producción pictórica, tanto española como italiana. Debe indicarse que las últimas aportaciones sobre este pintor se deben a Vitaliano Rocchiero, quien ha sacado a la luz nuevas obras de este autor.

En este contexto, debe mencionarse el trabajo de J. M. López VÁZQUEZ, que, en su capítulo dedicado a Serafín Avendaño en la Enciclopedia de Galicia (1995), se ocupa de la evolución pictórica del artista. Se trata de un artículo interesante porque los estudios dedicados a este pintor, tanto italianos como españoles, han prescindido de una visión conjunta de su pintura, centrándose sobre todo en aspectos concretos de su producción artística. 


\section{PARTE I \\ LA PINTURA ESPAÑOLA EN GÉNOVA}





\section{1 \\ LA PINTURA ESPAÑOLA DEL SIGLO XVII EN GÉNOVA}

\subsection{Valoración de la pintura española del Siglo de Oro y su dispersión}

Antes de pasar al estudio de las obras de pintura española conservadas en los diversos museos y colecciones genoveses, hay que aludir a las causas que motivaron la salida de pintura española del Siglo de Oro fuera de España, hecho relacionado con la valoración que esta pintura alcanza, principalmente, durante los siglos XVIII y XIX. Es preciso señalar que en la dispersión de la pintura española hacia Europa se encuentra el origen de las colecciones genovesas, tal como se verá a continuación.

Así, en las tres últimas décadas del siglo XVII se difunde la idea de que la era de los grandes pintores llegaba a su término. Entre 1680 y 1780 se manifestaron los primeros síntomas de divergencia entre la valoración crítica y la opinión del público, que desempeña, como bien es sabido, un papel decisivo en la evolución de la cultura europea. A esa misma época pertenece también el fenómeno opuesto: la «re-valorización». Durante el XVIII pintores «nuevos», correspondientes al siglo precedente, como Teniers, Cuyp, Hobemma o Murillo, entraron a formar parte de los «cánones» de valoración del llamado «hombre de gusto». De hecho, así lo pone de manifiesto el viaje que el coleccionista francés Le Brun realiza entre 1807 y 1808 a Italia y España, quedando impresionado por la pintura española: «Mi admiración ha suscitado en mí el deseo de sacar del olvido a muchos maestros desconocidos a quien viva 
al otro lado de España». ${ }^{2}$ A este respecto, cabe citar la opinión de Juan Antonio Gaya Nuño, quien considera que en la fama de Zurbarán y Murillo comienza la gran expansión de la pintura española. ${ }^{3}$

Antes del «saqueo» sistemático de Sevilla, Granada y de otras ciudades españolas por los generales napoleónicos, Le Brun ya había difundido por Europa el interés por la pintura española, llevándose a París una serie de cuadros atribuidos a Velázquez, Claudio Coello, Alonso Cano y Murillo. Le Brun ha sido uno de los primeros amantes del arte que intentó el "descubrimiento» de pintores olvidados, desempeñando un papel decisivo en la historia de la valoración crítica de la pintura.

Como puede imaginarse, la lista de aquellos que se «beneficiaron» de la campaña napoleónica es amplia. Juan Antonio Gaya Nuño trata esta cuestión en su obra, afirmando que la «verdadera liquidación» del patrimonio artístico español comienza en 1808. En relación con esto, será suficiente mencionar al mariscal francés Soult, calificado por este historiador como «ilustre malhechor», quien ordenaba a las iglesias y comunidades religiosas que le regalaran sus mejores cuadros. Así, cuando cruza Madrid, el 2 de marzo de 1813, Soult iba al frente de una caravana de furgones cargados de cuadros, andaluces en su mayoría. ${ }^{4}$ De este modo, Soult formó su estupenda colección de pintura española. La mayor parte de las obras adquiridas por el mariscal se vendieron por grandes sumas a coleccionistas ingleses. Es sabido que en Gran Bretaña el entusiasmo por la pintura española fue notable, tal como pone de manifiesto la siguiente expresión de Richard Ford (1832): «Aquí no hacemos otra cosa que vender y comprar, estamos locos por estos cuadros». 5

Dentro de este contexto, hay que decir que Gaya Nuño considera que la «fiscalización» del patrimonio artístico español, durante la invasión francesa y los ańos siguientes a ella, corrió a cargo de los siguientes personajes y hechos: Frédéric Quilliet, agregado como experto artístico del ejército ocupante de Andalucía, que se dedicó a reunir parte de la pintura andaluza que saldría más tarde de nuestras fronteras; el general Welling-

2 Citado por Haskell (1982), p. 53.

3 Gaya Nuño (1958), p. 14.

4 Ib., p. 17.

5 Tagliaferro (1991b), p. 884. 
ton, que recibió varios cuadros como obsequio, por ejemplo, de la Intendencia de Segovia, que se llevó después consigo a Inglaterra; Fernando VII, que, respondiendo a su política aduladora, regaló obras pictóricas a embajadores extranjeros; la desamortización de los bienes eclesiásticos, decretada por el Gabinete Mendizábal en 1836, que dio lugar a la dispersión de muchas obras; y el monarca francés Luis Felipe de Orleans, quien envió a nuestro país a dos sagaces técnicos, el barón Taylor y el pintor Dauzats, que se dedicaron a comprar «al por mayor», mandando todo lo adquirido a Francia. ${ }^{6}$

Por tanto, París fue durante un tiempo una ciudad privilegiada por la coexistencia de tres grandes colecciones de pintura, las tres nacidas del «despojo» español: la colección del mariscal Soult, la colección del monarca Luis Felipe y la colección del marqués de las Marismas, conocido como «Mr. Aguado» en la documentación escrita.

Alejandro María Aguado, hijo de los condes de Montelirios, había nacido en Sevilla en 1785. Acompañó a Francia a las tropas napoleónicas después de la derrota, permaneciendo en tierras francesas. No se conoce muy bien cómo formó su colección de pintura, pero, probablemente, se llevó cuadros de España o los adquirió después. De hecho, se sabe que escribía desde París a su familia sevillana en demanda de nuevas obras. Tras su muerte en Vigo, en 1842, se puso en venta su colección de pintura. Hay que destacar que el catálogo de la venta reseñaba trescientas noventa y cinco pinturas, doscientas treinta de ellas españolas. La muerte del marqués y la venta de la colección marcaron un hito importante en la dispersión de la pintura espańola.

Como bien señala la historiografía artística, muchos miembros de la aristocracia española fueron los responsables de la "pobreza» de España y de la dispersión de sus tesoros de arte. Así, del mismo modo que el siglo XVIII presenció la «evasión» de los cuadros de Murillo, el siglo XIX vio la salida de los cuadros de Zurbarán, Ribera y de otros maestros españoles del XVII.

En relación con esto, hay que indicar que la mayoría de las obras de pintura española del siglo XVII catalogadas en el presente estudio proceden de la colección Soult y de la colección Aguado, y las vías de llegada a Génova serán analizadas en el próximo apartado.

6 Gaya Nuño (1958), pp. 18-22. 


\subsection{Estudio de las obras de pintura española del siglo XVII en Génova}

El paso sucesivo a estas cuestiones de tipo preliminar es hacer referencia al ambiente genovés del siglo XIX, desde un punto de vista artístico-cultural, concretando quiénes fueron los protagonistas de la adquisición de las obras de pintura espańola. El procedimiento seguido es el de ir analizando museo por museo, con el fin de concretar el modo de llegada de las obras en cada caso.

\section{Galleria di Palazzo Bianco}

Una de las grandes familias genovesas del siglo XVII fue la Brignole Sale. En los años sesenta del siglo XVII esta familia llevó a cabo la construcción del Palazzo Rosso, en la Strada Nuova (actual via Garibaldi), con el fin de acoger a las dos primogenituras Brignole. El prestigio de los Brignole se manifestó, entre otros hechos, con la adquisición de obras de pintura, la mayoría de ellas procedentes de los Países Bajos (proporcionadas por dos miembros de la familia Brignole, Francesco y Teramo) y de Florencia. Estos cuadros se colocaron en las salas del Palazzo Rosso que los Brignole Sale habían hecho decorar con los frescos de los mejores pintores genoveses.

Un momento importante para la quadreria ('colección de cuadros') de los Brignole se produjo a mediados del siglo XVIII, cuando en menos de veinte años se redactaron tres catálogos de la colección Brignole. El más interesante para el tema en cuestión es el catálogo elaborado en 1756, en vida del duque Ridolfo II (1708-1774), porque cuando se describe la estancia cuarta de la sala grande del Palazzo Rosso se cita un Filósofo - media figura de un viejo, con un papel en la mano, de 2,6×3,4 palmos- como de José de Ribera, llamado lo Spagnoletto. Se desconoce su procedencia, aunque es posible que Ridolfo II lo adquiriera por herencia familiar. Cabe decir que en el inventario anterior que se hace del Palazzo Rosso, en 1748, no aparece citado. Hasta hace poco tiempo, este cuadro figuraba en la Galleria di Palazzo Rosso como de José de Ribera (Játiva, 1591-Nápoles, 1652), aunque actualmente se considera obra del pintor italiano Francesco Fracanzano.

Una situación parecida a esta se da con el Filósofo conservado en el depósito del Museo dell'Accademia Ligustica de Génova, que Davide Bene- 
detto delle Piane donó a la Accademia el 18 de enero de 1897 (AAL, parte $626 / 99.5$ ). En la parte posterior del cuadro hay una etiqueta que lo indica como "copia del Ribera. Época contemporánea». ${ }^{7}$ Como es sabido, son varios los cuadros pintados por Ribera con el tema del filósofo mendigo, que constituye uno de los aspectos más originales del arte de este maestro.

Maria Durazzo (viuda de Gio. Francesco Brignole Sale), interesada en mantener la política de prestigio familiar, y visto que sus nietos varones eran cuatro, decidió en 1711 adquirir el palacio situado frente al Palazzo Rosso, reconstruyéndolo de modo que sus puertas de ingreso se encontraran una frente a la otra. El nuevo palacio, construido por los Grimaldi, recibió con los Brignole Sale el nombre de Palazzo Bianco, y perteneció a esta familia hasta 1889, es decir, hasta el fallecimiento de Maria Brignole Sale (Génova, 1811-París, 1888), duquesa de Galliera, quien dispuso donarlo a la ciudad de Génova. En este contexto, es importante señalar que la duquesa de Galliera, personalidad con una educación de nivel europeo, entró a formar parte del ambiente genovés, de limitada dimensión cultural, imprimiendo un notable cambio en la mentalidad tradicional genovesa. La actividad de Maria Brignole Sale se desarrolló, principalmente, en el campo de la promoción cultural. Pero, no solo la duquesa de Galliera procedía de una familia donde el amor por las artes era una constante tradicional, sino que también su marido Raffaele De Ferrari, duque de Galliera, poseía una sensibilidad artística que le condujo a la adquisición de obras de arte.

La actividad de los duques de Galliera, Maria y Raffaele De Ferrari, como «comitentes» de obras de arte, enriqueció notablemente el patrimonio familiar y contribuyó a definir la alta calidad de las colecciones públicas genovesas. El hecho de residir en París permitió a los duques frecuentar las casas de venta y las exposiciones internacionales, que, sumado a su deseo de dotar a las residencias de rue d'Astorg, primero, y, luego, de rue de Varenne de objetos preciosos, son los motivos que impulsaron a los duques a la adquisición de obras de arte, muchas de ellas de valor excepcional.

Precisamente en la subasta de la colección Aguado, que tuvo lugar en la capital francesa el 25 de marzo de 1843, los duques de Galliera efectua-

7 Baccheschi (ed.) (1983, 1988), p. 159 de la edición de 1988. 
ron algunas adquisiciones, dos de las cuales tuvieron gran resonancia: la Magdalena de Canova y el San Francisco considerado de Murillo, por 15400 francos, tal como queda recogido en el siguiente texto:

L'altro ieri ho comprato un bellissimo quadro alla vendita di Mr. Aguado, è stata una follia non sapendo qui dove metterlo. È di Murillo e dicono sia uno dei più belli. Rappresenta San Francesco d'Assisi inginocchiato, avendo d'innanzi un cracifisso ed una testa di morto, apparendole un Angiolo, che le indica i statuti del suo Ordine.

Sia la vendita del Murillo che quella della Maddalena del Canova, comprata alla stessa asta, sono registrate in ricevute rosa della casa MM. Bonnefous de la Vialle, rue de Choiseul, 11. Il Murillo acquistato il 25 marzo, è stato pagato 15400 franchi ai quali sono da aggiungere 789,50 fr. percentuale [... ${ }^{8}$

En relación con el cuadro San Francisco recibe del ángel los siete privilegios de la Regla, hay que decir que en la actualidad se pone en duda su atribución a Murillo, considerándolo más bien copia de una obra de Ribera (ficha n. ${ }^{\circ}$ 1). Fue destinado a Génova por los duques de Galliera. En la actualidad se expone en la sala n. ${ }^{\circ} 11$ de la galería del palacio, que está dedicada a los pintores espańoles, aunque entre 1961 y 1990 estuvo expuesto en la Galleria di Palazzo Rosso de Génova.

Durante los años que los duques de Galliera vivieron en París, se desarrollaron en la capital francesa algunos acontecimientos de gran importancia en el mundo del coleccionismo: la venta, ya mencionada con anterioridad, de la colección Aguado, en 1843, y la subasta de la colección del mariscal Soult, en 1852. De la venta de la colección Aguado, la prensa

8 Este texto se halla recogido en una de las cartas que Raffaele De Ferrari escribe desde París a Bernardo Pellegrini el 23 de marzo de 1843. Véase A. S. C. G., DF, «Lettere a Bernardo Pellegrini», Lettere di Raffaele De Ferrari al Pellegrini, sc. 747. Citada también por Tagliaferro (1991b), p. 895. La traducción del texto es la siguiente: «El otro día compré un magnífico cuadro en la tienda de Mr. Aguado, ha sido una verdadera locura al no saber dónde colocarlo. Es de Murillo y dicen que es uno de los más bellos. Representa a san Francisco de Asís arrodillado ante un crucifijo y una calavera, y se le aparece un ángel que le indica los estatutos de su Orden [...]. Por el Murillo, adquirido el 25 de marzo, pagué 15400 francos, a los cuales hay que sumar 789,50 francos [...]». (Las traducciones realizadas al castellano de los documentos originales que aparecen en este trabajo han sido hechas por la autora). En este contexto, cabe decir que, a diferencia del Greco y Zurbarán, que en aquel entonces eran prácticamente desconocidos, Murillo, Velázquez, Claudio Coello y Alonso Cano atrajeron el interés de los coleccionistas. Así, como se ha indicado anteriormente, el francés Le Brun, en 1807-1808, se lleva cuadros de estos maestros a París y publica un catálogo sobre la pintura espańola. 
subrayaba su interés cultural, porque comprendía 230 cuadros de escuela española, 128 italianos, 35 flamencos y 50 esculturas. Como cabía esperar, la venta despertó una gran expectación entre los coleccionistas porque, según la crítica, era «la première qui nous eût mis à même d'apprecier les maîtres de Castille et d'Andalousie».

A mediados del siglo XIX, cuando los duques de Galliera participaban en los acontecimientos culturales y sociales parisinos, el interés por la pintura española era muy grande, y, por tanto, era natural que los duques «aseguraran» en su colección algunas piezas importantes. ${ }^{10}$ De este modo, en la subasta de la colección Soult, celebrada en la capital francesa en mayo de 1852, tras la muerte del mariscal, los duques adquirieron los siguientes cuadros españoles: ${ }^{11}$
fr. 680
La Vierge et l'Enfant Jesus par Ribera dit l'Espagnolet
fr. 2550
La vision de l'Agneau par Alonso Cano
fr. 3700
La vision de Dieu par Alonso Cano
fr. 1100
Sainte Ursule par Zurbaran (François)
fr. 1600 Sainte Euphémie par Zurbaran
fr. 51500
La fuite en Egypte par Murillo
fr. 7000 Un évêque faisant communier une jeune fille par Alonso Cano
fr. 2800 Saint Jean par Alonso Cano
fr. 2100 Saint Jacques par Alonso Cano
fr. 2500 Noces de Cana par Francisco Herrera el Joven
fr. 2000 Communion d'un Saint par Zurbaran

9 Genaille (1964).

10 Los coleccionistas y comerciantes de arte se dieron cuenta de los «beneficios» obtenidos con la ocupación napoleónica, y de la calidad de los maestros andaluces y castellanos, y su "preocupación" fue conseguir el máximo provecho de aquella.

11 Catalogue raisonné des tableaux de la Galérie de feu M. Le Maréchal Général Soult duc de Dalmatie, dont la vente aura lieu à Paris, Galérie Lebrun, 1852. A. S. C. G., DF, 447 Raffaele De Ferrari, Journal, 20 de mayo de 1852, cit. en Tagliaferro (1991b), p. 896. 
En total, adquirieron dieciséis pinturas, once de las cuales españolas, que sumaron ellas solas casi la totalidad de la cifra desembolsada (unos 85000 francos). Estas telas permanecieron en su residencia parisina (Hôtel Matignon de la rue de Varenne) hasta que Maria Brignole Sale, tras el fallecimiento de su esposo, dispuso trasladar algunas de ellas a Génova y donarlas, en 1889, a la Galleria di Palazzo Bianco, donde actualmente pueden contemplarse como uno de los más notables conjuntos de pintura española del Siglo de Oro en Italia.

En concreto, las dos santas, Santa Úrsula y Santa Eufemia (fichas n. 2 y n. ${ }^{\circ} 3$ ), se exponen como obras de Francisco de Zurbarán (Fuente de Cantos, 1598-Madrid, 1664). Probablemente, en origen formaban parte del ciclo decorativo de las diez santas que fue realizado para la sacristía de un convento sevillano. Estas dos pinturas podrían relacionarse, desde un punto de vista compositivo y estilístico (por la tipología de santa juvenil con postura elegante, plegado abundante del vestido, empleo de colores vivos, y por la representación iconográfica con el instrumento de martirio), con el resto de santas pintadas por Zurbarán en la década de los años treinta como, por ejemplo, Santa Justa de la National Gallery de Irlanda, en Dublín; Santa Rufina de la Hispanic Society of America, en Nueva York; o Santa Apolonia del Louvre, ${ }^{12}$ en París. En este contexto, es interesante destacar la opinión de Benito Navarrete Prieto, para quien la serie de santas mártires realizadas por Zurbarán muestra, en algunos de sus modelos y detalles, dependencia directa con las estampas de Alberto Durero; y, especialmente, con la estampa Boda española del Arco de Triunfo del emperador Maximiliano I, fechada hacia $1575 .{ }^{13}$

También el Viático de san Buenaventura o La última comunión de san Buenaventura (ficha n. ${ }^{\circ}$ ) figura como obra de Zurbarán, aunque las últimas investigaciones están poniendo en tela de juicio dicha atribución. Gaya Nuño considera que este viático es el quinto cuadro de la serie realizada para la iglesia del Colegio de San Buenaventura de Sevilla por Francisco de Herrera el Viejo y Zurbarán, y que permaneció en ella hasta que el mariscal Soult lo sacó de Sevilla. En concreto, esta serie estaba formada

12 Esta tela, propiedad también del mariscal Soult, quedó sin vender en 1852 y entró en el Louvre quince años después. Información recogida por Boccardo y Di Fabio (2004), p. 241.

13 Navarrete Prieto (1998), p. 98. 
por las siguientes obras: Oración de san Buenaventura (Dresde), San Buenaventura y santo Tomás de Aquino (Berlín), que desapareció en un incendio, San Buenaventura en el Concilio de Lyon y Funerales de san Buenaventura, ambos en el Louvre. ${ }^{14}$ Sin embargo, la pertenencia de la tela genovesa a Zurbarán ha sido puesta en discusión por María Luisa Caturla, quien, a partir del cotejo con obras como el Cristo servido por los ángeles del Palacio Real de Madrid y el Nacimiento de la Virgen en Pasadena (The Norton Simon Museum), ha propuesto resolver las dudas de atribución a favor de Pedro Díaz de Villanueva, pintor sevillano considerado tradicionalmente el maestro de Zurbarán. Pero esta atribución al pintor sevillano no ha sido hasta ahora corroborada por datos documentales. ${ }^{15}$

Otro de los cuadros conservados en la Galleria di Palazzo Bianco es La huida a Egipto (ficha n. ${ }^{\circ}$ 5), obra de Bartolomé Esteban Murillo (Sevilla, 1618-1682), probablemente realizada hacia 1645 para la iglesia del convento de la Merced Calzada de Sevilla, donde permaneció hasta 1810, fecha en la que su capítulo se vio forzado a donarlo al mariscal Soult. Como recoge el catálogo de la venta de la colección Soult, los duques de Galliera pagaron por esta obra la cantidad más elevada, 51500 francos, lo que pone de manifiesto el interés que había suscitado en París. Como señala Navarrete Prieto, en esta obra se constata la utilización por parte de Murillo de composiciones de Rubens. De hecho, si se compara el borrico de la pintura de Murillo con el que aparece en la composición del mismo asunto de Rubens grabada por Marinus, así como el velo de la Virgen y sus formas redondeadas, se aprecia la relación y el componente flamenco que muestra esta obra. ${ }^{16}$

Como se ha indicado anteriormente, entre las obras que los duques de Galliera adquirieron en la subasta de la colección Soult figuraban también otras telas españolas, como es el caso de las Bodas de Caná de Francisco Herrera el Joven (de la que se ha perdido hasta ahora el rastro) y una Virgen con Niño, considerada de Ribera. Esta última se expuso en la Galleria di Palazzo Bianco junto con el resto de la colección de los duques, y actualmente se encuentra en una colección genovesa. Orlando Grosso

14 Gaya Nuño (1958), p. 61.

15 Boccardo y Di Fabio (2004), p. 241.

16 Navarrete Prieto (1998), p. 198. 
considera que la obra es una copia de la Virgen de la Servilleta del Museo Provincial de Sevilla, ${ }^{17}$ atribuida a Murillo por Diego Angulo Ińíguez. ${ }^{18}$ Esta opinión conllevó que la obra de Génova fuera atribuida igualmente a Murillo, en lugar de a Ribera. Su atribución es todavía dudosa, aunque parece más probable que se trate de una obra de Murillo. Las restantes telas pertenecían a un retablo pintado por Alonso Cano (Granada, 16011667) para el convento de Santa Paula de Sevilla entre 1635 y 1637: un San Juan Evangelista y su visión del Cordero, un San Juan Evangelista y su visión de Dios, que acabaron posteriormente en el Ringling Museum de Sarasota; un San Juan Evangelista y un Santiago el Mayor, adquiridos por el Louvre en 1977; y un San Juan Evangelista da la comunión a la Virgen, conservado en la Galleria di Palazzo Bianco. De este conjunto también formaba parte el San Juan Evangelista y la visión de Jerusalén, comprado entonces por el cuarto marqués de Hertford —quien tenía una residencia en París y fue adquiriendo en esos mismos años tres de los Murillos pertenecientes en el siglo XVII a Giovanni Bielato-y hoy en la Wallace Collection de Londres. ${ }^{19}$

De todos estos cuadros, San Juan Evangelista da la comunión a la Virgen (ficha n. ${ }^{\circ}$ ) se conserva en la Galleria di Palazzo Bianco como obra de Alonso Cano. Sin embargo, la autoría ha sido hasta hace poco puesta en cuestión por la crítica. Al respecto, cabe recordar que autores como Gaya Nuño señalaban que esta obra fue en un principio atribuida a Alonso Cano, pero que posteriormente se consideró de escuela granadina. ${ }^{20}$ Asimismo, en opinión de H. E. Wethey, no había nada en el estilo de la obra genovesa que correspondiese a la producción de Alonso Cano, por lo que asignaba esta pintura a Juan del Castillo e incluso consideraba que podía tratarse de una copia del siglo XVIII. ${ }^{21}$ No solo la autoría del cuadro genovés ha sido discutida por la crítica, sino también su tema. Así, para algunos autores, como Gaya Nuño y Wethey, la mujer que recibe la comunión podría tratarse de la Virgen; ${ }^{22}$ en cambio, para otros, se trata de la comu-

17 Grosso (1920), p. 305.

18 Angulo Iñíguez (1981), p. 339.

19 Boccardo y Di Fabio (2004), pp. 241-243.

20 Gaya Nuño (1958), p. 98.

21 Wethey (1955), p. 186. En la edición española, pp. 43-44.

22 Gaya Nuño (1958), p. 98. 
nión de Santa Teresa impartida por un obispo. Por último, hay que indicar que el destino diverso de las distintas partes del retablo, que en 1852 estaban en el Hôtel Matignon, es posterior a la muerte del duque de Galliera, y está justificado por la voluntad de su viuda, Maria Brignole Sale, que dispuso el traslado a Génova, para la Galleria di Palazzo Bianco en construcción, solo de San Juan Evangelista da la comunión a la Virgen, mientras que al menos dos de los otros cuadros que siguieron decorando la residencia parisina debieron de ser enajenados después de $1884 .{ }^{23}$

En el depósito de la Galleria di Palazzo Bianco se encontraban también dos obras que, aunque no figuran entre las adquisiciones de los duques de Galliera, están atribuidas a maestros españoles. Una de ellas, San Juan de la Cruz (ficha n. $\left.{ }^{\circ} 7\right),{ }^{24}$ se consideraba obra de Alonso Cano, aunque las últimas investigaciones apuntan hacia el círculo del pintor Antonio Puga. Las únicas noticias documentales que se poseen es que se encontró a comienzos de la década de los años sesenta del siglo pasado en el campanario de la iglesia del convento de San Agustín de Génova. La segunda obra, San Jerónimo (ficha n. ${ }^{\circ}$ 8), se atribuye a la escuela de Ribera. La única información disponible sobre ella se refiere a su adquisición en 1902 en la casa de venta de Felicità Pedemonte.

En este sentido, y a través de la consulta de los trabajos de Grosso y Mayer, se constata que entre finales del siglo XIX y principios del XX en el depósito de la Galleria di Palazzo Bianco se hallaba también un San Francisco de Asís en éxtasis atribuido a Murillo. Esta obra se expuso, junto a las antes citadas, en la muestra Arte Antica celebrada en el Palazzo Bianco en 1892 , con motivo de su apertura al público como museo y conmemorando al mismo tiempo el cuarto centenario del descubrimiento de América. En 1900 se vendió en el extranjero, desconociéndose su localización actual. ${ }^{25}$ Se trata de una obra de gran sentimiento religioso, que representa a san Francisco de Asís arrodillado, en actitud de oración ante un crucifijo colocado en alto.

La renuncia de Filippo a la herencia familiar, en 1877, influyó en la determinación de su madre de destinar al público las obras que formaban

23 Boccardo y Di Fabio (2004), pp. 243-244.

24 Ib., pp. 238-239.

25 Mayer (1923b), p. 261. 
su colección de arte. El 31 de octubre de 1878, la duquesa de Galliera donó a la ciudad de París el edificio Museo Galliera junto a sus obras, y, con el testamento del 20 de marzo de 1884, estas fueron destinadas a su ciudad natal. Del mismo modo, y con el fin de conservar e incrementar en Génova el amor por las bellas artes, Maria y su hijo Filippo De Ferrari donaron a la ciudad de Génova el Palazzo Rosso en 1874, con su galería y biblioteca. Por deseo de la duquesa de Galliera, se realizaría la misma operación con el Palazzo Bianco en 1889, con el fin de que se convirtiese en sede de una galería pública que albergara las obras pertenecientes a la familia Brignole Sale y las adquisiciones llevadas a cabo en París. Por último, hay que decir que el inicio de la actividad del Palazzo Bianco como museo cívico coincide con la inauguración de la muestra Arte Antica en 1892 y con la celebración del cuarto centenario del descubrimiento de América. El museo «moderno» que la duquesa quiso para su ciudad se ha ido organizando con el tiempo.

\section{Galleria di Palazzo Reale}

El Palazzo Reale de Génova es una amplia residencia, edificada y engrandecida con el tiempo y decorada con esplendor por las principales dinastías de la aristocracia genovesa, como la de los Balbi (1643-1677) y la de los Durazzo (1679-1823), y otras italianas como la de los Saboya (1824-1919). De aquí deriva el nombre completo del palacio: Palazzo Balbi Durazzo Reale. Este palacio es probablemente el mayor edificio de los siglos XVII y XVIII existente en la capital ligur, y el único que conserva intactos sus interiores (decoración al fresco, mobiliario, cuadros, esculturas y tapices), tras los desastres de la Segunda Guerra Mundial. El segundo piso del palacio, piano nobile, funciona desde 1925 como museo público, y desde 1946 recibe el nombre de Galleria di Palazzo Reale.

Con respecto a la historia del palacio, se puede decir que en 1642 Stefano Balbi compró a G. B. Raggio el terreno sobre el que se halla emplazado. En 1679, el palacio cambia de propiedad: de la familia Balbi a otra de las grandes familias genovesas, la Durazzo. Cuando Eugenio Durazzo y su hermano Gio Luca compraron la residencia de Strada Balbi no había indicios de los cuadros pertenecientes a la colección de Gio. Battista Balbi (1623-1657), hecho que permite suponer que los Durazzo la compraron vacía o que en poco tiempo sustituyeron los bienes artísticos. Otro cam- 
bio de propiedad se produciría en 1824, cuando el rey de Cerdeña, Carlo Felice, compró el Palazzo Durazzo, que permaneció en propiedad de los Saboya hasta 1919, para pasar después a propiedad del Estado italiano.

En cuanto a las obras de artistas españoles (o atribuidas) conservadas en este palacio, las dudas son muchas por diversos motivos: se desconoce su procedencia, no aparecen citadas en ningún inventario familiar y su atribución es incierta. El único dato documentado que se posee al respecto es que aparecen citadas en torno a 1766, bajo la familia Durazzo, en la descripción que C. G. Ratti realiza del palacio y que está recogida en su obra Istruzione di quanto può vedersi di più bello in Genova in Pittura, Scultura ed Architettura (1. a edición). De este modo, la dispersión de los documentos y la ausencia de un estudio profundo sobre ellos crea esta laguna informativa.

Una vez dentro de la galería del palacio, hay que dirigirse a la Sala del Tiempo, que recibe este nombre por los frescos que decoran la bóveda, en la que se representa La Verdad descubierta por el Tiempo de Domenico Parodi, y que conserva una importante colección de pintura del siglo XVII, testimonio del gusto artístico de los Durazzo. Formando parte de esta colección se encuentra el cuadro titulado Muchacho que enciende una candela, conocido

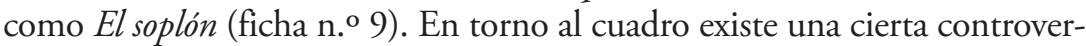
sia, ya que para algunos autores se trata de una obra de Jacopo Bassano; en cambio, para otros es una pintura del Greco. En la galería del palacio figura como copia de un original de este último artista, concretamente del que se encuentra en el Museo de Capodimonte de Nápoles. En relación con la cuestión de la autoría, a continuación se recogen las aportaciones de diversos autores sobre el tema. Así, basándose en las fuentes tradicionales (C. G. Ratti y Federico Alizeri), A. Morassi opina que esta obra pertenece al período maduro de Jacopo Bassano. ${ }^{26}$ En esta misma línea se encuentra P. Zampetti, quien señala que se trata de un tema característico del Bassano, repetido en diversas composiciones como en las Adoraciones de los pastores. ${ }^{27}$ Sin embargo, R. Pallucchini atribuye la obra al período joven del Greco, anterior a su llegada a Espańa, considerándola una copia del original que se encuentra en el Museo de Capodimonte de Nápoles, procedente de la colección farnesiana. ${ }^{28}$ Cabe señalar que otro original es el que se conserva en la

\footnotetext{
26 Morassi (1951), p. 69.

27 Zampetti (1957), p. 242.

28 Pallucchini (1962), p. 109.
} 
colección Paysson en Manhasset (Nueva York), y que en el Museo dell'Accademia Ligustica de Génova se halla una copia del cuadro del Palazzo Reale, realizada por Angela Serra Durazzo en torno a 1780, año en el que se donó a la Accademia. Asimismo, cabe destacar que todas las exposiciones en las que esta obra ha participado como, por ejemplo, la de Génova de 1946, Brescia de 1947 y la de Venecia de 1957 estaban dedicadas a Jacopo Bassano.

A pesar de estas contribuciones, la cuestión queda abierta. Se debe indicar que esta obra constituye un testimonio importante del encuentro entre los dos maestros, desde el punto de vista del gusto artístico, representando, indistintamente, un estudio experimental de los efectos de la luz artificial que fue bastante común entre los pintores manieristas.

La siguiente sala que debe visitarse es la Sala del Baño del Rey, que formaba parte en el siglo XVIII, bajo la familia Durazzo, de las salas denominadas de los "cuatro elementos», decoradas por Tommaso Aldobrandini; la actual Sala del Baño del Rey recibía el nombre de «Sala del Fuego». En esta sala se expone el Retrato de dama con perrito (ficha n. ${ }^{\circ} 10$ ), que no aparece citado en el inventario de palacio de 1823, que, según Orlando Grosso y en función del inventario de 1951, es una obra española del siglo XVII de un seguidor de Bartolomé González. ${ }^{29}$ De esta misma opinión es P. Torriti ${ }^{30}$ y B. Ciliento, ${ }^{31}$ que consideran que es una obra española del siglo XVII. En cambio, Leticia Lodi propone la atribución al artista milanés Carlo Francesco Nuvolone (1609-1661), clasificación que es la que figura en la galería. Esta historiadora establece algunas semejanzas con el «retrato de dama» perteneciente al cuadro La familia del pintor de la Pinacoteca de Brera (Milán), basándose en la tipología del rostro: frente alta, nariz alargada, y por la pincelada mórbida y «esfumada». También encuentra ciertas relaciones con el Retrato de dama del Museo Civico de Bolonia, datado en 1640, por la mencionada tipología del rostro, parecida ejecución y posición de las manos, como es el caso de la mano izquierda situada sobre el mueble, igual a la del retrato genovés. En función de estos dos retratos, y teniendo en cuenta otros elementos como el vestido, Lodi data el cuadro genovés hacia $1650 .^{32}$

29 Grosso (1932).

30 Torriti $(1963 a)$, p. 64.

31 Ciliento (1986), p. 25.

32 Lodi (1991), pp. 63-64 
En otra sala de la Galleria di Palazzo Reale, concretamente en la del Dormitorio de la Reina, figura el Retrato de Felipe IV, rey de España (ficha n. $\left.{ }^{\circ} 11\right)$, cuya autoría es discutible. Fue atribuido por F. Alizeri a Velázquez $^{33}$ y por Suida a Martínez del Mazo. ${ }^{34}$ P. Torriti reconoce la atribución del cuadro a escuela española del siglo XVII y propone el nombre de José Antolínez (Sevilla, 1593-Madrid, 1670), datándolo en la segunda mitad del siglo XVII. ${ }^{35}$ Según B. Ciliento, se trata de una obra de Juan Bautista Martínez del Mazo (1612-1667). ${ }^{36}$ Sin embargo, Caterina Olcese, quien elaboró la ficha O.A. del catálogo (SBAS, Soprintendenza Beni Ambientali Storici), mantiene que el cuadro genovés es una de las tantas copias del Retrato de Felipe II de Velázquez, cuyo original se conserva en el Museo del Prado de Madrid.

Antes de concluir el recorrido por la galería del palacio, nos detendremos en la Sala de la Reina, en la que se encuentra un cuadro que, por el nombre que aparece escrito en su margen derecho, representa a San Agustin de Canterbury, atribuido recientemente a Gerrit Van Honthorst (Utrecht, 1590-1656) por E. Giffi, quien lo data en torno a $1618 .{ }^{37}$ Como constata Leticia Lodi, es probable que este cuadro formara parte de la colección de Gio. Battista Balbi si se le identifica con el Santo Tomás de Aquino del Spagnoletto (Ribera), ${ }^{38}$ que aparece citado en el inventario redactado en 1658 , en vida de Battista Balbi, ${ }^{39}$ y que después pasó a propiedad de la familia Durazzo. En relación con esta obra, hay que indicar que la primera fuente que alude a ella es C. G. Ratti en su descripción de la ciudad de Génova de 1780, quien la recoge como San Bernardo, obra del Spagnoletto. ${ }^{40}$ En cambio, P. Torriti, en 1963, la atribuye a un maestro caravaggiesco. ${ }^{41}$ Presenta a san Agustín de Canterbury sentado, vestido

33 Alizeri (1875), p. 442.

34 Suida (1906), p. 160.

35 Torriti $(1963 a)$, p. 64.

36 Ciliento (1985), p. 25.

37 Giffi Ponzi (1990).

38 Lodi (1991), p. 74.

39 Véase A.S. G. Notaio Gio Luca Rossi, f. 6, 23 de mayo 1658: «Quadri del Quondam Magnifico Gio Batta Balbi», en Il Palazzo della Università di Genova. Génova, 1987, p. 81 .

40 Ratti (1780), p. 213.

41 Torriti (1963a), p. 64. 
con hábito blanco, y ante él hay un libro abierto en el que se puede leer: "Anglia» (Inglaterra). El santo dirige su mirada hacia una cruz, y su figura aparece iluminada mientras que la cruz permanece en penumbra.

En esta sala, concretamente en la pared sur, entre dos ventanas, está colocado un cuadro atribuido a Luca Giordano (Nápoles, 1634-1705), fechado en la segunda mitad del siglo XVII, que representa una Crucifixión. En opinión de P. Torriti (1963), Luca Giordano realiza un «homenaje a Ribera", si se piensa en el Llanto sobre Cristo muerto, datado en 1633, de la Colección Thyssen Bornemisza de Lugano, por la tipología del rostro de Cristo y de Magdalena.

Una vez mencionado el inventario de 1658 de la colección de pintura de Gio. Battista Balbi, es interesante señalar que en él aparecen citados dos cuadros como correspondientes al Spagnoletto: Cattone, figura del natural, y San Pietro in carcere con angeli, de 6,8 palmos, ${ }^{42}$ de los que se desconoce su localización actual. En relación con esto, cabe decir que en algunas ocasiones se llega a perder todo indicio de las obras, bien debido a las divisiones testamentarias, a las que se vieron sometidas muchas de las colecciones genovesas, o bien porque muchas de estas pinturas, que en algún momento se atribuyeron a maestros espańoles, con investigaciones recientes han recibido otra autoría. Así lo pone también de manifiesto el inventario del primero de junio de 1740 de la colección de Constantino Balbi, que recoge en el primer salón, sala n. ${ }^{\circ} 11$ del palacio, un Ritrato d'un vecchio con bastone del Spagnoletto, de 3,6×2,2 palmos, con un valor de 200 liras, cuyo rastro se ha perdido. ${ }^{43}$ Este cuadro podría identificarse con el Pellegrino, perteneciente a la colección de Gian Vincenzo Imperiale, del que igualmente se desconoce su localización. ${ }^{44}$

Respecto a la colección de pintura de Gian Vincenzo Imperiale, se puede decir que comenzó a formarla siendo joven. Varias fueron las vías utilizadas por Imperiale para adquirir cuadros fuera de la República genovesa: numerosas amistades, relaciones diplomáticas, viajes realizados y resi-

42 A.S.G. Notaio Gio Luca Rossi, f. 6, 23 de mayo 1658: "Quadri del Quondam Magnifico Gio Batta Balbi», p. 81.

43 A.S.G. Notaio Giuseppe Maria Montaldo, inventario de 1740 en propiedad de Balbi: ib., p. 86.

44 Martinoni (1983), «Il collezionismo dell'Imperiale. La quadreria», pp. 234 y 316. 
dencias en diversas ciudades europeas. De este modo, según Martinoni, Vincenzo Imperiale adquirió los cuadros del Spagnoletto que figuran en su colección. ${ }^{45}$ Sin olvidar que contó con la colaboración de hábiles expertos, residentes en Milán, Venecia, Roma y otras ciudades europeas, encargados de procurarle cuadros y enviárselos a Génova. La colección se disgregó al ponerse en venta tras el fallecimiento de Imperiale, el 21 de junio de 1648, y los 59 cuadros subastados fueron adquiridos por Francesco Maria Balbi el 2 de septiembre de 1665. Con motivo de la división de la colección Balbi entre los herederos Doria y Odescalchi, se perdió el rastro de los cuadros que integraban la colección.

\section{Galleria Nazionale di Palazzo Spinola}

El Palazzo Spinola fue, en un primer momento, la residencia de la familia Grimaldi y más tarde de la Spinola. El palacio se halla emplazado en el centro de un barrio medieval genovés. Consta de varios pisos, y en especial el segundo conserva en todo su esplendor la magnificencia que los Spinola dieron a su residencia en el siglo XVIII, y que se concreta en la magnífica colección de pintura repartida por las diferentes salas. C. G. Ratti es el primero que da cuenta de ella, en 1766 y en 1780, en su obra Istruzione di quanto può vedersi di più bello in Genova in Pittura, Scultura ed Architettura, donde recoge los cuadros más importantes existentes en aquel entonces en el palacio, que todavía pueden contemplarse en la actualidad.

Los marqueses Franco y Paolo Spinola donaron al Estado italiano, el 31 de mayo de 1958, todas estas obras de arte, junto con el palacio que las contiene, con el fin de que Génova fuera la primera ciudad de Liguria que contara con una colección de arte estatal, colección que los duques denominaron Galleria Nazionale di Palazzo Spinola. El Estado italiano ha ido adquiriendo nuevas obras con el tiempo, y también ha emprendido la restauración de algunos cuadros, permitiendo así aclarar muchas lagunas documentales existentes en torno a estas pinturas.

Dentro de la galería, concretamente en la sala primera del piso segundo, se encuentra el Martirio de san Lorenzo (ficha n. ${ }^{\circ} 12$ ), que figura como copia, de dimensiones ligeramente mayores, del cuadro de José de Ribera

45 Ib., p. 253. 
conservado en la Pinacoteca Vaticana, que a su vez se considera copia de un original perdido. La existencia de numerosas copias acredita la fama que Ribera alcanza en Italia; de hecho, de la copia vaticana se conocen a su vez varias copias más.

C. G. Ratti, en la descripción artística que hace de la ciudad de Génova en 1780 , la atribuye a Ribera. ${ }^{46}$ Es interesante señalar que Ratti cita esta obra en el salón del palacio donde hoy en día se expone. El historiador F. Alizeri, ${ }^{47}$ en la segunda edición (1875) que realiza de su guía artística, la atribuye a Caravaggio. Con esta misma atribución aparece en el inventario de la donación. En cambio, Pasquale Rotondi, alejándose de las fuentes tradicionales, opina que, probablemente, este cuadro es obra de un pintor ligur (desconocido) de finales del siglo XVII. ${ }^{48}$

En esta misma sala se localiza un San Jerónimo (ficha n. ${ }^{\circ} 13$ ), recogido en la descripción que C. G. Ratti hace del palacio, donde figura como de "estilo de Lanfranco». ${ }^{49}$ Sin embargo, F. Alizeri lo atribuye a Ribera, ${ }^{50}$ atribución con la que aparece en el inventario de la galería. Rotondi afirma que es una copia de un Ribera, con la incorporación de elementos giordanescos, realizada en el siglo XVII por un pintor probablemente napolitano. ${ }^{51}$

Como bien señala Piero Boccardo, José de Ribera trató muchas veces el tema de san Jerónimo, pero ninguno de los originales conservados puede estimarse el verdadero modelo de esta obra. Los originales más próximos son el del Ermitage y el de la Galleria Doria Pamphilj de Roma, por lo que la obra puede considerarse realizada en el taller del maestro. Este cuadro, según la ficha de catalogación de la galería, es una copia de un presunto original que podría estar relacionado con un grabado (del mismo tema), datado en 1621, del Metropolitan Museum de Nueva York (ficha de catalogación de la SBAS de Liguria, 1985).

Este recorrido por las diferentes salas de la galería no muestra todo lo que verdaderamente existe en el palacio. Así, en el depósito se conserva un

46 Ratti (1780), p. 139.

47 Alizeri (1875), p. 134.

48 Rotondi (1967), pp. 120-121.

49 Ratti (1780), p. 140.

50 Alizeri (1875), p. 134.

51 Rotondi (1967), pp. 120 y 122. 
cuadro, La Sagrada Familia de Jesús con san Zacarías, santa Isabel y san Juanito (ficha n. ${ }^{\circ}$ 14), que fue adquirido por el Estado el 18 de junio de 1954 en la Oficina de Exportación de Obras de Arte de Génova por 400000 liras. Esta adquisición aparece publicada, ese mismo año, en la sección "Acquisizioni dai Musei e Gallerie dello Stato» del Bolletino d'Arte, donde Roberto Longhi lo atribuye a Francisco de Zurbarán. ${ }^{52}$ En 1955, en la revista Goya se daba esta misma atribución al pintor español. ${ }^{53}$ No obstante, Rotondi dice que el único dato que podría indicar que esta obra corresponde al maestro es la presencia de su firma artefatta ('falsificada') en el libro que Zacarías tiene sobre sus rodillas, y que la dureza del modelado y del dibujo induce a pensar en una obra de escuela. ${ }^{54}$ De hecho, tal como se indica en la ficha de catalogación, si se establece una comparación con la producción artística de Zurbarán y se tiene en cuenta la calidad de la obra, es posible que esta corresponda a un imitador de Zurbarán (ficha de catalogación de la SBAS de Liguria).

Con el fin de completar este apartado, cabe mencionar que en esta galería hay otros dos cuadros de los que no se elaboró una ficha de catalogación debido a que inicialmente contaron con una atribución a José de Ribera, que ha sido modificada con los estudios recientes. Uno de ellos es el Martirio de san Bartolomé, colocado en una sala del segundo piso, que aparece citado en 1780, en la obra de Ratti, como de Ribera. ${ }^{55}$ Del mismo modo, Federico Alizeri, en 1875, en su guía artística de la ciudad de Génova, recoge este cuadro como de Ribera. ${ }^{56}$ Con esta misma atribución aparece en el inventario de la donación del palacio. Las últimas investigaciones, como en los casos antes citados, han sido llevadas a cabo por Rotondi, quien considera que la atribución a Ribera es insostenible y lo atribuye de modo dudoso al genovés Giovanni Battista Carlone (1592-1677). ${ }^{57}$

Con respecto al segundo cuadro, localizado en el depósito, este aparece citado por primera vez en el inventario de la donación y representa un

52 Bolletino d'Arte, 1954, año XXXIX, p. 375.

53 Goya (Madrid), 1955, p. 389.

54 Rotondi (1967), pp. 160-161.

55 Ratti (1780), p. 140.

56 Alizeri (1875), p. 134.

57 Rotondi (1967), p. 68. 
Retrato de hombre, atribuido igualmente a Ribera. Rotondi indica que esta atribución es inaceptable y propone el nombre de Anton Maria Vassallo (activo a mediados del XVII) por motivos de carácter estilístico. ${ }^{58}$ Pero es una atribución que debe verificarse.

Estas obras, como ya se ha dicho, son propiedad del Estado italiano, y su atribución a maestros españoles es dudosa, pero quizá las dudas puedan despejarse con futuras investigaciones. Por último, es interesante resaltar que la mayor parte de las obras pictóricas depositadas en la galería del palacio corresponden a pintores genoveses, que han sido objeto de estudio preferente por parte de los historiadores del arte de la región. Los cuadros catalogados en este apartado contaron con estudios pioneros que no han tenido una continuación y desarrollo en el tiempo, por lo que nos encontremos con una documentación que sería deseable se pusiera al día con la aportación de nuevos estudios.

\section{Palazzo Durazzo Pallavicini}

El Palazzo Durazzo Pallavicini se ubica en un terreno que originariamente era propiedad de la familia Balbi. Concretamente, Gio. Agostino Balbi encargó en 1618 al arquitecto Bartolomé Bianco la construcción de este palacio, que permaneció en propiedad de los Balbi hasta el 6 de abril de 1709, fecha en la que Bartolomé Balbi lo cede al marqués Marcello Durazzo.

La familia Durazzo, probablemente procedente de Albania, se trasladó a Génova a finales del siglo XIV. Su prioridad fue enriquecerse con el comercio y los negocios financieros. Con Marcello Durazzo (1634-1717), marqués de Gabiano, y con su hijo Giacomo Filippo II (1672-1764) se inició una etapa de gran desarrollo artístico y cultural para la familia, que se manifestó con la adquisición de cuadros, muebles, libros y otras piezas de arte. Las enormes riquezas conseguidas en el siglo anterior les permitieron moverse con más facilidad en el mercado artístico del siglo XVIII, consolidándose así su prestigio cultural y social, tal como se manifiesta con la fundación de la Academia Durazzo por Giacomo Filippo III, entre 1782 y 1787. Su promoción de las artes debe ponerse en relación con la cultura ilustrada del momento.

58 Ib., pp. 60-61. 
La ya rica colección de pintura Durazzo se vio incrementada en la segunda mitad del siglo XIX con la colección del marqués Ignazio Pallavicini, es decir, a través del matrimonio que su única hija, Teresa, contrajo con Marcello IV Durazzo (1821-1904), pasando de este modo a pertenecer a la familia Durazzo. ${ }^{59}$ De aquí deriva el nombre del palacio: Durazzo Pallavicini. Marcello IV tuvo solamente un hijo, Giacomo Filippo, que murió sin descendencia, quedando como heredera su esposa, Matilde Giustiniani. Después, el palacio pasó a su sobrina e hija adoptiva, Carlotta Fasciotti Giustiniani, viuda de Maurizio Cattaneo Adorno.

La quadreria ('colección de cuadros') Durazzo Pallavicini constituye un testimonio excepcional de tres siglos de coleccionismo genovés. La reciente organización del archivo Durazzo permite conocer cómo se fue formando su magnífica colección de pintura. A este respecto, es importante la consulta de los registros contables correspondientes a tres siglos (1587-1837), desde Agostino Durazzo a Marcello III, en los que aparecen documentados los cuadros, sus adquisiciones y ventas. En los registros contables no figuran ni las donaciones ni las herencias familiares.

Tras estas cuestiones de tipo preliminar, se pasa al estudio de la colección de pintura de la familia Durazzo, que se encuentra repartida en los nueve salones del piano nobile del palacio, distribuidos en torno a un patio central. Así, el salón central recibe el nombre de Salone d'Achille, a su derecha se abre la Sala de Van Dyck, denominada de este modo por la existencia de cuatro cuadros del pintor flamenco, y a continuación una sala de finales del siglo XVIII, decorada con seis cuadros mitológicos pintados por Bacigalupo. En esta secuencia se halla a continuación el Salotto Verde, que se caracteriza por el predominio de cuadros de artistas flamencos. Finalmente, y siguiendo en este mismo lado del palacio, se sitúa el Salotto Rosso.

59 En este contexto, es preciso señalar que el origen de las grandes colecciones de pintura pertenecientes a familias nobles genovesas se encuentra en la reunión, en la mayoría de las ocasiones, de diferentes colecciones familiares. Este es el caso de la colección Durazzo Pallavicini, que se enriqueció notablemente en 1781 con los cuadros que Teresa Pallavicini, esposa de Marcello IV Durazzo, recibió en herencia de su padre, produciéndose de este modo la unión de dos grandes colecciones genovesas: la Durazzo y la Pallavicini. En otras ocasiones sucede el fenómeno opuesto: las divisiones testamentarias, que pueden conllevar la disgregación o la dispersión de las colecciones familiares. 
En cuanto a las salas dispuestas en el lado izquierdo del Salone d'Achille, se abre en primer lugar la Sala de Guido Reni, denominada así por la existencia de cinco cuadros de este pintor. A continuación, la Sala de la Magdalena, que recibe este nombre por el cuadro que representa a Santa María Magdalena penitente, que fue adquirido como obra de Tiziano; y luego, la Sala de Muzio Scevola, llamada de este modo por el homónimo cuadro del Guercino. Finalmente y siguiendo a este lado del patio, se encuentra la última sala, el Salotto Giallo, que destaca por el gran retrato del último Durazzo, Giacomo Filippo, realizado por el genovés Traverso.

La primera sala a poniente es la Sala de Van Dyck, que es la más rica por la calidad de sus cuadros. En esta sala destacan los magníficos retratos de los miembros de la aristocracia genovesa realizados por Van Dyck, que fueron adquiridos por los Durazzo entre 1720 y 1721 . A esta misma década pertenecen los cuadros de maestros representativos como Rubens, Ribera y Domenichino, que se conservan en la galería del palacio.

La Sala de Van Dyck custodia tres cuadros de gran interés: Heráclito, Demócrito y Filósofo, atribuidos a José de Ribera (Játiva, 1591-Nápoles, 1652). Estos cuadros aparecen citados por primera vez en el registro contable del día 19 de septiembre de 1722 (libro 549), redactado en vida de Giacomo Filippo II (1672-1764), en el que se alude a la adquisición de estos cuadros del Spagnoletto:

A Pietro Andrea Saoli e C., deputati per lo magistrato dei Poveri, pagate Lire 769,3 per prezzo di n. 3 quadri dello Spagnoletto da me compri nella callega della signora M. Vittoria Spinola Grilla, rappresentanti uno cioè Democrito, altro Eraclito et altro un'altro filosofo, con loro cornici dorate di fresco (cfr. N. 129/54, 56-57). ${ }^{60}$

Como indica el texto, estas telas fueron adquiridas a Vittoria Spinola Grilla (heredera del marquesado de Lerma -Alessandria-), quien, a su vez, las había adquirido a finales del siglo XVII de la colección de Diego

60 Puncuh (1984), p. 191 (n. ${ }^{\circ} 87,19$ de septiembre de 1722, mastro 549, c. 297). Traducción del texto: "A Pietro Andrea Saoli y C., diputados por el magistrado de los Pobres, pagadas 769,3 liras por precio de n. 3 cuadros del Spagnoletto comprados por mí en la casa de ventas de la señora M. Vittoria Spinola Grilla, que representan uno a Demócrito, otro a Heráclito y otro a otro filósofo, con sus marcos dorados». 
Felipe de Guzmán (h. 1558-1655), ${ }^{61}$ el general al que el rey Felipe IV había honrado en 1627 con el título de marqués de Leganés.

Estos tres cuadros pasaron en herencia a su sucesor Marcello Durazzo II (1703-1787), tal como queda constatado en el registro contable del día 6 de diciembre de 1768, redactado en vida del marqués:

Pagate Lire 221 al pittor Giuseppe Galeotti per sua ricognizione e spese per avere accomodati cinque quadri del salotto a ponente, rappresentanti cioè tre filosofi di Giuseppe Ribera (n. 129/54, 56, 57), uno dei putti di Domenico Piola (n. 129/59, 63, 65), altro una stagione con satiri, scuola del Tiziano (n. 129/61). ${ }^{62}$

Siguiendo con la historia de los cuadros, hay que señalar que en el inventario y valoración, redactado el 31 de mayo de 1787, de los cuadros de S. E. el señor Giacomo Filippo Durazzo III (1729-1812) existentes en su palacio figuran en el salón primero a poniente, como obra del Spagnoletto: Filósofo (n. ${ }^{0} 54$ del inventario), con un valor de 256 liras; Demócrito (n. ${ }^{\circ} 56$ del inventario), con un valor de 256 liras; y Heráclito (n. ${ }^{\circ} 57$ ), con un valor de 256 liras. ${ }^{63}$

Como ha podido constatarse, los registros contables de la familia Durazzo son una fuente de gran valor porque permiten conocer la localización actual de los cuadros y su procedencia. Las obras fueron pasando de padres a hijos hasta el siglo presente, constituyendo uno de los pocos testimonios en los que una colección familiar se ha transmitido casi intacta e íntegra entre los herederos. Además, la localización actual de las obras coincide con la citada en el inventario del 31 de mayo de 1787.

61 Como indica Piero Boccardo, entre los cuadros pertenecientes a Vittoria Spinola (h. 1637-1722) se encontraban tres filósofos que procedían de la colección de Diego Felipe de Guzmán. Tras una estancia en Madrid a finales del siglo XVII, para reunirse con su marido Francesco Grillo (miembro de una de las familias genovesas que ya desde el XVI habían vinculado su suerte económica a España), regresó a Génova y dispuso por testamento que sus bienes fueran destinados al Albergo dei Poveri, donde, un mes después de su fallecimiento, fueron vendidos a un agente de Giacomo II Durazzo. Véase Boccardo (2004), pp. 190-191.

62 Puncuh (1984), p. 191 (n. ${ }^{\circ} 121,6$ de dicembre de 1768, giornale 678). Traducción del texto: «Pagadas 221 liras al pintor Giuseppe Galeotti por los gastos ocasionados al acomodar cinco cuadros en el salón de poniente, que representan tres filósofos de Giuseppe Ribera [...], un cuadro de putti de Domenico Piola [...] y una estación con sátiros, de la escuela de Tiziano [...]".

63 Puncuh (1984), p. 198. 
Heráclito (ficha n. $\left.{ }^{\circ} 15\right)$ y Demócrito (ficha n. ${ }^{\circ} 16$ ) fueron adquiridos por el marqués Giacomo Filippo II en 1722, y son considerados por algunos autores como obras de Ribera por la existencia en ambos de la firma del maestro y de la fecha: "Jusepe de Ribera Español. Valenciano F 1635». Sin embargo, otros autores los atribuyen a un anónimo imitador del pintor valenciano.

De este modo, la atribución a Ribera fue confirmada por C. G. Ratti en $1780,{ }^{64} \mathrm{e}$ igualmente puede encontrarse en el inventario de $1787 \mathrm{y}$ en el catálogo de la colección de 1792. Asimismo, Suida en $1906^{65}$ y Mayer en $1923^{66}$ los atribuyen también a Ribera. Orlando Grosso mantiene que se trata sin duda de dos magníficas pinturas del artista "hispano-italiano». ${ }^{67}$ A su vez, Gaya Nuño sostiene la atribución a Ribera. ${ }^{68}$ Sin embargo, Torriti no la acepta, pues, basándose en la indicación oral de Ferdinando Bologna, traslada estos cuadros al ámbito del autor de una serie de telas napolitanas datables en torno a los años cuarenta. ${ }^{69}$ En un principio, este pintor fue identificado erróneamente con Michelangelo Francazano, más tarde denominado «Maestro del Cristo en el Huerto» de la catedral de Pozzuoli, y, recientemente, ha sido identificado con Nunzio Rossi o Russo, citado varias veces en las fuentes del siglo XVIII por su actividad entre Nápoles, Bolonia y Mesina.

La atribución a Ribera tampoco fue aceptada por Felton ${ }^{70}$ ni por Nicola Spinosa. ${ }^{71}$ De hecho, Spinosa señala que, si se establece una relación con las series de los apóstoles y filósofos pintadas por el maestro espanól entre 1630 y $1632,{ }^{72}$ estos dos cuadros, Demócrito y Heráclito, presentan una calidad expresiva entre lo grotesco y lo caricaturesco, una sequedad de soluciones pictóricas y una dureza en los resultados formales, especialmente en el dibujo de las manos. Por otra parte, mientras que las

64 Ratti (1780), p. 183.

65 Suida (1906), p. 159.

66 Mayer (1923a), p. 197.

67 Grosso (1920), p. 304.

68 Gaya Nuño (1958), pp. 2302-2303.

69 Torriti (1967), pp. 61-66.

70 Felton (1971), pp. 397-398.

71 Spinosa (1995a), pp. 231-232.

72 En este sentido, cabe destacar el San Simón del Museo del Prado de Madrid y el Platón del Musée de Picardie de Amiens. 
medias figuras de los apóstoles y filósofos pintados por Ribera a principios de la década de los treinta se caracterizan por un vigoroso modelado y por la representación natural de la anatomía y de la expresión de sus rostros, estos dos cuadros presentan un marcado grafismo de las soluciones pictóricas. Para la fecha indicada en las dos telas, el año 1635, Ribera ya había iniciado, como puede advertirse en el San Zacarias de 1634 del Museo de Rouen, el proceso de enriquecimiento de las luces y de las materias cromáticas llevándole a composiciones luminosas, de fuerte intensidad humana y comunicativa en torno a 1632-1638. La calidad está ausente en las dos telas Durazzo, lo que llevaría a pensar en un anónimo imitador de los modos naturalísticos de Ribera en torno a 1630, independientemente del hecho de que estén firmados y fechados, probablemente activo en el mismo taller del maestro español con el fin de poder responder a la gran demanda originada por sus célebres medias figuras de santos y filósofos tomados del natural, teniendo como fuente de inspiración el mundo de los marginados del área napolitana. Debe ser abandonada, pues, la idea de que pueda tratarse de Nunzio Rossi, cuyos cuadros se caracterizan por una alta calidad pictórica en comparación con los aquí estudiados, exagerando en clave naturalista el grafismo de los primeros tiempos de Ribera como grabador. ${ }^{73}$

A pesar de estas aportaciones, la identidad del autor de las dos telas todavía permanece anónima; quizás podría identificarse con alguno de los seguidores e imitadores de José de Ribera presentes en su taller en los años treinta.

Además de estos dos cuadros, ahora citados, se adquirió un Filósofo (ficha n. ${ }^{\circ} 17$ ), y, como se ha señalado anteriormente, las tres telas asignadas a Ribera costaron con sus respectivos marcos dorados 769,3 liras. Es preciso mencionar que esta obra no ha sido tanto objeto de la crítica. En 1780 Ratti se refiere a ella como del Spagnoletto ${ }^{74}$ y con esta misma atribución figura en el inventario redactado en mayo de 1787 de los cuadros del marqués Giacomo Filippo Durazzo, y en el catálogo de la misma colección de 1792. Sin embargo, Torriti la atribuye con alguna duda a Ribera, estableciendo su cronología entre 1629 y 1630-1632, en relación con el

73 Spinosa (1995a), pp. 232-233

74 Ratti (1780), p. 183. 
San Andrés que forma parte de la serie del Apostolado del Museo del Prado y con el San Jerónimo de la Galleria Doria Pamphilj de Roma. ${ }^{75}$ En la misma línea se encuentra Felton, quien cataloga esta obra entre los cuadros del pintor español de dudosa atribución. ${ }^{76}$ En 1995 Nicola Spinosa recupera la autoría riberesca, basándose en el gran parecido estilístico que esta obra presenta con el San Andrés del Museo del Prado. ${ }^{77}$ De hecho, es preciso decir que el Filósofo aparece identificado como San Andrés en las guías de la ciudad de Génova del siglo XIX. Por último, Spinosa fija su datación entre 1630 y 1634-1635, cuando más decidido y avanzado es el proceso de superación de la precedente fase naturalista del maestro. ${ }^{78}$

Dentro de la galería del palacio hay que destacar la Sala de Guido Reni, donde se encuentra un cuadro magnífico, engrandecido en época moderna: Santiago el Mayor (ficha n. ${ }^{\circ}$ 18), atribuido a José de Ribera. Este cuadro aparece citado en el inventario del 31 de mayo de 1787, en propiedad del marqués Giacomo Filippo Durazzo III (1729-1812), como obra del Spagnoletto, en el primer salón a levante, con un valor de 200 liras. $^{79}$ Es posible que Giacomo Filippo Durazzo III lo recibiera en herencia de su padre Giacomo Filippo II, gran comitente de obras de arte.

C. G. Ratti, en su descripción artística de la ciudad de Génova, en 1780, es el primero que adscribe esta obra al Spagnoletto (Ribera). ${ }^{80}$ Con esta misma atribución aparece en el catálogo de la colección de Giacomo Filippo Durazzo redactado en el año 1792, donde se indica que estaba colocada en el primer salón a levante del palacio, actualmente denominada Sala de Guido Reni. Este cuadro ha sido considerado por la crítica, con la única excepción de Felton, ${ }^{81}$ que lo da como incierto, como seguro autógrafo del maestro español. En 1967 Torriti establece su datación entre 1640 y 1655, en una fase de avanzada experiencia pictórica, y lo considera el probable original del que derivan numerosas copias. ${ }^{82}$ Para Nicola

\footnotetext{
75 Torriti (1967), pp. 66-67.

76 Felton (1971), p. 399.

77 Spinosa (1995a), p. 230.

78 Ib.

79 Puncuh (1984), p. 197.

80 Ratti (1780), p. 181.

81 Felton (1971), p. 399.

82 Torriti (1967), p. 180
} 
Spinosa, si bien la tela de Casa Durazzo puede considerarse autógrafa, es una copia sin variantes y de gran calidad del original pintado por José de Ribera entre 1630 y 1632 para la famosa serie del Apostolado del Museo del Prado. De este último se conocen otras copias, como la realizada por su taller para la iglesia de Santa Teresa de Lecce (Italia). ${ }^{83}$

Con relación a este cuadro, hay que mencionar que en el inventario de la colección de Gian Vincenzo Imperiale, ya citado cuando se hizo referencia al Peregrino, figura un Santiago a la «maniera del Spagnolo», con 3 palmos de altura y 2 de anchura. El historiador Renato Martinoni constata que son numerosos los cuadros de Ribera con el tema del apóstol Santiago, y señala que el cuadro de la colección de Imperiale presenta el mismo tema y proporciones parecidas al que se halla en el Palazzo Durazzo. ${ }^{84}$ Recuérdese que la colección de pintura de Gian Vincenzo Imperiale se pone en venta en 1658 (tras su muerte), y esta cita es, por tanto, un elemento importante a tener en cuenta, aunque no quiere decir que se esté haciendo referencia al mismo cuadro.

Consultando los registros contables de la familia Durazzo salió a la luz un dato importante. En concreto, en el registro del 4 de noviembre de 1719 figura la adquisición por parte del marqués Giacomo Filippo II (1672-1764) de un San Jerónimo del Spagnoletto. ${ }^{85}$ Este cuadro fue comprado junto con otro de Tintoretto en Madrid, a través del señor Francesco Maria, por un precio de 1145,14 liras. Esta obra pasó por herencia a su hijo Giacomo Filippo Durazzo III (1729-1812), tal como queda constatado en el inventario de su colección del 31 de mayo de $1787 .{ }^{86}$ Como obra de Ribera aparece recogido en la guía de $\operatorname{Ratti}^{87}$ y, del mismo modo, en el catálogo de la colección de 1792. Sin embargo, Torriti lo atribuye, en 1967, al maestro holandés Hendrick van Somer (Ámsterdam, ¿1606?-1684). ${ }^{88}$ Con la misma atribución al maestro holandés aparece actualmente en la galería y por este motivo no se elaboró su ficha de catalogación.

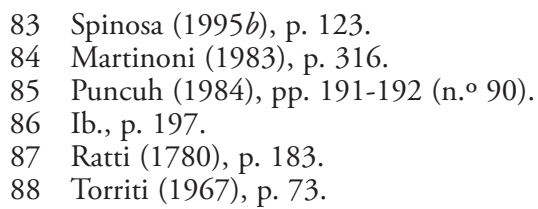


Como apéndice de este apartado hay que resumir diciendo que la mayoría de los cuadros originariamente atribuidos a José de Ribera, o comprados como tales por los nobles genoveses, con el paso del tiempo han sido estudiados de modo más profundo, lo que ha conducido a un cambio de autoría, aunque muchos de ellos estén firmados por el maestro. La explicación reside en el hecho de que José de Ribera, pintor valenciano activo en Nápoles desde aproximadamente el año 1626 (por lo que recibe el nombre de lo Spagnoletto), ya en vida fue un pintor muy demandado, admirado y valorado por sus retratos de filósofos y apóstoles, como bien pone de manifiesto la opinión de Francisco Pacheco: «[...] la diferencia que hace a los demás, por tener siempre delante el natural». ${ }^{89} \mathrm{La}$ abundante producción de Ribera ejerció una fuerte influencia en el área napolitana, provocando la proliferación de copias, pero también de imitaciones que, a veces, se acompañan con firmas y fechas apócrifas, por razones mercantiles, aun cuando se trata de obras de escasa calidad. Así lo constata De Dominici, quien habla de imitaciones «autorizadas» por el propio Ribera al pintor Bassante. ${ }^{90}$ De hecho, es sabido que muchas obras del pintor napolitano Bassante se venden como autógrafas de Ribera, por lo que no es improbable que algunos cuadros que se conservan, quizás también con la firma apócrifa del maestro español, puedan considerarse como obra de esta personalidad todavía desconocida.

\section{Iglesia de San Giorgio}

Antes de concluir el tema dedicado a la pintura española del siglo XVII en Génova, hay que mencionar el único testimonio de la presencia de un cuadro español de este siglo en una iglesia. De hecho, es extraño encontrar un cuadro español en una iglesia genovesa porque la mayoría de las obras fueron adquiridas por grandes familias con el fin de enriquecer sus colecciones privadas, como testimonio de prestigio familiar.

A diferencia de lo que podría pensarse, la iglesia de San Giorgio, en la que se halla el cuadro en cuestión, es de pequeńas dimensiones y con un culto muy limitado. En esta iglesia, concretamente en la capilla situada en

89 F. Pacheco, Arte de la pintura, Sevilla, 1649 (edición de F. J. Sánchez Cantón, Madrid, 1956, vol. II, p. 213), cit. en Ferrari (1986), p. 110.

90 De Dominici (1970), pp. 22-23. 
el lado del Evangelio próxima al altar, llamada Capilla de la Dolorosa, se encuentra una interesante Piedad (ficha n. ${ }^{\circ} 19$ ), atribuida a Alonso Sánchez Coello (Benifairó de les Valls, Valencia, 1531-Madrid, 1588). Su presencia en la iglesia se debe a la donación realizada por un fiel de san Giorgio (san Jorge), patrón de la ciudad de Génova, con el fin de que fuera venerada. Los estudios relativos a esta obra aportan algunos datos sobre la donación, que tuvo lugar en 1844, y solo dos años después Alizeri escribe con respecto a este cuadro y a su autor las siguientes líneas:

[...] È recentissimo dono il quadro della Pietà nella terza cappella a mancina nuovamente abbellita di marmi, il quale si da per opera di certo Coelio spagnuolo, ignoto del tutto fra noi e da giudicarsi quivi come non indegno seguace del Rubens. I colori sono in qualche parte anneriti; specialmente ne riflessi, caricati forse e men trasparenti che non domanda l'imitazione del gran fiammingo, ma vi si trovano bei toni locali, sovrattutto nelle carni del nudo. ${ }^{91}$

En este contexto, hay que aludir a la problemática surgida en torno a la autoría de esta obra. Como se ha indicado anteriormente, la Piedad figura en la iglesia como pintura de Alonso Sánchez Coello, de acuerdo a la atribución realizada por Franco Boggero, autor de la guía de la iglesia. Sin embargo, Alizeri y Grosso consideraron esta tela obra del pintor madrileño Claudio Coello (1642-1693). ${ }^{92}$ Grosso fundamenta su opinión en el único documento que se conserva sobre la procedencia y donación de esta obra, que fue recogido posteriormente por W. Piastra, en 1973. Concretamente, se trata de una carta escrita el 17 de octubre de 1844 por el donante, Antonio Ramorino hijo de Domenico, residente en San Petersburgo, destinada tanto al párroco de la iglesia como al gremio de los herreros de San Giorgio, en la que les pide lo siguiente:

[...] a voler accettare in dono un quadro grande con sua cornice di legno dorata, pittura giudicata originale di Claudio Cohelo Spagnuolo, rappresentante Maria Santissima Addolorata che tiene nelle braccia il Suo Divino Figliolo morto deposto dalla Croce. Ed essendo detto quadro per disposizione ultima del fu

91 Alizeri (1846-1847), vol. I, p. 428. Traducción del texto: «[...] Es recientísima la donación del cuadro de la Piedad de la tercera capilla, que se tiene por obra de cierto Coelio español, desconocido del todo entre nosotros y debe juzgarse aquí como un no indigno seguidor de Rubens. Los colores en parte se han ennegrecido; especialmente en los reflejos, quizás cargados y menos transparentes de cuanto sería necesario para la imitación del maestro flamenco, pero se encuentran buenos tonos, sobre todo en las carnaciones».

92 Grosso (1920), p. 306. 
Domenico Ramorino nostro amatissimo Padre di propietà delle mie sorelle Carlotta, Lucrezia e Dora, dichiaro averne alle istesse sborsato il prezzo convenuto, e perciò fattolo di mia propietà. Son certo che detti Signori Prevosto e Fabbricieri, vorranno continuare quella protezione che hanno finora usato a dette mie Sorelle, le quali spero non cesseranno di pregare Maria Santissima per la mia famiglia. Desidero finalmente che detto quadro sia esposto in venerazione in detta Chiesa di S. Giorgio di Genova al più presto che sarà commodo agli interessi della Chiesa medesima [....$^{93}$

Nada se sabe sobre la familia Ramorino, pero por la carta se deduce que el cuadro debía encontrarse en la ciudad. Complaciendo los deseos del donante, la tela fue colocada en la iglesia en 1845 , en la capilla situada en el lado del Evangelio junto al altar mayor, donde había un crucifijo de madera, siendo restaurada para la ocasión.

Otro texto que alude a este cuadro es el recogido por monseñor Lazzaro De Simoni en 1948, donde aparece atribuido igualmente al «Spagnuolo Claudio Coello", quien, en palabras de este autor, "muere de angustia» porque a Luca Giordano le admiten en El Escorial. De Simoni indica que en un principio la obra fue atribuida a Rubens, tal como recoge un libro del archivo parroquial, pero parece ser de Coello, a quien califica de «imitador apasionado del gran pintor flamenco». ${ }^{94}$

Si bien los documentos ahora citados hacen referencia a Claudio Coello, Franco Boggero opina que se trata de una obra del pintor valenciano Alonso Sánchez Coello, ${ }^{95}$ tal como aparece en la iglesia. Es decir, aun teniendo en cuenta el lamentable estado de la tela y la carencia de investigaciones recientes sobre el tema, en mi opinión parece más acer-

93 Piastra (1973), p. 45. Traducción del texto: «[...] querer aceptar en donación un gran cuadro con su marco de madera dorada, pintura juzgada original de Claudio Cohelo español, que representa a María Santísima Dolorosa que tiene en brazos a Su Divino Hijo muerto depuesto de la cruz. Este cuadro por disposición última de mi padre Domenico Ramorino pasó a propiedad de mis hermanas Carlotta, Lucrezia y Dora; declaro haberles pagado el precio convenido y haberlo hecho de mi propiedad. Sé que tanto el sacerdote como el gremio de los herreros querrán continuar con la protección dada a mis hermanas, las cuales espero no cesen de rezar a María Santísima por mi familia. Deseo finalmente que este cuadro sea expuesto para ser venerado en dicha iglesia de San Jorge de Génova lo antes posible para los intereses de la misma iglesia [...]». Un dato interesante a mencionar es que los Ramorino eran una familia noble piamontesa. Es posible que Antonio fuera a San Petersburgo a trabajar y que su familia permaneciese en Génova.

94 De Simoni (1948), pp. 264-265.

95 Boggero (1979), n. ${ }^{\circ} 84$, p. 13. 
tado relacionar esta obra, desde el punto de vista estilístico y formal, con la pintura española de finales del siglo XVII y, en ese caso, con la producción pictórica del primer período de Claudio Coello. Sin embargo, un juicio definitivo solo podrá venir después de la restauración que precisa este cuadro.

Con esta obra se concluye el tema dedicado a la pintura española del siglo XVII en Génova. Como se puede constatar, la mayoría de las obras catalogadas en este primer capítulo corresponden a la producción artística de José de Ribera o de su ambiente artístico. Si se consultan las fuentes tradicionales, C. G. Ratti y F. Alizeri, se advierte la notable presencia de obras de José de Ribera en villas y palacios genoveses de los siglos XVIII y XIX (Palazzo Serra, Palazzo Sopranis, Palazzo Gropallo, etc.), de las que se desconoce su localización actual, siendo probable que la mayoría de ellas se encuentren fuera de Italia. 



\section{2 \\ LA PINTURA ESPAÑOLA DEL SIGLO XVIII EN GÉNOVA}

\subsection{Consideraciones sobre la cultura artística de la segunda mitad del siglo XVIII en Liguria}

El siglo XVIII fue una época de grandes contradicciones, oscilante entre exigencias de cambio y fuertes resistencias por parte de la tradición, entre cosmopolitismo y regionalismo, capaces de marcar profundamente la sociedad del momento. En Liguria, el siglo XVIII se caracterizó por la estrecha interrelación entre las dinámicas culturales y sociales, tal como se refleja en la promoción de los acontecimientos culturales llevada a cabo por la aristocracia, importante protagonista de la vida económica.

$\mathrm{La}$ «crisis» del siglo XVIII se produjo fundamentalmente por la dialéctica entre renovación y tradición, que se manifestó en la "crisis» del lenguaje tardobarroco de la primera mitad de siglo, y en el creciente interés hacia el mundo clásico y su historia. En cuanto a la crisis del lenguaje tardobarroco, hay que señalar que esta se relacionó con las transformaciones realizadas en la enseñanza impartida por la Accademia Ligustica de Génova (fundada en 1751, conforme a la idea de las academias del siglo XVII), interesada en la renovación del contexto artístico local.

Con la difusión de la cultura ilustrada y del gusto neoclásico, las relaciones entre comitente y artista fueron de tipo intelectual más que económico, produciéndose un mayor interés por las «artes» en su papel de transformadoras de la sociedad. 


\subsection{Un ilustrado en Liguria: Gerolamo Grimaldi}

Gerolamo Grimaldi, ilustre diplomático de origen genovés, fue uno de los representantes de la "cultura de las Luces». Muy pronto, se desvinculó de su patria para entrar en contacto con el ambiente de la alta diplomacia y de las grandes cortes europeas. En 1736 Gerolamo Grimaldi entró a formar parte de la diplomacia espańola, al servicio del infante Felipe, iniciando de este modo una rápida carrera política. ${ }^{96}$

La fortuna de Gerolamo Grimaldi no cambió con la llegada del nuevo rey Carlos III, uno de los soberanos ilustrados de Europa. El duque de Grimaldi se ganó la estima del nuevo soberano, convirtiéndose en su ministro y entrando a formar parte del círculo de políticos extranjeros, como Wall y Esquilache; con ellos y con el grupo más culto y progresista de los aristócratas españoles (conde de Aranda, José Moñino y Campomanes) compartió las ideas regalistas y el vivo interés por la cultura de la Ilustración. Con la caída de Esquilache su figura entró también en declive. De hecho, la elegancia de sus modales, sus gustos refinados, el pertenecer a la clase de los llamados golillas y, sobre todo, sus orígenes genoveses fueron la causa de la antipatía que las clases menos acomodadas sintieron hacia él, lo que le condujo, a mediados de los años setenta, a abandonar España.

Gerolamo Grimaldi destacó por su gran cultura, dedicándose tanto a las artes como a las cuestiones técnicas y científicas. De hecho, se encargó de supervisar a partir de 1766 la ampliación de la residencia real de Aranjuez, realizada por Francesco Sabatini. Su papel en la corte española fue relevante, como se constata en la obra de Ponz, quien lo define como "celoso Protector» de la Academia y del Gabinete de Historia Natural. ${ }^{97}$

Como se ha mencionado anteriormente, la situación política en España se agravó en estos momentos, poniendo en peligro su persona. Sin embargo, gracias al prestigio que gozaba ante el rey, consiguió decidir no solo su próximo destino - la embajada en la Santa Sede—, sino también un sucesor que llevaría adelante su ideología política —José Moñino, futu-

96 En este contexto, es preciso mencionar que su padre, Francesco Maria, había desempeñado el cargo de representante de la República genovesa en Espańa desde 1712 hasta 1726.

97 Antonio Ponz, Viage de España en que se da noticia de las cosas más apreciables y dignas de saberse que hay en ella. Madrid, 1793, vol. v, pp. 271-275, cit. en Pessa (1990), p. 12. 
ro conde de Floridablanca, en ese momento embajador español en Roma-, y que compartiría el interés por el espíritu regalista. Así, en 1777 el duque de Grimaldi ocupó el cargo de embajador español en la Santa Sede, anteriormente desempeñado por Mońino, y participó activamente en el ambiente artístico romano. De hecho, Gerolamo Grimaldi entabló relación con Mengs ${ }^{98}$ y con Francisco Javier Ramos, alumno del pintor alemán y pensionado español en Roma. Es sabido que el duque se ocupó de mandar obras de Mengs a España y de comprar miniaturas y grabados de célebres obras italianas para el monarca Carlos III.

$\mathrm{Al}$ mismo tiempo, el duque se convirtió en un punto de referencia importante para los jóvenes artistas genoveses que iban a Roma a realizar un período de estudio. Este es el caso, por ejemplo, de Luigi Gismondi, quien, gracias al duque, pudo realizar una copia (un diseńo y después un grabado) del retrato que Anton von Maron había pintado del duque de Grimaldi. Este grabado le abrió las puertas al éxito artístico.

La muerte de su hermano Ranieri, en 1783, alejó a Gerolamo Grimaldi por primera vez de Roma, siendo sustituido de forma temporal por Nicolás de Azara, quien ocuparía su cargo, tras lo que el duque decidió establecerse en Génova. Con la muerte de Paolo Gerolamo, quien había heredado junto con su hermano Ranieri todo el patrimonio de bienes muebles e inmuebles dejado por su padre Francesco Maria, donó toda su colección al único sobrino varón, Francesco Maria, hijo de Ranieri. En 1898 las hermanas Ferrari heredaron el patrimonio Grimaldi-Pallavicini y en 1899 pusieron en venta los objetos más valiosos de la colección familiar. Coincidiendo con este hecho, en 1899 se redactó el catálogo de la venta, que da testimonio de la rica colección formada por obras de grandes maestros genoveses, flamencos y de otros europeos. Es interesante señalar que entre las obras catalogadas en 1899 figuran tres consideradas de escuela española: Retrato de Felipe II $(175 \times 135 \mathrm{~cm})$; Retrato de Felipe IV $(85 \times 62 \mathrm{~cm})$; y Retrato de María Gabriela de Saboya $(85 \times 62 \mathrm{~cm}) .{ }^{99}$ Tras la venta de 1899 ninguno de estos cuadros permaneció en la capital ligur, siendo la mayoría de ellos adquiridos por compradores extranjeros.

98 Anton Raphael Mengs estuvo al servicio del rey desde 1761, y gozó del favor de la corte y de la admiración de los hombres de cultura. El duque de Grimaldi estableció con el artista una relación de gran estima.

99 Pessa (1990), pp. 23-24. 


\subsection{Estudio de las obras de pintura española del siglo XVIII en Génova}

A diferencia de las obras del siglo XVII antes estudiadas, que fueron adquiridas principalmente en el XIX, en este caso se cuenta con una obra de época neoclásica en la que aparece retratado el propio comitente - el duque de Grimaldi, hombre de cultura ilustrada-, que «sobrevivió» a la dispersión que sufrió su colección a finales del ochocientos.

\section{Museo dell'Accademia Ligustica di Belle Arti}

La obra en cuestión se encuentra en el Museo dell'Accademia Ligustica, que fue fundada en 1751, de acuerdo con la idea de las academias de aprendizaje del siglo XVII, con una finalidad didáctica y promotora de la renovación artística local. En su depósito se conserva una obra de Francisco Javier Ramos (Madrid, 1744-1817), Retrato del duque Paolo Gerolamo Grimaldi (ficha n. ${ }^{\circ}$ 20), que G. B. Grimaldi Pietra cedió a la Accademia en 1790 , quien a su vez la había recibido del retratado a cambio de una serie de volúmenes sobre arquitectura militar. Como puede constatarse, el duque de Grimaldi aparece retratado con el traje de dignatario español, teniendo como fondo el Palacio de Aranjuez.

En el catálogo de la pinacoteca de la Accademia, publicado en 1983, la tela, en aquel entonces de difícil lectura por el mal estado de conservación, aparece citada con la atribución tradicional a Anton von Maron (Viena, 1733-Roma, 1802), seguidor de Mengs, y considerada como copia autógrafa del cuadro conservado en la colección Durazzo Pallavicini. ${ }^{100} \mathrm{Su}$ restauración en 1984 reveló la siguiente información: "Antonius de Maron/Xaverius Ramos pingendo tulit», que determinó la autoría de von Maron exclusivamente para el retrato Durazzo Pallavicini, que había llegado a la colección a través de la herencia Pallavicini, y la paternidad del menos conocido Ramos (alumno de Mengs) para el cuadro de la Accademia, que se considera copia del retrato de von Maron. ${ }^{101}$

100 Baccheschi (ed.) (1983, 1988), pp. 58-59 de la edición de 1983.

101 Ib., p. 113 de la edición de 1988. 
El retrato que se conserva en la Galleria Durazzo Pallavicini se dató en $1787,{ }^{102}$ sin tener en cuenta la cita de C. G. Ratti de 1779 , quien refiriéndose a Anton von Maron afirma: "Oigo hasta aquí la fama del retrato hecho por Vos del señor Duque [...]». ${ }^{103}$ La copia de la Accademia se fechó en $1784,{ }^{104}$ en función del grabado que Luigi Gismondi había realizado ese mismo año del retrato de Roma, del que se conserva un ejemplar en el Museo Luxoro de Génova-Nervi. Tanto en el cuadro Durazzo Pallavicini como en la copia de la Accademia se pueden apreciar, en el margen inferior derecho, algunos de los cargos desempeñados por el duque y una vaga referencia a la cronología: «...ado? en Roma de $177 . . . »$, quizás alusiva a la fecha de ejecución de aquella. ${ }^{105}$

El retrato de Anton von Maron fue realizado durante la estancia del duque en Roma, como embajador del rey de Espańa en la Santa Sede, cargo que ocupó a partir de $1777 .{ }^{106}$ La cita que hace Ratti en 1779 constituye un dato relevante para establecer la cronología de la obra de la Accademia, entre 1777 y 1779. Dentro de este contexto, cabe decir que el retrato de Anton von Maron ejerció una gran influencia en la retratística genovesa de la primera mitad del siglo XIX, tal como puede constatarse en algunos retratos de Matteo Picasso y de Sante Panario. ${ }^{107}$

Francisco Javier Ramos realizó este retrato gracias a las relaciones que su maestro Mengs (cuñado de von Maron) estableció con el duque de Grimaldi durante los ańos transcurridos en Roma, amistad nacida durante su estancia en España, y gracias a la gran demanda de obras de Mengs, que llevó a este pintor a permitir que sus alumnos realizaran copias de sus obras (práctica muy difundida en el ambiente artístico romano).

102 Torriti (1967), p. 263.

103 Ratti (1779), s.p.

104 Baccheschi (ed.) (1983, 1988), p. 59 de la edición de 1983.

105 Ib., p. 77 de la edición de 1988.

106 Escudero (1985), pp. 151-152.

107 Sborgi (1971a). 



\section{3 \\ LA PINTURA ESPAÑOLA DEL SIGLO XIX EN GÉNOVA}

La mayor parte de las obras de pintura española del siglo XIX existentes tanto en Génova como en el resto del territorio ligur corresponden a la producción artística del pintor vigués Serafín Avendaño, por lo que a continuación se realiza una presentación de dicho pintor, para pasar después al estudio de sus obras. En este apartado se deja constancia de la continuidad de las relaciones artísticas entre España y Liguria en el siglo XIX. Y de como Génova, después de haber perdido autonomía política, relevancia económica y ejemplaridad artística, conservaba, en cambio, en el camino hacia la Ciudad Eterna, una posición estratégica gracias a la cual fueron numerosos los hombres de cultura, y algunos de los artistas más prestigiosos a nivel internacional, que pasaron por ella, dejando valiosos testimonios autobiográficos y apreciaciones entusiastas por las secretas bellezas de la ciudad desveladas al forastero y por los sugestivos panoramas que ofrecían sus costas y montes. ${ }^{108}$

\subsection{Serafín Avendaño (Vigo, 1837-Valladolid, 1916) y el ambiente artístico ligur}

Serafín Avendaño nació en agosto de 1837 en Vigo, y se trasladó a Madrid muy joven. Realizó sus estudios iniciales de pintura en la Academia

108 Giubilei (2004), p. 259. 
de San Fernando con Antonio María Esquivel, pintor de historia religiosa y de retratos, y con Bernardo Villamil Marracchi, pintor de paisajes y de escenas taurinas. Más tarde, debido a la actividad diplomática de su padre, viajó a Estados Unidos, donde pintó las cataratas del Niágara, y visitó y examinó detenidamente los museos de pintura y principales galerías de España, Francia, Inglaterra y Düsseldorf. Con este bagaje de experiencias, en mayo de 1861 se presentó a la asignación de una beca para el pensionado artístico en Roma, que había sacado a concurso la Academia de San Fernando. La beca suponía una permanencia en Italia de tres años, con la obligación de residir en Roma durante doce meses. Junto con su compañero Martín Rico obtuvo dicha beca, y, quizás desde finales de 1861 y sin duda alguna desde 1862, se encontraba en Italia. En la capital italiana estuvo un año, y su presencia en Génova está documentada en $1863,{ }^{109}$ ciudad en la que su padre, Joaquín, había sido nombrado en 1859 cónsul general de España. Su asentamiento definitivo en la capital ligur no tuvo lugar hasta 1866. Por tanto, los motivos que le llevaron a Génova, y que le hicieron quedarse casi treinta años, fueron ante todo de carácter familiar y también artístico, pues fueron numerosos los amigos pintores y escultores que lo habían acogido desde los primeros momentos genoveses.

Alrededor de 1830, el ambiente pictórico genovés estaba en plena decadencia, ya que se mantenían las tendencias neoclásicas y románticas que dificultaban la asimilación de nuevos aportes. En relación con esto, cabe citar al pintor francés Camille Corot, quien estuvo en Génova en 1834 pintando vistas que no dejaron huella en el ambiente pictórico genovés a causa de la fuerte persistencia del tradicionalismo académico. De hecho, el primer pintor ligur que consiguió imponerse fue Matteo Picasso. Inmediatamente después surgieron tres pintores casi coetáneos: Giuseppe Isola, Giuseppe Frascheri y Federico Peschiera. Entre 1845 y 1850 se produjeron una serie de novedades importantes para el porvenir artístico de la región ligur: en 1846 la Accademia Ligustica di Belle Arti organizó una exposición a nivel nacional; y en 1850 se fundó la Società Promotrice di Belle Arti di Genova.

109 En una pintura realizada por el joven Ernesto Rayper (Génova, 1840-Gameragna, 1873), fechada el 27 de septiembre de 1863, el rostro de Avendaño aparece entre los pintores que retrata este artista genovés, ocupados en pintar en plein air en la localidad de Carcare. Véase Giubilei (2004), p. 260. 
Los jóvenes pintores genoveses, entre los que hay que destacar a Gandolfi, Tammar Luxoro y Nicolò Barabino, compartieron sus experiencias con los artistas extranjeros que llegaban a tierras ligures. De este modo apareció una generación, nacida entre 1830 y 1840, defensora del «verismo». El primer genovés que estableció las bases de la pintura de paisaje fue Tammar Luxoro (Génova, 1825-1899), que tuvo como maestro a Antonio Fontanesi, uno de los treinta fundadores de la Società Promotrice y artífice de ese cambio decisivo en el ámbito de la pintura. Asimismo, fue nombrado académico de mérito de la Ligustica en 1864 y luego director de paisaje del natural. Por tanto, Luxoro tenía ya un papel oficial en el seno de la Accademia cuando Avendaño empezó a visitar Génova, ciudad que podía ofrecerle una buena integración social y cultural.

En 1854 llegó a Génova el portugués Alfredo de Andrade (Lisboa, 1839-Génova, 1915), convirtiéndose en alumno de Luxoro. Entretanto, este último había encontrado otro prosélito en su alumno Ernesto Rayper (Génova, 1840-Gameragna, 1873), quien iba a las colinas de Carcare (cerca de Génova) a pintar en plein air, relacionándose al mismo tiempo con artistas suizos y franceses. En 1863 algunos jóvenes pintores comenzaron a reunirse en las colinas de Carcare para pintar la naturaleza y el paisaje del natural. Con los encuentros de Carcare y de las orillas del Bormida (río ligur-piamontés) tomó forma el movimiento pictórico renovador genovés conocido con el nombre de Scuola Grigia ('Escuela Gris'). El período de Carcare señala, por tanto, la fundación del nuevo lenguaje como modelo poético de interpretación del natural.

Como se ha indicado antes, Serafín Avendaño se estableció definitivamente en Génova en 1866, en Quarto dei Mille, y junto con otros pintores se alojó en casa de la marquesa Isabella Salvago (Nina, que estuvo casada con el barón Giuseppe Ravina, quien en los años setenta desempeńo el cargo de vicecónsul de Espańa en Génova), que más tarde se convertiría en su alumna. Parece ser que fue en casa de Nina Salvago donde entró en contacto por primera vez con Andrade, Rayper y Luxoro (teórico y portavoz del cenáculo de los innovadores genoveses) y donde pudo conocer a Giuseppe y Giuseppina Verdi, llegados también a la capital ligur en 1866. Por tanto, el pintor vigués elige, como indica Maria Flora Giubilei, la comparación y el diálogo con los compañeros más orientados hacia las poéticas del natural en plena sintonía con su sensibilidad y experiencia de 
paisajista madurada en su país y en otros lugares del mundo hasta ese momento. ${ }^{110}$

La existencia de este grupo de pintores queda reflejada en la literatura de la época. Así, el escritor Anton Giulio Barrili habla en su novela Amori alla macchia de Avendaño, Rayper y Andrade, entre otros, refiriéndose a ellos con las siguientes palabras: «[...] Todos los veranos, al pasar por el valle, no se veían más que sombrillas blancas derechas como setas campestres». ${ }^{111}$

Como señala Mario Labó, los "grises» se llamaron de este modo en homenaje a la abolición de los innaturales blancos y negros de la paleta y a su amor por las medias tintas y los claros. Este autor añade que Avendaño, en fraternidad con Rayper, se olvidó de Corot y Daubigny por el rechazo a los oscuros. ${ }^{12}$ Según D. Martelli, el término Scuola Grigia podría derivar del «ton gris» del que habla Altamura: "Fue él quien [...] comenzó a hablar del "ton gris" de moda en París y todos al escucharlo y después al practicarlo, ayudándose de un espejo negro que, al decolorarlo, permite captar antes la tonalidad del claro-oscuro, la macchia». ${ }^{113}$

Las reuniones de Carcare provocaron la protesta de los conservadores, tal como se observa en la crítica que hicieron de los cuadros de paisaje que se expusieron con motivo de la muestra genovesa de Bellas Artes (1869):

¡Esta gente ha perdido la brújula, se han vuelto locos, no comprenden nada! Cogen todo lo sobrante en la paleta, aquellos colores sucios que uno al final de un día de trabajo tiraría, y con una espátula los van poniendo sobre la tela y enseguida obtienen un cuadro como estos.

Ante esta situación, el autor de la revista de la Exposición de Bellas Artes, celebrada en la Accademia Ligustica en 1869, dio la siguiente respuesta:

Mirad vuestro catálogo y veréis que estos borrones y aquellas cosas hechas por casualidad tienen un nombre, que se encuentra también en los mapas y diccionarios geográficos: Savignone, Rapallo, Rivara, Carcare, Bave-

110 Ib., p. 261.

111 Barrili (1885).

112 Labó (1926), p. 19.

113 Martelli (1952), p. 204. 
no, Castel Fusano, Bride-les-Bains. ¿Queréis saber realmente cómo Avendaño, Andrade, Pittara, Rayper, Signorini, Scifoni, Musso, Pastoris, Bertea y Lega pintan sus cuadros? Para representar el campo, empiezan yendo a buscarlo. Echan encima sus equipajes, y apretados en un fajo el caballete, la sombrilla, la banqueta, las telas, los bastidores y los demás arneses del oficio, se encaminan hacia los lugares que mejor se adaptan a sus gustos, buscando temas. Hacen cien bocetos hasta encontrar el motivo, la línea, el claro-oscuro, la elegancia; y ahora les queda el color, ahora el efecto, la frescura o la tristeza del lugar. De este modo, pasarán semanas de investigación para luego elegir entre todos los bocetos el mejor para pasarlo a la tela. ${ }^{114}$

Si en Carcare y en el Bormida tenían lugar los encuentros veraniegos, en invierno estos jóvenes pintores se reunían para trabajar tres tardes a la semana en el Palazzetto Doria, ${ }^{115}$ donde tenían un estudio llamado Scuola Grigia. Durante las reuniones invernales, los «grises» dibujaban y pintaban del natural, sirviéndose de modelos vestidos o desnudos. Después de la jornada de trabajo, frecuentaban el Café Omnibus para conversar e intercambiar opiniones.

Además de la formación de una pintura de paisaje auténticamente ligur, con carácter unitario, los "grises» entraron en contacto con los piamonteses (Escuela de Rivara), toscanos (Escuela de Pergentina) y napolitanos (Escuela de Résina). De hecho, Somaré señala en 1928 que la Escuela de Rivara era un cenáculo mixto que contaba entre sus fundadores con Avendaño, Rayper e Issel, de ahí que lo denomine «cenáculo ligur-piamontés». ${ }^{116}$ Los pintores de Rivara tenían, igualmente, como punto de referencia el natural a la hora de pintar sus cuadros, y a menudo los terminaban también al natural. De este modo, Rivara y sus prados verdes se convirtieron en la «Babilonia» de la pintura de paisaje. ${ }^{117}$

Como indica Bernardi, «interregionalismo e internacionalismo» caracterizaron las reuniones de Rivara; y lo verdaderamente importante fue que por primera vez se producía el encuentro entre hombres de cultu-

114 Rocchiero (1960), p. 19.

115 A modo de apunte, es interesante mencionar que el músico Giuseppe Verdi estuvo viviendo en el Palacio Doria entre 1874 y 1900. El trato, por parte del pintor vigués, de Verdi, testimoniado por el intercambio de cartas, desembocó en el encargo directo de numerosas pinturas a Avendaño. Véase Giubilei (2004), pp. 263-264.

116 Somaré (1944).

117 Camerana (1872). 
ra diversa, permitiendo una renovación general del arte en Italia. ${ }^{118}$ Así, el eje Carcare-Rivara constituyó la base de la renovación del lenguaje pictórico, que se vio consolidada por el aporte de experiencias toscanas. Todos ellos tuvieron en Fontanesi su fuente de inspiración y tendieron a la búsqueda de un lenguaje íntimo.

Serafín Avendaño se formó en las postrimerías del Romanticismo y asistió a los iniciales intentos de "liberación» de la pintura. En sus viajes juveniles conoció, principalmente, la obra de los ingleses Constable y Bonington, y algo más tarde la de Corot, Courbet y la de la Escuela de Barbizon. Como afirma Vitaliano Rocchiero, el pintor vigués, liberándose de las trabas del academicismo y de las influencias de Corot y Fontanesi, dio cuerpo a una pintura airosa, verídica y moderna, lo que explica su inclusión en la Escuela Gris (cenáculo de artistas ligures renovadores de la pintura de paisaje) y en la Escuela de Rivara (cenáculo de artistas piamonteses renovadores de la pintura paisajística), mereciendo así el aplauso de los innovadores del paisaje. ${ }^{119}$

De hecho, en la producción de Serafín Avendaño se constata una evolución estilística, representativa de la seguida por gran parte de la pintura de paisaje europeo en la segunda mitad del siglo XIX, que transcurre paralelamente a la del paisaje francés, e incluso parte de él, pero desemboca en una alternativa al impresionismo.

Dentro del mismo contexto, es preciso decir que en este momento en Europa grupos de pintores, casi todos jóvenes, fueron abandonando las enseñanzas académicas para buscar el estudio del natural. De hecho, la renovación pictórica fue llevada a cabo por grupos de paisajistas. La nueva pintura, como indica Gianfranco Bruno, nació en torno a la idea innovadora que recorría Europa de que el arte debía inspirarse en el motivo natural, entendido como «lugar» del que emana y en el que se verifica la emoción del pintor. ${ }^{120}$

Serafín Avendaño se sintió atraído por la tierra y el mar, y por los cambios producidos en los diferentes momentos del día. Prefirió los temas

118 Bernardi (1942), «La Scuola di Rivara», p. 33.

119 Rocchiero (1991), p. 16.

120 Bruno (1993), p. 17. 
marinos ambientados en la costa ligur y las composiciones tomadas a la luz del día, a excepción de la obra Efectos de luna, que capta un paisaje nocturno. Mostró predilección por las composiciones en horizontal, con amplios horizontes, que sugieren sensación de profundidad. En su obra, el verdadero protagonista es el paisaje, un paisaje sereno y límpido. La figura humana a veces aparece, en reducidas dimensiones, formando un unicum con el paisaje. Compartió con los grigi la exaltación de los tonos locales, recurriendo a la gama de los verdes densos y grises delicados y sobrios. Común a todos ellos era la voluntad de captar el paisaje en sus aspectos más melancólicos y trépidos. No se interesaron por las elegancias formales, y su deseo era reproducir las cosas más humildes. En opinión de Rocchiero, de los grigi, Avendaño fue el más sabio, el que hizo menos concesiones a las elegancias formales. ${ }^{121}$

Con el fin de aproximarnos a la personalidad artística de Avendaño, se cita a continuación la definición que Rosa E. Caamaño Fernández, gran estudiosa del pintor vigués, hizo de este artista:

Pintor esencial ante todo, simplifica los planos de color, ligados por manchas de luminosidad atmosférica, pinceladas menudas e intensas y vibrantes, y finalmente con profunda y captante intuición de sus mágicas olas de vitalidad, que recorren prados, ríos, roquedales, comunicando un universo invisible y animístico. ${ }^{122}$

Avendaño huía del «arte compuesto», afirmando:

No hay otro arte sino el que reproduce lo que en la naturaleza nos impresiona, sea por el efecto de luz que por la belleza del lugar, o por lo sonriente o lo triste que nos impresiona [...], y para obtener esto es preciso dejar tal cual los árboles, las piedras, los animales y las sombras siguiendo el ejemplo de Velázquez. ${ }^{123}$

Mario Labó, con motivo de la exposición de 1926, nos lo define con las siguientes palabras:

Justísimo en la elección de los motivos, también el más variado en la composición de sus cuadros. Dibujante minucioso e incisivo, se complace en los

121 Rocchiero (1963), p. 8.

122 Caamaño Fernández (1991), p. 13.

123 Calderini (1901), p. 146. 
detalles, siguiendo la irregularidad de una escollera o la rugosidad de un tronco de árbol, o, también, de un vestido de seda. Su pintura es de una perfecta limpieza. Se ve en él la madura experiencia y el dominio de los medios. Como los macchiaioli, pero sin el rigor de estos, se preocupa del color, de la luminosidad natural, del amor a la luz solar, que dan a sus cuadros un largo respiro y un perpetuo sentido de alegría. Que Signorini le estimara tanto no es de extrańar porque el principio de la macchia aflora en sus cuadros del período genovés. ${ }^{124}$

Fortuny, Morelli, Meissonier, Jules Breton y Fontanesi fueron sus pintores favoritos. T. Calderini escribió sobre él:

Aceptó resueltamente en sus paisajes las figuras vulgares, ciudadanos, aunque también personas elegantes si debían estar [...], siendo de los primeros de este género en Italia. ${ }^{125}$

Serafín Avendaño y sus compañeros acabaron imponiéndose en Génova, frente a los académicos, para los que no existía pintura sin "dibujo, colorido y perfección». El tipo de paisaje cultivado por los "grises» representó el centro del movimiento antiacadémico ligur, denominado por los académicos Scuola degli spinaci ('Escuela de las espinacas'), por la exaltación del color local.

Fue el descubrimiento, como constata Gianfranco Bruno, de la poética de lo efímero, después de las tradicionales composiciones de historia y del paisajismo de la pintura oficial. ${ }^{126}$ De este modo, es preciso señalar que no solo el grupo de los "grises», con Ernesto Rayper y Serafín Avendaño a la cabeza, influyó y renovó las escuelas pictóricas de los grupos italianos hermanos, sino que la obra de Avendaño, a través de las numerosas exposiciones (Génova, desde 1867 hasta 1896; Turín, desde 1867 hasta 1890; Milán, desde 1872 hasta 1886; Parma, 1870; Roma, 1883; y Venecia, 1887), contribuyó al desarrollo de la renovación pictórica italiana. Así queda reflejado en la afirmación que Telemaco Signorini realizó con motivo de la Exposición de la Società Promotrice celebrada en Parma en 1870:

Avendaño pinta paisajes excelentes [...] quizás sea de él de quien el arte en Italia puede esperar una dirección más saludable. ${ }^{127}$

124 Labó (1926), p. 23.

125 Calderini (1901), p. 147.

126 Bruno (1971), p. 451.

127 Signorini (1870), p. 192. 
Del mismo modo, Rocchiero señala que el encanto de las telas de Avendaño era tal que a principios del siglo XX se exponían en los mercados de arte más famosos, como el de Londres, despertando el interés de los más refinados coleccionistas italianos (Angelo Balbi, Stefano Rebaudi, Orlando Grosso y Bartolomeo Pellerano) y de las colecciones públicas (Accademia Ligustica di Belle Arti de Génova, Galleria d'Arte Moderna de Génova, Museo Civico de Turín y Museo de Arte Moderno de Madrid). ${ }^{128}$

Antonio Stella, comentando la exposición de Turín de 1892-1893, dice de este pintor:

Sobresale por el color, que fue elemento importantísimo del movimiento de arte piamontés en esta década, por la influencia ejercida en la escuela y por su valor artístico excepcional, el portugués De Avendaño, ${ }^{129}$ paisajista de primer orden, individual y potentísimo en la interpretación del natural. ${ }^{130}$

En 1892 Avendaño se presentó a la Exposición Nacional de Bellas Artes en Madrid. Cansado de la intensa lucha por renovar el arte de la pintura, decidió volver a su ciudad natal. En 1896 (año del fallecimiento de Nina Salvago), regresó definitivamente a España y, después de unos meses en Madrid, se instaló en Vigo. Su vuelta y su estancia definitiva tuvieron una buena acogida en Galicia. Debido a su salud deteriorada (padecía arteriosclerosis) se estableció en Valladolid, donde falleció el 25 de agosto de 1916.

A modo de colofón, cabe citar las merecidas palabras que Vitaliano Rocchiero dedicó en elogio de este pintor:

A Serafín De Avendaño le otorgo todos los honores por haber contribuido notablemente a la realización de una auténtica pintura genovesa de paisaje, compacta y unida, siempre basada en una misma gama de color apagada y tranquila que se impone por la precisión del tono, por el sentido de frescura de lo real, por la refinada elección de los motivos tomados del natural y por la capacidad de dar un tono sentimental y estético a través de un simple objeto representativo. ${ }^{131}$

128 Rocchiero (1960), p. 19.

129 Error que comete a menudo la historiografía artística al considerar a Avendaño y a Andrade como compatriotas portugueses.

130 Stella (1893), pp. 507-508.

131 Rocchiero (1960), p. 20. 
Asimismo, Gianfranco Bruno coloca a Serafín Avendaño entre los artistas más representativos de la pintura ligur de la segunda mitad del siglo XIX. ${ }^{132}$

\subsection{Estudio de las obras de Serafín Avendaño}

Las obras de Serafín Avendaño pueden datarse, casi en su totalidad, en los dos últimos cuartos del siglo XIX, y la mayoría de ellas están firmadas, lo que evita, en general, los problemas de atribución.

En un primer momento se estudiará la producción de este pintor en los museos y galerías genoveses, para pasar posteriormente a la existente en colecciones privadas. En estas obras se ponen de manifiesto las características artísticas antes analizadas, y también a lo largo de nuestro estudio queda reflejada la evolución estilística de Avendaño, desde un inicio plenamente romántico hasta lograr unas obras totalmente iluministas, como consecuencia del influjo de Aureliano de Beruete y de Sorolla, que se advierte, especialmente, a partir de su instalación definitiva en Vigo ( $L a$ carreta de algas, Museo de Pontevedra). ${ }^{133}$

\subsubsection{Estudio de las obras de Serafín Avendaño conservadas en museos genoveses}

\section{Museo dell'Accademia Ligustica di Belle Arti}

En el Museo dell'Accademia Ligustica di Belle Arti se conserva una obra muy significativa de la producción artística de Serafín Avendaño, en la que se aprecia la superación del paisaje romántico para abrazar la poética naturalista. Se trata del cuadro A orillas del Bormida (ficha n. ${ }^{\circ} 21$ ), datado hacia 1866 y firmado en el margen inferior izquierdo: «S. De Avendaño». Este cuadro llegó a la Accademia con la donación de Maglione Oneto, en 1934 (AAL, parte 626/995). El pintor capta el discurrir del Bormida (río ligur-piamontés), con un sereno paisaje. Se advierte la pre-

132 Bruno (1981a), p. 37.

133 La evolución estilística de la obra pictórica de Avendaño ha sido estudiada por J. M. López Vázquez. Véase López Vázquez y Seara Morales (1995), pp. 172 y 174. 
dilección de Avendaño por la composición horizontal, con amplio horizonte, y por la luminosidad difusa que unifica la orilla del río y el cielo. Se constata la influencia de los pintores ingleses Constable y Bonington y de los pintores barrocos holandeses. Además, la obra guarda relación con la Escuela de Barbizon, como se aprecia en la soltura de la mancha y en el franco contraste cromático entre los verdes y los tierras. Composición en la que entran en constante lucha las luces con las sombras, definiendo una naturaleza cuya principal característica es la densidad.

Gianfranco Bruno dio a conocer los dos estudios preparatorios de esta obra, realizados con toda probabilidad en plein air. El primer estudio se titula Sobre las orillas del Bormida (óleo sobre lienzo, $28 \times 42,5 \mathrm{~cm}$ ) y está datado en torno a 1866. Se trata de una composición poética sin figuras y se encuentra en una colección privada de Génova. El segundo estudio, titulado Orillas del Bormida (óleo sobre tabla, $14 \times 23,5 \mathrm{~cm}$ ), originariamente también sin figuras, que fueron añadidas posteriormente. Presenta una visión más amplia y próxima a la obra definitiva. Procede de una colección privada genovesa y, actualmente, se encuentra en una colección privada de Milán. ${ }^{134}$

El protagonista en estas tres telas es el Bormida, donde el pintor acudía con los "grises» a pintar y celebrar sus reuniones, y donde se pusieron en práctica los principios de la escuela traduciendo su primitivo realismo paisajístico a un poético sentimiento de la naturaleza.

\section{Galleria d'Arte Moderna}

En 1920 se decidió que las obras de arte moderno se expusieran en la Galleria di Palazzo Rosso. Pero, cuando el Ayuntamiento de Génova adquirió en 1927 al ingeniero Carlo Barabino la villa situada en los parques de Nervi (Génova), se consideró que era una buena oportunidad para exponer las colecciones de arte moderno. De este modo, la Villa Saluzzo Serra se destinó a Galleria d'Arte Moderna, cuyo patrimonio se enriqueció con las diferentes donaciones efectuadas por ciudadanos genoveses y con las adquisiciones realizadas por la ciudad de Génova en las Società Promotrici di Belle Arti y en las Biennali de Venecia.

134 Bruno (1981a), pp. 37-38. 
En la Galleria d'Arte Moderna se hallan tres telas de Serafín Avendaño, una de ellas es Savignone (ficha n. ${ }^{\circ} 22$ ), originariamente colocada en la sala tercera del primer piso. Representa el paisaje de un pueblo cercano a Génova llamado Savignone. El cuadro fue donado al Ayuntamiento de Génova, junto con otras numerosas obras, por Agostino Vigo (deliberación n. ${ }^{o} 1559$ del 1 de agosto de 1946). Como señalan A. Dragone y J. Dragone Conti, se podría identificar con un cuadro del mismo tema que se expuso en la Promotrice turinesa de 1870, con el título Vista de Savignone Ligur. ${ }^{135}$ En la parte posterior del cuadro genovés aparece una primera atribución al pintor V. Grana y el título Savignone.

La segunda tela se titula San Bartolomé de Vallecalda (ficha n. ${ }^{\circ} 23$ ) y, como la anterior, estuvo colocada en la sala tercera del primer piso de la Galleria. Este cuadro fue adquirido por el Ayuntamiento de Génova en la casa de ventas de Antonio Gaggero (deliberación n. ${ }^{\circ} 100$ del 13 de marzo de 1924), por un precio de 400 liras. Se representa el pueblo ligur de San Bartolomé de Vallecalda en el fondo de un valle. Como indica Maria Flora Giubilei, este pequeño cuadro posee una perspectiva paisajística parecida, aunque más cercana, a la de la obra anterior, y se presenta como una especie de boceto preparatorio de ella, realizado con una técnica común a la empleada por los artistas de la Scuola di Rivara. Se data en torno a 1869-1871, período en el que Avendaño afronta temáticas del interior de Liguria. ${ }^{136}$

La tercera tela, de una calidad extraordinaria, es testimonio de la vena poética de Serafín Avendaño. Tiene como título Ribera de Génova (ficha n. $\left.{ }^{\circ} 24\right)$ y originariamente estuvo expuesta en la tercera sala del primer piso de la Galleria, como las dos obras antes citadas. Este cuadro está firmado y datado: «S. Avendaño 1881», y fue adquirido por el Ayuntamiento de Génova a la Dirección de los Hospitales Civiles (deliberación n. ${ }^{\circ} 1426$ del 18 de julio, donde la obra aparece citada como Marina del pintor De Avendana), por 5000 liras. Maria Flora Giubilei indica que se trata del cuadro Ribera de Génova, que participó en la Promotrice de 1881. De hecho, en la parte posterior de la tela, se encuentra la etiqueta de dicha exposición, en la que todavía puede leerse el precio: «L. 4.000» (precio ele-

135 Dragone y Dragone Conti (1947), p. 254.

136 Giubilei (1990), p. 140. 
vado para la época). ${ }^{137}$ Este cuadro fue adquirido por Luigi Pasquale Gandolfo, comerciante de profesión, que al premio de 2000 liras ganadas por extracción tuvo que añadir otras 2000 para poder comprarlo. ${ }^{138} \mathrm{En}$ fin, se desconoce la fecha y la vía exacta por la que llegó a los Hospitales Civiles: bien pudo ser por donación, o bien por testamento. Sin embargo, se sabe con certeza que el Ayuntamiento de Génova adquirió este cuadro y que lo catalogó como Escollo de Quarto, por la similitud que esta porción de costa ligur, cercana a Génova, presenta con la de Quarto. En la actualidad se expone en la Galleria d'Arte Moderna bajo el título Ribera de Génova. ${ }^{139}$

\subsubsection{Estudio de las obras de Serafín Avendaño existentes en colecciones privadas genovesas}

Como se ha indicado anteriormente, los testimonios de la producción artística de Avendaño existentes en Génova son numerosos y la mayor parte de ellos se encuentran en colecciones privadas. El acceso a estas colecciones es difícil y la información disponible es bastante limitada.

A continuación, se pasa a enumerar las obras de Avendaño localizadas en colecciones privadas, que responden a las características pictóricas anteriormente expuestas. Se trata de las siguientes:

En la montaña o El abrevadero o Le triste retour (ficha n. ${ }^{\circ} 25$ ), datada en torno a 1866 y firmada, en el margen inferior izquierdo, con el monograma del pintor. Este cuadro procede de la colección Luigi Parodi y actualmente se encuentra en la colección Luigi Masini de Génova. Es una obra del período rivariano, que emplea el amarillo limón, característico en su producción pictórica de los años sesenta. A. Stella señala que, cuando Serafín Avendaño expuso esta tela en la XXXI Exposición de Bellas Artes de Turín, consiguió imponerse a todos y callar las polémicas surgidas en torno a sus cuadros, cautivando todas las simpatías del público y de la crítica. ${ }^{140}$ La exposición supuso la afirmación de la fama de Avendaño como gran paisajista y, a partir de entonces, pasó a ser admirado y comprendido en toda su intimidad poética y pintoresca.

137 Ib.

138 Véase Rendiconto de 1881, p. 4.

139 Giubilei (2004), p. 264.

140 Stella (1893), pp. 508-509. 
Paisaje (ficha n. ${ }^{\circ}$ 26), datada en torno a 1866 y firmada en el margen inferior derecho. Forma parte de la colección Alessandro Pernecco de Génova. Como indica Gianfranco Bruno, en esta obra se conjuga la práctica fontanesiana de recurrir a un fondo sepia, sobre el que emergen las formas gracias a la luz, con el lírico erguirse de los árboles en movimiento, que podría recordar las orillas de Bonington y los cielos tempestosos de Constable. ${ }^{141}$

Casas de montaña (ficha n. ${ }^{\circ} 27$ ), fechada hacia 1866 , dedicada y firmada en el margen inferior izquierdo: "Al amico Luxoro. S. De Avendaño». ${ }^{142}$ Esta obra proviene de la colección del experto de arte y académico Giovanni Ravaschio de Génova, y actualmente se localiza en una colección privada de la misma ciudad.

La granja (ficha n. ${ }^{\circ} 28$ ), datada en torno a 1866 y firmada en el margen inferior derecho: «S. Avendaño». Se halla en una colección privada de Génova.

Paisaje. Vastedad campestre (ficha n. ${ }^{\circ} 29$ ), fechada en torno a 1866 y firmada en el margen inferior derecho: «S. De Avendaño». Se encuentra en la colección T. Pelizza, Génova. Esa obra constituye un buen testimonio de la predilección de Avendaño por la composición horizontal con amplio cielo.

Campo con moreras (ficha n. ${ }^{\circ} 30$ ), fechada en torno a 1866, firmada y dedicada en el margen inferior derecho: «S. Avendaño al amigo Calderini». Se encuentra en la colección T. Pelizza (Génova) y fue adquirida hace unos treinta años en una galería de Turín. Gianfranco Bruno señala que este cuadro es típico de los ańos de Rivara, posterior a 1868, y significativo de la vena poética de Serafín Avendaño. Se emplean pocos tonos, aplicados con intensas pinceladas, recurriendo al lenguaje de la macchia. ${ }^{143}$ Es una obra significativa del contacto de Avendaño con los macchiaioli toscanos, por la franqueza de la mancha.

Efectos de luna (ficha n. ${ }^{\circ}$ 31), firmada y datada en 1867 en el margen inferior derecho. Luigi Rocca, con motivo de la participación de esta obra en la Exposición Nacional celebrada en Parma en 1870, escribió estas líneas:

141 Bruno (1981a), p. 37.

142 Vitaliano Rocchiero opina que este cuadro no está dedicado a Luxoro ("teórico» del cenáculo de los innovadores genoveses) sino a L. Lomoro, amigo del pintor.

143 Bruno (1993), p. 151. 
Desde hace algunos años Avendaño expone varias obras en las que, mientras que los autores de la nueva escuela encuentran en todo una recóndita belleza, sin el más leve defecto, muchos otros, en cambio, reconociendo en él una singular habilidad, hablan con desprecio de su forma de tratar el pincel, sacrificando todo a un cierto efecto no muy bien conseguido. ${ }^{144}$

Con los efectos de luces, conseguidos en esta obra, Serafín Avendaño logró notables éxitos como, por ejemplo, en la exposición genovesa de 1896. Esta obra pone de manifiesto la deuda del pintor con Corot, en la minuciosidad descriptiva, en el dibujo y en la pincelada pastosa.

Convento de Castaña (ficha n. ${ }^{\circ}$ 32), fechada en 1875. Procede de la colección del profesor Francesco S. Mosso, senador y presidente comisario promotor de la Mostra di Pittura Ligure dell'Ottocento, que se celebró en Génova en 1926. En estos momentos, forma parte de la colección privada T. Pelizza (Génova). Se representa el convento de la localidad ligur de Castaña, recurriendo a una paleta luminosa, testimonio de la pintura clara y límpida de Avendaño.

Escollera, Arrecife o Marina (ficha n. ${ }^{\circ}$ 33), datada en 1882 y firmada en el margen inferior izquierdo: «S. Avendaño». Este cuadro se expuso en la XXXI Exposición de la Società Promotrice di Belle Arti de Génova, en 1882, en la que figuró con el n. ${ }^{\circ} 104$, y fue adquirido por el Círculo Artístico Tunnel de Génova. Actualmente se encuentra en la colección V. E. Rota (Génova).

Paisaje ligur (ficha n. ${ }^{\circ}$ 34), fechada en torno al último cuarto del siglo XIX y firmada en el margen inferior derecho con el monograma del artista. Procede de la colección del experto y crítico de arte Stefano Rebaudi. En la exposición Pittori liguri dell'Ottocento, celebrada en Génova en 1938, figuró como propiedad de Rebaudi, para pasar después a propiedad de Franco Bandini. Actualmente se halla en la colección I. Mazzola (Génova).

Golfo de la ribera ligur (ficha n. ${ }^{\circ}$ 35), firmada en el margen inferior izquierdo: «De Avendaño». Proviene de la colección del pintor Andrea Figari de Génova (1858-1945) y ahora se encuentra en una colección privada genovesa.

144 Cit. en Stella (1893), p. 508. 
Árbol aislado y césped (ficha n.o 36), fechada en torno al último cuarto del siglo XIX. Procede de la colección del experto en arte Giovanni Ravaschio de Génova. Actualmente se conserva en la colección privada de Elzo Colonna.

Retrato de Nina Salvago (ficha n. ${ }^{\circ}$ 37), datada en el último cuarto del siglo XIX. Procede de la colección Tiscornia Quattro de Génova y actualmente se encuentra en una colección privada de esta ciudad.

Árboles (ficha n.o 38), firmada en el margen inferior derecho: «S. Avendańo», y fechada en torno al último cuarto del siglo XIX. Forma parte de la colección privada de Bartolomeo Pellerano (Génova).

Puerto de ribera, al norte de Vigo (ficha n.o 39), está sin datar, pero, según Rosa E. Caamaño Fernández, por el colorido oscuro, parece de época temprana. ${ }^{145}$ Firmada en el margen inferior derecho: «S. Avendaño». Procede de la colección de Emilio y Luigi Parodi de Génova, presidentes de la Società Promotrice di Belle Arti desde 1910 hasta 1926. Actualmente se halla en una colección privada de Génova.

Pescadores a contraluz (ficha n.o 40), firmada en el margen inferior izquierdo: «Avendaño». Este cuadro es casi idéntico al realizado por Benedetto Musso, conservado en Laigueglia. Parece que se trata de una obra sin terminar, no está fechada ni estudiada, y hasta hace poco permanecía inédita en los fondos del Museo Luxoro de Nervi. ${ }^{146}$

Domingo en la playa (ficha n. ${ }^{\circ} 41$ ), fechada en torno al último cuarto del siglo XIX y firmada en el margen inferior izquierdo: «S. Avendaño». Procede de la colección de Luigi Parodi, presidente de la Società Promotrice di Belle Arti de Génova, entre 1924 y 1926. Actualmente se encuentra en una colección privada de Génova.

Cazadores en reposo, bajo los abedules (ficha n. ${ }^{\circ} 42$ ). En torno a 1872, Avendaño comenzó a interesarse por temas cinegéticos. De hecho, presentó en la exposición genovesa de 1872 un Convenio de cazadores. Este cuadro procede del estudio del pintor, donde fue adquirido por el marchante de arte Gallino, de Génova, y más tarde por Orlando Grosso, quien lo legó

145 Serafin Avendaño, 1837-1916, 1991, p. 132.

146 Ib., p. 133. 
a su discípulo el profesor Vitaliano Rocchiero de Génova, pasando a formar parte de su colección.

Paisaje marino con promontorio (ficha n. ${ }^{\circ} 43$ ), fechada por Vitaliano Rocchiero entre 1887 y 1888. Proviene de la colección de Luigi Parodi, y actualmente se encuentra en una colección privada de Génova.

Marina con pino (ficha n. ${ }^{\circ} 44$ ), firmada en el margen inferior izquierdo: «S. Avendaño». Procede de la colección de Emilio y Luigi Parodi. En estos momentos forma parte de una colección privada de Génova.

Escollera marina (ficha n. ${ }^{\circ} 45$ ), firmada en el margen inferior derecho: «S. Avendaño» y fechada en torno al último cuarto del siglo XIX. Procede de la colección de Gerolamo Vasallo de Sampierdarena (Génova). Actualmente se localiza en una colección privada de esta ciudad.

Valle montañés (ficha n. ${ }^{\circ} 46$ ), firmada en el margen superior izquierdo: «S. Avendaño» y fechada en torno al último cuarto del siglo XIX. Proviene, como la obra anteriormente citada, de la colección de Gerolamo Vasallo de Sampierdarena (Génova). En la actualidad se encuentra en una colección privada de la misma ciudad.

Marina con promontorio de escollera (ficha n. ${ }^{\circ} 47$ ), firmada en el margen inferior izquierdo: «S. Avendaño». Se halla en una colección privada de Génova.

Colinas piamontesas con figura femenina (ficha n. ${ }^{\circ} 48$ ), fechada en torno al último cuarto del siglo XIX y firmada en el margen inferior izquierdo. Procede de la colección de Luigi Parodi y actualmente se conserva en una colección privada de Génova.

Pescador con caña sobre el escollo (ficha n. ${ }^{\circ}$ 49) procede de la colección A. Ruta de Génova. Alessandro Ruta atribuyó esta obra, el 21 de octubre de 1972, a Avendańo. Se encuentra en una colección privada de Génova.

Costa maritima franco-ibérica (ficha n. ${ }^{\circ}$ 50), firmada en el margen inferior izquierdo y fechada en 1913. Se trata de una de las últimas obras de Serafín Avendaño. Procede de una colección de Bordighera (Imperia) y ahora se encuentra en una colección privada de Génova. Rocchiero advierte en esta composición algún parecido con la costa de Vigo. 
Además de estas obras, se cuenta con la presencia de otras más en colecciones privadas genovesas, de las cuales no se elaboró una ficha de catalogación porque la información existente acerca de ellas es escasa y porque se carece de reproducción fotográfica. De todas formas, se citan a continuación:

Paisaje ligur con arboleda (óleo sobre tabla, $26 \times 34 \mathrm{~cm}$ ). Proviene de la colección de Luigi Parodi y actualmente se encuentra en una colección privada de Génova.

Bahia del Merula en Andora (óleo sobre lienzo, $26 \times 40 \mathrm{~cm}$ ). Procede de la colección de L. Parodi de Génova y ahora forma parte de una colección privada de Génova. Se representa la ensenada del torrente Merula, cerca del burgo marinero de Andora, en la ribera ligur del Poniente. Este tema fue muy cultivado por los pintores ligures, entre otros por Orlando Grosso.

Escollera (óleo sobre lienzo, $85 \times 130 \mathrm{~cm}$ ), firmada en el margen inferior derecho: «S. Avendaño». Presenta las mismas dimensiones que Ribera de Génova (ficha n. $\left.{ }^{\circ} 24\right)$. Actualmente se conserva en una colección privada de Génova.

Quarto dei Mille (óleo sobre lienzo, $52 \times 105 \mathrm{~cm}$ ). Este cuadro se expuso en la Promotrice de 1870, y Federico de Pastoris realizó un aguafuerte de él. Procedencia y localización actual desconocidas.

Marina, bordeada de pinos, con barcas (óleo sobre lienzo, $39,5 \times 72,5 \mathrm{~cm})$. Firmada y fechada en el margen inferior derecho: «S. Avendaño 1891». Actualmente se encuentra en una colección privada de Génova.

Puerto de Génova, con linterna, visto desde lo alto (óleo sobre lienzo, $40 \times 62 \mathrm{~cm}$ ). Esta obra fue atribuida por Alessandro Ruta a Serafín Avendaño. Se halla en una colección privada de Génova.

Paisaje del interior de Liguria (óleo sobre tabla, $26 \times 35,5 \mathrm{~cm}$ ). Firmada en el margen inferior izquierdo: «S. Avendaño». Atribuida por Vitaliano Rocchiero a Serafín Avendaño. Proviene de la Galería Manzoni de Milán. Forma parte de una colección privada de Génova.

Río de Vigo (óleo sobre lienzo, $39 \times 56 \mathrm{~cm}$ ). Esta obra participó en la exposición Pittura ligure dell'Ottocento, celebrada en Génova en 1893, 
como propiedad del Consiglio Provinciale Corporazioni, actual Cámara de Comercio de Génova. De hecho, el cuadro figura en el inventario de dicha entidad, con el n. ${ }^{\circ} 1459$, pero se desconoce su localización concreta. Además, en el despacho del presidente de la Cámara de Comercio hay un cuadro inventariado con el número ahora citado, que representa un paisaje nocturno que no responde a la obra analizada. Respecto al tema en cuestión, Vitaliano Rocchiero afirma que el cuadro fue destruido durante la guerra, tal como le fue comunicado el 15 de noviembre de 1956.

Consultando los diferentes catálogos de las exposiciones en las que participó Serafín Avendaño salen a la luz otras obras de este pintor, de las cuales se desconoce su actual localización y propietario. A continuación, se lleva a cabo una reseña de ellas:

Serafín Avendaño participó en la Exposición Nacional de Parma de 1870 y en la de Turín de 1872, en las que expuso La Torre Gropallo (Nervi). Asimismo, esta obra figuró en 1889 en la colección privada de Giulia Moreno.

En la Promotrice de 1883 se presentó como propiedad de Giuseppe Bertollo una obra de Avendaño titulada En el mar; y en la Mostra di Pittura ligure dell'Ottocento, celebrada en Génova en 1926, la obra del pintor El lago Maggiore en Meina aparecía como perteneciente a Enrichetta Ghiglini.

En el catálogo que Orlando Grosso realiza de la exposición Pittori liguri dell'Ottocento, celebrada en el Palazzo Rosso de Génova en 1938, se citaban dos cuadros de Serafín Avendaño: Las flores (óleo sobre lienzo), como propiedad de Luigi Della Valle, y Playa (boceto).

Por último, en la exposición Pittori della Scuola di Rivara, inaugurada en Turín en 1942, se expuso la obra de Avendaño titulada La procesión en San Hilario.

Como se puede comprobar, la producción pictórica de Serafín Avendaño en tierras ligures, en especial genovesas, es muy amplia y significativa. La explicación radica en el hecho de que Serafín Avendaño vivió durante un período de treinta años en Génova, participando activamente en el ambiente y en las tendencias artístico-culturales del momento. 


\subsection{Otro representante de la pintura española entre finales del siglo XIX e inicios del XX: Joaquín Sorolla y Bastida (Valencia, 1863-Cercedillo, Madrid, 1923)}

Una vez analizada la personalidad artística de Serafín Avendaño, cabe aludir a Joaquín Sorolla, quien junto con el pintor vigués son los dos grandes representantes de la pintura española del siglo XIX en Génova. En relación con el pintor valenciano, hay que referirse a las colecciones Frugone de Génova-Nervi, porque conservan dos obras suyas, una de ellas datada en 1896 y la otra en 1904.

\section{Colecciones Frugone de Villa Grimaldi Fassio}

La Villa Grimaldi Fassio, inmersa en los parques de Nervi (Génova), conserva las importantes colecciones de los hermanos Lazzaro Giobatta y Luigi Frugone, que comprenden cuadros, esculturas, grabados y diseños fechados entre 1860 y 1930. Estas dos colecciones fueron donadas al Ayuntamiento de Génova en 1935 y 1953, respectivamente. Se expusieron, por primera vez, en la Galleria di Palazzo Bianco de Génova, en 1938; después, se depositaron en el Museo dell'Accademia Ligustica di Belle Arti, donde permanecieron hasta 1982, año en el que, tras la adquisición por parte del Ayuntamiento de Génova de la Villa Grimaldi Fassio (1979), se decidió traspasar las obras al nuevo edificio. En 1984 se organizó una exposición de los cuadros y esculturas de la colección Luigi Frugone. Y entre 1988 y 1993 las obras se fueron depositando en la Galleria d'Arte Moderna de Villa Serra, mientras se llevaba a cabo la restauración y preparación de la Villa Grimaldi como museo permanente de estas colecciones. El museo fue inaugurado el 21 de marzo de 1993, con el nombre de Museo Luxoro.

Con respecto a los hermanos Frugone, es interesante decir que Lazzaro Giobatta Frugone, dedicado al comercio de la lana, mostró un especial gusto artístico por las obras modernas, generalmente de pequeńas dimensiones, eligiendo autores de tendencia histórica. Por su parte, su hermano Luigi era comerciante de cereales y por motivos de trabajo tuvo que viajar a Sudamérica, París y Londres, hecho que le permitió entrar en contacto con los grandes mercados de arte y con artistas contemporáneos.

Dentro de este contexto, cabe destacar a Ferruccio Stefani, comerciante y coleccionista de arte, que fue el consejero artístico de los hermanos Frugone. Como señala Maria Flora Giubilei, Stefani organizaba expo- 
siciones en Sudamérica (Montevideo, Valparaíso, Buenos Aires y Río de Janeiro), y de este modo daba a conocer la producción artística italiana y europea contemporánea. ${ }^{147}$ En relación con esto, es interesante indicar que Stefani fomentaba, principalmente, las obras de los famosos artistas ingleses, franceses, españoles y holandeses.

La colaboración de Ferruccio Stefani en la Biennale veneciana de 1926 marcó un hito importante en las colecciones Frugone, favoreciendo la adquisición de obras. Tras el fallecimiento de Stefani, en 1928, gran parte de su colección fue vendida a los hermanos Frugone.

Las colecciones Frugone son extraordinariamente valiosas en obras de pintores españoles, ingleses, americanos y húngaros, procedentes de las exposiciones internacionales.

La pintura española en estas colecciones está representada por artistas de la talla de Joaquín Sorolla. En concreto, en la sala n. 8 del Museo Luxoro, dedicada a los pintores extranjeros, se encuentran dos magníficos cuadros de Sorolla, procedentes de la colección de Luigi Frugone, que tras su muerte (1953) pasaron al municipio de Génova. ${ }^{148}$ A este respecto, Maria Flora Giubilei indica que probablemente Luigi Frugone adquirió estas dos obras a través de Ferruccio Stefani, quien organizaba exposiciones del pintor valenciano en Sudamérica. No hay que olvidar que por aquel entonces Sorolla contaba ya con una gran fama; de hecho, sus obras participaban en las grandes exposiciones y salones nacionales e internacionales.

La primera pintura se titula Sueñecito en barca (ficha n. ${ }^{\circ}$ 51), y está firmada y fechada en el margen inferior derecho (en la barca): «J. Sorolla y Bastida 1896». Esta obra correspondería a su período de formación, que

147 Giubilei (1994), p. 155. Es probable que Luigi Frugone conociera, en uno de sus viajes a Sudamérica, a Ferruccio Stefani.

$148 \mathrm{Al}$ respecto, es preciso señalar que, además de estas dos obras de Sorolla conservadas en el Museo Luxoro, se tiene constancia de la existencia de otra obra del pintor valenciano en una colección privada de Génova. Lleva por título El sabio, fumador de pipa (acuarela sobre cartón, $53 \times 43 \mathrm{~cm}$ ), y se encuentra firmada en el margen superior derecho: "J. Sorolla». Esta obra procede de la colección genovesa de Natalia Badino (1860-1925), quien, a su vez, la había recibido de un amigo suyo. Después, pasó a propiedad de la familia Camposampiero de Génova. Estos datos fueron proporcionados por Vitaliano Rocchiero en una entrevista mantenida con él durante mi estancia en la capital ligur. La autenticidad de la obra está todavía por confirmar, pudiendo pertenecer al período italiano de Sorolla. 
comprende desde sus primeros pasos como pintor hasta 1903. En estos años se va definiendo como pintor del mar y de las playas, de la naturaleza y de la gente, y su interés por los efectos de la luz constituirá el tema principal de su obra. Como señala Blanca Pons-Sorolla, el único afán del pintor valenciano, desde que ingresó en la Academia de Bellas Artes de Valencia, fue crear una pintura franca, una pintura que interpretase la naturaleza tal como es verdaderamente, tal como debe verse. ${ }^{149}$ Sorolla era un hombre mediterráneo por excelencia, sensual en su limitada capacidad para aprehender la belleza y la vida del mundo que le rodeaba: su deseo era plasmar en los lienzos cuanto él era capaz de ver y amar. ${ }^{150}$

En la misma línea está la segunda obra, titulada La vuelta de la pesca (ficha n. ${ }^{\circ}$ 52), firmada y fechada en el margen inferior izquierdo: «J. Sorolla y Bastida 1904». Igual que la anterior, procede de la colección de Luigi Frugone y pertenece al período de formación del pintor. En opinión de Orlando Grosso, este cuadro se caracteriza por una composición segura y sintética, con la presencia de los seguros y sólidos valores del arte español. ${ }^{151}$

En estas dos obras Sorolla no solo consigue plasmar la luz solar, que crea y hace visibles la forma y el color, sino también el aire, ese ambiente que existe entre objeto y espectador.

En el depósito del Museo Luxoro hay otro cuadro, de pequeñas dimensiones, atribuido también a un artista de origen español. Se trata de una obra de Narciso Díaz de la Peña (Burdeos, 1807-Mentone, 1876) titulada Paisaje con patos, que está firmada en el margen inferior izquierdo: «Díaz». No se ha elaborado una ficha de catalogación de este cuadro porque, aunque Díaz de la Peña era hijo de inmigrantes españoles en Francia, su formación y actividad artística está más relacionada con el ambiente pictórico de ese país y, en concreto, con la Escuela de Barbizon. El cuadro formaba parte de la colección de Lazzaro G. B. Frugone y en 1935 fue donado a la ciudad de Génova.

Con el estudio de estas obras se cierra el apartado dedicado a las obras de pintura española del siglo XIX existentes en Génova, para pasar a continuación al estudio y análisis de la pintura española conservada en el resto de Liguria.

149 Pons-Sorolla (1993), p. 91.

150 Ib.

151 Grosso (1938a), p. 24. 


$$
\begin{gathered}
\text { PARTE II } \\
\text { LA PINTURA ESPAÑOLA } \\
\text { EN EL RESTO DE LIGURIA }
\end{gathered}
$$





\section{1 \\ LA PINTURA ESPAÑOLA \\ DE LOS SIGLOS XV-XVIII \\ EN EL RESTO DE LIGURIA}

Liguria está constituida por las provincias de Imperia, Savona, Génova y La Spezia. El estudio de la pintura española en el resto de Liguria es más general debido a una limitación de tipo temporal, y al hecho de que la mayor parte de las obras de pintura española se encuentran en Génova, siendo así menor su presencia en el resto del territorio ligur.

En este segundo apartado se irán viendo, según un criterio cronológico, las obras localizadas en cada una de las provincias de Liguria.

\subsection{La Spezia}

El único testimonio de pintura espańola existente en La Spezia se encuentra en el Museo Civico de esta ciudad, fundado en 1997, que contiene la magnífica colección de arte que el fundador, Amedeo Lia, donó a su ciudad.

\section{Museo Civico Amedeo Lia}

El Museo cuenta con tres magníficas obras atribuidas a un anónimo español. La primera de estas es una tabla que representa la Virgen entronizada con el Niño, ángeles músicos y donante (ficha n. ${ }^{\circ}$ 53), datada hacia 1450. La pintura procede de la colección de Marcello Massarenti de 
Roma, donde era considerada obra de la escuela de Gentile da Fabriano, y fue adquirida en 1902, junto con toda la colección, por Henry Walters, quien la vendió en febrero de 1922. Más tarde, Amedeo Lia la adquirió a través de un anticuario italiano de Londres, quien la había comprado en Nueva York.

La tabla, de extraordinaria calidad, presenta, en opinión de Federico Zeri, elementos de la cultura flamenca de la primera mitad del siglo XV, con alusiones a Roger van der Weyden. ${ }^{152}$ La misma mano, y quizás también el mismo donante, se constata en una tabla $(164 \times 66 \mathrm{~cm})$, datada hacia 1480 y procedente de la colección Malvezzi-Campeggi de Roma, que representa a San Andrés, de cuerpo entero, con la cruz del martirio y a cuyos pies aparece el donante, de dimensiones más reducidas, del cual parte una inscripción muy parecida a la de la tabla Lia. En la parte superior, a ambos lados de la cabeza del santo, se representa fruta que podría recordar la de las obras de Carlo Crivelli. Además, las dos tablas presentan una elaboración del fondo de oro muy parecida. Este análisis conjunto lleva a Zeri a considerar que se trata de dos pinturas de un artista originario de la costa oriental de Espańa que marchó a Italia y tomó elementos de la cultura lombarda y piamontesa. ${ }^{153}$

La segunda obra es una magnífica Naturaleza muerta (ficha n. ${ }^{\circ} 54$ ), atribuida igualmente a un anónimo español. En opinión de A. G. De Marchi, la tipología de esta naturaleza muerta es española y su cronología podría establecerse en el segundo cuarto del siglo XVII. Si bien no es posible dar un nombre concreto, este historiador opina que podría estar relacionada con la producción de Moriel, conocido por alguna tela firmada existente en colecciones privadas, y, desde el punto de vista compositivo, con las obras del pintor madrileño Juan van der Hamen (1596-1631). Precisamente, a este último fue atribuida cuando se expuso en una galería de Milán, en $1973 .{ }^{154}$

La tercera pintura representa una Naturaleza muerta con cesto y fruta (ficha n. ${ }^{\circ}$ 55), atribuida por Federico Zeri a un anónimo español, basán-

152 Zeri, ficha crítica de la tabla, en Zeri y De Marchi (1997), p. 394.

153 Ib.

154 De Marchi, ficha crítica de Naturaleza muerta, en Zeri y De Marchi (1997), p. 396. 
dose en la composición de la obra. Además, este historiador considera que la obra pudiera ser la parte central de una naturaleza muerta sevillana que, en un principio, comprendería tres telas, y que fue dividida con fines comerciales. ${ }^{155}$

\subsection{Gavi Ligure}

\section{Oratorio dei Rossi}

En el resto del territorio ligur, como se ha indicado anteriormente, pocos son los testimonios conservados de pintura espańola; una de las excepciones es Gavi Ligure, pequeña localidad piamontesa que se incluye en este estudio debido a su proximidad, tanto geográfica como cultural, con Liguria.

Gavi Ligure posee un oratorio, construido en la segunda mitad del siglo XVII, en cuyo interior se encuentra una tela atribuida a escuela española que representa un San Sebastián (ficha n. ${ }^{\circ}$ 56). Las condiciones de conservación de la obra no son muy buenas, dificultando su lectura e interpretación. A pesar de estos inconvenientes, Giovanni Meriana estima que se trata de una obra de escuela espańola, datable en la primera mitad del siglo XVII. ${ }^{156}$

El modelo iconográfico de san Sebastián está muy difundido en Italia. De hecho, es uno de los santos más venerados e invocados en este país junto con san Roque, ambos protectores contra la peste.

\subsection{Chiusanico (Imperia)}

Iglesia de Santo Stefano

Chiusanico es una pequeña localidad de montaña cuya parroquia presenta cinco telas consideradas de procedencia espańola, probablemente sevillana, de las que se desconocen las vías de llegada a la iglesia. El mismo

155 Zeri, ficha crítica de Naturaleza muerta con cesta y fruta, en Zeri y De Marchi (1997), p. 397.

156 Meriana y Manzitti (1975), p. 80. 
problema se plantea cuando se analiza la cronología, que se establece teniendo como punto de referencia la reconstrucción de la parroquial (1824-1834), entre la segunda mitad del siglo XVII y el XVIII. ${ }^{157}$

A pesar de que existe una gran incertidumbre en torno a las obras, se incluyen en este trabajo por su importancia desde el punto de vista compositivo e iconográfico, y porque al mismo tiempo sirven como testimonio de las relaciones que existieron entre el sur de Espańa y Liguria durante los siglos XVII y XVIII (y que se remontan a época medieval). ${ }^{158}$ De hecho, como señala G. Levi, se tiene constancia de que en este período llegaron muchos jóvenes a Cádiz procedentes de los valles de Imperia con el fin de hacer fortuna. ${ }^{159}$

Las cinco telas tienen en común un marco de color blanco, probablemente colocado en el siglo XIX, que llevó a pensar en una procedencia idéntica. La primera representa una Alegoría de la muerte (ficha n. ${ }^{\circ} 57$ ), y está colocada cerca del altar mayor de la iglesia. Alessandro Giacobbe la ha atribuido a un seguidor del pintor Ignacio de Ries, estableciendo su cronología a mediados del siglo XVII. ${ }^{160}$ Este historiador fundamenta dicha atribución en las notables semejanzas que presenta el cuadro, desde el punto de vista temático y estilístico, con la Alegoría del árbol de la vida de Ries, conservada en la capilla de la Concepción de la catedral de Segovia. ${ }^{161}$ En relación con este pintor, Valdivieso advierte que, aunque no se puede constatar con seguridad, debió de ser oriundo del norte de Alemania o flamenco. Se sabe que en Sevilla estuvo vinculado con pintores de esta zona. La obra de la catedral de Segovia incidió en la cultura simbólica sevillana, relacionada con la transitoriedad de la vida y la fugacidad de los gozos terrenales. La obra de Ries está datada en 1653, año en el que don Pedro Fernández de Miñano y Contreras (gobernante de Cádiz y almirante de la Flota de la Plata al servicio del rey Felipe IV) debió de con-

157 Los autores que se han ocupado de esta son Franco Boggero, Luciano L. Calzamiglia y Alessandro Giacobbe. Gracias al último, se pudo visitar la iglesia de San Esteban de Chiusanico.

158 Sobre las relaciones económico-comerciales y culturales entre Génova y España, véase Boccardo, Colomer y Di Fabio (dirs.) (2004).

159 Levi (1984).

160 Giacobbe (1995), p. 130.

161 Para el comentario y análisis de esta obra, véanse, entre otras publicaciones, Brasas Egido (1988) y Navarrete Prieto (2001). 
tratar con Ries la ejecución de esta obra, junto con El bautismo de Cristo, La conversión de san Pablo y El martirio de san Hermenegildo, para la capilla que el almirante poseía en la catedral de Segovia. ${ }^{162}$

Como puede comprobarse, la obra conservada en Segovia y la de Chiusanico tienen en común el árbol de la vida, como eje compositivo, que está siendo cortado por la Muerte, que simboliza el alma humana. En la tela de Segovia, la copa del árbol acoge al grupo de los vividores, que representan la vida disoluta y las vanidades mundanas, ejemplificadas en la diversión y en la abundante comida. Y, a los lados, aparecen unas inscripciones que dicen lo siguiente: «Mira que te has de morir, mira que no sabes cuándo", "Mira que te mira Dios, mira que te está mirando», y que no se encuentran en la tela de Chiusanico. Esta última presenta otros elementos, en la parte inferior, que no aparecen en la obra segoviana, y que enriquecen notablemente la composición: la figura del pecador, entre el ángel y el diablo que se disputan su alma, y la de la Virgen, que se halla junto a Cristo, como intercesora a favor del hombre.

Fulvio Cervini indica que se trata de una especie de ars moriendi en versión figurada, en la que el pecador es objeto de disputa entre las fuerzas del bien (el ángel) y del mal (el diablo), para poseer su alma. Cristo debe tocar la campana, que determinará la salvación eterna, conseguida gracias a la intercesión de la Virgen. Además, este historiador considera que las dos telas constituyen una versión moderna de la "predicación del arte del bien morir» de Jerónimo Savonarola, ilustrada en numerosas xilografías. ${ }^{163}$

El tema del árbol de la vida ha sido muy estudiado. En este contexto, cabe mencionar a Vetter, quien habla de algunas estampas que sirvieron como fuente de inspiración, entre las que destaca la usada por Ignacio de Ries para la obra de la capilla del almirante Contreras, que tiene como título El árbol de la vida. ${ }^{164}$ Además, esta pintura se inspira en otra estampa del mismo asunto (fugacidad de la vida y de los bienes terrenales y la

162 Valdivieso (1986), pp. 191-192.

163 F. Cervini, "Allegoria della morte» (ficha n. ${ }^{\circ}$ 12), en Boggero y Ciliento (eds.) (1995), p. 132.

164 E. Vetter, «Media Vita», Spanische Forschungen der Goerresgesellschaft, 16, Münster, 1960, pp. 190-196, cit. en Navarrete Prieto (2001), p. 250. 
inesperada llegada de la muerte), que fue realizada por Hieronymus Wierix. ${ }^{165}$ Por último, hay que decir que el tema del árbol de la vida ejerció una notable influencia en la pintura andaluza e hispanoamericana de aquella época.

La segunda tela representa la Virgen de Guadalupe (ficha n. ${ }^{\circ} 58$ ) y está colocada en la pared izquierda del presbiterio de la iglesia. De esta pintura existe una copia, de menores dimensiones, en la sacristía, que representa igualmente una Virgen de Guadalupe (ficha n. ${ }^{\circ} 59$ ). Como en la obra anterior, se desconocen las vías de llegada a la iglesia.

Antes de pasar al análisis de dichas obras, cabe recordar la leyenda del origen de la imagen de Guadalupe, que se remonta al 9 de diciembre de 1531, cuando la Virgen se apareció al indio Juan Diego sobre el monte Tepeyac, localizado a las afueras de la ciudad de México. La Virgen pidió a Juan Diego que transmitiera al obispo de México, Juan de Zumárraga, su deseo de construir un santuario en la ciudad. Ante la incredulidad del obispo, la Virgen pidió al indio que fuera a la cima del Tepeyac a recoger en pleno invierno rosas para llevárselas como prueba al obispo. Precisamente, en el momento en el que el indio mostró las rosas a Juan de Zumárraga, la imagen de la Virgen quedó impresa sobre la tilma (manta de algodón) del indio. Tras este suceso, el obispo dio a la representación mexicana el mismo nombre de la imagen de Nuestra Señora de Guadalupe de Extremadura. A este respecto, es preciso señalar que en España la Virgen de Guadalupe era objeto por entonces de una gran veneración. De hecho, el santuario construido bajo su advocación, durante los siglos XIV y XVI, se convirtió en un importante centro de peregrinación y de piedad. El culto a la Virgen de Guadalupe tuvo tanta difusión que su iconografía se difundió por otros países, como Italia. ${ }^{166}$

Estas dos obras han sido objeto de estudio por parte de Luciano L. Calzamiglia, quien considera que están inspiradas en la imagen mexicana de la Virgen de Guadalupe, tratándose así de «copias devocionales». ${ }^{167}$

165 M. Mauquoy-Hendrickx, Les estampes des Wierix conservées au Cabinet des estampes de la Bibliothèque royale Albert I ${ }^{\text {er }}$. Bruselas, 1978, t. II, p. 200, n. ${ }^{\circ}$ 1487, cit. en Navarrete Prieto (2001), p. 250.

166 En Roma, la primera imagen que se constata de la Virgen de Guadalupe se fecha en 1669, y fue llevada por un fraile agustino.

167 Calzamiglia (1992), p. 101. 
Este autor fundamenta su opinión en la presencia, en los márgenes del cuadro, de cuatro misterios o escenas en las que se narra la aparición de la Virgen al indio Juan Diego. Al mismo tiempo, se advierte el interés del pintor por introducir algunos detalles característicos del simbolismo popular mexicano. Así, aparecen las cintas negras sobre el pecho de la Virgen, que aluden a una costumbre azteca con la que las mujeres embarazadas indicaban su futura maternidad. De este modo, la imagen de Guadalupe, en lugar de representar a la Virgen con el Niño en brazos, conforme a la iconografía tradicional de las Iglesias latina y oriental, muestra la maternidad divina de María recurriendo a esa usanza azteca. ${ }^{168}$ En relación con esto, se debe decir que la maternidad viene indicada también con la representación del Espíritu Santo en forma de paloma sobre la cabeza de la Virgen.

Con respecto a la cronología de la "telas mexicanas», tal como las llama L. L. Calzamiglia, ${ }^{169}$ solo se cuenta con un testimonio oral que informa que los cuadros conservados en la sacristía de la parroquia de Chiusanico proceden de España, y que fueron donados a la iglesia por la familia Ghersi, de Chiusanico. ${ }^{170}$ En esta línea, hay que señalar que la representación en las dos telas de la ciudad de México a los pies de la Virgen proporciona un dato interesante a la hora de establecer su cronología. En la representación de la ciudad de México aparecen una serie de elementos: la capilla que se construyó en 1557 sobre el monte Tepeyac, en honor a la Virgen de Guadalupe; la «iglesia de los indios», dedicada a la Virgen en 1622; y la nueva basílica, con su cúpula y cuatro campaniles, que se inauguró el 27 de abril de 1709. Cerca de la basílica hay una fuente que fue realizada a mediados del siglo XVIII. La relación de estos datos, en especial los referidos a la nueva basílica, permite fijar la cronología para ambas obras entre 1750 y $1777 .{ }^{171}$ Asimismo, podría hacerse una precisión, desde el punto de vista cronológico, y considerar la tela de la sacristía posterior a la colocada en el presbiterio.

Otra de las dudas surgida en torno a estas obras es la relativa a quién las llevó hasta la iglesia. De hecho, las hipótesis son muchas: bien pudo

168 Ib., pp. 102-103.

169 Ib., pp. 104.

170 Memoria oral transmitida por el Rvdo. Mons. Fiorenzo Gerini.

171 Calzamiglia (1992), pp. 105-106. 
tratarse de un emigrado que regresó a su país; de un marinero que embarcó en una nave española rumbo a las Américas; o bien pudieron ser compradas por una familia noble que intentaba estar a la moda adquiriendo cuadros españoles.

A pesar de todas estas lagunas documentales, lo que no se pone en cuestión es su procedencia espańola, probablemente sevillana, teniendo presente la importante actividad financiera y cultural que existió en época moderna entre Sevilla y las Indias, y, a su vez, entre los puertos de Sevilla y Génova.

Además de estas dos obras conservadas en la iglesia de Chiusanico, es preciso mencionar que en Liguria se conservan otras dos telas de la imagen de Guadalupe: una en la parroquia de San Esteban de Aveto y otra en la iglesia de San Esteban de Borgio Verezzi. ${ }^{172}$

También perteneciente a este grupo y colocada en la sacristía de la iglesia se encuentra una Inmaculada (ficha n. ${ }^{\circ}$ 60). El estudio llevado a cabo por Nicola Serrato permitió revelar la firma del autor: «Luis Mena», probablemente sevillano. Está datada entre la segunda mitad del siglo XVII e inicios del XVIII. ${ }^{173} \mathrm{La}$ obra figura en la sacristía como Inmaculada, por las semejanzas que la obra presenta, desde el punto de vista iconográfico, con la Inmaculada Concepción. Se trata de una variante iconográfica poco frecuente, que representa un episodio del Apocalipsis (12, 1-14).

Dentro de este contexto, cabe mencionar algunos datos sobre el origen de la imagen apocalíptica. Como indica Navarrete Prieto, a la hora de configurar la imagen de la Inmaculada apocalíptica se tuvo muy en cuenta la estampa de Jan Sadeler sobre composición de Martin de Vos de san Juan Evangelista en Patmos, que utilizaron tanto Pacheco como Velázquez. Otra fuente en el caso de la Inmaculada está en la obra del jesuita Luis del Alcázar Vestigatio Arcani sensu in Apocalypsi, ilustrada con estampas realizadas sobre dibujos de Juan de Jáuregui. El eco más directo de esta estampa de Jáuregui se encuentra en la obra del mexicano Juan Correa (1675-1714), la Virgen del Apocalipsis del Museo Nacional del Virreinato

172 La tela de la imagen de la Virgen de Guadalupe, conservada en la iglesia de San Esteban de Borgio Verezzi, pertenece, como las dos de Chiusanico, a la diócesis AlbengaImperia.

173 Giacobbe (1992), p. 126. 
de Tepotzotlán. En ella, principalmente en la parte superior donde se representa a Dios Padre con el Niño y los ángeles, se sigue muy directamente el modelo de Jáuregui. ${ }^{174}$

En la sacristía se conserva, también, la quinta y última tela «ibérica» de fuerte «sabor popular». Representa una Virgen Dolorosa (ficha n. ${ }^{\circ}$ 61), datada entre la segunda mitad del siglo XVII y el XVIII. En opinión de Alessandro Giacobbe, se trata evidentemente de una «Virgen de los Dolores», tipología mariana muy venerada en el sur de España. ${ }^{175}$

El amplio margen cronológico establecido para estas obras no permite aclarar cuáles fueron los motivos de su presencia en la iglesia de Santo Stefano de Chiusanico. Según la tradición popular, estas obras proceden de familias nobles (Ghersi y Daporto) de Chiusanico, pero dicha procedencia no está documentada.

A pesar de estas dudas, es preciso destacar que las cinco telas constituyen un ejemplo de los vínculos comerciales y culturales existentes durante la época moderna entre el sur de España y Liguria. Al mismo tiempo, reflejan una cultura artística que no se limitaba a las fronteras geográficas de cada territorio sino que iba más allá de ellas, originando una circulación tanto de artistas como de obras que favorecería la difusión de las corrientes artísticas. Como ya se ha mencionado, está constatado que en el sur de España, de donde probablemente proceden estas obras, existían colonias de trabajadores procedentes de Liguria. De hecho, ciudades como Cádiz o Sevilla se convirtieron en importantes focos de atracción para los jóvenes que querían hacer fortuna.

Con el estudio de estas obras se quiere poner de manifiesto la necesidad de estudiar estos pequeños centros que, a veces, como en este caso, son fundamentales para comprender el «ir y venir» de las formas culturales y artísticas.

174 Navarrete Prieto (2001), pp. 56 y 59.

175 Giacobbe (1992), p. 127. 



\section{2 \\ LA PINTURA ESPAÑOLA DEL SIGLO XIX EN EL RESTO DE LIGURIA}

\subsection{La producción pictórica de Serafín Avendaño en el resto de Liguria}

Como ha podido constatarse en el capítulo anterior, la producción pictórica de Serafín Avendaño existente en Génova es notable. Sin embargo, en el resto del territorio ligur no es tan abundante. Las provincias que comprenden Liguria, a excepción de La Spezia, cuentan con obras del pintor vigués, la mayoría de ellas conservadas en colecciones privadas.

\subsubsection{Estudio de las obras de Serafín Avendaño} conservadas en museos

\section{Pinacoteca Civica de Imperia}

En la Pinacoteca Civica de Imperia existe una obra de Avendaño que constituye una excepción, ya que la mayor parte de las obras del pintor se encuentran en colecciones privadas. El cuadro en cuestión se titula Primavera en Liguria (ficha n. ${ }^{\circ}$ 62), fechado en torno a 1868 y firmado en el margen inferior derecho: «S. Avendaño». Procede de la colección de S. Rebaudi de Génova-Pegli, quien la donó a la ciudad de Imperia. 


\subsubsection{Estudio de las obras de Serafín Avendaño existentes en colecciones privadas de Savona}

Las obras que a continuación se presentan comparten las características pictóricas anteriormente mencionadas, por lo que únicamente se procede a su enumeración:

Vista de Cannes, desde el mar (ficha n. ${ }^{\circ}$ 63), firmada en el margen inferior izquierdo: «S. Avendaño» y datada en 1875. Procede de la colección de G. Robaldo y D. Tiscione de Albisola (Savona). Actualmente se encuentra en una colección privada de Savona.

Arboleda desnuda en invierno (ficha n. ${ }^{\circ}$ 64), firmada en el margen inferior derecho: «S. Avendaño». Proviene de la colección Robaldo-Tiscione de Albisola (Savona). En la actualidad se halla en una colección privada de Savona.

«Macchia» de árboles y césped (ficha n. ${ }^{\circ}$ 65), firmada en el margen inferior izquierdo: «S. Avendaño». Procede de la colección Robaldo-Tiscione de Albisola (Savona). En estos momentos forma parte de una colección privada de Savona.

Además de estas tres obras se cita otra, de la que se carece de material fotográfico:

Paisaje fluvial, con «stradale» (tríptico, óleo sobre lienzo; $31 \times 39 \mathrm{~cm}$ : central, $26 \times 34 \mathrm{~cm}$ : laterales). Firmada en el margen inferior izquierdo: «S. Avendaño». Este tríptico ha sido atribuido a Serafín Avendańo por Vitaliano Rocchiero. Proviene de la Galleria La Navicella de Savona, y actualmente se encuentra en una colección privada de Savona.

A modo de colofón, cabe decir que no solo Liguria cuenta con la presencia de obras del pintor vigués, sino que también su pintura se localiza en otras ciudades italianas. Así, cabe destacar: Turín (Galleria d'Arte Moderna: La rosa, óleo sobre tabla, $35,5 \times 21 \mathrm{~cm}$, fechada en 1875); Cuneo (colección privada de Caraglio: Baños de Livorno, óleo sobre lienzo, $48 \times 25,5 \mathrm{~cm}$, firmado en el margen inferior derecho); Piacenza (Galleria Oddi Ricci); Busseto, Parma (colección Carrara-Verdi); Roma (Galleria Nazionale: Primavera, óleo sobre lienzo, $68 \times 119 \mathrm{~cm}$, datada en 1882).

Cuando Serafín Avendaño regresó a España continuó pintando. De hecho, algunos museos españoles exponen obras de este pintor como, por 
ejemplo, el Museo del Prado, Madrid (Paisaje en las cercanias de Génova); Museo de la Real Academia de Bellas Artes de San Fernando de Madrid (Paisaje con lago, Paisaje en la casa de campo); Colección Caixavigo, Vigo (Paisaje con gallega, etc.); Museo Provincial de Lugo (Paisaje otoñal, etc.); y Museo de Pontevedra (La carreta con algas, etc.).

La amplia producción pictórica de Avendaño refleja una personalidad incansable, cantora tanto de la tierra ligur como de la natal. Rayper, Andrade, Issel y Avendaño formaron la Scuola Grigia de paisaje (Génova) y la de Rivara (Piamonte), siendo los artífices de la renovación pictórica local y, al mismo tiempo, de la renovación general del arte en Italia. 



\section{3 \\ LA PINTURA ESPAÑOLA DEL SIGLO XX EN EL RESTO DE LIGURIA}

\subsection{Savona}

Al conjunto de obras antes estudiadas hay que añadir también las correspondientes al siglo XX. En concreto, en la provincia de Savona la existencia de colecciones privadas con obras de pintura española contemporánea es abundante. Debido a la disponibilidad temporal, en este estudio se incluyen solo una parte de las obras de pintura española conservadas en territorio savonés, que se encuentran localizadas en la colección de Roberto Debenedetti y de su esposa, Silvia Bottaro, quienes muy amablemente me mostraron su colección de pintura y, al mismo tiempo, me proporcionaron otros nombres de coleccionistas privados que poseen pintura española.

En la casa de estos coleccionistas se conserva un cuadro de Juan Segura García (Palma de Mallorca, 1955) que representa la Familia Real de Carlos $I V$ (ficha n. ${ }^{\circ}$ 66). La pintura está firmada y fechada en el margen inferior izquierdo: «Familia Real de Carlos IV J. Segura 1985». Roberto Debenedetti adquirió este cuadro en 1985, en el estudio que Juan Segura compartía con el pintor Enzo L'Acqua en Savona. La obra cuenta con un boceto preparatorio realizado con lápiz y con algún toque de color, y está dedicado al coleccionista Debenedetti: «Afectuosamente para Roberto Debenedetti. Savona Junio 1985». Roberto Debenedetti y su esposa son dos grandes amantes del arte contemporáneo, y la adquisición de esta obra responde tanto a una cuestión de gusto artístico como a la amistad que les une al pintor. 
Dentro de este contexto, es interesante señalar que Segura pasa, en general, sus veranos en tierras ligures, tiempo que aprovecha para exponer sus cuadros y dar a conocer su producción pictórica fuera de España. Asimismo, organiza exposiciones de pintura, como la que tuvo lugar en Albisola (Savona) en 1997.

Perteneciente igualmente a Juan Segura García y en la misma colección destaca la obra titulada Los elefantes (ficha n. ${ }^{\circ}$ 67), firmada en el margen superior izquierdo: «J. S.». Esta pintura está formada por tres pequeños cuadros, en cada uno de los cuales se representa un elefante, prácticamente en la misma posición, pero en diferente color.

Además, la colección de pintura de Roberto Debenedetti y de Silvia Bottaro incluye una obra de Antoni Tàpies (Barcelona, 1923) que se titula Composición (ficha n. ${ }^{\circ}$ 68), firmada en el margen inferior derecho. El cuadro procede de la Sala Gaspar de Barcelona y en 1961 pasó a una colección privada de Milán, donde permaneció hasta que Roberto Debenedetti lo compró en la Galería Farsetti de Prato, en 1986.

La colección es muy rica y comprende otros dos lienzos de pintores españoles. Uno de ellos es una obra de José Ortega (1921, Arroba de Los Montes, Ciudad Real-1991) titulada Ginestas (ficha n. ${ }^{\circ}$ 69), que está firmada y fechada en 1973. Roberto Debenedetti adquirió este cuadro en la Casa d'aste Pitti de Florencia, el 29 de noviembre de 1991. A este respecto, es preciso decir que José Ortega estuvo muy relacionado con Italia, llegando a organizar numerosas exposiciones en Turín, Roma y otras ciudades italianas. De este modo, sus pinturas se dieron a conocer y se difundieron entre el público y los coleccionistas de arte de este país.

La segunda y última obra de pintura española conservada en esta colección es un cuadro de Eduardo Arroyo (Madrid, 1937) titulado Personaje (ficha n. ${ }^{\circ} 70$ ), fechado en 1976 . Roberto Debenedetti lo compró en Albisola, en 1982.

Con estas obras se concluye la catalogación de la pintura española existente en Liguria. Pero, como anteriormente se ha mencionado, se trata de un estudio inicial, porque tanto en Savona como en Loano existen colecciones privadas que poseen obras de pintores españoles, que podrían ser objeto de estudio en futuras investigaciones. 


\section{CONCLUSIÓN}

En opinión de Juan Antonio Gaya Nuño, la salida de pintura española fuera de nuestras fronteras estuvo determinada por dos causas principales: unas, naturales, y otras, artificiales. A las primeras pertenecen el trabajo y la estancia del artista en tierra "extraña», las cesiones realizadas en vida o las operadas por sus inmediatos clientes. Sin embargo, las segundas no implican nada de lo anterior, y son debidas a la confiscación y compra, producidas a través de diferentes medios. ${ }^{176}$ De hecho, ambas situaciones se dan en la pintura española conservada en Liguria.

Como se indicó al inicio del estudio, en este apartado se recogen las conclusiones más importantes de la investigación, relativas a las vías de llegada de la pintura espańola a Liguria, su importancia global dentro de la pintura espańola y su influencia en el ambiente cultural y artístico genovés.

En cuanto a las vías de llegada de pintura española hasta Liguria, se puede concluir afirmando que la salida de pintura de nuestro país estuvo determinada por circunstancias distintas, según se trate de pintura correspondiente a los siglos XVII, XVIII, XIX o XX. Es preciso decir que no se incluye aquí la obra del siglo XV conservada en el Museo Civico Amedeo Lia de La Spezia porque, aunque está atribuida a un anónimo español, no parece propiamente una obra espańola sino más bien alemana de la segunda mitad del siglo XV. Al mismo tiempo, el inventario de los cuadros españoles permite apreciar la importancia global de esta pintura «emigrada» den-

176 Gaya Nuño (1958), p. 10. 
tro del contexto evolutivo de la pintura española, viendo qué pintores y qué géneros de pintura fueron los preferidos.

Con respecto a la pintura española del siglo XVII, hay que señalar que su llegada a territorio ligur se produjo a través de dos vías: la adquisición por parte de M. Vittoria Spinola Grilla de algunas de las obras de la colección española de Diego Felipe de Guzmán, que luego fueron vendidas a Giacomo Filippo Durazzo II; y las subastas parisinas del siglo XIX. En cuanto a la primera vía, es necesario tener en cuenta la valoración que a nivel europeo había alcanzado la pintura española, que dio lugar a que muchos coleccionistas de arte, entre ellos los nobles genoveses, se interesasen por la adquisición de estas obras. En dicho contexto, es preciso decir que las familias nobles genovesas adquirieron las obras de maestros espańoles del Siglo de Oro, bien a través de los comercios de venta de pintura italianos, o bien a través de algún marchante de arte. Como puede comprobarse, en algún caso se desconoce la procedencia de estas pinturas, que solo aparecen recogidas en los inventarios familiares. En cuanto a la segunda vía, hay que destacar que quienes verdaderamente se dieron cuenta del valor "comercial» de la pintura española del siglo XVII, hasta ese momento prácticamente desconocida, fueron, en primer lugar, los viajeros que recorrían el territorio español, entre los que cabe citar al coleccionista francés Le Brun, que ya a principios del siglo XIX había rescatado del olvido a muchos maestros españoles, dando a conocer su obra en Francia; y, en segundo lugar, aquellos que, teniendo conocimiento de dicha importancia, aprovecharon la circunstancia de encontrarse en territorio español para llevarse con ellos estas obras, tal como sucedió en la Guerra de la Independencia, siendo extraídas en su mayoría de iglesias y conventos. Los artífices de esta campaña fueron principalmente generales franceses, como es el caso del mariscal Soult o del general Lévy, o españoles de ideología filofrancesa, que, como el marqués de las Marismas («Mr. Aguado»), se llevaron consigo obras de pintura española a París. De hecho, como ha podido constatarse, la mayor parte de la pintura española del siglo XVII conservada en museos y colecciones genovesas fue adquirida en París por nobles genoveses que se beneficiaron de la venta de algunas colecciones, entre ellas la del marqués de las Marismas, en 1843, y la del mariscal Soult, en 1852. Las obras que fueron adquiridas en París pasaron más tarde a conformar los fondos de las colecciones de pintura de la aristocracia genovesa que actualmente se exponen en los palacios 
Rosso y Bianco de Génova. Sin embargo, otras obras fueron adquiridas en el siglo XX, tal como sucede con la Sagrada Familia, atribuida a Francisco de Zurbarán, conservada en la Galleria Nazionale di Palazzo Spinola, que fue adquirida en 1954.

Finalmente, se constata algún otro caso en el que se desconoce la procedencia de estos fondos hispanos, como ocurre con las pinturas del $\mathrm{Pa}$ lazzo Reale, debido a la dispersión de los archivos del palacio, o bien son el resultado de donaciones privadas (las naturalezas muertas procedentes del Museo Civico Amedeo Lia de La Spezia).

En cuanto a la valoración global de esta pintura, cabe subrayar que sobre todo se produjo la demanda masiva de pintura andaluza y castellana, que comprende obras (óleos sobre lienzo) de temática principalmente religiosa, a las que hay que sumar algún retrato de corte, bodegones y el conocido tema de los filósofos de Ribera. En relación con esto, es preciso señalar que la mayoría de las obras aquí catalogadas, sean originales o copias, corresponden a maestros representativos de la pintura española de los siglos XVI y XVII, tales como el Greco, José de Ribera, Francisco de Zurbarán, Bartolomé Esteban Murillo, Alonso Cano, Claudio Coello y Juan Bautista Martínez del Mazo. Dichos pintores fueron los que atrajeron el interés de los coleccionistas de arte europeos, principalmente de ingleses y franceses. A diferencia de Ribera, Murillo, Velázquez, Claudio Coello y Alonso Cano, que ya eran conocidos en el siglo XVIII, el Greco y Zurbarán empezaron a ser estimados a partir del siglo XIX. En cuanto a Ribera, es preciso recordar que residió, durante un período prolongado de su vida en Nápoles, lo que hace suponer que sus obras fueron adquiridas, en la mayoría de las ocasiones, dentro del propio territorio italiano.

Respecto a la pintura espańola del siglo XVIII conservada en Liguria, hay que decir que compone un conjunto de pinturas menor, constituido por dos grupos diferenciados de obras. Así, por un lado, se encuentra la tela de Francisco Javier Ramos conservada en el Museo dell'Accademia Ligustica de Génova; y, por otro, las cinco telas pertenecientes a la iglesia de Santo Stefano de Chiusanico (Imperia). En cuanto a la pintura del artista madrileño F. Javier Ramos, alumno de Mengs y pensionado español en Roma, se sabe que es una copia del retrato que el pintor Anton von Maron (cuńado de Mengs) había realizado del duque de Grimaldi durante la estancia de este en Roma como embajador de la Santa Sede. En este 
caso, constituye un ejemplo de pintura salida por causas naturales fuera de las fronteras españolas, atendiendo a la división realizada por J. A. Gaya Nuño. En cuanto a las cinco telas de la iglesia de Chiusanico, se trata de obras del siglo XVIII, a excepción de la Alegoría de la muerte, que puede datarse hacia mediados del siglo XVII, como realizada por algún seguidor de Ries, a pesar de lo cual se incluye en este apartado por constituir un conjunto unitario. Las cinco telas son consideradas por los historiadores del arte italianos como de procedencia española, probablemente sevillana. De hecho, pudieron estar vinculadas con las estrechas relaciones de tipo económico-comercial que existieron en época moderna entre el sur de España y Liguria, y que tuvieron que ver con el movimiento de la flota genovesa, dando lugar a un importante intercambio mercantil (y, por supuesto, cultural). Además, se constata que muchos jóvenes procedentes de los valles de Imperia fueron a Cádiz y a otras ciudades del sur de España con el fin de hacer dinero. La forma en que llegaron las telas hasta Chiusanico se desconoce, aunque pudieron haber sido llevadas por algún emigrante que regresara a su país, por algún marinero embarcado con rumbo a las Américas, o como resultado de la adquisición de alguna familia noble que intentaba «estar a la moda» comprando cuadros espańoles. De hecho, así lo expresa la tradición oral, según la cual los cuadros colocados en la sacristía de la iglesia de esta localidad proceden de España y fueron donados por la familia Ghersi de Chiusanico.

Como valoración global de este conjunto pictórico, hay que destacar la obra de F. Javier Ramos por su extraordinaria calidad, y por tratarse de un modelo de retrato oficial de gusto neoclásico. En cambio, las cinco telas de la iglesia de Chiusanico no presentan una factura muy buena, pero son interesantes desde el punto de vista iconográfico y simbólico, ya que tratan diferentes temas, tales como el del árbol de la vida, la iconografía mariana vinculada con México (Virgen de Guadalupe) o una variante iconográfica poco habitual de la Inmaculada Concepción.

Por su parte, la pintura española del siglo XIX existente en Liguria tiene dos procedencias diferentes: una, haber sido comprada por coleccionistas de arte; y otra, haber sido realizada por artistas españoles residentes en esta región. Al primer caso responde la obra de Joaquín Sorolla, mientras que dentro del segundo se encuentra la pintura de Serafín Avendaño. 
En relación con las dos obras de Sorolla conservadas en las colecciones Frugone de Génova-Nervi, hay que decir que fueron adquiridas por Luigi Frugone (1862-1953), probablemente a través del comerciante y coleccionista de arte Ferruccio Stefani. En cambio, la producción pictórica de Serafín Avendaño localizada en Liguria, principalmente en Génova y en colecciones privadas, está relacionada con su residencia en Italia, $y$, en concreto, en la localidad genovesa de Quarto dei Mille, durante treinta años (1866-1896). De este modo, cuando el pintor vigués regresa definitivamente a su patria, deja en territorio ligur una gran cantidad de obras (veinticuatro óleos sobre lienzo, ocho óleos sobre tabla, un óleo sobre cartón, una acuarela sobre cartón, un óleo sobre papel pegado a cartón y un pastel sobre cartulina), fundamentalmente de temática paisajística, junto con algún retrato. La mayoría de las obras de Avendaño fueron adquiridas en exposiciones nacionales y, excepcionalmente, fueron compradas por el Ayuntamiento de Génova o regaladas por el propio artista a un amigo. Como puede comprobarse, cuando se trata de colecciones privadas, algunas de estas pinturas ya no se encuentran en su ubicación primera, sino que han podido ser vendidas y tener nuevos propietarios.

En cuanto a la importancia de esta pintura del siglo XIX, debe señalarse que las obras de Sorolla son dos paisajes marinos que permitirán completar el catálogo pictórico del artista correspondiente a su período de formación. Y, en lo que atañe a Serafín Avendaño, se puede concluir diciendo que su obra en Liguria es fundamental para reconstruir la producción artística de este pintor vigués. De hecho, su pintura evoluciona, desde el punto de vista estilístico, cuando entra en contacto con los pintores ligures y toscanos, lo que le lleva a superar el Romanticismo inicial para abrazar la poética del paisaje tomado del natural.

En cuanto a la pintura espańola del siglo XX conservada en Liguria, se debe indicar que esta es el resultado de las adquisiciones llevadas a cabo por coleccionistas de arte en diferentes galerías italianas y españolas, o, en alguna ocasión concreta, como fruto de las estancias periódicas de un artista español en territorio ligur, es decir, de la salida de pintura española de España debido a causas naturales, si se tiene en cuenta lo expresado por Juan Antonio Gaya Nuńo. En concreto, las obras están localizadas en territorio savonés, y se encuentran en la colección de Roberto Debenedetti y 
Silvia Bottaro. En cuanto a la autoría, incluye pinturas de Tàpies (una pintura al temple), Eduardo Arroyo (un collage sobre papel), José Ortega (una pintura al temple) ${ }^{177}$ y Juan Segura García (un óleo sobre lienzo y una pintura al temple). Este último pintor, habitualmente, pasa sus veranos en tierras ligures, tiempo que aprovecha para exponer sus cuadros y dar así a conocer su producción fuera de España. De hecho, Roberto Debenedetti adquirió las dos obras de su propiedad en el propio estudio de pintura que este artista tenía en Savona.

Finalmente, en lo referente a la influencia de la pintura española en el ambiente artístico genovés, hay que centrarse de forma casi exclusiva en la figura de Serafín Avendaño, pintor que residió por un período de treinta años (1866-1896) en Génova. Antes de la llegada de Avendaño a Liguria, el ambiente pictórico genovés estaba en plena decadencia, debido a la supervivencia de las tendencias neoclásicas y románticas, que dificultaban la asimilación de nuevos aportes. De hecho, habría que esperar hasta el año 1845 para que se produjeran una serie de novedades importantes para el porvenir de la región, tales como la fundación de la Accademia Ligustica de Génova y de la Società Promotrice di Belle Arti. En torno a 1863 se produjo la llegada a Liguria de jóvenes pintores, como el portugués Andrade, que siguiendo al pintor genovés Tammar Luxoro fueron estableciendo las bases de la pintura de paisaje al natural. Con la llegada de Avendaño en 1866 y con las reuniones de estos pintores en las colinas de Carcare, Rivara y a las orillas del Bormida, fue tomando forma el movimiento pictórico renovador genovés conocido con el nombre de Scuola Grigia ('Escuela Gris'). El grupo de los "grises», con Avendaño a la cabeza, influyó y renovó las escuelas pictóricas de los grupos italianos hermanos (en Piamonte, la Escuela de Rivara; en Florencia, la Escuela de Pergentina; en Nápoles, la Escuela de Résina). Y, además, acabó imponiéndose en Génova frente a los académicos. La pintura de paisaje de Avendaño, que denota una especial predilección por los temas marinos, cosechó notables éxitos en las exposiciones nacionales, y su personalidad artística fue no solo valorada por los coleccionistas de arte sino también por los escritores italianos contemporáneos, como A. G. Barrili, quien en su obra Amori alla macchia (1885)

177 La obra de Pepe Ortega conservada en la colección de Savona se aparta del expresivo realismo social, que caracteriza una gran parte de su producción pictórica, para abordar un tipo de temática más abstracta. 
deja constancia de las innovaciones llevadas a cabo por este artista en el terreno pictórico ligur. Al respecto, cabe citar la opinión de Gianfranco Bruno, quien coloca a Serafín Avendaño entre los artistas más representativos de la pintura ligur de la segunda mitad del siglo XIX. En esta línea, no debe faltar la opinión de Vitaliano Rocchiero, quien otorga a Avendaño todos los honores por haber contribuido notablemente a la realización de una auténtica pintura genovesa de paisaje, compacta y unida.

Antes de concluir, cabe expresar que no toda la pintura española que existió en un principio en Liguria se conserva en la actualidad. De hecho, se tiene conocimiento, a través de la documentación escrita, de que existieron en este territorio italiano más obras de maestros españoles, que, con el tiempo, se han ido dispersando por diferentes museos internacionales. Así, a modo de ejemplo, en la iglesia de la Santissima Concezione de Génova se conservan seis telas: Inmaculada, Santa Maria Magdalena, La venta de José, Natividad, Santo Tomás de Villanueva impartiendo caridad y Descanso en la huida a Egipto, datadas entre los siglos XVIII y XIX, que son una copia realizada por el padre capuchino Venanzio de Bernardis (Génova, 1791-1840) de otros tantos originales dispersos, ejecutados por B. Esteban Murillo. Se sabe que las seis obras originales de Murillo fueron donadas a esta iglesia por el genovés Giovanni Bielato, en $1679 .{ }^{178}$ En la descripción que Ratti hizo de la iglesia en 1780, las telas se encontraban aún en el coro. ${ }^{179}$ Gaya Nuño señala que estas pinturas de Murillo fueron adquiridas entre 1803 y 1806 por Mr. Irvine para el marchante de arte inglés Buchanan, quien a su vez las vendió. La localización actual de los seis originales de Murillo se debe a Gaya Nuño: la Magdalena se encuentra en el Museo Ludwig de Colonia; La venta de José, Santo Tomás de Villanueva y la Natividad se conservan en la Wallace Collection; el Descanso durante la huida a Egipto se halla en el Museo de Wrotham Park, en Middlesex; y la Inmaculada, en el Museo de Ringling, en Sarasota. ${ }^{180}$ Es posible, por tanto, que Venanzio de Bernardis realizara estas seis copias entre finales del siglo XVII y principios del XVIII, antes de que se vendieran, tratándose, pues, de un testimonio más del interés que históricamente ha habido en Génova por los artistas y obras de pintores españoles del Siglo de Oro.

178 Vita e cultura cappuccina. Chiesa della SS. Concezione a Genova, 1984, p. 61.

179 Ratti (1780), p. 349.

180 Gaya Nuño (1958), p. 106. 



\section{CATÁlogo I \\ LA PINTURA ESPAÑOLA EN GÉNOVA}





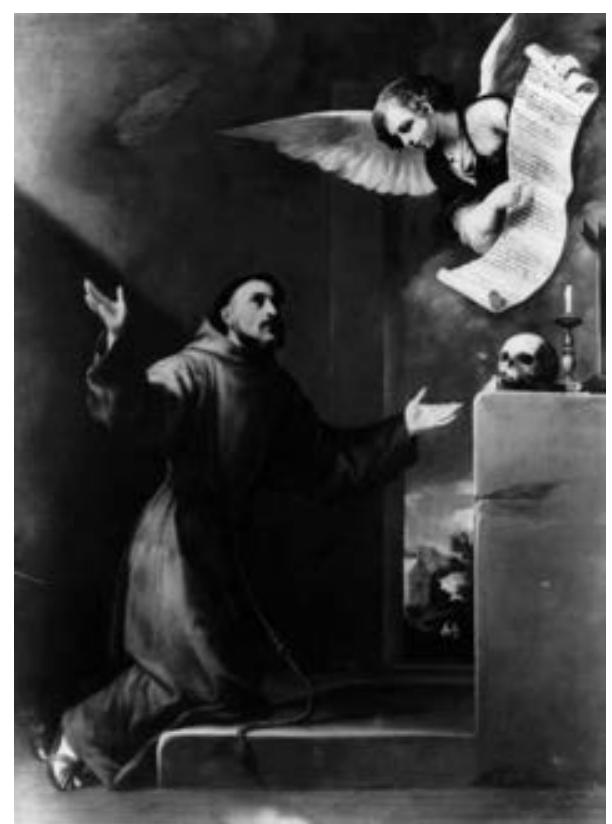

FICHA CATALOGRÁFICA

N. ${ }^{\circ}$ orden: 1

Galleria di Palazzo Bianco, Génova

San Francisco recibe del ángel los siete privilegios de la Regla, copia de un original de José de Ribera, Galleria di Palazzo Bianco, Génova.

Autor-atribución. Titulo de la obra: Una primera atribución a Murillo; actualmente se considera copia de un original de José de Ribera: San Francisco recibe del ángel los siete privilegios de la Regla.

A. L. Mayer (1923b) lo considera obra de Murillo. O. Grosso (1932, p. 141), en el catálogo de los museos de Génova, duda entre Ribera y Murillo, y finalmente lo atribuye a un anónimo napolitano.

J. A. Gaya Nuño (1958, p. 240) considera más verosímil que se trate de una copia de un original perdido de José de Ribera, conocido a través de otras copias, entre las cuales se cita una, fechada en 1639, conservada en una colección privada madrileña. Angulo Iñíguez (1981, pp. 484-485) indica que si se tratase de una obra de Murillo correspondería a un período excesivamente juvenil; por tanto, es más verosímil que sea copia de un Ribera.

Estilo-cronología: Gaya Nuño (1958, p. 240) establece su cronología en 1639 y Mayer (1923b) hacia 1645.

Tipo de obra, material y técnica: Cuadro. Óleo sobre lienzo.

Dimensiones: $240 \times 178 \mathrm{~cm}$. 
Elementos autógrafos: No está firmado.

Localización y procedencia: Génova, Galleria di Palazzo Bianco, sala n. ${ }^{o} 11$ (dedicada a los pintores espańoles).

Este cuadro fue obtenido en España por el general Lévy (siglo XIX) y, después, pasó a la colección de Alejandro María Aguado (marqués de las Marismas del Guadalquivir). Fue adquirido por Raffaele De Ferrari (duque de Galliera) en la subasta de la colección Aguado, celebrada en París el 25 de marzo de 1843 , por 15400 francos, al ser considerado como una obra maestra de Murillo. Estuvo expuesto en su residencia parisina (Hôtel Matignon) de la rue de Varenne hasta el fallecimiento del duque de Galliera, tras lo cual su viuda, Maria Brignole Sale (1811-1888), dispuso su traslado a Génova. Desde 1892 se conserva en la Galleria di Palazzo Bianco, aunque entre 1961 y 1990 estuvo expuesto en la Galleria di Palazzo Rosso de Génova.

Descripción: Se representa a san Francisco de Asís, fundador de las tres órdenes franciscanas, y una de las personalidades más representativas de la Iglesia y de la humanidad. El santo está arrodillado con los brazos abiertos ante un crucifijo y una calavera, y ante él hay un ángel sobre el altar que señala los estatutos de la Orden Franciscana. Lleva barba, un hábito marrón con una cuerda blanca a la cintura, con tres nudos, en alusión a los tres votos religiosos (obediencia, pobreza y castidad). Esta escena se desarrolla en un primer plano, mientras que en el fondo de la composición se abre un paisaje con una iglesia, probablemente perteneciente a la Orden Franciscana. Destaca el rico juego de luces y sombras. Se aprecia un intenso foco de luz, procedente del lateral izquierdo, que ilumina el rostro del santo, al ángel y al rollo que contiene los estatutos de los franciscanos, mientras que los demás elementos compositivos permanecen en penumbra. La obra se caracteriza por el predominio de colores oscuros, sobre todo marrones y negros, y por el naturalismo y sencillez compositiva.

Historia de la pieza: Estado de conservación: bueno. Fue restaurado en 1961. Noticias documentales inéditas: Inv. P. B. 216.

Exposiciones: Fue expuesto en la muestra Arte Antica, celebrada en el Palazzo Bianco de Génova en 1892, con motivo de su apertura al público (como museo), conmemorando al mismo tiempo el cuarto centenario del descubrimiento de América.

Catálogos:

Catalogue de tableaux anciens des écoles espagnole, italienne, flamande, hollandaise et allemande, statues anciennes et modernes, marbres, etc. Composant la 
Galérie de M. Aguado Marquis de las Marismas dont la vente aux enchères publiques en son hôtel, rue Grange Batelière 6, à Paris, 20-28 mars 1843. París, Maule et Renou, 1843.

Angulo Iñíguez (1981), pp. 484-485.

Bibliografía:

A. S. C. G., "Carta a Bernardo Pellegrini», sc. 747, DF-Cartas de Raffaele De Ferrari a Pellegrini. París, 23 de marzo de 1843.

Biblioteca Sanctorum, 1964, vol. v, pp. 1052-1131.

Boccardo y Di Fabio (2004), pp. 239-241.

Botto y Tagliaferro (eds.) (1977b).

Di Fabio (1992), pp. 76-81.

Gaya Nuño (1958), p. 240.

Gaya Nuño (presentación) (1978), p. 114.

Genaille (1964).

Grosso (1920).

Grosso (1932), p. 141.

Mayer (1923b).

Pérez Sánchez (presentación) (1978), pp. 131-132.

Tagliaferro (1991b).

Tagliaferro y Di Fabio (1991), p. 59. 


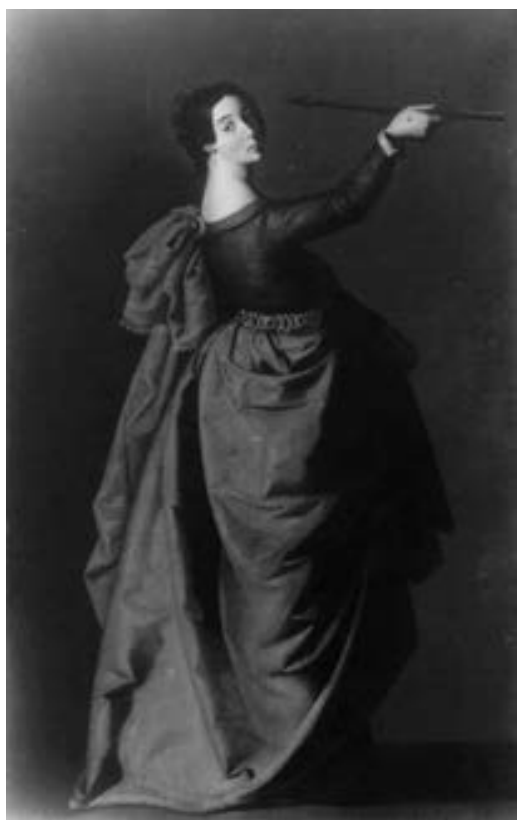

\section{FICHA CATALOGRÁFICA}

N. ${ }^{\circ}$ orden: 2

Galleria di Palazzo Bianco, Génova
Santa Úrsula, Francisco de Zurbarán,

Galleria di Palazzo Bianco, Génova.

Autor-atribución. Titulo de la obra: Francisco de Zurbarán (Fuente de Cantos, 1598-Madrid, 1664): Santa Úrsula.

En la Galleria di Palazzo Bianco figura como atribución segura al maestro. Estilo-cronología: J. M. Soria (1953, p. 160) fija su conología hacia 1636. De la misma opinión es J. A. Gaya Nuño (1958, p. 339).

Tipo de obra, material y técnica: Cuadro. Óleo sobre lienzo.

Dimensiones: $171 \times 105 \mathrm{~cm}$.

Elementos autógrafos: No está firmado, pero el nombre de la santa aparece escrito en el margen inferior izquierdo.

Localización y procedencia: Génova, Galleria di Palazzo Bianco, sala n.o 11 (dedicada a los pintores españoles). Fue sacado de Sevilla por el mariscal francés Soult, a principios del siglo XIX, y adquirido en París el 20 de mayo de 1852, en la venta de la colección Soult, por Raffaele De Ferrari, por 1100 francos. Permaneció en la capital francesa, en la residencia Galliera de la rue de Varenne, hasta el fallecimiento del duque de Galliera, tras lo cual su viuda, 
Maria Brignole Sale (1811-1888), dispuso su traslado a Génova. Este cuadro fue donado por deseo de Maria Brignole Sale, duquesa de Galliera, a la Galleria di Palazzo Bianco, donde se expone desde 1892.

En opinión de Gaya Nuño (1958, p. 339), se trata de una de las diez vírgenes y mártires pintadas por Zurbarán, hacia 1636, para la sacristía de un convento de Sevilla. De la misma opinión es Soria (1953, p. 160). Papone desconoce la colocación originaria de esta tela, pero opina que pudo formar parte del ciclo decorativo de la sacristía de un convento sevillano, junto a Santa Rufina (Nueva York, Hispanic Society of America), Santa Isabel de Hungría (Montreal) y el resto de santas. Además, esta autora data la obra entre 1635 y 1640, y advierte la existencia de otra versión en la colección Díaz de Madrid, aunque la de Génova sería la obra original (Papone, 1991, p. 70).

Descripción: Santa Úrsula fue martirizada hacia el 304, al no aceptar casarse con el jefe de los hunos, ya que había consagrado su virginidad a Dios. Se trata de una figura de cuerpo entero, captada de perfil y con el rostro girado hacia el espectador. Destaca su carácter volumétrico, conseguido, en gran medida, por los abundantes pliegues del vestido y por el rico contraste de luces y sombras que dotan de corporeidad a la composición. Se advierte el empleo de una gama de colores ricos y vivos: verde para el corsé y amarilloocre para la falda, que se enriquecen con un cinto de rubíes y esmeraldas entrelazados con oro, y con un manto rojo. Su rostro refleja serenidad y aceptación ante el instrumento de su martirio, la flecha, que porta en su mano derecha. La figura de la santa destaca sobre un fondo neutro y oscuro, creando un espacio sugestivo, casi metafísico; testimonio del fervor religioso de Zurbarán.

Historia de la pieza: Excelente estado de conservación. Fue restaurado entre 1996 y 1997 en el Laboratorio de Restauración Zanolini de Rávena.

Noticias documentales inéditas: Inv. P. B. 235.

Exposiciones: Fue expuesto en la muestra Arte Antica, celebrada en el Palazzo Bianco de Génova en 1892, con motivo de su apertura al público (como museo), conmemorando al mismo tiempo el cuarto centenario del descubrimiento de América.

Catálogos:

Catalogue raisonné des tableaux de la Galérie de feu M. le Maréchal Général Soult duc de Dalmatie, dont la vente aura lieu à Paris. París, Galérie Lebrun, 1852. 
Bibliografia:

A. S. C. G., «DF-sc. 447 Raffaele De Ferrari», Journal, París, 20 de mayo de 1852.

Biblioteca Sanctorum, 1967, vol. IX, pp. 1251-1268.

Boccardo y Di Fabio (2004), pp. 239-243.

Botto y Tagliaferro (eds.) (1977b).

Camón Aznar (1985), p. 293.

Di Fabio (1992), pp. 76-81.

Gaya Nuño (1958), p. 339.

Grosso (1920).

Grosso (1932), p. 142.

Guinard (1960).

Gregori (presentación) (1973), p. 99.

Papone (1991), pp. 70-71.

Soria (1953), p. 160.

Tagliaferro (1991b).

Tagliaferro y Di Fabio (1991), pp. 14, 36 y 59. 


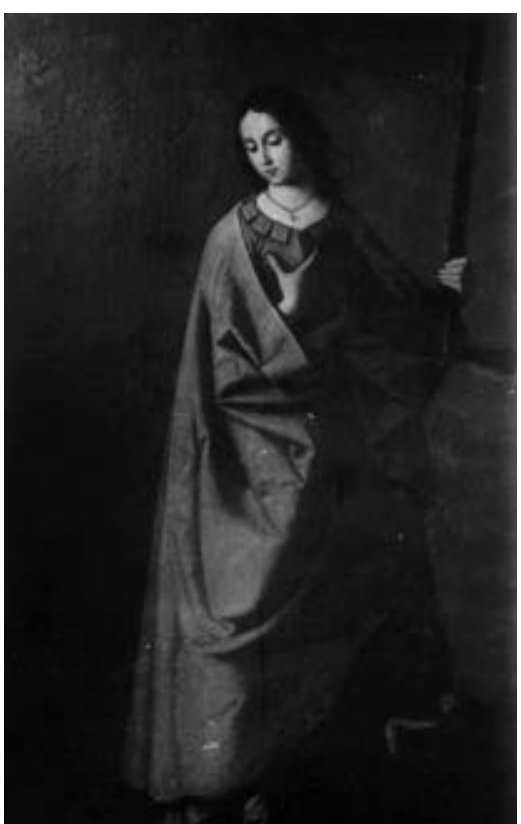

\section{FICHA CATALOGRÁFICA}

N. ${ }^{\circ}$ orden: 3

Galleria di Palazzo Bianco, Génova
Santa Eufemia, Francisco de Zurbarán, Galleria di Palazzo Bianco, Génova.

Autor-atribución. Título de la obra: Francisco de Zurbarán (Fuente de Cantos, 1598-Madrid, 1664): Santa Eufemia.

En la Galleria di Palazzo Bianco figura como atribución segura al maestro. Estilo-cronología: Datado en torno a 1635-1640.

Tipo de obra, material y técnica: Cuadro. Óleo sobre lienzo.

Dimensiones: $172 \times 106 \mathrm{~cm}$.

Elementos autógrafos: No está firmado, pero el nombre de la santa aparece escrito en el margen inferior izquierdo, en color rosa claro.

Localización y procedencia: Génova, Galleria di Palazzo Bianco, sala n.o 11 (dedicada a los pintores espańoles).

Fue obtenido en Sevilla por el mariscal francés Soult, a principios del siglo XIX, y adquirido en París en la subasta de la colección Soult (el 20 de mayo de 1852), por Raffaele De Ferrari, por 1600 francos. Permaneció en París, en la residencia Galliera de la rue de Varenne, hasta el fallecimiento del duque de Galliera, tras lo cual su viuda, Maria Brignole Sale (1811-1888), dispuso su traslado a 
Génova. Este cuadro fue donado por deseo de Maria Brignole Sale, duquesa de Galliera, a la Galleria di Palazzo Bianco, donde se expone desde 1892.

En opinión de J. A. Gaya Nuño (1958, p. 339), se trata de una de las diez vírgenes y mártires pintadas por Zurbarán, hacia 1636, para la sacristía de un convento sevillano. De la misma opinión es M. Soria (1953, p. 160). Para Clario di Fabio (1992, p. 14) formaría parte, junto con Santa Úrsula (ficha n. ${ }^{\circ} 2$ ), de los ciclos de vidas de santos y fundadores de órdenes religiosas, tan difundidos por España.

Descripción: Esta obra se encuentra en la misma línea, desde el punto de vista estilístico, que la anterior. Destaca igualmente por la serenidad espiritual de la santa, que tiene en su mano izquierda el instrumento de martirio: la sierra, mientras que la otra mano descansa sobre el pecho.

El martirio de santa Eufemia de Calcedonia se produjo en el año 303 d. C., al negarse a ofrecer sacrificio a los dioses. Va vestida con un corsé verde y una falda de color naranja, enriquecidos con un cinto de rubíes y esmeraldas entrelazados con oro, y con un manto de color verde. A diferencia de santa Úrsula, tiene posición frontal y conduce su mirada hacia abajo. La fuente de luz procede de un lateral, generando sombras en los numerosos pliegues del vestido, e iluminando el rostro de la santa. Destaca sobre un fondo neutro, oscuro, que crea en torno a la figura un espacio sugestivo. Como en la imagen anterior, se aprecia su dependencia de las estampas de Durero. M. Gregori (1973, p. 98) opina que esta tela recuerda la Santa Eufemia conservada en la colección privada Díaz de Madrid, observándose alguna variante en el instrumento del martirio.

Historia de la pieza: Estado de conservación: excelente. Fue restaurado entre 1996 y 1997 en el Laboratorio de Restauración Zanolini de Rávena.

Noticias documentales inéditas: Inv. P. B. 225.

Exposiciones: Fue expuesto en la muestra Arte Antica, celebrada en el Palazzo Bianco de Génova en 1892, con motivo de su apertura al público (como museo), conmemorando al mismo tiempo el cuarto centenario del descubrimiento de América.

Catálogos:

Catalogue raisonné des tableaux de la Galérie de feu M. le Maréchal Général Soult duc de Dalmatie, dont la vente aura lieu à Paris. París, Galérie Lebrun, 1852.

Bibliografia:

A. S. C. G., «DF-sc. 447 Raffaele De Ferrari», Journal, París, 20 de mayo de 1852. 
Biblioteca Sanctorum, 1964, vol. v, pp. 154-162.

Boccardo y Di Fabio (2004), pp. 239-243.

Botto y Tagliaferro (eds.) (1977b).

Camón Aznar (1985), p. 293.

Di Fabio (1992), pp. 14 y 76-81.

Gaya Nuño (1958), p. 339.

Gregori (presentación) (1973), pp. 98-99.

Grosso (1920).

Grosso (1932), p. 142.

Guinard (1960).

Papone (1991), pp. 70-71.

Soria (1953), p. 160.

Tagliaferro (1991b).

Tagliaferro y Di Fabio (1991), pp. 14 y 59. 


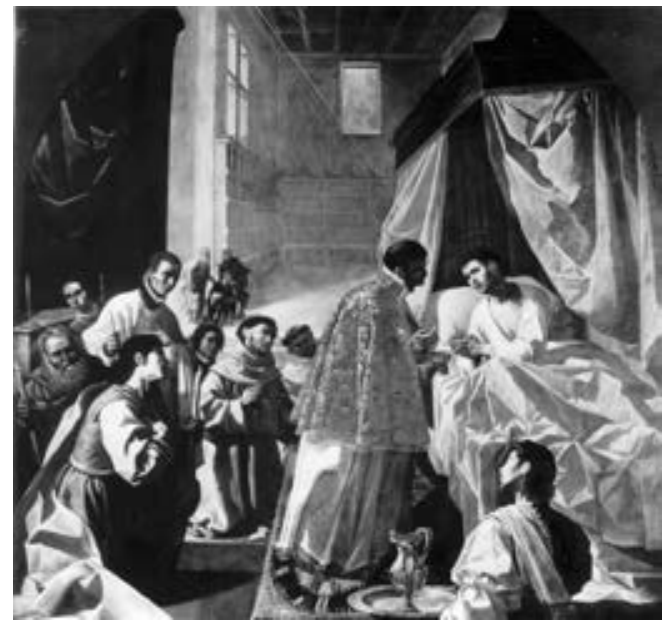

FICHA CATALOGRÁFICA

N. ${ }^{\circ}$ orden: 4

Galleria di Palazzo Bianco, Génova

Viático de san Buenaventura o La última comunión de san Buenaventura, Francisco de Zurbarán, Galleria di Palazzo Bianco, Génova.

Autor-atribución. Titulo de la obra: Atribuido a Francisco de Zurbarán (Fuente de Cantos, 1598-Madrid, 1664): Viático de san Buenaventura o La última comunión de san Buenaventura.

M. Soria (1953, p. 160) no considera esta obra de Zurbarán. En cambio, P. Guinard (1960) la cree de su mano, por el empleo de ricos colores, y da razones para su posible colocación en el colegio sevillano de San Buenaventura. J. Camón Aznar (1985, p. 248) considera que no puede pertenecer a la serie pintada para el colegio sevillano, y, aunque esté atribuido a Zurbarán, no parece del maestro extremeño por su composición abigarrada. Di Fabio (1992, p. 80) considera que fue realizada por este maestro con la ayuda de un colaborador.

La pertenencia de la tela genovesa a Zurbarán ha sido puesta en discusión por distintos autores, entre ellos María Luisa Caturla (1994, p. 241), quien ha propuesto resolver las dudas de atribución en favor de Pedro Díaz de Villanueva, pintor sevillano considerado tradicionalmente el maestro de Zurbarán, aunque dicha atribución no resulta hasta ahora corroborada por datos documentales.

Estilo-cronología: O. Grosso (1920, p. 306) establece su cronología hacia 1630. Tipo de obra, material y técnica: Cuadro. Óleo sobre lienzo.

Dimensiones: $293 \times 311 \mathrm{~cm}$.

Elementos autógrafos: No está firmado. 
Localización y procedencia: Génova, Galleria di Palazzo Bianco, sala n. ${ }^{0} 11$ (dedicada a los pintores españoles).

Fue sacado de Sevilla por el mariscal francés Soult, a principios del sigloXIX, y adquirido en París por Raffaele De Ferrari, en la subasta de la colección Soult celebrada el 22 de mayo de 1852, por 2000 francos. Estuvo expuesto en su residencia parisina (Hôtel Matignon) de la rue de Varenne hasta el fallecimiento del duque de Galliera, tras lo cual su viuda, Maria Brignole Sale (1811-1888), dispuso su traslado a Génova. Este cuadro fue donado por deseo de Maria Brignole Sale, duquesa de Galliera, a la Galleria di Palazzo Bianco, donde se expone desde 1892.

J. A. Gaya Nuño (1958, p. 61) considera que es el quinto cuadro perteneciente a la serie realizada por Zurbarán y Herrera el Viejo para la iglesia del colegio de San Buenaventura de Sevilla. Sin embargo, el cuadro de la Galleria di Palazzo Bianco se diferenciaría, por formato y por la proporción de las figuras, del resto de la serie. Es posible que estuviera colocado en la sacristía de la iglesia de este colegio.

Descripción: Se trata de una composición de carácter monástico, representada con sencillez y con una amplia profundidad de campo. Se aprecia cierta riqueza decorativa, principalmente en los tejidos y vestimentas, que se acompaña de una austeridad, casi metafísica, que parece materializarse en la biblioteca del fondo. Representa el momento de la última comunión de san Buenaventura, quien, temeroso de no poder recibir la hostia sagrada antes de morir, decide incorporarse, y en ese momento la sagrada forma se incrusta en su pecho. La acción se desarrolla en un primer plano y se ve reforzada por la luz proveniente de un lateral, que ilumina la composición. Del mismo modo, el fondo de la estancia aparece iluminado, pero la luz procede de la entrada a la biblioteca. Contrasta el amplio vacío del fondo con la concentración de varios personajes, en un primer plano. Se recurre a la gama de los verdes, rosas, blancos y granates, de gran intensidad emotiva.

Grosso (1920, p. 306) advierte que el sacerdote que imparte la comunión a san Buenaventura repite el gesto del Santo Tomás de Aquino del Kaiser Friedrich Museum de Berlín.

Historia de la pieza: Estado de conservación: bueno. Fue restaurado entre 1948 y 1949.

Noticias documentales inéditas: Inv. P. B. 229.

Exposiciones: Fue expuesto en la muestra Arte Antica, celebrada en el Palazzo Bianco de Génova en 1892, con motivo de su apertura al público (como 
museo), conmemorando al mismo tiempo el cuarto centenario del descubrimiento de América.

Catálogos:

Catalogue raisonné des tableaux de la Galérie de feu M. le Maréchal Général Soult duc de Dalmatie, dont la vente aura lieu à Paris. París, Galérie Lebrun, 1852.

Bibliografía:

A. S. C. G., «DF-sc. 447 Raffaele De Ferrari», Journal, París, 20 de mayo de 1852.

Boccardo y Di Fabio (2004), pp. 239-244.

Botto y Tagliaferro (eds.) (1977b).

Camón Aznar (1985), p. 248.

Caturla (1994).

Di Fabio (1992), pp. 76-81.

Gaya Nuño (1958), p. 61.

Gregori (presentación) (1973), p. 117.

Grosso (1920).

Grosso (1932), p. 142.

Guinard (1960).

Soria (1953), p. 160.

Tagliaferro (1991b).

Tagliaferro y Di Fabio (1991), pp. 14 y 59. 


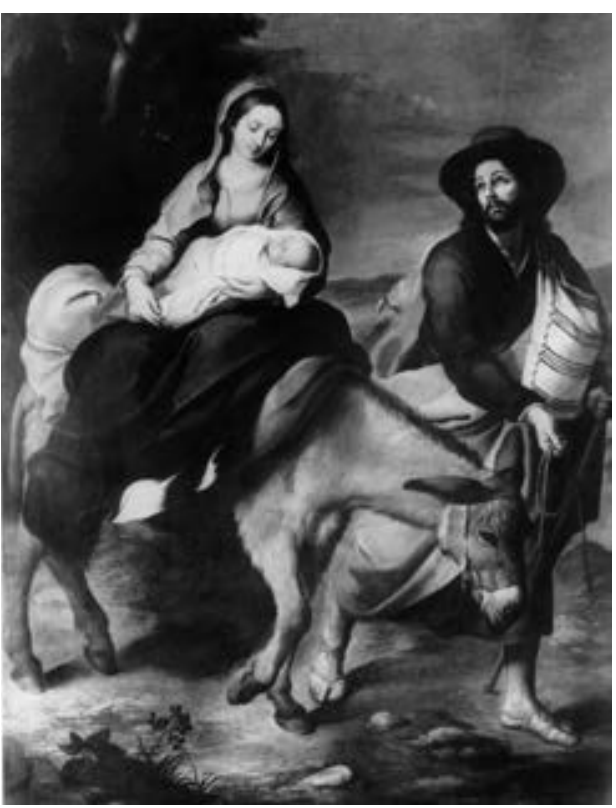

FICHA CATALOGRÁFICA

N. ${ }^{\circ}$ orden: 5

Galleria di Palazzo Bianco, Génova
La huida a Egipto, Bartolomé Esteban Murillo, Galleria di Palazzo Bianco, Génova.

Autor-atribución. Titulo de la obra: Bartolomé Esteban Murillo (Sevilla, 16181682): La huida a Egipto.

Estilo-cronología: Mayer (1923b, p. 289) fija su cronología en 1648 y Papone (1991, p. 71) hacia 1645. Boccardo y Di Fabio (2004, p. 241) consideran que fue ejecutada hacia 1645, poco antes de la versión del Detroit Institute of Arts.

Tipo de obra, material y técnica: Cuadro. Óleo sobre lienzo.

Dimensiones: $210 \times 163 \mathrm{~cm}$.

Elementos autógrafos: Firmado en el ángulo inferior izquierdo.

Localización y procedencia: Génova, Galleria di Palazzo Bianco, sala n. ${ }^{o} 11$ (dedicada a los pintores españoles).

Fue sacado de Sevilla por el mariscal francés Soult, a principios del siglo XIX, y adquirido en París, en la venta de la colección Soult celebrada el 20 de mayo de 1852, por Raffaele De Ferrari (duque de Galliera), por 51500 francos. Permaneció en la capital francesa, en la residencia de los duques de Galliera (Hôtel Matignon, en rue Varenne), hasta el fallecimiento del duque, 
tras lo cual su viuda, Maria Brignole Sale (1811-1888), dispuso su traslado a Génova. Este cuadro fue donado por deseo de Maria Brignole Sale, duquesa de Galliera, a la Galleria di Palazzo Bianco, donde se expone desde 1892.

J. A. Gaya Nuńo (1958, p. 240) indica que fue realizado en 1648 para la iglesia del convento de la Merced Descalza de Sevilla, siendo «exigido» por el mariscal Soult al cabildo en 1810, y depositado en el Alcázar de Sevilla junto con otras obras, hasta que Soult se las llevó a Francia.

Existen otros cuadros de Murillo con la misma temática, como, por ejemplo, los conservados en el Institute of Arts de Detroit, en el Museo de San Diego, en el Ermitage de Leningrado, en la Galería de Glasgow y en el Museo de Budapest.

Descripción: San José, con sombrero de caminante, lleva del ronzal al asno, que transporta a la Virgen y al Niño dormido. Se trata de una representación naturalista e íntima del episodio evangélico. Se emplean colores suaves, aplicados con una pincelada ágil y suelta. Destacan las formas redondeadas y delicadas. Papone (1991, p. 71) relaciona esta obra, desde el punto de vista iconográfico, con las imágenes divulgadas en estampas nórdicas. También presenta analogías compositivas con una tela atribuida a Francisco de Zurbarán conservada en la iglesia de San Agustín de Résina (Nápoles). De hecho, Rosses señala que Murillo utilizó composiciones de Rubens para sus obras. Así, debe mencionarse la composición que del mismo asunto realizó Rubens y que fue grabada por Marinus (1887-1892).

Historia de la pieza: Estado de conservación: bueno.

Noticias documentales inéditas: Inv. P. B. 241.

Catálogos:

Catalogue raisonné des tableaux de la Galérie de feu M. le Maréchal Général Soult duc de Dalmatie, dont la vente aura lieu à Paris. París, Galérie Lebrun, 1852.

Angulo Iñíguez (1981), p. 209.

Bibliografia:

A. S. C. G., "Carta a Bernardo Pellegrini», sc. 747, DF-Cartas de Raffaele De Ferrari a Pellegrini, París, 23 de marzo de 1843.

Boccardo y Di Fabio (2004), pp. 239-242.

Botto y Tagliaferro (eds.) (1977b).

Camón Aznar (1985), p. 545.

Di Fabio (1992), pp. 76-81. 
Gaya Nuño (1958), p. 240.

Gaya Nuño (presentación) (1978).

Genaille (1964).

Grosso (1920).

Grosso (1932), p. 140.

Mayer (1923b), p. 289.

Navarrete Prieto (1998), p. 198.

Papone (1991), pp. 70-71.

Tagliaferro (1991b).

Tagliaferro y Di Fabio (1991), p. 59. 


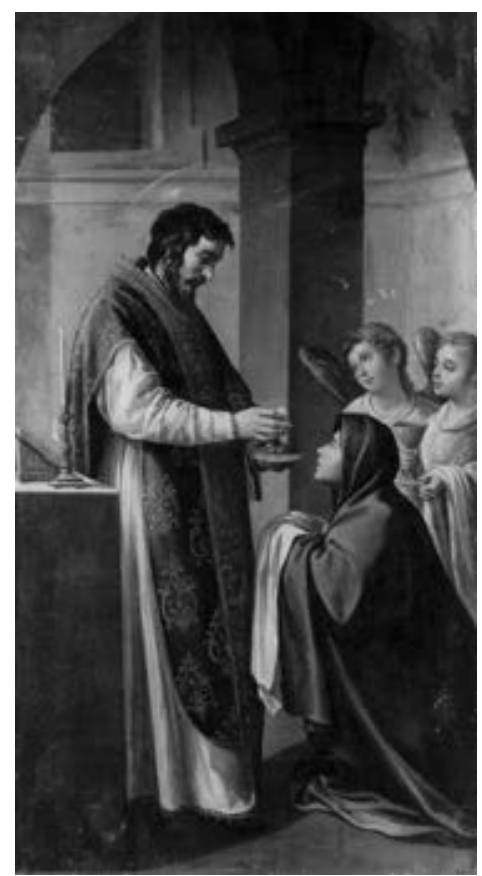

FICHA CATALOGRÁFICA

N. ${ }^{\circ}$ orden: 6

Galleria di Palazzo Bianco, Génova
San Juan Evangelista da la comunión a la Virgen, Alonso Cano, Galleria di Palazzo Bianco, Génova.

Autor-atribución. Titulo de la obra: Alonso Cano (Granada, 1601-1667): San Juan Evangelista da la comunión a la Virgen.

Grosso (1932, p. 141) consideraba este cuadro de escuela granadina. Gaya Nuño (1958, p. 98) compartía esta misma opinión. Wethey ([1955] 1983, pp. 43-44) indicaba que no hay nada en el estilo de la obra genovesa que corresponda a la producción de Alonso Cano. La solución sería asignar la pintura genovesa a Juan del Castillo, aunque puede incluso tratarse de una copia del siglo XVIII. Recientemente se ha confirmado la autoría de Alonso Cano.

Estilo-cronología: Gaya Nuño (1958, p. 98) data esta obra a finales del siglo XVII.

Tipo de obra, material y técnica: Cuadro. Óleo sobre lienzo.

Dimensiones: $82 \times 45 \mathrm{~cm}$.

Elementos autógrafos: No está firmado.

Localización y procedencia: Génova, Galleria di Palazzo Bianco. 
Puede proceder del retablo pintado por Alonso Cano para el convento de Santa Paula de Sevilla entre 1635 y 1637. Fue sacado de España por el mariscal Soult y, posteriormente, adquirido por Raffaele De Ferrari como obra de Alonso Cano (por 7000 francos) en la venta de la colección Soult celebrada en París el 20 de mayo de 1852. Permaneció en la capital francesa, en la residencia de los duques de Galliera de la rue de Varenne, hasta el fallecimiento del duque de Galliera, tras lo cual su viuda, Maria Brignole Sale (1811-1888), dispuso su traslado a Génova. Este cuadro fue donado por deseo de Maria Brignole Sale, duquesa de Galliera, a la Galleria di Palazzo Bianco en 1889.

Descripción: Aparece san Juan Evangelista impartiendo la comunión a una mujer arrodillada que, según Wethey ([1955] 1983, p. 186), sería la Virgen. En cambio, otros autores opinan que se trata de Santa Teresa. Por su parte, Gaya Nuño (1958, p. 98) afirma que en este cuadro se representa a Jesús y María, porque tras esta aparecen dos ángeles, uno de ellos con el cáliz.

Esta obra figuraba en el depósito de la Galleria di Palazzo Bianco como Santa Teresa recibiendo la comunión, título que, tras la restauración efectuada en 2004, se ha sustituido por el de San Juan Evangelista da la comunión a la Virgen. Atendiendo al motivo inicial de la obra, se hacía referencia a Teresa de Jesús — santa del siglo XVI, reformadora de la orden carmelitana, personalidad relevante de la reforma católica—, que buscó la perfección, entendida como comunicación constante con Cristo. Es interesante destacar que en la Biblioteca Sanctorum (1964-1967, vol. VI, 1967, pp. 417-418), cuando se trata la iconografía teresiana, se dice que uno de los temas habituales era la representación de la comunión de la santa impartida por san Pedro de Alcántara o por san Antonio de Padua, defensores de la pobreza evangélica, vestidos como diáconos. Por tanto, la cuestión relativa al motivo representado quedaría abierta. La escena principal se desarrolla en un interior, en un primer plano, bastante iluminado. En el fondo de la composición se aprecia, gracias a la luz, este interior arquitectónico. Se advierte el predominio de colores oscuros y el rico contraste de luces y sombras.

Historia de la pieza: Estado de conservación: bueno. Restaurado en 2004.

Noticias documentales inéditas: Inv. P. B. 223.

Exposiciones: Fue expuesto en la muestra Arte Antica, celebrada en el Palazzo Bianco de Génova en 1892, con motivo de su apertura al público (como museo), conmemorando al mismo tiempo el cuarto centenario del descubrimiento de América. 
Catálogos: Catalogue raisonné des tableaux de la Galérie de feu M. le Maréchal Général Soult duc de Dalmatie, dont la vente aura lieu à Paris. París, Galérie Lebrun, 1852.

Bibliografia:

A. S. C. G., «DF-sc. 447 Raffaele De Ferrari», Journal, París, 20 de mayo de 1852.

Biblioteca Sanctorum, 1967, vol. vI, pp. 395-419.

Boccardo y Di Fabio (2004), pp. 241-244.

Botto y Tagliaferro (eds.) (1977b).

Di Fabio (1992), pp. 76-81.

Gaya Nuño (1958), p. 98.

Grosso (1920).

Grosso (1932), p. 141.

Tagliaferro (1991b).

Tagliaferro y Di Fabio (1991).

Wethey ([1955] 1983), pp. 43-44. 


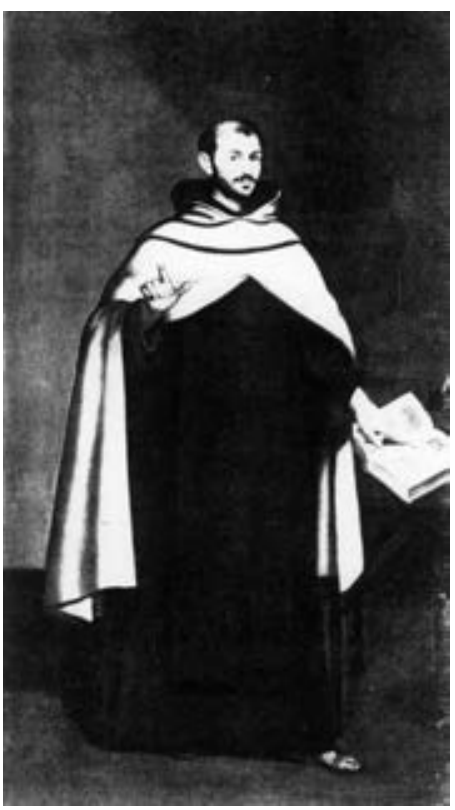

FICHA CATALOGRÁFICA

N. ${ }^{\circ}$ orden: 7

Galleria di Palazzo Bianco, Génova
San Juan de la Cruz, Antonio Puga (círculo de), Galleria di Palazzo Bianco, Génova.

Autor-atribución. Título de la obra: Atribuido al círculo de Antonio Puga (Granada, 1601-1667): San Juan de la Cruz.

Originalmente fue atribuido a Alonso Cano (Granada, 1601-1667). Sin embargo, Clario di Fabio (Tagliaferro y Di Fabio, 1991) opina que esta obra no puede atribuirse a dicho pintor, sino que podría pertenecer al ámbito cultural de las telas recogidas por la crítica bajo el nombre de Antonio Puga.

Estilo-cronología: Datado en la primera mitad del siglo XVII.

Tipo de obra, material y técnica: Cuadro. Óleo sobre lienzo.

Dimensiones: $221 \times 124 \mathrm{~cm}$.

Elementos autógrafos: No está firmado.

Localización y procedencia: Génova, Galleria di Palazzo Bianco.

Fue encontrado a comienzos de la década de los años sesenta en el campanario de la iglesia del convento de San Agustín de Génova. Su ingreso definitivo en la Galleria di Palazzo Bianco se remonta a agosto de 1963, sin que desde entonces se haya podido averiguar su procedencia. Es posible que estuviera colocado en uno de los monasterios carmelitas de la ciudad. 
Descripción: Aparece representado de pie, sobre un fondo neutro. Como es sabido, san Juan de la Cruz, santo del siglo XVI, fue el primer carmelitano descalzo. Su magisterio, dentro de la reforma teresiana, fue tanto oral como escrito, y su misión fue la de padre y maestro en las vías del espíritu. San Juan de la Cruz escribió varias obras, entre las que cabe citar Cántico espiritual y Monte de Perfección, inspiradas en la idea fundamental de «la unión del alma con Dios». En este contexto, hay que decir que su hermano de orden Jerónimo de San José fijó su imagen en la obra Historia (1641, pp. 786-787), que coincide con la aquí representada: «el venerable padre era de estatura pequeña, delgado. Su rostro redondo, con una venerable calvicie con algún cabello, la frente amplia, los ojos negros y su mirada suave, la nariz rectilínea, un poco aguileña. Vestido con un hábito amplio. Todo su aspecto era modesto». El santo tiene su mano derecha alzada y con el dedo índice hace un gesto de llamada de atención, probablemente hacia lo que su mano izquierda señala en el libro apoyado sobre una mesa, en alusión a su magisterio escrito o a un pasaje teológico. Lleva un hábito sencillo de color marrón y una capa blanca. Destaca el rico contraste de luces y sombras.

Historia de la pieza: Estado de conservación: excelente. Fue restaurado recientemente.

Noticias documentales inéditas: Inv. P. B. 1886.

Bibliografia:

Biblioteca Sanctorum, 1967, vol. VI, pp. 701-731.

Boccardo y Di Fabio (2004), pp. 238-239.

Botto y Tagliaferro (eds.) (1977).

Tagliaferro y Di Fabio (1991). 


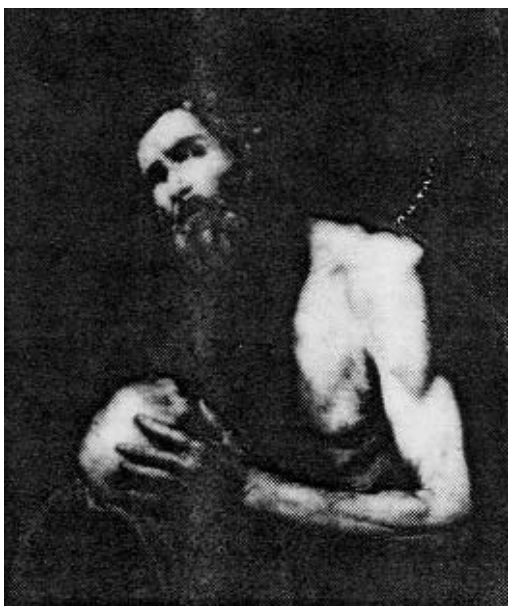

\author{
FICHA CATALOGRÁFICA \\ N. ${ }^{\circ}$ orden: 8 \\ Galleria di Palazzo Bianco, Génova
}

San Jerónimo, atribuido a la escuela de José de Ribera, Galleria di Palazzo Bianco, Génova.

Autor-atribución. Título de la obra: Atribuido a la escuela de José de Ribera: San Jerónimo.

Orlando Grosso (1932, p. 141) considera este cuadro de la escuela de Ribera.

Para J. A. Gaya Nuño (1958, p. 287) pertenece igualmente a la escuela de Ribera. Por su parte, Alfonso Pérez Sánchez (1978, p. 339) considera que se trata de una elaboración escolástica, de calidad modesta, de probable origen riberesco.

Con la atribución a la escuela de José de Ribera figura en la Galleria di Palazzo Bianco.

Estilo-cronología: Datado en el siglo XVII.

Tipo de obra, material y técnica: Cuadro. Óleo sobre lienzo.

Dimensiones: $91 \times 77 \mathrm{~cm}$.

Elementos autógrafos: No está firmado.

Localización y procedencia: Génova, Galleria di Palazzo Bianco, en depósito.

Fue adquirido, en 1902, en la casa de ventas de Felicità Pedemonte. Se desconoce su procedencia.

Descripción: Se representa a san Jerónimo, santo y doctor de la Iglesia de los siglos IV-V, de medio cuerpo, como un hombre anciano. Su vida se caracterizó por un duro y constante ascetismo, con grandes penitencias practicadas en 
el desierto, en compañía únicamente de animales, alejado de la vida mundana, pero participando activamente en la vida intelectual del momento. De hecho, destaca su flacidez y sus vestiduras harapientas. Como puede comprobarse, el santo alza la cabeza y dirige la mirada hacia lo alto, mientras sujeta con sus manos una calavera, atributo de inspiración flamenca. Se recurre a un rico juego de claros y oscuros, que resaltan la figura del santo sobre la oscuridad del fondo.

Historia de la pieza: Estado de conservación: bueno.

Noticias documentales inéditas: Inv. P. B. 226.

Bibliografía:

Biblioteca Sanctorum, 1967, vol. VI, pp. 1109-1137.

Botto y Tagliaferro (eds.) (1977b).

Gaya Nuño (1958), p. 339.

Gregori (presentación) (1978), p. 133.

Grosso (1932), p. 142.

Tagliaferro y Di Fabio (1991). 


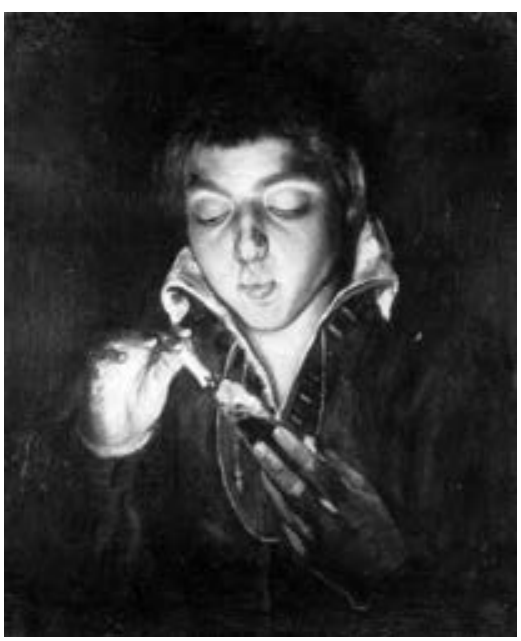

\section{FICHA CATALOGRÁFICA}

N. ${ }^{\circ}$ orden: 9

Galleria di Palazzo Reale, Génova

El soplón o Muchacho encendiendo una candela, atribuido a Jacopo Bassano o considerado copia de un original del Greco, Galleria di Palazzo Reale, Génova.

Autor-atribución. Título de la obra: Atribuido a Jacopo Bassano (1517-1592) o considerado copia de un original de Doménico Theotokópulos conocido como el Greco (Candía, 1541-Toledo, 1614): El soplón o Muchacho encendiendo una candela.

En torno a esta obra existe una cierta controversia, ya que algunos autores la atribuyen a Jacopo Bassano y otros al Greco. Sobre este tema del «muchacho que enciende un candela» se conocen dos obras autógrafas del Greco, una en la colección Paysson de Manhasset de Nueva York y la otra en el Museo de Capodimonte de Nápoles.

En la Galleria di Palazzo Reale figura como copia de un original del Greco, concretamente del que se encuentra en el Museo de Capodimonte. La atribución del cuadro a Bassano se fundamenta en las fuentes locales del siglo XIX, pero las tendencias críticas más recientes no aceptan esta atribución:

A. Venturi (1929, p. 209), teniendo presente el cuadro del Museo de Capodimonte (Nápoles), atribuido al Greco, reivindica la «paternidad» de Jacopo Bassano para el cuadro genovés.

A. Morassi (1951, p. 69) considera que este cuadro pertenece al período maduro de Jacopo Bassano, por la peculiaridad del sujeto y por las relaciones estilísticas con la pintura de Jacopo (el ímpetu y el empaste cromático). El Greco trató también el tema con muchas variantes, bien con el muchacho solo, o bien acompañado. Es de suponer que la «invención» corresponda a Jacopo. 
P. Zampetti (1957, p. 142) opina que el tema del muchacho que sopla una candela es característico del Bassano, quien lo repitió en diversas composiciones suyas, como en las Adoraciones de los pastores. Es indudable que él sea el inventor.

En cambio, R. Pallucchini (1947, p. 109) atribuye esta obra al período joven del Greco, anterior a su llegada a España, considerándola una copia de la que se encuentra en el Museo de Capodimonte de Nápoles. Destacan en el cuadro genovés un sentido del color y una sensibilidad en la pincelada (las sombras en el rostro) que permiten descartar que su autor fuera Bassano. El hecho de que el Greco se pudiera inspirar en el tema del «soplón» de Bassano no lo pone en duda (Pallucchini, 1947, p. 109).

M. Soria (1954, p. 213) lo atribuye al Greco.

E. Arslan (1960, p. 343) lo considera como obra no bassanesca.

E. H. Wethey (1962, p. 78), en su monografía dedicada al Greco y a su escuela, publica las varias versiones del muchacho que enciende una candela, y destaca la de la colección Paysson y la del Museo de Capodimonte, aproximadamente contemporáneas (1570-75), considerándolas las únicas originales del Greco, mientras que la versión de Génova sería una copia de finales del siglo XVI.

L. Lodi (1991, pp. 30-31) considera este cuadro como una buena copia de taller del original del Greco, conservado en el Museo de Capodimonte, datado entre 1570 y 1575 . Esta autora opina que la versión de Génova es «inferior» en calidad a los dos originales de Paysson y Capodimonte; parece, de hecho, una copia de finales del siglo XVI. Lodi fundamenta su opinión tanto en el diferente color de la chaqueta (amarilla clara, en la obra de Nápoles, y amarilla oscura, en la obra del Palazzo Reale) como en el cierre más redondo de los botones. El cuadro de Génova (repintado en el siglo XIX y oscurecido) se caracteriza por una pincelada corpórea, tal como se puede apreciar en la mano izquierda del muchacho, en la cadena y en el cuello de la camisa. Sin embargo, en el rostro se recurre a una pincelada más plana y de menor soltura que en el original napolitano. En el Museo dell'Accademia Ligustica de Génova se conserva una copia del cuadro del Palazzo Reale, realizada por Angela Serra Durazzo y fechada hacia 1780, año en el que se donó a la Accademia.

A pesar de estas contribuciones, la cuestión de su autoría sigue abierta.

Estilo-cronología: Datado por Gaya Nuño (1958, p. 186) hacia 1570-1573. M. Soria (1954, p. 221) atribuye este cuadro al período romano del Greco, junto al del Museo de Capodimonte y al de la colección Paysson (1570-1572). 
Tipo de obra, material y técnica: Cuadro. Óleo sobre lienzo.

Dimensiones: $60 \times 50 \mathrm{~cm}$.

Elementos autógrafos: No está firmado.

Localización y procedencia: Génova, Galleria di Palazzo Reale, en la Sala del Tiempo.

Procedencia desconocida. Aparece documentado en torno a 1766, cuando C. G. Ratti, en su obra Istruzione di quanto può vedersi di più bello a Genova, in Pittura, Scultura ed Architettura, realiza la descripción de esta sala.

Los documentos relativos al archivo del Palazzo Reale de Génova están dispersos, lo que dificulta el estudio de su procedencia.

Descripción: Se representa a un muchacho, de medio cuerpo y captado de frente, que está avivando con su soplo la llama de un tizón encendido para poder prender fuego a una vela. El joven va vestido con una camisa de color amarillo oscuro, con algún toque de marrón, y cuello blanco. Destaca el tratamiento de las luces y sombras, resaltando a la luz el rostro y una de las manos del muchacho, mientras que el resto del cuerpo se sumerge en la penumbra. Se presta atención al detalle y a la aproximación natural de lo representado. Predomina la gama de los colores oscuros, que han sido aplicados con una pincelada densa. Es un verdadero estudio experimental de los efectos de la luz artificial.

Historia de la pieza: Estado de conservación: deteriorado.

Noticias documentales inéditas: Inv. 527.

\section{Exposiciones:}

Exposición dedicada a Jacopo Bassano, celebrada en el Palazzo Reale de Génova del 28 junio al 31 agosto de 1946.

Muestra dedicada a Jacopo Bassano, celebrada en Brescia de abril a junio de 1947. Jacopo Bassano, celebrada en el Palazzo Ducale de Venecia del 29 de junio al 27 de octubre de 1957.

\section{Catálogos:}

Morassi (1946), pp. 70-71.

Pallucchini (1947), p. 184.

Zampetti (1957).

Bibliografia:

Alizeri (1846-1847), vol. II, parte I, p. 152.

Alizeri (1875), p. 44. 
Arslan (1960), vol. I, p. 343.

Banchero (1846a), p. 10.

Camón Aznar (1985).

Gaya Nuño (1958), p. 186.

Gudiol (1982), pp. 35-36.

Inventario dei Beni Artistici del Palazzo Reale di Genova, 1950.

Lodi (1991), pp. 30-31.

Manzini (presentación) (1969), p. 93.

Marías (1997), p. 97.

Morassi (1951), p. 69.

Pallucchini (1962).

Poleggi ([1969] 1974), p. 75.

Ratti (1780), vol. I, p. 209.

Soria (1954).

Spinosa (1994), p. 86.

Torriti (1963a), pp. 22 y 26, fig. 15.

Venturi (1929), p. 209.

Wethey (1962), vol. II, pp. 78 y 195. 


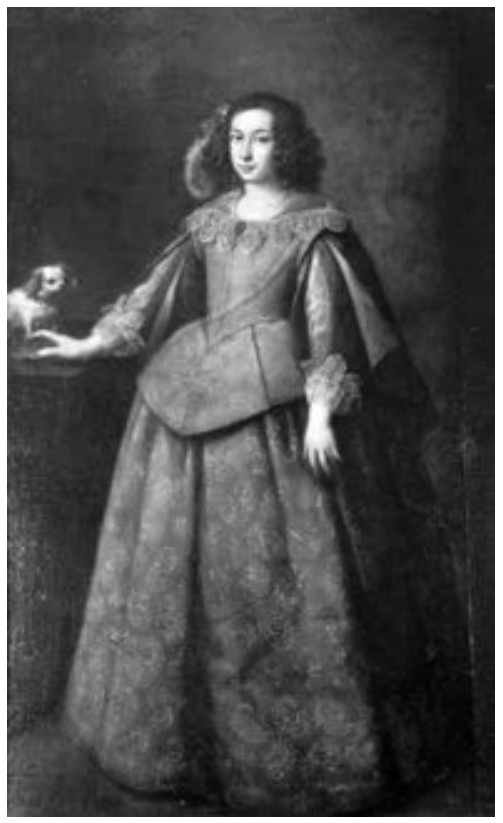

\author{
FICHA CATALOGRÁFICA \\ N. ${ }^{\circ}$ orden: 10 \\ Galleria di Palazzo Reale, Génova
}

Dama con perrito,

atribuido a Carlo Francesco Nuvolone, Galleria di Palazzo Reale, Génova.

Autor-atribución. Título de la obra: Una primera atribución a Bartolomé González; actualmente atribuido a Carlo Francesco Nuvolone (Milán, 16091661): Dama con perrito.

Para O. Grosso (1932) se trata de una obra española en torno a Bartolomé González (retratista y bodegonista). Esta opinión fue confirmada por Torriti (1963a, p. 64) y por Ciliento (1986, p. 25), que la consideran como «válida obra española del siglo XVII».

L. Lodi (1991, pp. 63-64) la atribuye al milanés Nuvolone. Esta autora advierte ciertas relaciones con el «retrato de dama» (centro) de La familia del pintor de la Pinacoteca de Brera de Milán y con el Retrato de dama del Museo Civico de Bolonia.

Estilo-cronología: Lodi (1991, p. 64) establece su cronología hacia 1650, atendiendo a los retratos anteriormente citados (1640) y a las características del vestido.

Tipo de obra, material y técnica: Cuadro. Óleo sobre lienzo.

Dimensiones: $204 \times 114 \mathrm{~cm}$. 
Elementos autógrafos: No está firmado.

Localización y procedencia: Génova, Galleria di Palazzo Reale, Baño del Rey, sala n. ${ }^{\circ} 16$.

Procedencia desconocida, aparece documentado en torno a 1766, cuando Ratti realiza la descripción de esta sala. No aparece citado en el inventario del Palazzo Reale de 1823.

Los documentos concernientes al archivo del Palazzo Reale de Génova están dispersos, hecho que dificulta el estudio de su procedencia.

Descripción: Retrato de dama de cuerpo entero con un perrito, dentro de la tipología de retratos de corte. La dama va vestida conforme a la época, su rostro es alargado, con nariz prominente y ojos rasgados. Su mano derecha está apoyada sobre un mueble, y cerca de ella se encuentra el perro. Presenta una pincelada mórbida y esfumada, con delicadas sombras sobre el cuello de la dama. Destaca el rico juego de luces y sombras, resaltando la parte superior del cuerpo de la dama, en especial su rostro, mientras que el resto de la composición queda sumida en la penumbra.

Según L. Lodi (1991, p. 64), el cuadro constituye un testimonio de la influencia española en la retratística milanesa. O. Grosso (1932) relaciona este retrato con la producción de Bartolomé González y, en concreto, con obras como el retrato de Isabel de Francia, esposa de Felipe IV.

Historia de la pieza: Estado de conservación: bueno.

Bibliografia:

Ciliento (1986), p. 25.

Grosso (1932).

Lodi (1991), pp. 63-64.

Torriti (1963a), p. 64. 


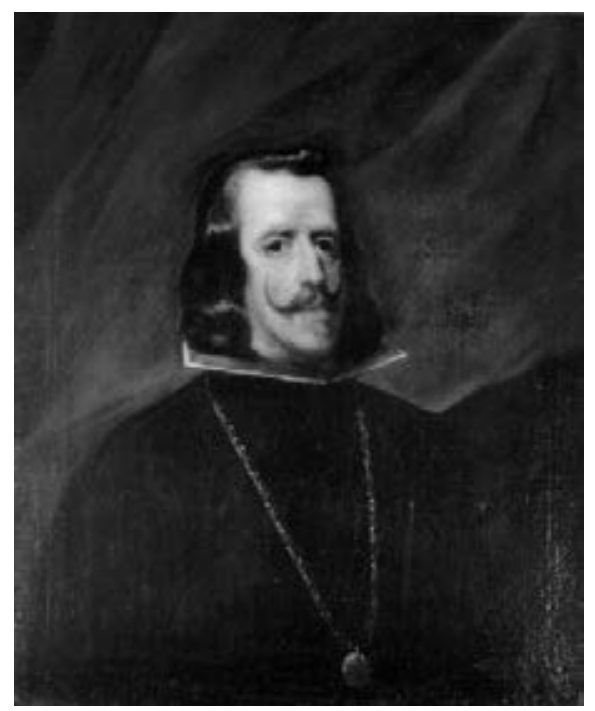

FICHA CATALOGRÁFICA

N. ${ }^{\circ}$ orden: 11

Galleria di Palazzo Reale, Génova
Retrato de Felipe IV, rey de España, atribuido a Juan Bautista Martínez del Mazo, Galleria di Palazzo Reale, Génova.

Autor-atribución. Título de la obra: Atribuido a Juan Bautista Martínez del Mazo (Cuenca, 1613-Madrid, 1667): Retrato de Felipe IV, rey de España.

F. Alizeri (1875, p. 442) adscribe este cuadro a Velázquez. Suida (1906, p. 160) piensa en la escuela de Velázquez y propone el nombre de Mazo. P. Torriti (1963a, p. 64) lo considera de escuela espańola del siglo XVII y, en concreto, de Antolínez (Sevilla, 1593-Madrid, 1670). B. Ciliento (1986, p. 25) opina que se trata de una obra de Juan Bautista Martínez del Mazo. C. Olcese, en la ficha del catálogo (SBAS), señala que el cuadro genovés es una de las tantas copias del Retrato de Felipe II de Velázquez, conservado en el Museo del Prado de Madrid.

Estilo-cronología: P. Torriti (1963a, p. 64) fija su cronología en la segunda mitad del siglo XVII.

Tipo de obra, material y técnica: Cuadro. Óleo sobre lienzo.

Dimensiones: $80 \times 86 \mathrm{~cm}$.

Elementos autógrafos: No está firmado.

Localización y procedencia: Génova, Galleria di Palazzo Reale, en el Dormitorio de la Reina, sala n. ${ }^{\circ} 11$. 
Procedencia desconocida. Aparece documentado hacia 1766, cuando Ratti realiza la descripción del palacio.

Descripción: Retrato de medio cuerpo, dentro de la tipología de retratos de corte. El rey luce traje oficial, de color negro, en el que solo resalta, gracias a la luz, el cuello blanco y la cadena dorada, que pende del cuello. Resalta la majestuosidad y seriedad del retratado. La figura del monarca destaca sobre el fondo de la composición, en el que aparece una cortina. Se recurre a colores apagados, como son los marrones y negros, aplicados con una pincelada mórbida y esfumada.

Historia de la pieza: Estado de conservación: bueno.

\section{Bibliografia:}

Alizeri (1875), p. 442.

Ciliento (1986), p. 25.

Grosso (1932).

Guida d'Italia. Liguria, 1982, p. 170.

Lodi (1991), p. 64.

Suida (1906), p. 160.

Torriti (1963a), p. 64. 


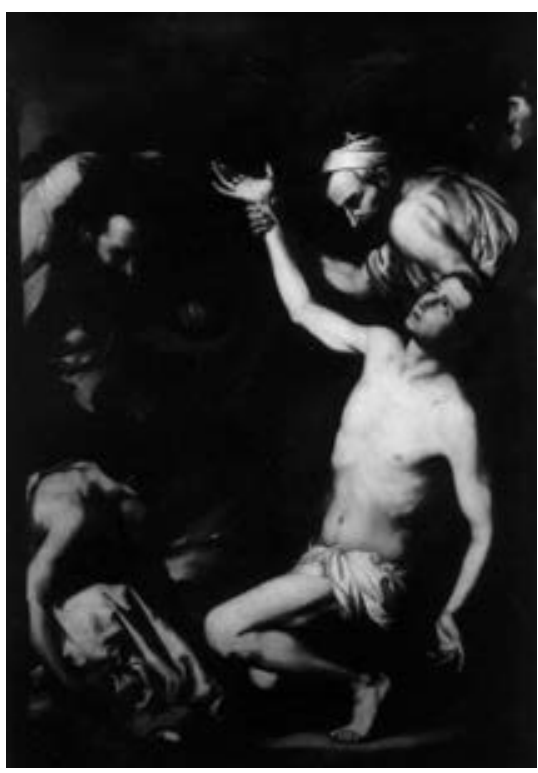

\section{FiCHA CATALOGRÁFICA}

N. ${ }^{\circ}$ orden: 12

Galleria Nazionale di Palazzo Spinola, Génova
Martirio de san Lorenzo, copia de un original de José de Ribera,

Galleria Nazionale di Palazzo Spinola, Génova.

Autor-atribución. Título de la obra: Copia de un original de José de Ribera, conocido como lo Spagnoletto: Martirio de san Lorenzo.

C. G. Ratti (1780, p. 139), refiriéndose a Caravaggio, lo asigna a Ribera. Esta opinión fue compartida por Alizeri (1846-1847, p. 471), quien más tarde aceptó la atribución a Caravaggio (Alizeri, 1875, p. 134), tal como aparece en el inventario de la donación del palacio.

P. Rotondi (1967, p. 120) considera que se trata de una copia, de dimensiones ligeramente mayores, de un cuadro de Ribera conservado en la Pinacoteca Vaticana, que, a su vez, es copia de un original perdido. La ejecución, con variantes, es obra de un pintor ligur desconocido.

Estilo-cronología: P. Rotondi (1967, p. 120) data este cuadro hacia finales del siglo XVII.

Tipo de obra, material y técnica: Cuadro. Óleo sobre lienzo.

Dimensiones: $222 \times 164 \mathrm{~cm}$.

Elementos autógrafos: No está firmado.

Localización y procedencia: Génova, Galleria Nazionale di Palazzo Spinola, segundo piso, primera sala. 
Se desconoce su procedencia. Fue donado por los marqueses Franco y Paolo Spinola al Estado italiano el 31 de mayo de 1958.

Descripción: Se capta el momento previo al martirio de san Lorenzo, que tuvo lugar el 10 de agosto del $258 \mathrm{~d}$. C. El santo se encuentra a la derecha de la composición, en un primer plano, casi arrodillado. Se consigue una representación natural de la figura del santo. La silueta masculina que sujeta al santo por la mano derecha podría representar al legendario carcelero Hipólito. En el fondo de la composición se perciben dos rostros que emergen de la oscuridad, que se corresponderían con los diáconos Ciriaco y Esteban. La composición se equilibra con la aparición, a la izquierda, de unos pobres con las ropas y la bolsa del tesoro distribuidas por el santo. Detrás de ellos hay una figura masculina que transporta leña para encender fuego. No debe olvidarse que Lorenzo fue martirizado en una parrilla. Destaca el rico juego de luces y sombras, dentro de la línea caravaggiesca. La luz incide sobre el cuerpo del santo, que mira hacia el cielo, clamando piedad, mientras que el grupo compositivo de la izquierda permanece en sombra. Predominio de los marrones oscuros, aplicados con delicadeza.

Historia de la pieza: Estado de conservación: bueno.

Noticias documentales inéditas: Inv. 9.

\section{Exposiciones:}

Exposición celebrada en la Galería Trafalgar de Londres del 13 de noviembre al 13 de diciembre de 1996.

Bibliografía:

Alizeri (1846-1847), vol. II, p. 473.

Alizeri (1875), p. 134.

Biblioteca Sanctorum, 1967, vol. VIII, pp. 107-130.

Guida d'Italia. Liguria, 1982, p. 95.

Poleggi ([1969] 1974), p. 17.

Ratti (1780), p. 139.

Rotondi (1967), pp. 120-122.

Rotondi Terminiello (1976), p. 16. 


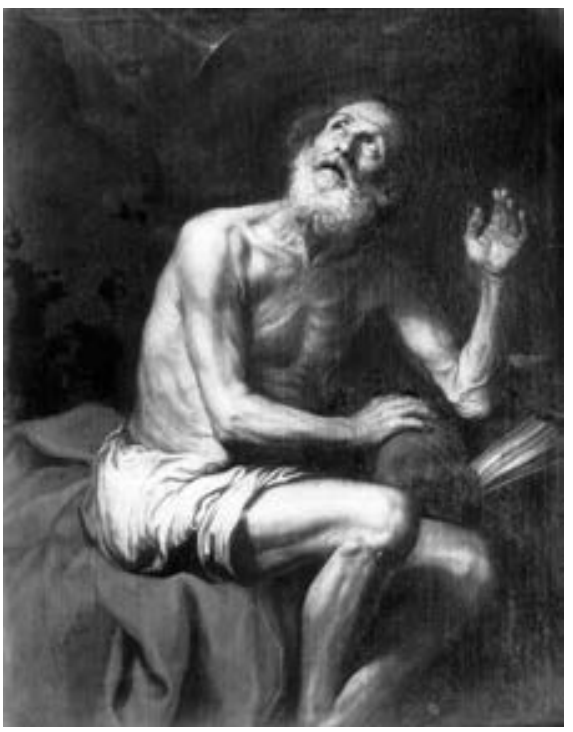

\author{
FICHA CATALOGRÁFICA \\ N. ${ }^{\circ}$ orden: 13 \\ Galleria Nazionale di Palazzo \\ Spinola, Génova
}

San Jerónimo oyendo la trompeta del Juicio Final, copia de un original de José de Ribera o perteneciente al taller de Ribera,

Galleria Nazionale di Palazzo Spinola, Génova.

Autor-atribución. Titulo de la obra: Copia de un original de José de Ribera o perteneciente al taller de Ribera: San Jerónimo oyendo la trompeta del Juicio Final.

C. G. Ratti (1780, p. 140) define este cuadro como «del estilo de Lanfranco». F. Alizeri (1846-1847, p. 473; 1875, p. 134) lo considera de Ribera, indicado así en el inventario de la Galleria, al ponerlo en relación con otros cuadros del mismo tema realizados por el maestro.

P. Rotondi (1967, p. 120) considera que es una copia de un Ribera, con elementos giordanescos, ejecutado por un pintor probablemente napolitano del siglo XVII.

Estilo-cronología: Siglo XVII.

Tipo de obra, material y técnica: Cuadro. Óleo sobre lienzo.

Dimensiones: $119 \times 95 \mathrm{~cm}$.

Elementos autógrafos: No está firmado.

Localización y procedencia: Génova, Galleria Nazionale di Palazzo Spinola, segundo piso, sala segunda.

Se desconoce su procedencia. Fue donado por los marqueses Franco y Paolo Spinola al Estado italiano el 31 de mayo de 1958. 
Descripción: Se representa a san Jerónimo, santo y doctor de la Iglesia de los siglos IV-V d. C. Su vida se caracterizó por un duro y constante ascetismo, con largas penitencias practicadas en el desierto, en compañía solo de animales. En concreto, se representa el episodio de la leyenda en el que san Jerónimo escucha las trompetas del Juicio Universal. Aparece sentado, con torso desnudo, que permite apreciar su edad avanzada y la extrema delgadez de su cuerpo, a causa de las penitencias llevadas a cabo en el desierto. Tiene la mano derecha apoyada sobre un cráneo; en cambio, su brazo izquierdo descansa sobre un libro, que, probablemente, haga referencia a su actividad como escritor y erudito. De la oscuridad del fondo, desde lo alto a la izquierda, surge una trompeta que alude al Juicio Final, hacia la cual el santo vuelve la cabeza. Cabe destacar el gran naturalismo y el magnífico juego de luces y sombras. Predominio de colores oscuros, aplicados con una pincelada densa.

Historia de la pieza: Estado de conservación: excelente. Fue restaurado en 1997.

Noticias documentales inéditas: Inv. 45.

Bibliografia:

Alizeri (1846-1847), p. 473.

Alizeri (1875), p. 134.

Biblioteca Sanctorum, 1967, vol. VI, pp. 1109-1137.

Guida d'Italia. Liguria, 1982, p. 95.

Poleggi ([1969] 1974), p. 17.

Ratti (1780), p. 140.

Rotondi (1967), pp. 120-122.

Rotondi Terminiello (1976), p. 24. 


\section{FICHA CATALOGRÁFICA}

N. ${ }^{\circ}$ orden: 14

Galleria Nazionale di Palazzo Spinola, Génova

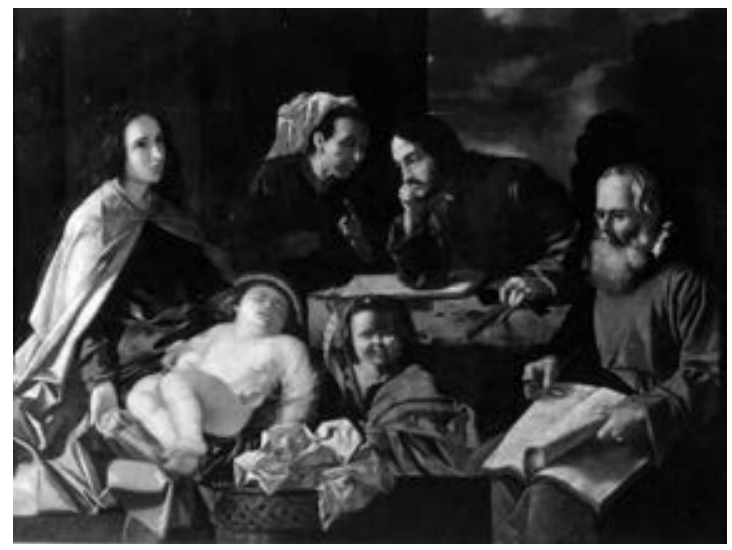

La Sagrada Familia de Jesús con san Zacarías, santa Isabel y san Juanito, ¿Francisco de Zurbarán?, Galleria Nazionale di Palazzo Spinola, Génova.

Autor-atribución. Título de la obra: Atribuido a Francisco de Zurbarán (Fuente de Cantos, 1598-Madrid, 1664): La Sagrada Familia de Jesús con san Zacarías, santa Isabel y san Juanito.

La atribución a Zurbarán aparece en el Bolletino d'Arte (1954) y en la revista Goya (1955). Rotondi (1967, p. 160) señala que la firma «falsificada» de Zurbarán del libro que Zacarías tiene sobre sus rodillas y las durezas en el modelado hacen pensar en una obra de escuela.

En la ficha del inventario de la Galleria di Palazzo Spinola figura como perteneciente a un pintor español desconocido, sin ser atribuido específicamente a Zurbarán. Comparto esta misma opinión, fundamentada en la poca relación que tiene con un cuadro del mismo tema realizado por el maestro extremeño hacia 1628, conservado en la colección del marqués de Perinat.

Estilo-cronología: Datado a mediados del siglo XVII.

Tipo de obra, material y técnica: Cuadro. Óleo sobre lienzo.

Dimensiones: $139 \times 179 \mathrm{~cm}$.

Elementos autógrafos: P. Rotondi (1967, p. 160) constata la firma «falsificada» de Zurbarán sobre el libro que tiene abierto Zacarías. 
Localización y procedencia: Génova, Galleria Nazionale di Palazzo Spinola, en depósito.

En el Bolletino d'Arte (1954, p. 373) se indica que el 18 de junio de 1954 se presentó en la Oficina de Exportación de Obras de Arte de Génova un grupo de cuadros de los siglos XVII-XIX. Reconocido su alto valor artístico, el soprintendente (administrador, responsable artístico del Estado) decidió adquirir cinco obras, asignándolas a las galerías de Génova. Una de las telas adquiridas fue la Sagrada Familia con san Zacarias, santa Isabel y san Juanito. Importante cuadro que, por su estilo, sugiere el inmediato recuerdo de Francisco de Zurbarán, maestro a quien es atribuido por Roberto Longhi. El cuadro fue adquirido por la suma declarada de 400000 liras.

Descripción: Se representa la Sagrada Familia de Jesús. Así, a la izquierda de la composición aparece la Virgen con el Niño dormido sobre sus rodillas y, cerca de este, san Juanito, que lleva una cruz de la que pende la siguiente inscripción: «Ecce Agnus Dei Qui Tollit Peccata Mundi». A la derecha de la composición se encuentra san Zacarías leyendo un libro sobre el cual puede leerse la firma artefatta de «Francisco Zurbarán». En el centro, y en un segundo plano, aparece san José con las herramientas de su oficio, en diálogo con santa Isabel. Y en el fondo se abre un paisaje. Como puede comprobarse, san José mira hacia María y su hijo. La luz incide de modo diferente sobre los tres grupos compositivos, iluminando sobre todo al Niño Jesús y al libro, creando ricos contrastes de luces y sombras en los pliegues de los vestidos. Predominio de tonalidades oscuras, aplicadas con una pincelada compacta.

Historia de la pieza: Estado de conservación: bueno.

Noticias documentales inéditas: Inv. 260.

Bibliografia:

"Acquisizioni dai Musei e Gallerie dello Stato», 1954, pp. 373-374.

Goya, 1955, p. 389.

Rotondi (1967), pp. 160-161. 


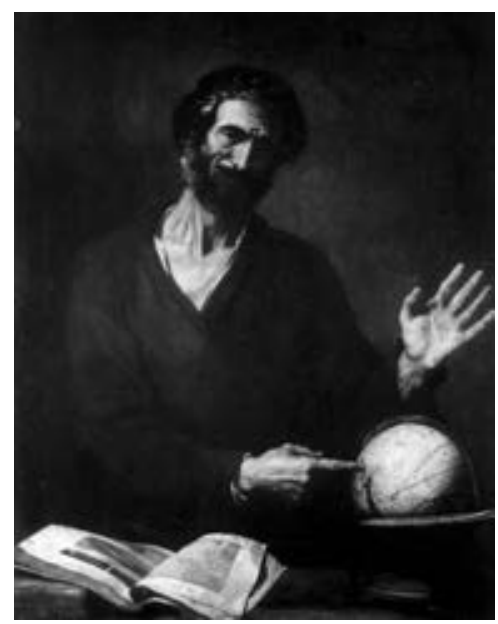

FiCHA CATALOGRÁFICA

N. ${ }^{\circ}$ orden: 15

Colección privada, Génova

Heráclito, atribuido a José de Ribera, colección privada, Génova.

Autor-atribución. Título de la obra: Atribuido a José de Ribera (Játiva, 1591Nápoles, 1652), conocido como lo Spagnoletto: Heráclito.

La atribución a Ribera fue confirmada por Mayer (1923a, p. 187) y por J. A. Gaya Nuño (1958, pp. 2302-2303). P. Torriti (1967, p. 61) considera que esta obra probablemente no pertenece al pincel del Spagnoletto, aunque esté firmada y datada. Por indicación de F. Bologna ha sido considerada como obra del maestro de la Oración en el Huerto de la catedral de Pozzuoli, después identificado como el napolitano Nunzio Rossi.

N. Spinosa (1995a, pp. 231-233) cita este cuadro como anónimo, obra de un imitador de Ribera. De la misma opinión es Felton (1971, pp. 397-398).

Estilo-cronología: Datado en la primera mitad del siglo XVII. Spinosa (1995a, p. 233) concreta la cronología en 1630.

Tipo de obra, material y técnica: Cuadro. Óleo sobre lienzo.

Dimensiones: $121 \times 95 \mathrm{~cm}$.

Elementos autógrafos: Firmado y datado en el margen inferior derecho: «Jusepe de Ribera Español Valenciano 1635».

Localización y procedencia: Génova, colección privada.

Adquirido en 1722 por el marqués Giacomo Filippo Durazzo II, junto al Filósofo y al Demócrito, a M. Vittoria Spinola Grilla, con un marco dorado, por un precio (los tres) de 769,3 liras. 
Descripción: Filósofo, de media figura, que señala con un dedo el globo terráqueo, y a cuya derecha, hay un libro abierto. Algunos autores, como P. Torriti (1967, p. 61), destacan en esta obra la sequedad de la solución pictórica y la dureza de los resultados formales; elementos que les conducen a considerarla como no perteneciente al pincel del Spagnoletto, aunque esté firmada. En la misma línea se encuentra N. Spinosa (1995a, p. 232), quien advierte soluciones de grafismo y una escasa compactibilidad pictórica. Por ello, este autor piensa en un anónimo imitador de los modos naturalistas de Ribera, probablemente activo en el mismo taller del maestro valenciano. Se aprecia un predominio de los marrones y negros, con algún toque de blanco, y el empleo de un empaste denso y un rico juego de luces y sombras.

Historia de la pieza: Estado de conservación: bueno.

\section{Catálogos:}

"Catalogo dei quadri e pitture esistenti nel palazzo di S. E. il sig. marchese Giacomo Filippo Durazzo, 1792: A. D.», pp. 14-15. Felton (1971), pp. 397-398.

\section{Bibliografia:}

A. D. G., Catalogo, 1792, pp. 14-15.

Alizeri (1846-1847), p. 410.

Alizeri (1875), p. 410.

Boccardo (2004), pp. 189-191.

Ferrari (1986).

Gaya Nuño (1958), pp. 2302-2303.

Grosso (1920).

Mayer (1923a), p. 197.

Pérez Sánchez (1978), p. 139.

Puncuh (1984), pp. 192, 193 y 198.

Ratti (1780), p. 183.

Spinosa (1995a), pp. 231-233.

Torriti (1967), pp. 61-66. 


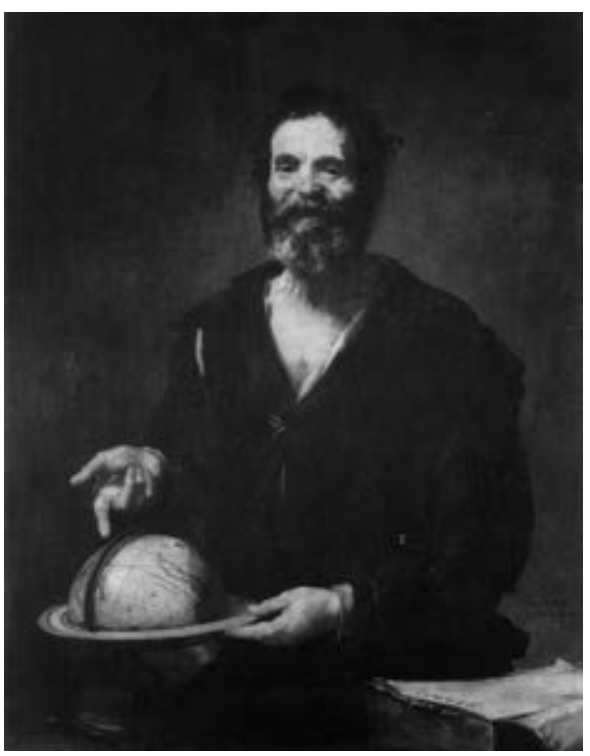

FICHA CATALOGRÁFICA

N. ${ }^{\circ}$ orden: 16

Colección privada, Génova

Demócrito, atribuido a José de Ribera, colección privada, Génova.

Autor-atribución. Título de la obra: Atribuido a José de Ribera (Játiva, 1591Nápoles, 1652), conocido como lo Spagnoletto: Demócrito.

La atribución a Ribera fue confirmada por A. Mayer (1923a, p. 193) y por J. A. Gaya Nuño (1958, pp. 2302-2303). P. Torriti (1967, p. 61) considera que probablemente no pertenece al pincel del Spagnoletto, y por indicación de F. Bologna ha sido considerado como obra del desconocido maestro de la Oración en el huerto de la catedral de Pozzuoli, autor de numerosos cuadros atribuidos a Ribera y a Francisco Fracanzano e identificado después como el napolitano Nunzio Rossi. N. Spinosa (1995a, p. 233) lo reconoce como obra de un anónimo imitador de Ribera.

Estilo-cronología: Datado en la primera mitad del siglo XVII. Spinosa (1995a, p. 233) establece su cronología en 1630.

Tipo de obra, material y técnica: Cuadro. Óleo sobre lienzo.

Dimensiones: $121 \times 95 \mathrm{~cm}$.

Elementos autógrafos: Firmado y datado en el margen inferior derecho: «Jusepe de Ribera Español Valenciano 1635».

Localización y procedencia: Génova, colección privada. 
Adquirido en 1722 por el marqués Giacomo Filippo Durazzo II, junto al Filósofo y al Heráclito, a M. Vittoria Spinola Grilla, con un marco dorado, por un precio (los tres) de 769,3 liras.

Figura como obra de Ribera en Ratti (1780, p. 183), en el inventario de 1787 de la colección del marqués Giacomo Filippo Durazzo III y en el catálogo de su colección de 1792. Recogido también por Alizeri (1875, p. 410).

Descripción: Filósofo representado de medio cuerpo, mirando hacia el espectador mientras con su mano derecha señala el globo terráqueo. A su izquierda hay un libro abierto que probablemente aluda a su pensamiento filosófico.

Como en el caso anterior, P. Torriti (1967, p. 62) define la expresión de este filósofo entre la caricatura y lo grotesco, apartándose así de la seriedad. Del mismo modo, N. Spinosa (1995a, p. 232) destaca que se recurre a soluciones de grafismo, lo que le conduce a pensar en un anónimo imitador de los modos de Ribera, probablemente activo en el mismo taller del maestro. Pero, independientemente de estas opiniones, se observa un estudiado contraste de luces y sombras, que inciden en la composición concediendo valores de corporeidad y volumen a los elementos representados. Se emplean tonos marrones y negros, con algún toque de blanco, aplicados con densidad.

Historia de la pieza: Estado de conservación: bueno.

Catálogos: "Catalogo dei quadri e pitture esistenti nel palazzo di S. E. il sig. marchese Giacomo Filippo Durazzo, 1792: A. D.», pp. 14-15.

Felton (1971), pp. 397-398.

\section{Bibliografia:}

A. D. G., Catalogo, 1792, pp. 14-15.

Alizeri (1846-1847), p. 410.

Alizeri (1875), p. 410.

Ferrari (1986).

Gaya Nuño (1958), pp. 2302-2303.

Grosso (1920).

Mayer (1923a), p. 193.

Pérez Sánchez (presentación) (1978), p. 139.

Puncuh (1984), pp. 191-193 y 198.

Ratti (1780), p. 183.

Spinosa (1995a), pp. 231-233.

Torriti (1967), pp. 61-66. 


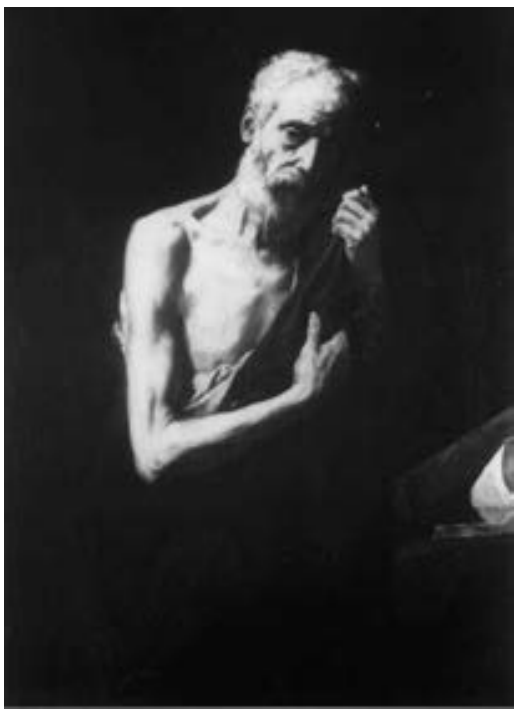

\author{
FICHA CATALOGRÁFICA \\ N. ${ }^{\circ}$ orden: 17 \\ Colección privada, Génova
}

Filósofo, atribuido a José de Ribera,

colección privada, Génova.

Autor-atribución. Título de la obra: Atribuido a José de Ribera (Játiva, 1591Nápoles, 1652): Filósofo.

P. Torriti (1967, pp. 66-67) atribuye este cuadro, con alguna duda, a Ribera, en relación con el San Andrés perteneciente a la conocida serie del Apostolado del Museo del Prado. Recuerda también, según este autor, al San Jerónimo de la Galleria Doria Pamphilj de Roma. C. Felton (1971, p. 399) establece su catalogación entre los cuadros del maestro español de dudosa atribución.

N. Spinosa (Pérez Sánchez, present., 1978, p. 138) confirma la autoría riberesca, en concreto por las afinidades estilísticas con el San Andrés del Museo del Prado.

Estilo-cronología: P. Torriti (1967, pp. 66-67) fija su cronología entre 1629 y 1630-1632. En la misma línea se encuentra N. Spinosa, quien lo data a principios de la década de 1630, y no más allá de 1635 .

Tipo de obra, material y técnica: Cuadro. Óleo sobre lienzo.

Dimensiones: $125 \times 88 \mathrm{~cm}$.

Elementos autógrafos: No está firmado.

Localización y procedencia: Génova, colección privada. 
Adquirido en 1722 por el marqués Giacomo Filippo Durazzo II, junto al Demócrito y al Heráclito, a M. Vittoria Spinola Grilla, con un marco dorado, por un precio (los tres) de 769,3 liras.

Aparece citado en Ratti (1780, p. 183), en el inventario del 31 de mayo de 1787 de la colección del marqués Giacomo Filippo Durazzo III y en el catálogo de su colección de 1792. Recogido también en la obra de Alizeri (1875, p. 410) con referencia al maestro español.

Descripción: Se representa un filósofo, casi de cuerpo entero, que presenta el torso desnudo. Destaca el gran naturalismo con el que se representa su anatomía, particularmente evidente en la delgadez física y en las arrugas del rostro. Este filósofo, no identificado, tiene entre sus manos un manto de color negro, y a su izquierda hay un libro abierto, que podría hacer referencia a su pensamiento filosófico. Destaca el contraste de luces y sombras, en la línea de Caravaggio. Se emplean colores marrones, con algún toque de blanco, caracterizados por su densidad.

Historia de la pieza: Estado de conservación: bueno.

Catálogos:

"Catalogo dei quadri e pitture esistenti nel palazzo di S. E. il sig. marchese

Giacomo Filippo Durazzo, 1792: A. D.», p. 13.

Felton (1971), p. 399.

\section{Bibliografia:}

A. D. G., Catalogo, 1792, p. 13.

Alizeri (1846-1847), p. 410.

Alizeri (1875), p. 410.

Bussolino (1877), p. 262.

Ferrari (1986).

Mayer (1923a).

Pérez Sánchez (presentación) (1978), p. 99.

Puncuh (1984), pp. 191-192, 195 y 198.

Ratti (1780), p. 183.

Spinosa (1995a), p. 230.

Torriti (1967), pp. 66-67. 


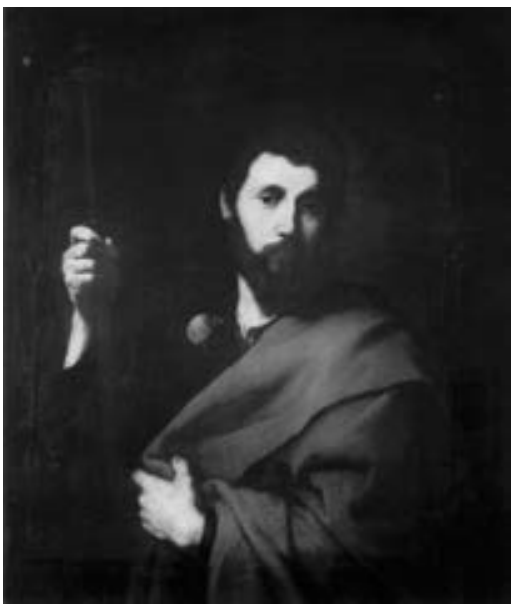

\author{
FICHA CATALOGRÁFICA \\ N. ${ }^{\circ}$ orden: 18 \\ Colección privada, Génova
}

Santiago el Mayor, atribuido a José de Ribera, colección privada, Génova.

Autor-atribución. Título de la obra: Atribuido a José de Ribera (Játiva, 1591Nápoles, 1652): Santiago el Mayor.

P. Torriti (1967, p. 180) considera este cuadro el posible original del cual derivan numerosas copias autógrafas o de taller y algunas variantes realizadas también por pintores de ámbito no napolitano. Para C. Felton (1971, p. 399) se encuentra entre los cuadros de incierta atribución al maestro.

Para N. Spinosa (1995b, p. 123) se trata de una versión autógrafa del "prototipo» del Museo del Prado de Madrid, pintado por Ribera entre 1630 y 1632 para la serie del Apostolado, respecto al cual no presenta variantes y del que se conocen otras copias, como la de la Galería Helikon de Londres y la de la iglesia de Santa Teresa de Lecce.

Estilo-cronología: P. Torriti (1967) establece su cronología entre 1635 y 1640 , igual que S. Martinoni (1983, p. 316). Sin embargo, N. Spinosa (1995b) la adelanta unos años, entre 1633 y 1634.

Tipo de obra, material y técnica: Cuadro. Óleo sobre lienzo.

Dimensiones: $77 \times 62 \mathrm{~cm}$.

Elementos autógrafos: No está firmado.

Localización y procedencia: Génova, colección privada.

Aparece citado en Ratti (1780, p. 181), en el inventario de 1787 de la colección del marqués Giacomo Filippo Durazzo III y en el catálogo de la misma colección de 1792. 
Descripción: Se representa a Santiago el Mayor, de medio cuerpo, con posición frontal, sobre un fondo neutro. Aparece como peregrino, evangelizador y mártir, en plena madurez. Lleva una toga de color negro con una concha (atributo), un manto rojo y bastón. Como puede apreciarse, ha sido captado con un gran naturalismo. Destaca el juego de luces y sombras, que inciden sobre los elementos compositivos, sacando a la luz el rostro del santo y sumergiendo el resto en penumbra. Predominio de los marrones oscuros y del negro, aunque se emplea también un rojo intenso para el manto. Se recurre a una pincelada de gran soltura, mórbida y delicada.

P. Torriti (1967, p. 180) se basa en la serenidad del rostro del apóstol para datar la obra en el período de madurez del artista, después de 1635, cuando Ribera abandona el crudo realismo de carácter caravaggiesco.

Este cuadro podría relacionarse con la serie de los apóstoles y filósofos realizados por el maestro valenciano en los años treinta, como, por ejemplo, con el San Pedro del Museo del Prado y el San Jerónimo del Museo Lázaro Galdiano, en Madrid.

Historia de la pieza: Estado de conservación: bueno. El cuadro fue engrandecido en época moderna.

\section{Catálogos:}

«Catalogo dei quadri e pitture esistenti nel palazzo di S. E. il sig. marchese

Giacomo Filippo Durazzo, 1792: A. D.», p. 12.

Felton (1971), p. 399.

Bibliografia:

A. D. G., Catalogo, 1792, p. 44.

Alizeri (1846-1847).

Alizeri (1875), p. 413.

Biblioteca Sanctorum, 1967, vol. VI, pp. 363-387.

Bussolino (1877), p. 261.

Martinoni (1983), p. 316.

Pérez Sánchez (presentación) (1978), p. 101.

Puncuh (1984), pp. 185-186, 190, 192 y 199.

Ratti (1780), p. 181.

Spinosa (1995b), pp. 122-123.

Torriti (1967), p. 180, fig. 165. 


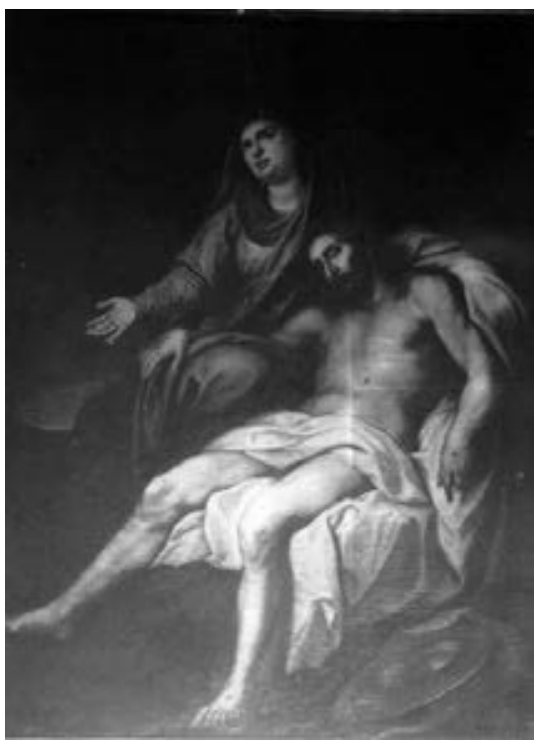

FICHA CATALOGRÁFICA

N. ${ }^{\circ}$ orden: 19

Iglesia de San Giorgio, Génova
Piedad, atribuido a Alonso Sánchez Coello, iglesia de San Giorgio, Génova.

Autor-atribución. Título de la obra: Atribuido a Alonso Sánchez Coello (Benifairó de les Valls, Valencia, 1531-Madrid, 1588): Piedad.

F. Alizeri (1846-1847, p. 428) considera esta obra como de «Coelio Spagnuolo», seguidor de Rubens. Grosso (1920, p. 306) opina también que es obra del pintor madrileño Claudio Coello. W. Piastra (1973, p. 45) recoge el documento de la donación, en el que se reconoce original de "Claudio Cohelo Spagnuolo». Sin embargo, F. Boggero (1979, p. 13) opina que se trata de una pintura de Alonso Sánchez Coello, tal como figura en la iglesia.

En mi opinión, la atribución a Alonso Sánchez Coello debe ser revisada. Además, esta obra, desde el punto de vista estilístico, está más relacionada con la pintura de finales del siglo XVII y, concretamente, con la producción pictórica de Claudio Coello.

Estilo-cronología: Datado en el siglo XVI, si se admite la atribución a Sánchez Coello, aunque parece más exacto datar esta obra a finales del XVII.

Tipo de obra, material y técnica: Cuadro. Óleo sobre lienzo.

Dimensiones: $152 \times 210 \mathrm{~cm}$.

Elementos autógrafos: No está firmado. 
Localización y procedencia: Génova, iglesia de San Giorgio, colocado en la capilla lateral izquierda, próxima al altar central, denominada Capilla de la Dolorosa.

Este cuadro fue donado a la iglesia de San Giorgio en 1844 por Antonio Ramorino, residente en San Petersburgo, quien lo recibió a su vez de su padre, Domenico Ramorino. La obra fue colocada en la tercera capilla del lado del Evangelio, donde había un crucifijo de madera, que fue restaurado para la ocasión (Piastra, 1973, p. 45).

Descripción: Representa a Jesús después de la deposición, en brazos de su madre. La Virgen, con la mirada en alto, extiende un brazo clamando piedad, movimiento que atrae la mirada del espectador hacia la composición. Los numerosos pliegues de los paños confieren a las figuras corporeidad y volumen, reforzados a su vez por los contrastes de luces y sombras. Se trata de una composición dinámica, tal como se aprecia en el cuerpo de Cristo, que transmite sensación de inestabilidad, y en la Virgen que alza un brazo. Hay un fondo neutro sobre el que destacan las figuras. Gama cromática reducida a base de marrones y grises, con algún toque de blanco.

Historia de la pieza: Estado de conservación: deteriorado.

Bibliografia:

Alizeri (1846-1847), p. 428.

Balestreri y Piastra (1973), p. 45.

Boccardo y Di Fabio (2004), pp. 237-238.

Boggero (1979), n. ${ }^{\circ} 84$, p. 13.

Boggero (1990).

Cappellini (1942).

De Simoni (1948), pp. 264-265.

Grosso (1920).

Guida d'Italia. Liguria, 1982.

Novella (1898).

Sullivan (1989). 


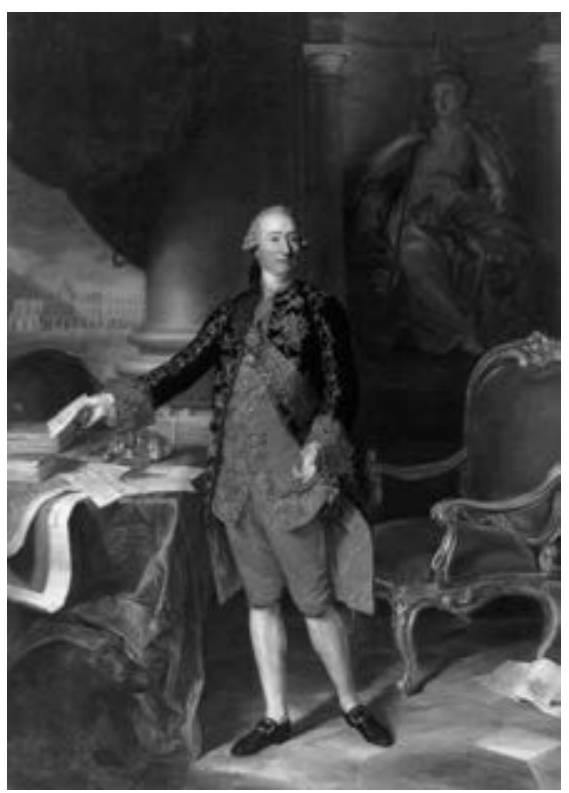

FICHA CATALOGRÁFICA

N. ${ }^{\circ}$ orden: 20

Museo dell'Accademia Ligustica di Belle Arti, Génova
Retrato del duque Paolo Gerolamo Grimaldi, Francisco Javier Ramos,

Museo dell'Accademia Ligustica di Belle Arti, Génova.

Autor-atribución. Titulo de la obra: Francisco Javier Ramos (Madrid, 17441817): Retrato del duque Paolo Gerolamo Grimaldi.

En el catálogo de la Accademia, publicado en 1983, esta obra aparece citada con la atribución tradicional (Ratti, Alizeri y Torriti) a Anton von Maron (Viena, 1733-1808), seguidor de Anton Raphael Mengs. Tras su restauración en 1984, apareció la firma, revelando que se trata de una copia antigua (realizada por Francisco Javier Ramos) del retrato que Anton von Maron realizó del duque Paolo Gerolamo Grimaldi, durante la estancia de este en Roma como embajador del rey de Espańa, y que actualmente está colocado en el Palazzo Durazzo Pallavicini de Génova. Se considera, pues, la autoría de Anton von Maron solo para este último retrato (Baccheschi, ed., 1983, p. 58).

Estilo-cronología: Datado hacia 1784, en función del grabado que Luigi Gismondi realizó en 1784 del retrato de Anton von Maron.

Tipo de obra, material y técnica: Cuadro. Óleo sobre lienzo.

Dimensiones: $276 \times 189 \mathrm{~cm}$.

Elementos autógrafos: Firmado en el margen inferior izquierdo: «Antonius de Maron/Xaverius Ramos pingendo tulit». 
Localización y procedencia: Génova, Museo dell'Accademia Ligustica di Belle Arti.

El cuadro fue donado a la Accademia Ligustica en 1790 por G. B. Grimaldi Pietra, a cambio de una serie de volúmenes sobre arquitectura militar. Grimaldi Pietra lo había recibido del duque Paolo Gerolamo Grimaldi.

Por tanto, Francisco Javier Ramos realiza, como pensionado español en Roma, una copia del retrato que Anton von Maron había ejecutado del duque de Grimaldi, durante la estancia de este como embajador en la Santa Sede. El encargo del pintor madrileño se explica gracias a las relaciones que el duque Paolo Gerolamo Grimaldi estableció con su maestro Mengs (cuñado de Anton von Maron) durante los ańos transcurridos en Roma.

Descripción: Retrato oficial del duque Paolo Gerolamo Grimaldi, de cuerpo entero. El duque, que fue mecenas y académico de la Ligustica, ministro de la República genovesa en Madrid y después embajador extraordinario del monarca español Carlos III en la Santa Sede, ha sido representado con gran magnificencia. Además, como figura en el papel que el duque tiene en su mano derecha, fue promotor del Pacto de Familia (1762) entre Espańa y Francia.

El duque aparece, en un primer plano, en una sala de ambientación neoclásica, junto a un escritorio, sobre el cual hay una serie de documentos. Lleva el traje de dignatario español, en paño azul y chaleco rojo, bordado en oro, y sobre el pecho lucen algunas de las condecoraciones de órdenes caballerescas recibidas en mérito a su honor como, por ejemplo, la del Toisón de Oro (1765), la de Carlos III y la del Espíritu Santo. Además, abajo, a la derecha de la composición, se aprecia un documento en el que se alude a dichas condecoraciones y cargos honoríficos. En esta estancia se abre un fondo de paisaje que permite ver el Palacio de Aranjuez. La presencia de este palacio se explica porque el duque de Grimaldi se ocupó de su ampliación en 1773. Destaca la intensidad y viveza de los colores, la serenidad compositiva y el naturalismo de la representación.

Historia de la pieza: Estado de conservación: excelente. La restauración del cuadro fue llevada a cabo en 1984 por Katrin Pillon, del Laboratorio de Restauración de la Accademia Ligustica.

Noticias documentales inéditas: Inv. 680.

Exposiciones:

Fasti della burocrazia. Uniformi civili e di corte nei secoli XVIII-XIX, celebrada en

Génova en 1984. 
Catálogos:

Baccheschi (ed.) (1983), pp. 58-59.

Baccheschi (ed.) (1988), pp. 112-113.

Bibliografia:

Alizeri ([1846-1847] 1864), 2. ${ }^{\text {a }}$ edición, p. 310.

Alizeri (1875).

A. S. G., ms. 448, Disposizioni di ultima volontà del fu Eccelentissimo signor Duca Paolo Gerolamo Grimaldi. Génova, Scionico, 1794.

Escudero (1985), pp. 151-152.

Pessa (1990).

Ratti (1779).

Ratti (1780).

Sborgi (1971a).

Staglieno (1862-1867), parte I, 1862, p. 41.

Thieme y Becker (1907-1954), vol. XXIV, 1930, p. 127.

Torriti (1963b), tab. XC.

Torriti (1967), pp. 205-207. 
FICHA CATALOGRÁFICA

N. ${ }^{\circ}$ orden: 21

Museo dell'Accademia Ligustica

di Belle Arti, Génova

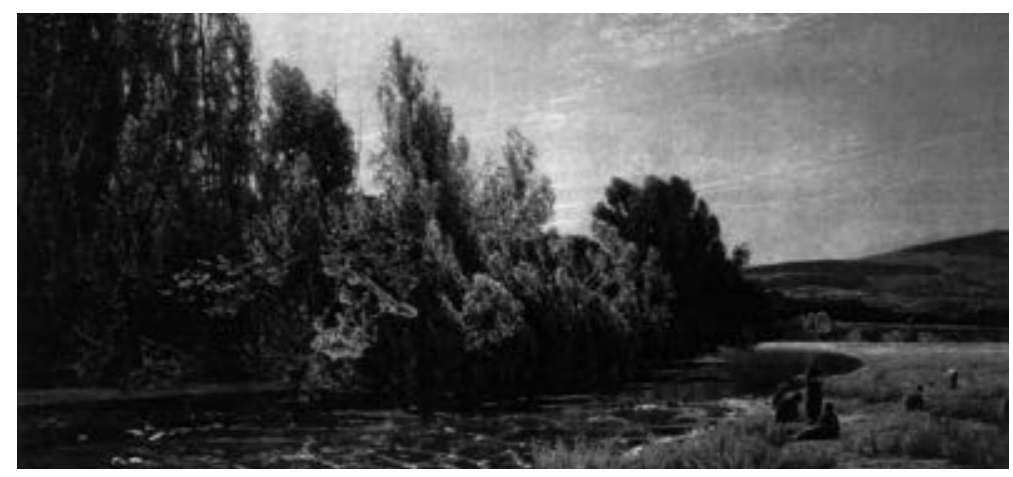

A orillas del Bormida, Serafín Avendaño, Museo dell'Accademia Ligustica di Belle Arti, Génova.

Autor-atribución. Título de la obra: Serafín Avendaño (Vigo, 1837-Valladolid, 1916): A orillas del Bormida.

Estilo-cronología: Fechado hacia 1866.

Tipo de obra, material y técnica: Cuadro. Óleo sobre lienzo.

Dimensiones: $75,5 \times 151 \mathrm{~cm}$.

Elementos autógrafos: Firmado en el margen inferior izquierdo: «S. De Avendaño».

Localización y procedencia: Génova, Museo dell'Accademia Ligustica di Belle Arti.

Esta obra fue donada a la Accademia Ligustica por el coleccionista genovés Maglione Oneto en 1934. Gianfranco Bruno (1981a, pp. 38, 155 y 156) dio a conocer los dos estudios preparatorios de esta obra, realizados con toda probabilidad en plein air, y localizados en colecciones privadas.

Descripción: Obra significativa de la producción pictórica de Avendaño, indicativa de la superación del paisaje romántico y del contacto con la poética naturalista. Se representan las orillas del Bormida, río ligur-piamontés, donde el pintor acudía junto con sus compañeros a captar las diferentes impresiones del 
natural. Destaca el amplio cielo, de azul intenso, atravesado por nubes sutiles, y la densa vegetación. Se recurre a una única gama de color, los verdes, que transmiten serenidad y frescura. Son verdes fríos y luminosos, que se reflejan en el agua inmóvil. Sorprende el amplio horizonte, surcado de montes realizados a base de grandes pinceladas, que podrían recordar los montes de las obras de Daubigny, de quien el pintor vigués era admirador. Esta obra recuerda también al paisajismo inglés del siglo XIX. La composición está dominada por una luminosidad difusa, que unifica la orilla del río y el cielo. Se incluyen figuras en el paisaje, de reducidas dimensiones, que no alteran el natural equilibrio de la naturaleza. De hecho, el verdadero protagonista de la composición es el paisaje.

Historia de la pieza: Estado de conservación: bueno.

Noticias documentales inéditas: Inv. 616.

\section{Exposiciones:}

Pittori liguri del secolo XIX, celebrada en el Palazzo Rosso de Génova en 1938. La pittura in Liguria tra '800 e '900, celebrada en el Salón de la Cassa de Risparmio de Génova en 1981.

La Scuola Grigia a Carcare, celebrada en la Villa Barrili de Carcare en 1986. Serafin Avendaño, 1837-1916, celebrada en Vigo en 1991.

\section{Catálogos:}

Grosso (1938b), pp. 28 y 81-82.

Bruno (1981b).

Baccheschi (ed.) (1988), pp. 14-45.

Serafin Avendaño, 1837-1916, 1991, p. 133.

Bibliografia:

Bruno (1971).

Bruno (1978).

Bruno (1981a), pp. 37-38, 155-156 y 163.

Bruno (1981c), p. 11.

Bruno (1983), pp. 37-38.

Bruno (1993), p. 151.

Bruno y Perissinotti (1989), p. 65.

Giubilei (2004), pp. 261-262.

Rocchiero (1960).

Sborgi (1971a), pp. 39 y 64.

Sborgi (1990), p. 20.

Thieme y Becker (1907-1954), vol. II, 1930, p. 274.

Torriti (1963b), tab. CI. 


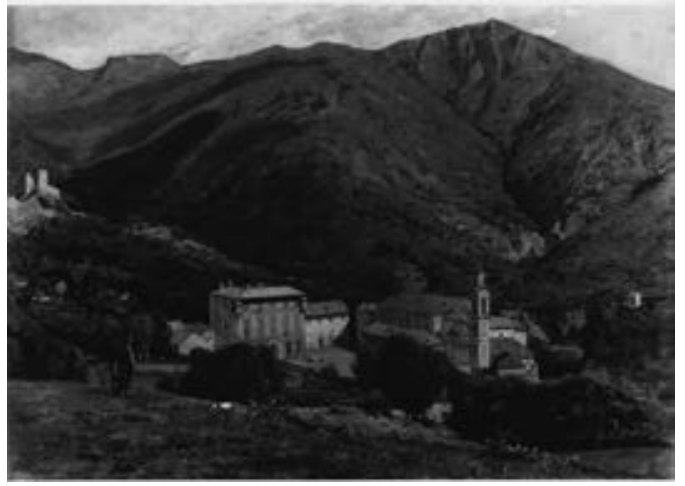

FICHA CATALOGRÁFICA

N. ${ }^{\circ}$ orden: 22

Galleria d'Arte Moderna, Génova

Savignone, Serafín Avendaño, Galleria d'Arte Moderna, Génova.

Autor-atribución. Título de la obra: Serafín Avendaño (Vigo, 1837-Valladolid, 1916): Savignone.

En la parte posterior del cuadro aparece una antigua atribución al pintor V. Grana y el título de la obra: Savignone.

Estilo-cronología: Datado entre 1870 y 1871, período en el que Avendaño afronta temas del interior de Liguria.

Tipo de obra, material y técnica: Cuadro. Óleo sobre lienzo.

Dimensiones: $45,5 \times 63,5 \mathrm{~cm}$.

Elementos autógrafos: Firmado en el margen inferior derecho con el monograma enlazado del pintor: «S. A.».

Localización y procedencia: Génova-Nervi, Galleria d'Arte Moderna, en Villa Saluzzo Serra.

Originariamente estuvo colocado en el primer piso de la galería, en la sala n. ${ }^{\circ}$ 3. El cuadro fue donado al Ayuntamiento de Génova, junto con otras obras, por el coleccionista genovés Agostino Vigo (deliberación n. ${ }^{\circ} 1459$ del 1 de agosto de 1946).

Descripción: Se trata de una magnífica vista del pueblo de Savignone (Liguria), que aparece en el fondo de un valle. De hecho, el pintor capta la imagen desde un punto de vista elevado respecto al terreno en el que se emplaza el núcleo rural, y en diagonal, ofreciendo así una amplia visión de conjunto. Como puede verse, el paisaje es el verdadero protagonista de la composición. En un primer plano y de reducidas dimensiones, se incluyen dos figuras, que no alteran la serenidad del ambiente. Estos personajes se hallan, aproximadamente, en el lugar desde el cual el pintor ha realizado esta obra, y están contemplando el paisaje. 
Los edificios han sido representados de manera detallada, a diferencia de las laderas que los rodean, donde se aprecia una pincelada más densa y menos precisa. Eso sí, es una pincelada corta y de gran soltura. Los colores son solares y esmaltados, y se observa la predilección del autor por la gama de los verdes. Se aprecia el gusto por los colores tenues y las medias tintas, el rechazo de los negros, la atención al estudio tonal y a la luz natural. Estas características hicieron que la escuela de la que formaba parte fuera denominada Scuola Grigia. Del contacto con los "grises» (desde 1866) deriva la claridad tonal que se advierte en sus cuadros, con la que desaparece la composición severa de sus paisajes. En este contexto, no debe olvidarse que Avendaño estuvo influenciado por el paisajismo de Corot, por el naturalismo y los empastes luminosos de Fontanesi y por la pintura de macchia ('mancha'). La tendencia a la composición horizontal, rica de zonas arboladas y profundas, con vastos cielos, tiene como punto de referencia la pintura franco-inglesa. Se trata de una pintura de gran limpieza y claridad compositiva.

Historia de la pieza: Estado de conservación: excelente. Fue restaurado en 1990.

Noticias documentales inéditas: Inv. G. A. M. 1126.

Exposiciones:

Exposición Nacional celebrada en Parma en 1870.

XXIX Exposición de la Società Promotrice di Belle Arti, celebrada en Turín en 1870.

La pintura de paisatge a Ligúria entre el Vuit-Cents i el Nou, celebrada en Barcelona en 1990.

Exposición celebrada en el Museo de San Agustín de Génova en 1990.

Serafin Avendaño, 1837-1916, celebrada en Vigo en 1991.

Catálogos:

Bruno (1981b), pp. 10, 157 y 490.

Bruno (1983), p. 38.

Serafin Avendaño, 1837-1916, 1991, p. 79.

Bibliografia:

Bruno (1971).

Bruno (1981a), p. 157.

Giubilei (1990), pp. 139-140.

Giubilei (2004), pp. 262-263.

Guida d'Italia. Liguria, 1982, pp. 265-66.

Rocchiero (1960). 


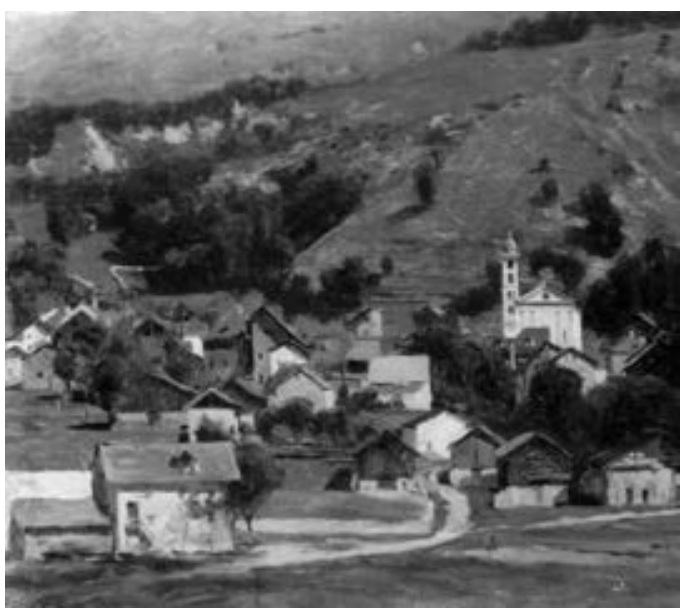

FichA CATALOGRÁFICA

N. ${ }^{\circ}$ orden: 23

Galleria d'Arte Moderna,

Génova

San Bartolomé de Vallecalda,

Serafín Avendaño,

Galleria d'Arte Moderna, Génova.

Autor-atribución. Título de la obra: Serafín Avendaño (Vigo, 1837-Valladolid, 1916): San Bartolomé de Vallecalda.

Estilo-cronología: Datado en torno a 1869-1871, período en el que Avendaño cultiva temas de paisajes del interior de Liguria.

Tipo de obra, material y técnica: Cuadro. Óleo sobre lienzo.

Dimensiones: $37 \times 50 \mathrm{~cm}$.

Elementos autógrafos: Firmado en el margen inferior izquierdo: «S. Avendaño». Localización y procedencia: Génova-Nervi, Galleria d'Arte Moderna, en Villa Saluzzo Serra.

Originariamente estuvo colocado en el primer piso de la galería, en la sala n. ${ }^{\circ} 3$. El cuadro fue adquirido por el Ayuntamiento de Génova al coleccionista genovés Antonio Gaggero (deliberación n. ${ }^{\circ} 100$ del 13 de marzo de 1924), por un precio de 400 liras.

Descripción: Representación del pueblo de San Bartolomé de Vallecalda (Liguria), que se halla en el fondo de un valle. Es una composición en horizontal, tomada desde un punto de vista próximo al objeto representado. Maria Flora Giubilei señala que puede tratarse de una especie de boceto preparatorio de la obra Savignone, pues propone una perspectiva parecida a la de esta, si bien un poco más cercana, y con una pincelada menos precisa. La técnica pictórica aquí empleada fue común a los pintores de la Scuola di Rivara (formada por 
ligures y piamonteses), que pintaban juntos al aire libre, sintiéndose atraídos por los aspectos más íntimos del campo, por la claridad y la luz atmosférica.

Se emplean grises, verdes y blancos, con la voluntad de captar el paisaje en sus aspectos más trépidos y melancólicos. Los colores son esmaltados y solares. El pintor estuvo atento a los cambios de luz y a sus efectos sobre el paisaje. Se trataba del descubrimiento de la poesía de lo efímero, en contraposición a la composición de historia y a la pintura oficial.

Historia de la pieza: Estado de conservación: excelente. Fue restaurado en 1990.

Noticias documentales inéditas: Inv. G. A. M. 383.

Exposiciones:

Exposición celebrada en el Museo de San Agustín de Génova en 1990.

Serafin Avendaño, 1837-1916, celebrada en Vigo en 1991.

Catálogos:

Serafin Avendaño, 1837-1916, 1991, p. 80.

Bibliografia:

Bruno (1971).

Bruno (1983), p. 38.

Giubilei (1990), pp. 139-140.

Rocchiero (1960), p. 17. 


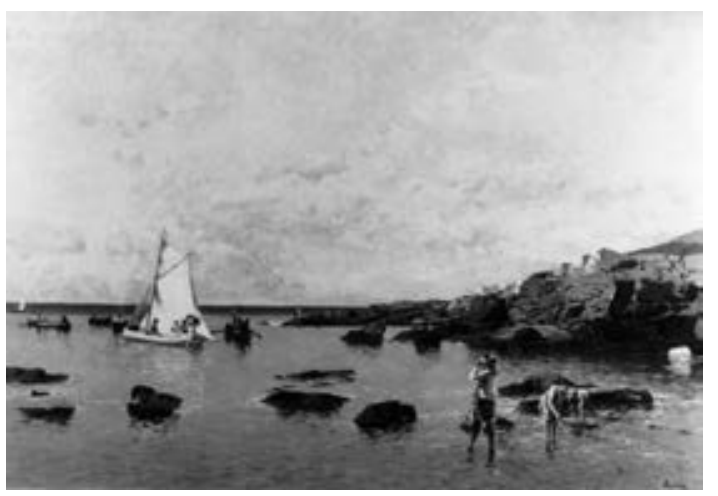

Ficha CATALOGRÁFICA

N. ${ }^{\circ}$ orden: 24

Galleria d'Arte Moderna, Génova

Ribera de Génova,

Serafín Avendaño,

Galleria d'Arte Moderna, Génova.

Autor-atribución. Título de la obra: Serafín Avendaño (Vigo, 1837-Valladolid, 1916): Ribera de Génova.

Estilo-cronología: Datado en 1881, cuando Avendaño afronta temáticas paisajísticas de Liguria.

Tipo de obra, material y técnica: Cuadro. Óleo sobre lienzo.

Dimensiones: $85 \times 132 \mathrm{~cm}$.

Elementos autógrafos: Firmado y datado en el margen inferior derecho: «S. Avendaño 1881».

Localización y procedencia: Génova-Nervi, Galleria d'Arte Moderna, en Villa Saluzzo Serra.

Originariamente este cuadro estuvo colocado en el primer piso de la Galleria, en la sala n. ${ }^{\circ} 3$. Fue adquirido por el Ayuntamiento de Génova a la Dirección de los Hospitales Civiles, por un precio de 5000 liras. En la deliberación n. ${ }^{\circ} 1426$ del 18 de julio, aparece citada como Marina del pintor «De Avendana».

Este cuadro participó, con el título Ribera de Génova, en la Promotrice di Belle Arti de 1881. De hecho, en el armazón figura la etiqueta de dicha exposición, en la que se indica el precio de 4000 liras. La obra fue adquirida por Luigi Pasquale Gandolfo, quien, al premio conseguido de 2000 liras, debió añadir otras 2000 para poder comprar el cuadro.

Al Hospital San Martín de Génova llegó como donación en época no conocida, para después ser adquirido, como ya se ha indicado, por el Ayuntamiento de la capital ligur e inventariado como Escollo de Quarto. En la actualidad se expone en la Galleria d'Arte Moderna bajo el título Ribera de Génova. 
Descripción: Paisaje marino que recoge la escollera de Quarto (ribera genovesa de Levante), incluyendo figuras humanas y barcas. Se trata de una composición en horizontal, muy del gusto del autor, que transmite sensación de profundidad, reforzada a su vez por las diagonales que dominan en ella. En esta obra se constata la evolución estilística de Serafín Avendaño, a través de la representación del efecto atmosférico que envuelve la composición, que comienza a ser predominante y fundamental en su pintura, y de la mayor riqueza y variedad del color, habiéndose suprimido los negros densos, que hasta entonces eran un recurso imprescindible en la constitución de las sombras. Esta obra guarda relación con la pintura napolitana contemporánea, por su carácter mediterráneo, recurriendo a colores esmaltados, solares e intensos, entre los que sobresalen los espléndidos azules, violetas y rojos. Destaca la gran maestría cromática, desconocida en la pintura genovesa de la época. Se emplea una pincelada densa, que no altera la definición neta y rígida de la composición. El amor a la luz solar otorga a sus cuadros un largo respiro, un perpetuo sentido de alegría.

Historia de la pieza: Estado de conservación: excelente. Fue restaurado en 1990.

Noticias documentales inéditas: Inv. G. A. M. 944.

Exposiciones:

XXX Exposición de la Società Promotrice di Belle Arti, sala n.o 3, celebrada en Génova en 1881.

Exposición celebrada en el Palacio Nacional de Brera, Milán, en 1882.

La pintura de paisatge a Ligúria entre el Vuit-Cents i el Nou-Cents, celebrada en Barcelona en 1990.

Serafin Avendaño, 1837-1916, celebrada en Vigo en 1991.

Catálogos:

Bruno (1981b), pp. 159 y 490.

Bruno (1983), p. 38.

Serafin Avendaño, 1837-1916, 1991, p. 81.

Bibliografia:

Bruno (1971).

Bruno (1981a), p. 39.

Giubilei (1990), pp. 139-140.

Giubilei (2004), p. 264.

Guida d'Italia. Liguria, 1982, pp. 265-266.

Rocchiero (1960). 


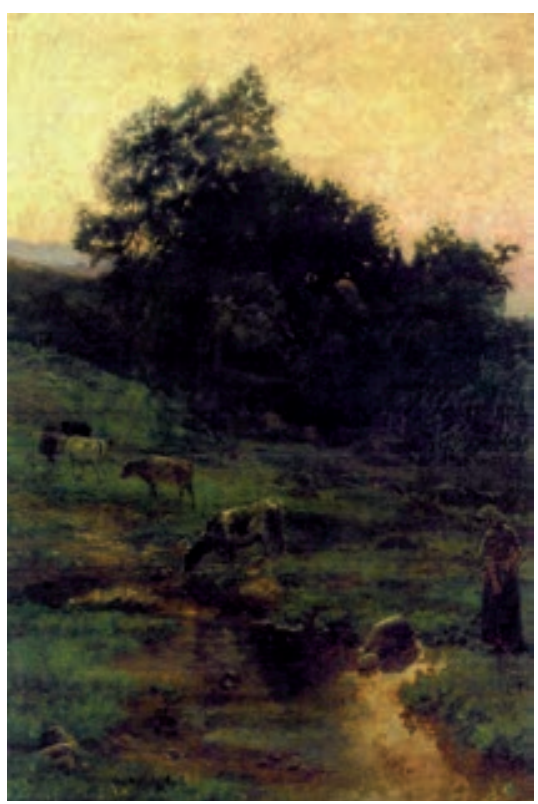

FICHA CATALOGRÁFICA

N. ${ }^{\circ}$ orden: 25

Colección privada, Génova

En la montaña o El abrevadero,

Serafín Avendaño,

colección privada, Génova.

Autor-atribución. Titulo de la obra: Serafín Avendaño (Vigo, 1837-Valladolid, 1916): En la montaña o El abrevadero.

Estilo-cronología: Datado hacia 1866.

Tipo de obra, material y técnica: Cuadro. Óleo sobre lienzo.

Dimensiones: $76 \times 51 \mathrm{~cm}$.

Elementos autógrafos: Firmado en el margen inferior izquierdo con el monograma del pintor: «S. Avendaño».

Localización y procedencia: Génova, colección privada de L. Masini.

Procede de la colección de Luigi Parodi de Génova.

Descripción: Se representa el momento del atardecer en la montaña piamontesa. Se incluye una pastorcilla en la orilla de un riachuelo, en el que abrevan cinco vacas. Se trata de una composición interesante porque se recurre al formato alargado-vertical, que no corresponde al empleado en la mayoría de sus obras. Es una pintura compacta, creativa y sintética. El paisaje está basado en una paleta luminosa que realza los verdes suaves y el amarillo limón, con algu- 
nas pinceladas gruesas, cortas y de gran soltura. La visión a través de Avendańo adquiere, desde el punto de vista pictórico, un carácter íntimo, tentando un naturalismo sin límites. La perspectiva aérea se consigue con el vivo contraste de los colores. La obra es un claro testimonio de las palabras que Calderini (1901, p. 146) dedicó a Avendaño: «huía del arte "compuesto", afirmando que el arte consiste en captar en la naturaleza aquello que impresiona al pintor, sea por efecto de luz o por la belleza de un lugar [...]; y para obtener esto es necesario dejar tal y como son los árboles, las piedras, los animales, las sombras, etc., según el ejemplo de Velázquez».

Historia de la pieza: Estado de conservación: bueno.

Exposiciones:

XXXI Exposición de la Società Promotrice di Belle Arti, celebrada en Turín en 1872.

Una collezione di dipinti dell'Ottocento ligure, celebrada en el Palacio de los Gigantes de Génova en 1985.

Serafin Avendaño, 1837-1916, celebrada en Vigo en 1991.

L'alba del vero, celebrada en la Accademia Ligustica di Belle Arti de Génova en 1993.

Catálogos:

Stella (1893), p. 508.

Serafin Avendaño, 1837-1916, 1991, p. 133.

Bibliografia:

Bruno (1971).

Bruno (1978).

Bruno (1981a).

Bruno (1993), p. 147.

Calderini (1901), p. 146.

Dragone y Dragone Conti (1947), pp. 127-130 y 140-141.

Marini (1986).

Rocchiero (1960).

Rocchiero (1985), p. 10.

Sborgi (1990), p. 20. 
FICHA CATALOGRÁFICA

N. ${ }^{\circ}$ orden: 26

Colección privada, Génova

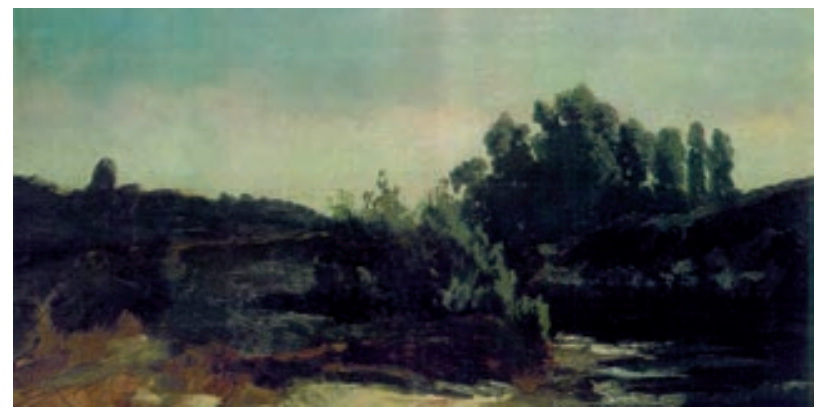

Paisaje, Serafín Avendaño, colección privada, Génova.

Autor-atribución. Título de la obra: Serafín Avendaño (Vigo, 1837-Valladolid, 1916): Paisaje.

Estilo-cronología: Fechado hacia 1866.

Tipo de obra, material y técnica: Cuadro. Óleo sobre lienzo.

Dimensiones: $17 \times 25,5 \mathrm{~cm}$.

Elementos autógrafos: Firmado en el margen inferior derecho: «S. Avendaño». Localización y procedencia: Génova, colección privada de Alessandro Pernecco. Este cuadro fue comprado hace unos veinte ańos por el actual propietario.

Descripción: Se representa un paisaje, que, como en obras anteriores, es el protagonista de la composición. En este caso, no se incluyen figuras. El pintor capta el lento discurrir de un río, circundado por una abundante vegetación que recuerda la obra $A$ orillas del Bormida (ficha n. ${ }^{\circ} 21$ ). Se trata de una composición en horizontal, muy del gusto de Avendańo, que le permite ofrecer una amplia visión de conjunto. Recurre, como los pintores "grises» (grigi), a tonos verdes, marrones y sepias, con algún toque de blanco, que introduce luminosidad en la composición. Se emplea una pincelada corta, de extraordinaria soltura. Es un paisaje sereno y melancólico, dotado de un poético sen- 
timiento hacia la naturaleza. Este rasgo fue compartido por sus compañeros de escuela.

Gianfranco Bruno (1981a, p. 37) indica que en esta pequeña obra de paisaje sin figuras se conjuga la práctica fontanesiana de recurrir a un fondo sepia, sobre el que emergen las formas, con el lírico erguirse de los árboles en movimiento en la claridad del cielo, que podría recordar las orillas de Bonington y los cielos ventosos de Constable.

Historia de la pieza: Estado de conservación: bueno.

Exposiciones:

Serafin Avendaño, 1837-1916, celebrada en Vigo en 1991.

Catálogos:

Serafin Avendaño, 1837-1916, 1991, p. 133.

Bibliografia:

Bruno (1971).

Bruno (1978).

Bruno (1981a), pp. 37 y 154.

Bruno (1993), p. 148.

Rocchiero (1960).

Rocchiero (1985), p. 10.

Sborgi (1990), p. 20. 


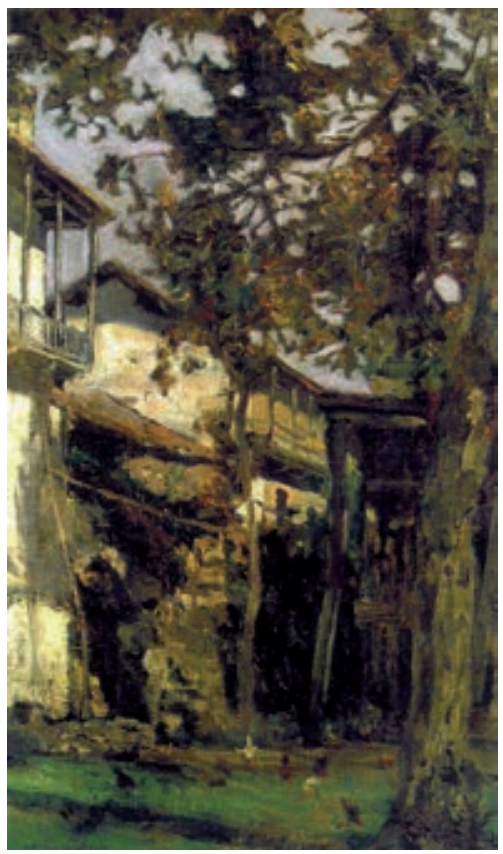

FICHA CATALOGRÁFICA

N. ${ }^{\circ}$ orden: 27

Colección privada, Génova

Casas de montaña, Serafín Avendaño,

colección privada, Génova.

Autor-atribución. Titulo de la obra: Serafín Avendaño (Vigo, 1837-Valladolid, 1916): Casas de montaña.

Estilo-cronología: Datado en torno a 1866.

Tipo de obra, material y técnica: Cuadro. Óleo sobre lienzo.

Dimensiones: $41 \times 26 \mathrm{~cm}$.

Elementos autógrafos: Dedicado y firmado en el margen inferior izquierdo: «Al amico Luxoro. S. De Avendaño».

Localización y procedencia: Génova, colección privada.

Procede de la colección del experto de arte y académico Giovanni Ravaschio de Génova. La obra fue adquirida hace unos treinta años en una galería de Génova.

Descripción: Las protagonistas de la composición son unas casas representativas de la arquitectura tradicional de las zonas de montaña. Presenta formato alargado-vertical, que permite al pintor capturar en todo su esplendor este rin- 
cón de fuerte sabor pintoresco. En la obra se advierten una serie de elementos que la apartan de las primeras producciones del pintor; en concreto, el empleo de una paleta más luminosa, reforzada por una pincelada corta y gruesa. De hecho, los verdes serios y oscuros — presentes en las obras antes analizadasdejan paso a tonos más suaves, con un claro dominio del blanco y del amarillo. Así, se logra una composición solar, que transmite alegría y vida. Esto se debe al contacto de los grigi con los compañeros toscanos, los macchiaioli, cuyo lenguaje pictórico se fundamentaba en el principio de la macchia ('mancha'). La obra posee un carácter íntimo, que pone de manifiesto la gran sensibilidad del artista.

Historia de la pieza: Estado de conservación: bueno.

Exposiciones:

Fortune dell'Ottocento pittorico, celebrada en la Galleria d'Arte Sant'Andrea de Génova en 1964.

L'alba del vero, celebrada en la Accademia Ligustica di Belle Arti de Génova en 1993.

Catálogos:

Ravaschio (1964), tab. II.

Ottocento. Catalogo dell'Arte Italiana dell'Ottocento, n. ${ }^{\circ}$ 15, 1986.

Bruno y Perissinotti (1989).

Serafin Avendaño, 1837-1916, 1991, p. 138.

Bibliografía:

Bruno (1971).

Bruno (1978).

Bruno (1981a), pp. 37 y 154.

Bruno (1993), p. 149.

Calderini (1901), p. 146.

Rocchiero (1960).

Sborgi (1990), p. 20. 


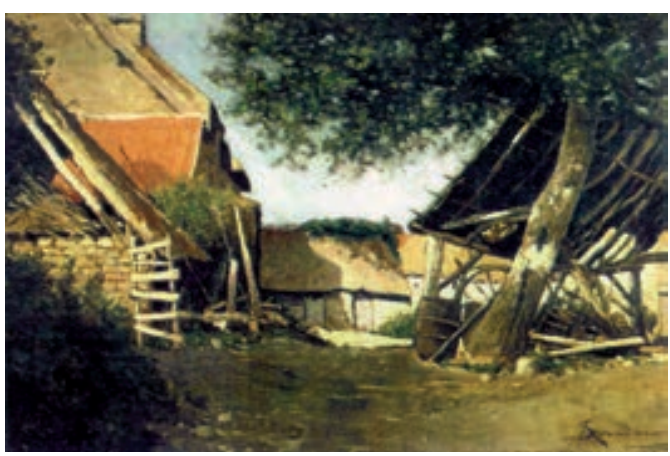

FICHA CATALOGRÁFICA

N. ${ }^{\circ}$ orden: 28

Colección privada, Génova
La granja, Serafín Avendaño, colección privada, Génova.

Autor-atribución. Título de la obra: Serafín Avendaño (Vigo, 1837-Valladolid, 1916): La granja.

Estilo-cronología: Fechado hacia 1866.

Tipo de obra, material y técnica: Cuadro. Óleo sobre lienzo.

Dimensiones: $48,5 \times 73 \mathrm{~cm}$.

Elementos autógrafos: Firmado en el margen inferior derecho: «S. Avendaño». Localización y procedencia: Génova, colección privada.

La obra fue adquirida en una galería de arte de Génova hace unos treinta años, por el actual propietario.

Descripción: Esta obra se encuentra en la línea de la anterior (ficha n. ${ }^{\circ} 27$ ), pues recoge un lugar pintoresco y humilde, inundado por una intensa luminosidad. Se trata de una composición en horizontal, que capta unas construcciones rurales. Se logra representar los efectos atmosféricos mediante el rico contraste cromático y la densa y corta pincelada. El pintor estudia la incidencia de la luz sobre los elementos compositivos, prestando una especial atención a los contrastes de luces y sombras. Este paisaje sin figuras pone de manifiesto la sensibilidad y el gusto sutil de Avendaño.

Historia de la pieza: Estado de conservación: bueno.

Bibliografia:

Bruno (1981a), pp. 37 y 154.

Bruno (1993), p. 150.

Labó (1926), p. 23.

Rocchiero (1960).

Sborgi (1990), p. 20. 
FICHA CATALOGRÁFICA

N. ${ }^{\circ}$ orden: 29

Colección privada, Génova

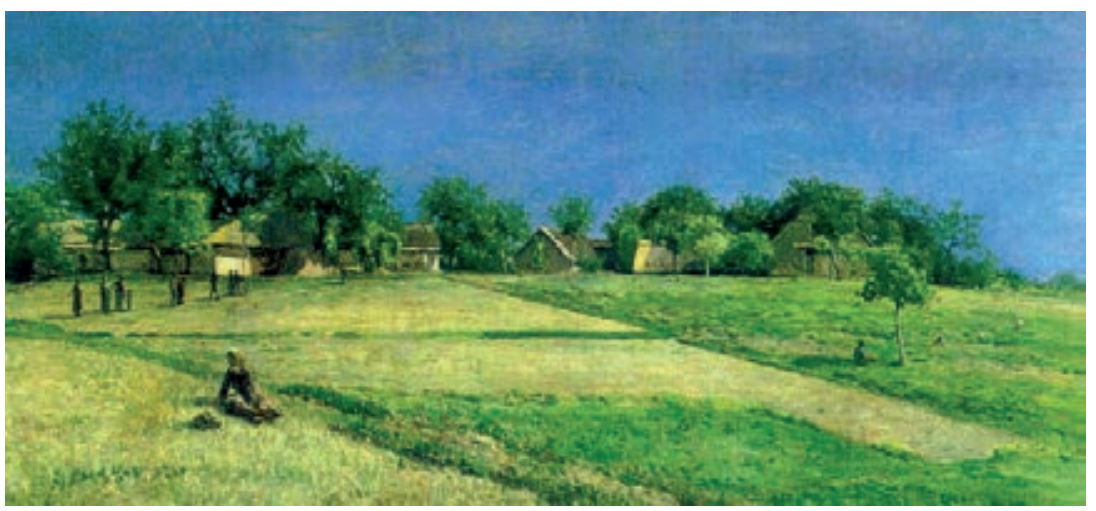

Paisaje. Vastedad campestre, Serafín Avendaño, colección privada, Génova.

Autor-atribución. Título de la obra: Serafín Avendaño (Vigo, 1837-Valladolid, 1916): Paisaje. Vastedad campestre.

Estilo-cronología: Datado hacia 1866.

Tipo de obra, material y técnica: Cuadro. Óleo sobre lienzo.

Dimensiones: $52 \times 103 \mathrm{~cm}$.

Elementos autógrafos: Firmado en el margen inferior derecho: «S. De Avendaño». Localización y procedencia: Génova, colección privada T. Pelizza.

Descripción: Se representa un paisaje rural, que incluye casas y figuras, dentro del gusto del pintor por captar lugares pintorescos y alejados. Se trata de una composición en horizontal, que ofrece una amplia visión en profundidad. El verdadero protagonista es el campo, que se abre en un primer plano, a diferencia de las casas, que aparecen al fondo. La figura humana ocupa un lugar intermedio en la composición, y se representa en reducidas dimensiones. Destaca la maestría cromática y la minuciosidad en la descripción de la naturaleza, que dota a la obra de gran belleza. De este modo, se recurre a suaves y límpidos tonos verdes y azules, con algún toque de amarillo y blanco, aplicados 
con una pincelada pastosa. Se capta el efecto atmosférico. El color y la luminosidad transmiten un largo respiro y un inmenso sentido de sosiego a quien la contempla. Estas características explican la definición que Rosa E. Caamaño (1991, p. 14) hizo de Avendaño, denominándolo «verista» convencido.

Historia de la pieza: Estado de conservación: bueno.

Exposiciones:

La Scuola Grigia a Carcare, celebrada en la Villa Barrili de Carcare en 1989. Serafin Avendaño, 1837-1916, celebrada en Vigo en 1991.

L'alba del vero, celebrada en la Accademia Ligustica di Belle Arti de Génova en 1993.

Catálogos:

Bruno (1983), p. 37.

Serafin Avendaño, 1837-1916, 1991, p. 135.

Bibliografia:

Bruno (1971).

Bruno (1993), p. 153.

Bruno y Perissinotti (1989), p. 68.

Marini (1986).

Rocchiero (1960).

Rocchiero (1981), p. 277.

Sborgi (1990). 


\section{FICHA CATALOGRÁFICA}

N. ${ }^{\circ}$ orden: 30

Colección privada, Génova

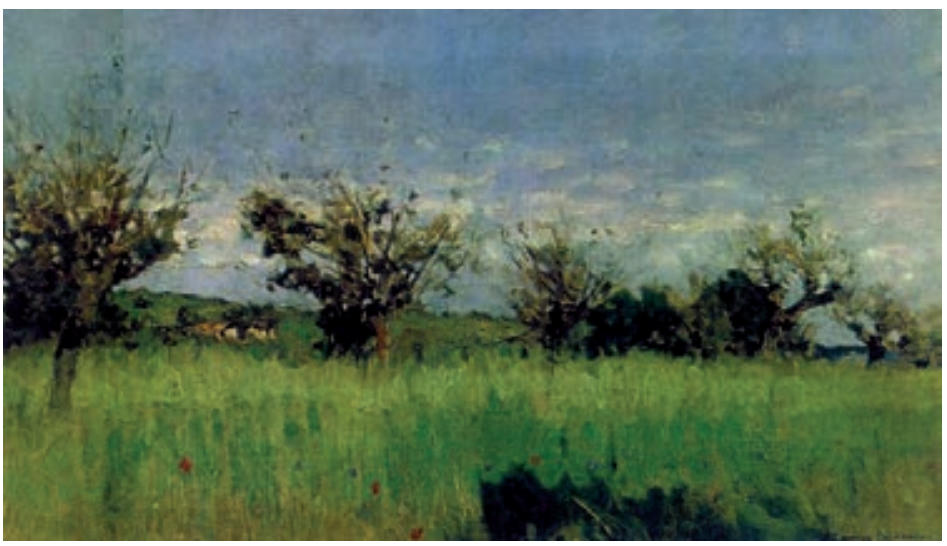

Campo con moreras, Serafín Avendaño, colección privada, Génova.

Autor-atribución. Título de la obra: Serafín Avendaño (Vigo, 1837-Valladolid, 1916): Campo con moreras.

Estilo-cronología: Fechado en torno a 1866.

Tipo de obra, material y técnica: Cuadro. Óleo sobre lienzo.

Dimensiones: $25 \times 40 \mathrm{~cm}$.

Elementos autógrafos: Firmado y dedicado en el margen inferior derecho: «S. Avendaño al amigo Calderini».

Localización y procedencia: Génova, colección privada T. Pelizza.

T. Pelizza adquirió este cuadro en una galería de arte de Turín hace unos treinta años.

Descripción: Se representa un campo con moreras, que refleja el interés de Avendaño por los elementos de la naturaleza. Se trata de una composición en horizontal, que ofrece una vista en profundidad. Se recurre a una paleta luminosa, a base de suaves verdes y azules, con algún toque de blanco, que permite captar un campo florido a la luz del día. Es una composición de singular 
belleza, que destaca por la maestría cromática, confiriendo a la obra una profunda serenidad. Se emplea una pincelada corta y pastosa, que refuerza la emotividad interior.

Gianfranco Bruno (1993, p. 154) señala que esta obra se remonta a los años de Rivara, después de 1868, y que es significativa de la vena poética de Serafín Avendaño porque usa pocos tonos, con intensas pinceladas de color, recurriendo al lenguaje de la macchia ('mancha'), consiguiendo interpretar la luz del amanecer sobre el campo, realizada en plein air. En la misma línea se encuentra Rafael Úbeda, quien indica que Serafín Avendaño nos transmite, a través de su profunda espiritualidad, una pintura de carácter preimpresionista, reflejando, con sus impulsos creadores, una nueva y sonora realidad (Caamaño Fernández, 1991, p. 19).

Historia de la pieza: Estado de conservación: bueno.

Exposiciones:

Pittori del secolo XIX, celebrada en la Galleria Fogliato de Turín en 1982.

Da Bagetti a Reycend, celebrada en la Società Promotrice di Belle Arti de Turín en 1986.

La Scuola Grigia a Carcare, celebrada en la Villa Barrili de Carcare en 1989.

Catálogos:

Pittori dell'800, 1982.

Bruno (1983), p. 38.

Dragone (1986), p. 115.

Bibliografia:

Bruno (1971), p. 437.

Bruno (1993), p. 154.

Bruno y Perissinotti (1989), p. 70.

Caamaño Fernández (1991), p. 14.

Rocchiero (1960).

Sborgi (1990). 


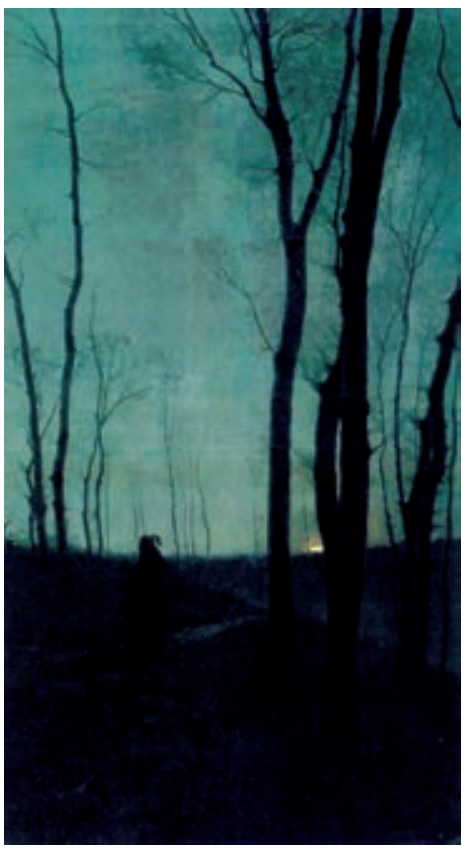

FICHA CATALOGRÁFICA

N. ${ }^{\circ}$ orden: 31

Colección privada, Génova

Efectos de luna, Serafín Avendaño, colección privada, Génova.

Autor-atribución. Titulo de la obra: Serafín Avendaño (Vigo, 1837-Valladolid, 1916): Efectos de luna.

Estilo-cronología: Datado en 1867.

Tipo de obra, material y técnica: Cuadro. Óleo sobre lienzo.

Dimensiones: $150 \times 85 \mathrm{~cm}$.

Elementos autógrafos: Firmado y datado en el margen inferior derecho: «S. Avendaño 1867».

Localización y procedencia: Génova, colección privada.

Este cuadro fue encontrado en la década de los años setenta en la bodega de una casa de Génova. Fue restaurado por Gianfranco Bruno, quien después lo vendió al actual propietario.

Descripción: Aparece un magnífico paisaje nocturno con dos figuras, que constituye la única obra de Avendańo de estos años que no ha sido realizada a plena luz del día. Se trata de una gran tela en vertical, siendo una de las pocas 
excepciones, pues, como se ha visto en las obras antes analizadas, Avendaño sentía predilección por las composiciones en horizontal. Como señala Gianfranco Buno (1981a, p. 38), el dibujo en esta obra es de una sutilidad corotiana, acompañado de un color vibrante, plateado, de luz nocturna, como en el mejor Ravier. Es preciso recordar que Ravier y Fontanesi fueron un punto de referencia para la genovesa Escuela de los Grises. Se aprecia el predominio de los azules y grises profundos, en un delicado contraluz que incide sobre la luminosidad del cielo, surcada por las sutiles ramas de los árboles. El cielo aparece iluminado por una luz tenue, de gran fuerza emotiva. Se captan los efectos de la luna sobre el paisaje, estudiando así las luces y las sombras, y sobre las personas, que contemplan, sumidas en la oscuridad, el dominio naciente de esta. Se produce una gran intensidad de emociones. La madurez del artista se expresa en la obra a base de pocos tonos, infinitamente variados. Se recurre a una pincelada menuda e intensa.

Historia de la pieza: Estado de conservación: bueno. Fue restaurado por Gianfranco Bruno entre 1977 y 1978.

\section{Exposiciones:}

Exposición Nacional celebrada en Parma en 1870.

XXIX Exposición de la Società Promotrice di Belle Arti, celebrada en Turín en 1870.

Exposición celebrada en el Palacio Nacional de Brera, Milán, en 1871.

Pittura in Liguria tra '800 e '900, celebrada en el Salón de la Cassa de Risparmio de Génova en 1981.

La Scuola Grigia a Carcare, celebrada en la Villa Barrili de Carcare en 1989. Serafin Avendaño, 1837-1916, celebrada en Vigo en 1991.

\section{Catálogos:}

Bruno (1981b).

Bruno (1983), p. 38.

Serafin Avendaño, 1837-1916, 1991, p. 134.

Ottocento. Catalogo dell'Arte Italiana dell'Ottocento, n. ${ }^{\circ}$ 21, 1992, p. 111.

Bibliografia:

Bruno (1981a), pp. 38-39 y 158.

Bruno (1993), pp. 160-61.

Bruno y Perissinotti (1989), p. 64.

Dragone y Dragone Conti (1947), p. 142.

Rocchiero (1960).

Stella (1893). 


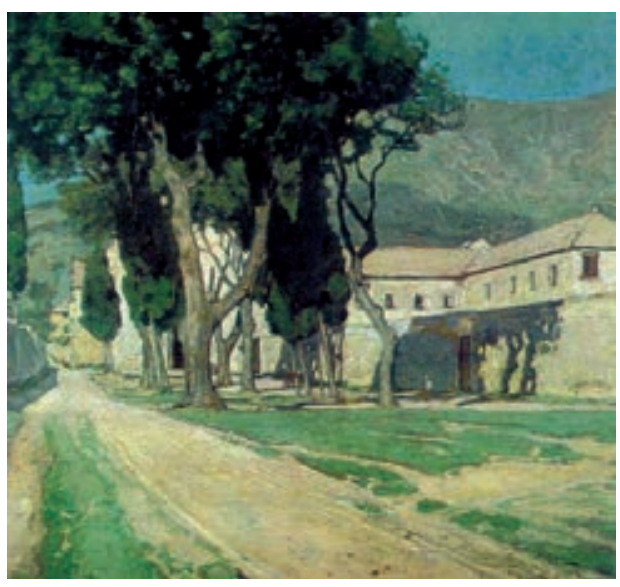

FichA CATALOGRÁFICA

N. ${ }^{\circ}$ orden: 32

Colección privada, Génova

Convento de Castaña, Serafín Avendaño, colección privada, Génova.

Autor-atribución. Título de la obra: Serafín Avendaño (Vigo, 1837-Valladolid, 1916): Convento de Castaña.

Estilo-cronología: Fechado en 1875.

Tipo de obra, material y técnica: Cuadro. Óleo sobre lienzo.

Dimensiones: $16 \times 17 \mathrm{~cm}$.

Elementos autógrafos: Firmado y datado en el margen inferior izquierdo: «S. Avendaño 1875».

Localización y procedencia: Génova, colección privada.

Procede de la colección del profesor Francesco S. Mosso, que fue presidente y comisario promotor de la Mostra di Pittura Ligure dell'Ottocento, celebrada en el Teatro Carlo Felice de Génova en 1926. Posteriormente pasó a formar parte de la colección de la familia Tiscornia Quattro, y actualmente pertenece a otro coleccionista de arte.

Descripción: La obra se titula Convento de Castaña, pues se representa el convento de esta localidad ligur. Sin embargo, como puede observarse, el edificio no es el protagonista de la composición, que aparece en el fondo, casi oculto por el arbolado, ya que aquello que verdaderamente interesa a Avendańo es el estudio del paisaje y los contrastes de luces y sombras. Así, en un primer plano, se abre un ancho camino que se adentra hacia el fondo de la composición, confiriéndole profundidad. Es una composición rigurosa, atenta al deta- 
lle. De ahí que Mario Labó (1926, p. 23) definiera a Avendaño, con motivo de la exposición celebrada en Génova en 1926, con las siguientes palabras: «dibujante minucioso e incisivo, se complace en los detalles». Se aprecia el empleo de una paleta luminosa y límpida, centrada en los efectos de la luz solar sobre los elementos compositivos. La perspectiva aérea está conseguida a través del vivo contraste de los colores. Es preciso señalar que en esta obra se constata una pincelada menuda e intensa, a diferencia de la empleada, por ejemplo, en otras obras como Campo de moreras (ficha n. ${ }^{\circ} 30$ ), en la que se recurre a una pincelada más densa.

Historia de la pieza: Estado de conservación: bueno.

Exposiciones:

XXXV Exposición de la Società Promotrice di Belle Arti, celebrada en Turín en 1876.

Pittura ligure del secolo XIX, celebrada en el Teatro Carlo Felice de Génova en 1926.

La Scuola Grigia a Carcare, celebrada en la Villa Barrili de Carcare en 1989. Maestri liguri tra il secolo XIX e XX, celebrada en la Galería de Arte Casa de Génova en 1989.

Serafin Avendaño, 1837-1916, celebrada en Vigo en 1991.

L'alba del vero, celebrada en la Accademia Ligustica di Belle Arti de Génova en 1993.

\section{Catálogos:}

Società Promotrice di Belle Arti (1876), p. 15.

Labó (1926), pp. 23 y 36.

Bruno (1983).

X Mostra Maestri liguri tra il secolo XIX e XX, 1989.

Serafin Avendaño, 1837-1916, 1991, p. 135.

Bibliografia:

Bruno (1993), p. 157.

Bruno y Perissinotti (1989), pp. 70-71.

Comanducci (1934), p. 181.

Dragone y Dragone Conti (1947), p. 142.

Labó (1976) p. 581.

Mallé (1976), p. 75.

Rocchiero (1960).

Somaré (1928), tab. 321. 
FICHA CATALOGRÁFICA

N. ${ }^{\circ}$ orden: 33

Colección privada, Génova

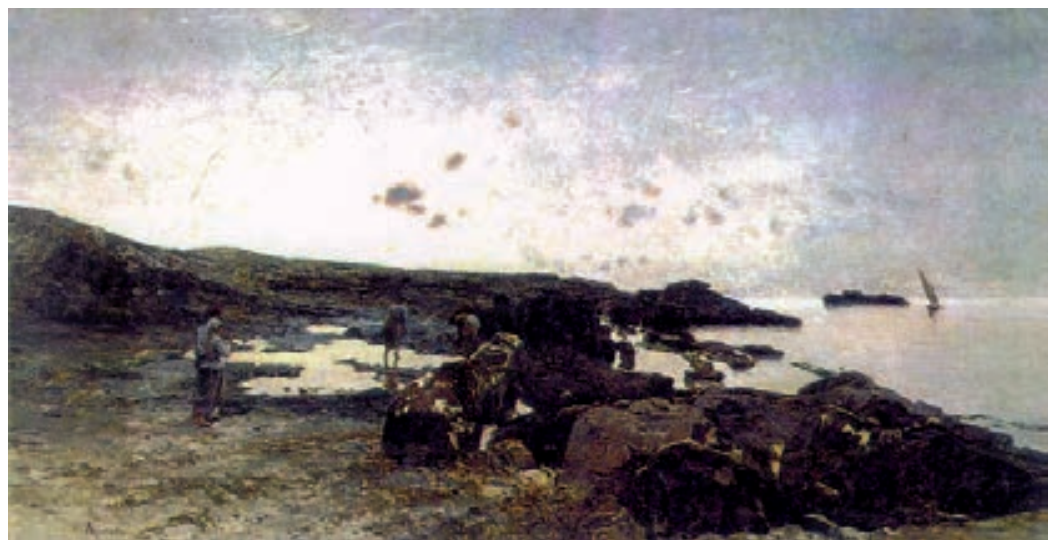

Escollera o Marina, Serafín Avendaño, colección privada, Génova.

Autor-atribución. Título de la obra: Serafín Avendaño (Vigo, 1837-Valladolid, 1916): Escollera o Marina.

Estilo-cronología: Datado en 1882.

Tipo de obra, material y técnica: Cuadro. Óleo sobre lienzo.

Dimensiones: $50 \times 97 \mathrm{~cm}$.

Elementos autógrafos: Firmado en el margen inferior izquierdo: «S. Avendaño».

Localización y procedencia: Génova, colección privada de V. E. Rota. Procede del Círculo Artístico Tunnel de Génova, que lo adquirió en la XXXI Exposición de la Società Promotrice di Belle Arti, celebrada en Génova en 1882, donde aparecía con el n. ${ }^{\circ} 104$. Es interesante señalar que esta obra figuró en dicha exposición como propiedad de la Società Promotrice y que después pasó a la colección donde se encuentra actualmente.

Descripción: Paisaje marino con figuras, de gran contenido poético, que responde al gusto del pintor por captar, en unión, el mar y la tierra. De hecho, se complementan, llegando incluso a fundirse, tal como sucedía en Ribera de 
Génova (ficha n. ${ }^{\circ}$ 24). Es una composición en horizontal, formada por diversos planos que dan sentido de profundidad. Se emplea una paleta luminosa, plateada, que permite captar los efectos de la luz sobre los elementos de la naturaleza, creando una atmósfera cálida y emotiva. Avendaño aprovecha las irregularidades de las rocas para crear bellos contrastes de luces y sombras.

Rosa E. Caamaño (1991, p. 13), en el catálogo de la exposición dedicado a Serafín Avendaño, destaca que Serafín es un pintor esencial ante todo, porque simplifica los planos de color, unidos por manchas de luminosidad atmosférica; con sensible fidelidad transcriptiva, entretejida de pinceladas menudas, intensas y vibrantes.

Historia de la pieza: Estado de conservación: bueno.

Exposiciones:

XXXI Exposición de la Società Promotrice di Belle Arti, celebrada en Génova en 1882.

Pittura ligure del secolo XIX, celebrada en el Teatro Carlo Felice de Génova en 1926.

La Scuola Grigia a Carcare, celebrada en la Villa Barrili de Carcare en 1989. Serafin Avendaño, 1837-1916, celebrada en Vigo en 1991.

L'alba del vero, celebrada en la Accademia Ligustica di Belle Arti de Génova en 1993.

Catálogos:

Bruno (1983), p. 38.

Serafin Avendaño, 1837-1916, 1991, p. 136.

Bibliografia:

Bruno (1981a), p. 39.

Bruno (1993), p.159.

Bruno y Perissinotti (1989), p. 69.

Labó (1976), p. 36.

Rocchiero (1960).

Rocchiero (1981).

Società Promotrice di Belle Arti in Genova (1882), p. 13.

Società Promotrice di Belle Arti in Genova (1883), p. 9. 
FICHA CATALOGRÁFICA

N. ${ }^{\circ}$ orden: 34

Colección privada, Génova

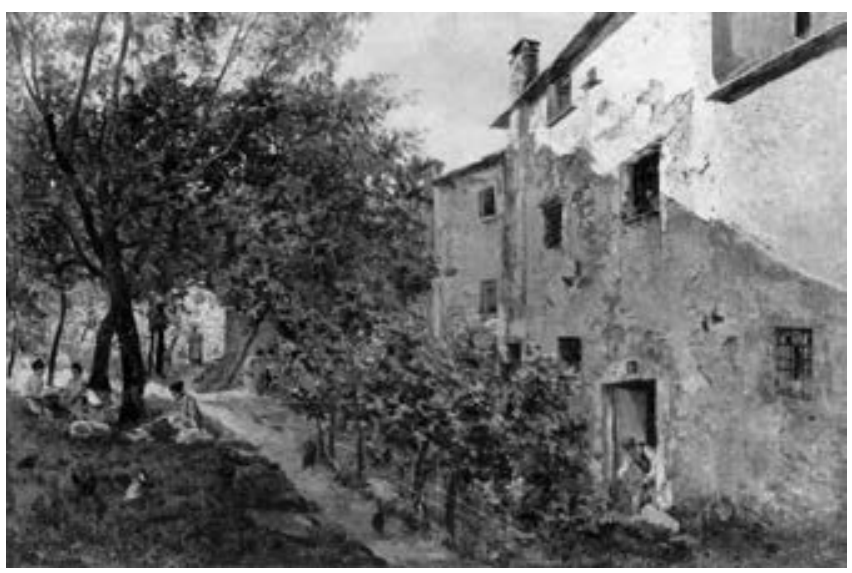

Paisaje ligur, Serafín Avendaño, colección privada, Génova.

Autor-atribución. Título de la obra: Serafín Avendaño (Vigo, 1837-Valladolid, 1916): Paisaje ligur.

Estilo-cronología: Fechado en el último cuarto del siglo XIX.

Tipo de obra, material y técnica: Cuadro. Óleo sobre lienzo.

Dimensiones: $45 \times 64 \mathrm{~cm}$.

Elementos autógrafos: Firmado en el margen inferior derecho con el monograma del artista: «S. A.».

Localización y procedencia: Génova, colección privada, propiedad de I. Mazzola.

Procede de la colección genovesa de Stefano Rebaudi, experto y crítico de arte. Después, pasó a la colección genovesa de F. Bandini y de aquí a la colección de I. Mazzola, donde se conserva actualmente.

Descripción: El pintor titula la obra Paisaje ligur y ofrece un paisaje rural típico de esta región italiana, que tantas veces fue tema inspirador de su obra. De hecho, Avendaño se aplicó al estudio en plein air, visitando los lugares más 
pintorescos, captando en la naturaleza aquello que le impresionaba. Ambienta la composición en un pueblo con casas y personas, que forman parte del paisaje, «humanizándolo» pero sin alterar su equilibrio natural. La composición en horizontal permite al pintor recoger esta visión de conjunto. Se ofrece un ambiente singular, captado en perspectiva. Se recurre a los característicos verdes suaves y grises delicados, en la línea de los grigi ('grises'), y se introducen toques de blanco y amarillo, que crean ricos contrastes de luces y sombras. La composición transmite frescura, alegría y, sobre todo, serenidad y emotividad. La pincelada es menuda, intensa, vibrante y vital. Como indica Rosa E. Caamaño (1991, p. 13), en el catálogo de la exposición dedicado a Avendaño, el pintor no abandona el dibujo compositivo de herencia espańola, y el valor tonal aparece siempre unido a un riguroso planteamiento.

Historia de la pieza: Estado de conservación: bueno.

Exposiciones:

Pittori liguri dell'Ottocento, celebrada en el Palazzo Rosso de Génova en 1938. Scuola Grigia genovese ed altri valori ottocenteschi, celebrada en el Palazzo

Cattaneo Mallone de Génova en 1961.

Serafin Avendaño, 1837-1916, celebrada en Vigo en 1991.

Catálogos:

Grosso (1938b), pp. 81-83.

Serafin Avendaño, 1837-1916, 1991, p. 136.

Bibliografia:

Rocchiero (1960).

Rocchiero (1963), p. 32.

Rocchiero (1981), p. 279. 


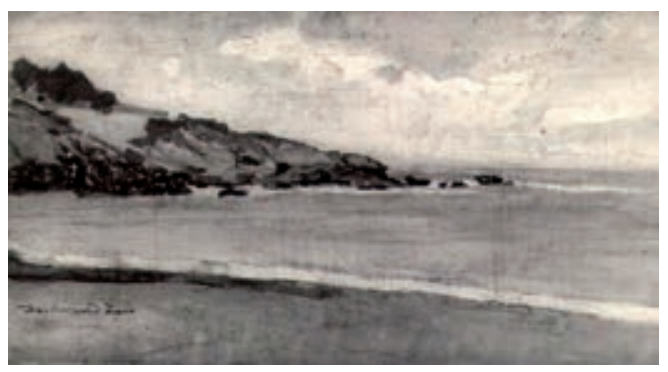

\section{FiCHA CATALOGRÁFICA}

N. ${ }^{\circ}$ orden: 35

Colección privada, Génova

Golfo de la ribera ligur,

Serafín Avendaño,

colección privada, Génova.

Autor-atribución. Titulo de la obra: Serafín Avendaño (Vigo, 1837-Valladolid, 1916): Golfo de la ribera ligur.

Estilo-cronología: Datado en el último cuarto del siglo XIX.

Tipo de obra, material y técnica: Cuadro. Óleo sobre lienzo.

Dimensiones: $12,5 \times 24 \mathrm{~cm}$.

Elementos autógrafos: Firmado en el margen inferior izquierdo: «Serafín Avendaño». Localización y procedencia: Génova, colección privada.

Procede de la colección privada del pintor genovés Andrea Figari (1858-1945).

Descripción: Se representa un aspecto de la riviera ligur, que responde a la predilección del pintor por los temas marinos, especialmente ligures. Destaca de nuevo la composición en horizontal, dominada por diagonales. La obra de Avendaño rinde tributo a la naturaleza, pues unifica, en armonía, la tierra, el mar y el cielo. La luz solar es el elemento unificador, que se refuerza con una pincelada precisa e intensa. Esta obra trasluce un mundo fresco y poético.

Historia de la pieza: Estado de conservación: bueno.

Exposiciones:

Scuola Grigia genovese ed altri valori ottocenteschi, celebrada en el Palazzo

Cattaneo Mallone de Génova en 1961.

Serafin Avendaño, 1837-1916, celebrada en Vigo en 1991.

Catálogos:

Serafin Avendaño, 1837-1916, 1991, p. 137.

Bibliografia:

Rocchiero (1960).

Rocchiero (1963), p. 32.

Rocchiero (1981), p. 94. 


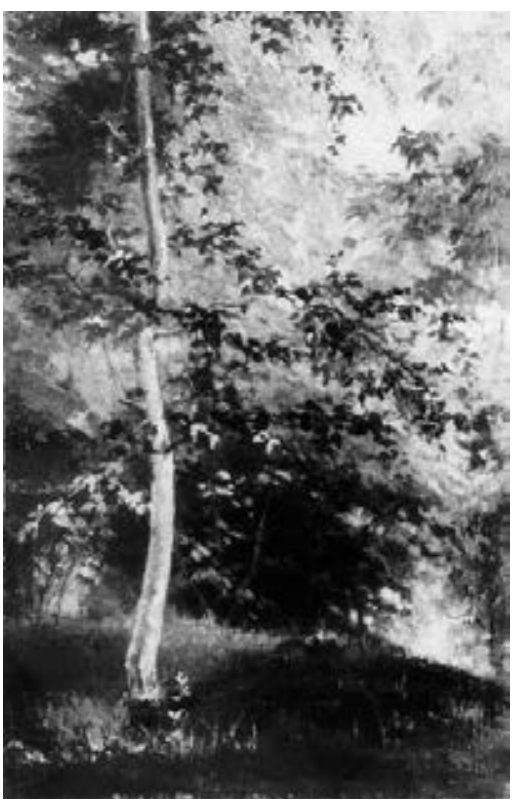

FICHA CATALOGRÁFICA

N. ${ }^{\circ}$ orden: 36

Colección privada, Génova

Árbol aislado y césped, Serafín Avendaño, colección privada, Génova.

Autor-atribución. Título de la obra: Serafín Avendaño (Vigo, 1837-Valladolid, 1916): Árbol aislado y césped.

Estilo-cronología: Datado en el último cuarto del siglo XIX.

Tipo de obra, material y técnica: Cuadro. Óleo sobre lienzo.

Dimensiones: $40 \times 26,5 \mathrm{~cm}$.

Localización y procedencia: Génova, colección privada.

Procede de la colección del experto de arte Giovanni Ravaschio de Génova. De aquí pasó a propiedad del abogado Elzo Colonna, para integrarse después en la colección donde actualmente se encuentra.

Descripción: El pintor se centra en un aspecto concreto de la naturaleza, interesándose, en este caso, por un árbol rodeado de césped. Como puede comprobarse, ofrece una vista cercana, atendiendo al detalle. Como señala Mario Labó (1926, p. 23), Serafín Avendaño fue preciso en la elección de los motivos, y también el más variado en la composición de los cuadros. Recurre a una paleta luminosa y solar, empleando una pincelada suelta, precisa y densa. Es una pintura de perfecta limpieza. 
Historia de la pieza: Estado de conservación: bueno.

Exposiciones:

Pittori liguri dell'Ottocento, celebrada en el Palazzo Rosso de Génova en 1938. Scuola Grigia genovesa ed altri valori ottocenteschi, celebrada en el Palazzo Cattaneo Mallone de Génova en 1963.

Fortune dell '800 pittorico, celebrada en el Palacio Cattaneo Mallone de Génova en 1964.

Serafin Avendaño, 1837-1916, celebrada en Vigo en 1991.

Catálogos:

Grosso (1938b), pp. 81-83.

Ravaschio (1964).

Serafin Avendaño, 1837-1916, 1991, p. 137.

Bibliografia:

Labó (1926), p. 23.

Rocchiero (1960).

Rocchiero (1963), p. 32.

Rocchiero (1981), p. 94. 


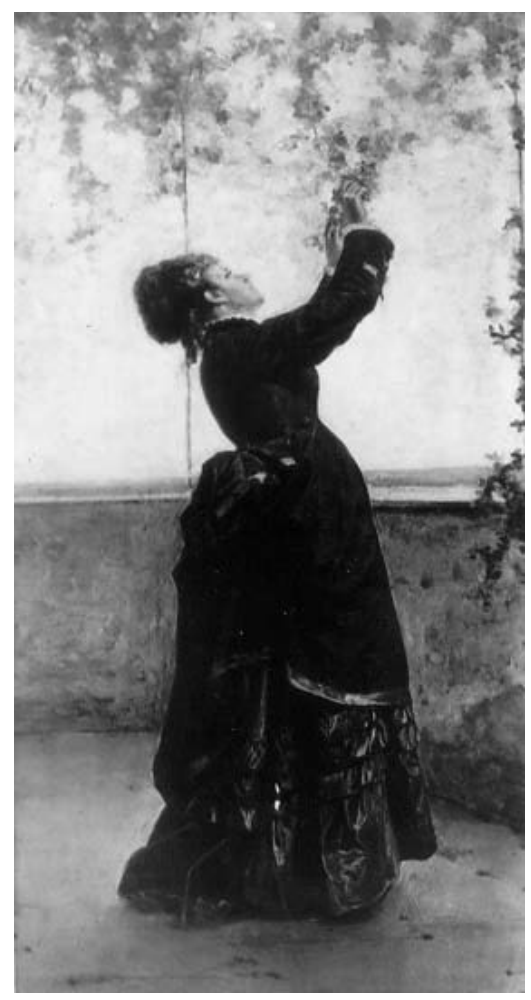

FICHA CATALOGRÁFICA

N. ${ }^{\circ}$ orden: 37

Colección privada, Génova
Retrato de Nina Salvago, Serafín Avendaño, colección privada, Génova.

Autor-atribución. Titulo de la obra: Serafín Avendaño (Vigo, 1837-Valladolid, 1916): Retrato de Nina Salvago.

Estilo-cronología: Fechado en el último cuarto del siglo XIX.

Tipo de obra, material y técnica: Cuadro. Óleo sobre lienzo.

Dimensiones: $100 \times 45 \mathrm{~cm}$.

Elementos autógrafos: Firmado en el margen inferior derecho.

Localización y procedencia: Génova, colección privada.

Procede de la colección de Tiscornia Quattro de Génova. En el catálogo de la exposición genovesa Pittura ligure dell'Ottocento (1926), realizado por M. Labó, aparece citado como propiedad de Gina Tiscornia Quattro. De esta colección pasó a la actual. 
Descripción: Como ya se ha indicado, Avendaño se estableció definitivamente en Génova en 1866, en concreto, en Quarto dei Mille, en casa de la marquesa Isabella Salvago (Nina), que aparece aquí representada. Esta señora abrió su casa a los artistas genoveses y extranjeros. De hecho, es posible que el pintor vigués conociera allí a Andrade, Rayper y Luxoro. Además, Nina Salvago fue alumna suya y participó en alguna exposición de pintura.

Se trata de un retrato que capta con naturalidad al personaje femenino. Es el único cuadro que tiene como protagonista a una figura humana, aunque la naturaleza también está presente en la composición. De hecho, se relacionan, pues la mujer acaricia las hojas de un árbol, que caen sobre ella con delicadeza. Serafín Avendaño no fue solo pintor de paisajes, sino que también concedió importancia en su producción pictórica a las figuras, que no alteran el equilibrio natural de la composición. Se advierte la elegancia de la postura femenina y la emotividad que emana de esta obra. El dibujo es de una gran sutilidad y la paleta es luminosa, aplicada con una pincelada de gran soltura.

Historia de la pieza: Estado de conservación: bueno.

\section{Exposiciones:}

Pittura ligure del secolo XIX, celebrada en el Teatro Carlo Felice de Génova en 1926.

Catálogos:

Labó (1926).

Piceni (1974).

Serafin Avendaño, 1837-1916, 1991, p. 136.

Bibliografia:

Rocchiero (1960). 


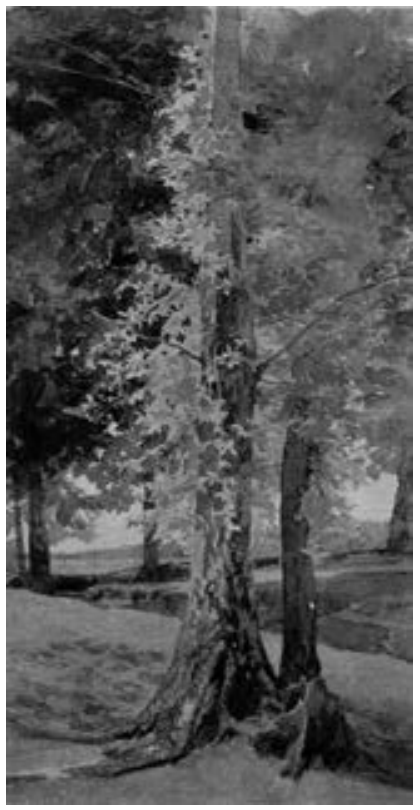

\author{
FICHA CATALOGRÁFICA \\ N. ${ }^{\circ}$ orden: 38 \\ Colección privada, Génova
}

Árboles, Serafín Avendaño, colección privada, Génova.

Autor-atribución. Título de la obra: Serafín Avendaño (Vigo, 1837-Valladolid, 1916): Árboles.

Estilo-cronología: Datado en el último cuarto del siglo XIX.

Tipo de obra, material y técnica: Cuadro. Acuarela sobre cartón.

Dimensiones: $20,5 \times 11 \mathrm{~cm}$.

Elementos autógrafos: Está firmado en el margen inferior derecho: «S. Avendaño». Localización y procedencia: Génova, colección privada.

En la exposición Pittori liguri dell'Ottocento, celebrada en Génova en 1938, esta obra figuró como propiedad de Bartolomeo Pellerano. Actualmente forma parte de otra colección privada.

Descripción: Se representan dos árboles, en un primer plano, que recuerdan la obra Árbol aislado y césped (ficha n. ${ }^{\circ}$ 36). Como puede constatarse, a diferencia de la mayoría de las obras hasta ahora estudiadas, aquí el pintor se decanta por la composición en vertical, que le permite profundizar en el estudio de este elemento de la naturaleza. Se recurre al empleo de verdes delicados y gri- 
ses plateados, que dan a la composición una sensación de frescor y alegría. Avendaño se aplicó al estudio en plein air, reproduciendo todo aquello que le impresionaba, plasmándolo a través del lenguaje de la macchia.

Historia de la pieza: Estado de conservación: bueno.

Exposiciones:

Pittori liguri dell'Ottocento, celebrada en el Palazzo Rosso de Génova en 1938. Pittori della Scuola di Rivara, celebrada en Turín en 1942.

Serafin Avendaño, 1837-1916, celebrada en Vigo en 1991.

Catálogos:

Grosso (1938b), p. 81.

Bernardi (1942), p. 34.

Serafin Avendaño, 1837-1916, 1991, p. 138.

Bibliografia:

Bruno (1971).

Bruno (1981a), p. 160.

Rocchiero (1960). 


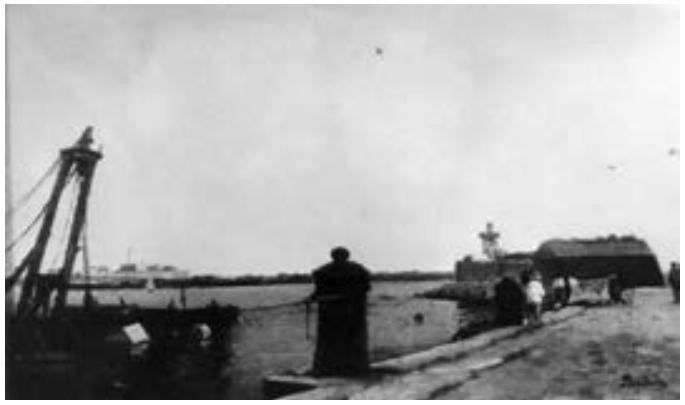

FICHA CATALOGRÁFICA

N. ${ }^{\circ}$ orden: 39

Colección privada,

Génova

Puerto de ribera, al norte de Vigo, Serafín Avendaño,

colección privada, Génova.

Autor-atribución. Título de la obra: Serafín Avendaño (Vigo, 1837-Valladolid, 1916): Puerto de ribera, al norte de Vigo.

Estilo-cronología: Está sin fechar, pero, según R. E. Caamaño (1991, p. 132), por el colorido oscuro parece de época temprana.

Tipo de obra, material y técnica: Cuadro. Óleo sobre lienzo.

Dimensiones: $24 \times 39 \mathrm{~cm}$.

Elementos autógrafos: Firmado en el margen inferior derecho: «S. Avendaño».

Localización y procedencia: Génova, colección privada.

Procede de la colección de Emilio y Luigi Parodi de Génova.

Descripción: Paisaje marino que presenta un puerto al norte de Vigo, ciudad natal de Avendaño. Esta obra responde a la predilección del pintor por la temática marina. Se trata de una composición en horizontal, que permite ofrecer, en perspectiva, una mayor visión de conjunto. Es preciso señalar que, a diferencia de las obras que recogen, con luminosidad y sentido poético, aspectos de las costas ligures, en esta obra se advierte una mayor frialdad en el tratamiento de los elementos componentes. Se recurre al empleo de los grises y azules (serios y profundos), y a un dibujo riguroso. Destaca la pincelada de gran soltura y densidad.

Historia de la pieza: Estado de conservación: bueno.

Exposiciones:

Serafin Avendaño, 1837-1916, celebrada en Vigo en 1991.

Catálogos:

Serafin Avendaño, 1837-1916, 1991, p. 132.

Bibliografia:

Bruno (1971).

Rocchiero (1960). 


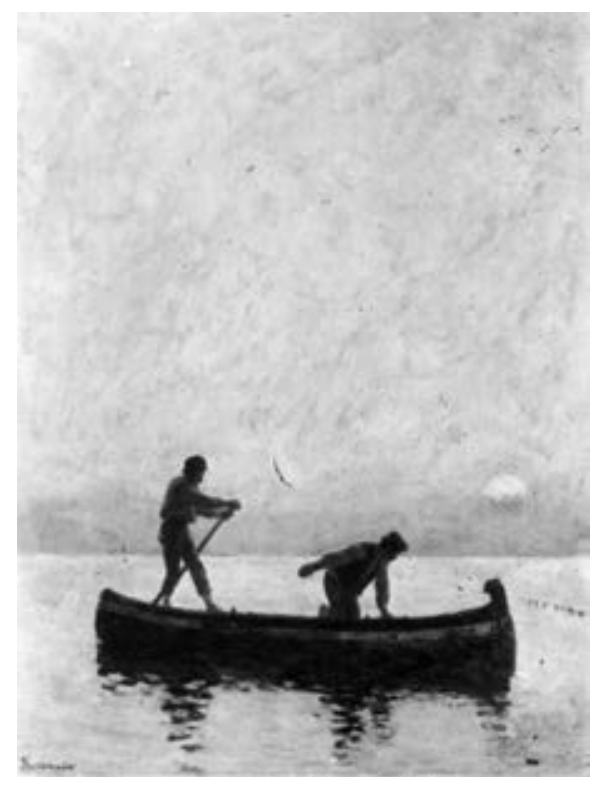

\section{FICHA CATALOGRÁFICA}

N. ${ }^{\circ}$ orden: 40

Colección privada, Génova

Pescadores a contraluz, Serafín Avendaño, colección privada, Génova.

Autor-atribución. Título de la obra: Serafín Avendaño (Vigo, 1837-Valladolid, 1916): Pescadores a contraluz.

Estilo-cronología: No está fechado.

Tipo de obra, material y técnica: Cuadro. Óleo sobre lienzo.

Elementos autógrafos: Firmado en el margen inferior izquierdo: "Avendaño».

Localización y procedencia: Colección privada, Génova.

Hasta hace pocos años permaneció inédito en los fondos del Museo Luxoro de Génova-Nervi. Actualmente se encuentra en una colección privada.

Descripción: Es una composición en vertical de pequeñas dimensiones. Se representan dos pescadores en una sencilla barca, en plena faena marina. La composición se capta a contraluz y el pintor se deleita en el estudio de las luces y las sombras, que se ve reforzado por una pincelada suelta y densa. Destaca el amplio horizonte que se unifica con el mar, aunque se aprecia la línea que delimita a ambos. Se recurre a los colores grisáceos, esmaltados y luminosos, con toques de rosa anaranjado. Parece que está sin terminar, y, si se tiene en cuenta la técnica pictórica, podría considerarse de época temprana. 
Historia de la pieza: Estado de conservación: bueno.

Exposiciones:

Serafin Avendaño, 1837-1916, celebrada en Vigo en 1991.

Catálogos:

Serafin Avendaño, 1837-1916, 1991, p. 133.

Bibliografia:

Bruno (1971).

Rocchiero (1960). 
FICHA CATALOGRÁFICA

N. ${ }^{\circ}$ orden: 41

Colección privada, Génova

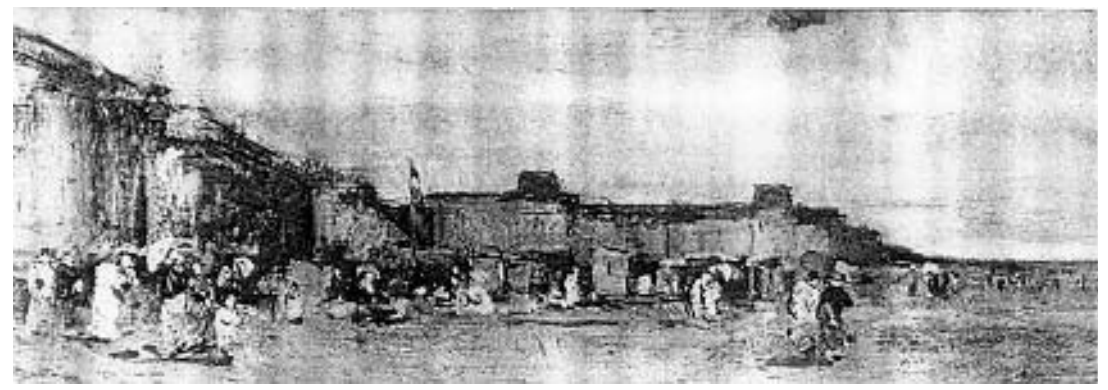

Domingo en la playa, Serafín Avendaño, colección privada, Génova.

Autor-atribución. Título de la obra: Serafín Avendaño (Vigo, 1837-Valladolid, 1916): Domingo en la playa.

Estilo-cronología: Datado en el último cuarto del siglo XIX.

Tipo de obra, material y técnica: Cuadro. Óleo sobre tabla.

Dimensiones: $11 \times 38 \mathrm{~cm}$.

Elementos autógrafos: Firmado en el margen inferior izquierdo.

Localización y procedencia: Génova, colección privada.

Procede de la colección del abogado Luigi Parodi de Génova, que fue presidente de la Società Promotrice di Belle Arti entre 1924 y 1926. Actualmente se encuentra en otra colección de la misma ciudad.

Descripción: Se representa un promontorio y las antiguas fortificaciones de Livorno. Es una composición en horizontal, que ofrece un instante de cómo era un domingo en la playa. Se aprecian varios planos compositivos; así, en un primer plano, se capta la vida cotidiana, ejemplificada en las personas que pasean por la playa; en un segundo plano, se levanta la fortificación de la ciudad; y, por último, se encuentra un amplio cielo. Es una pintura airosa, verídica y moderna.

Historia de la pieza: Estado de conservación: bueno. 
Exposiciones:

Serafín Avendaño, 1837-1916, celebrada en Vigo en 1991.

Catálogos:

Serafín Avendaño, 1837-1916, 1991, p. 135.

Bibliografia:

Bruno (1971).

Labó (1926), p. 23.

Rocchiero (1960). 


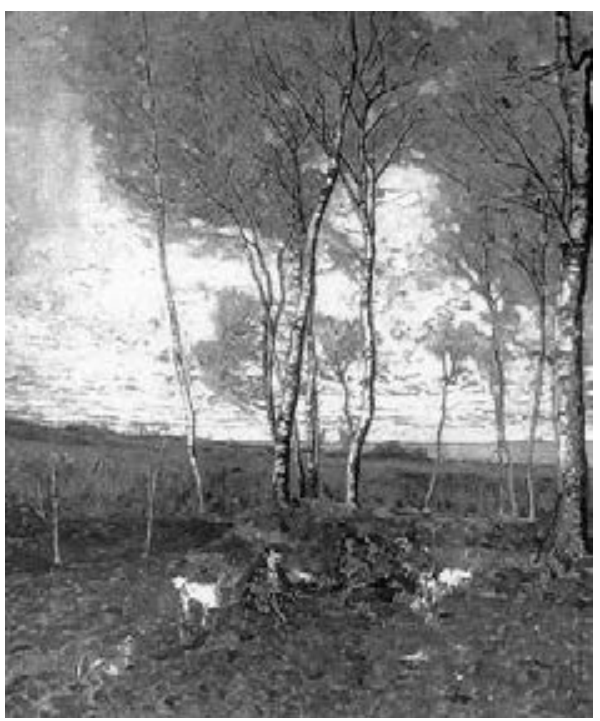

FICHA CATALOGRÁFICA

N. ${ }^{\circ}$ orden: 42

Colección privada, Génova
Cazadores en reposo, bajo los abedules, Serafín Avendaño,

colección privada, Génova.

Autor-atribución. Título de la obra: Serafín Avendaño (Vigo, 1837-Valladolid, 1916): Cazadores en reposo, bajo los abedules.

Estilo-cronología: Datado hacia 1872.

Tipo de obra, material y técnica: Cuadro. Óleo sobre lienzo.

Dimensiones: $120 \times 100 \mathrm{~cm}$.

Elementos autógrafos: Firmado en el margen inferior izquierdo.

Localización y procedencia: Génova, colección privada de Vitaliano Rocchiero.

Procede del estudio del pintor, donde fue comprado por el marchante de arte Gallino, de Génova, y más tarde fue adquirido por el genovés Orlando Grosso, quien lo regaló a su alumno, el profesor V. Rocchiero.

Descripción: Se trata de un tema cinegético, que presenta a unos cazadores descansando bajo unos abedules. La obra está dotada de un gran sentido de profundidad, en la que aflora el lenguaje de la macchia ('mancha'), característico del período genovés. De hecho, las figuras se funden con el paisaje, dominado por la pincelada suelta y densa. V. Rocchiero considera que se trata de una obra non finita, es decir, sin acabar. Se aprecia la predilección del pintor por los verdes densos y los grises delicados y profundos. 
Historia de la pieza: Estado de conservación: bueno.

Exposiciones:

Serafin Avendaño, 1837-1916, celebrada en Vigo en 1991.

Catálogos:

Piceni (1969).

Serafin Avendaño, 1837-1916, 1991, p. 136.

Bibliografia:

Bruno (1971).

Rocchiero (1960).

Rocchiero (1981). 


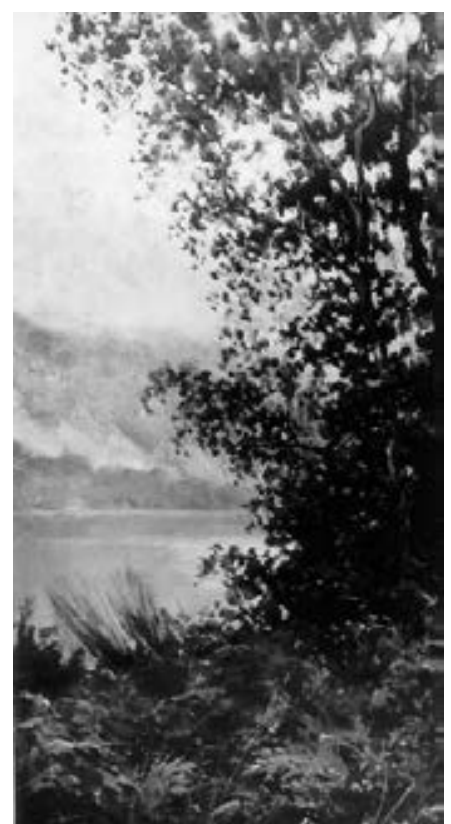

FICHA CATALOGRÁFICA

N. ${ }^{\circ}$ orden: 43

Colección privada, Génova

Paisaje marino con promontorio, Serafín Avendaño, colección privada, Génova.

Autor-atribución. Título de la obra: Serafín Avendaño (Vigo, 1837-Valladolid, 1916): Paisaje marino con promontorio.

Estilo-cronología: Datado por el profesor Vitaliano Rocchiero entre 1887 y 1888.

Tipo de obra, material y técnica: Cuadro. Óleo sobre tabla.

Dimensiones: $55 \times 30 \mathrm{~cm}$.

Elementos autógrafos: Firmado en el margen inferior izquierdo.

Localización y procedencia: Génova, colección privada.

Proviene de la colección del abogado Luigi Parodi; actualmente se encuentra en otra colección de Génova.

Descripción: Presenta composición en vertical, que permite al pintor ofrecer una vista singular de este paisaje. De hecho, se captan, en distintos planos en profundidad, la tierra, el mar y el cielo, dando así una visión unificadora de la naturaleza. La obra refleja el sentimiento poético que inspira toda la producción pictórica de Avendaño. Como señalaba su amigo Calderini (1901, p. 146), 
Avendaño huía del arte "compuesto» y, para él, el arte consistía en reproducir aquello que llamaba la atención del pintor, fuera por el efecto de luz o por la belleza de un lugar; y, para obtener esto, era necesario dejar tal y como eran los árboles, las piedras, los animales, las sombras, etc. Este paisaje se caracteriza por una paleta luminosa que realza los verdes suaves y los amarillos, con algunas pinceladas gruesas, esmaltadas, descubriendo una sensibilidad especial $\mathrm{y}$ un gusto sutil.

Historia de la pieza: Estado de conservación: bueno.

Exposiciones:

Serafin Avendaño, 1837-1916, celebrada en Vigo en 1991.

Catálogos:

Serafín Avendaño, 1837-1916, 1991, p. 137.

Bibliografia:

Bruno (1971).

Calderini (1901), p. 146.

Rocchiero (1960), pp. 17-20. 


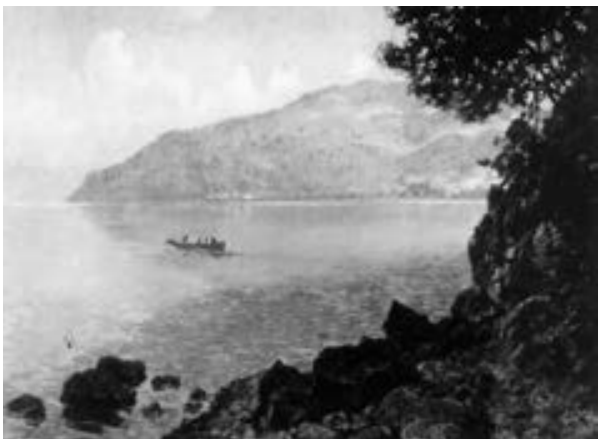

\section{FICHA CATALOGRÁFICA}

N. ${ }^{\circ}$ orden: 44

Colección privada,

Génova

Marina con pino, Serafín Avendaño, colección privada, Génova.

Autor-atribución. Título de la obra: Serafín Avendaño (Vigo, 1837-Valladolid, 1916): Marina con pino.

Estilo-cronología: Datado en el último cuarto del siglo XIX.

Tipo de obra, material y técnica: Cuadro. Óleo sobre lienzo.

Dimensiones: $50 \times 66 \mathrm{~cm}$.

Elementos autógrafos: Firmado en el margen inferior izquierdo: «S. Avendaño». Localización y procedencia: Génova, colección privada.

Proviene de la colección genovesa de Emilio y Luigi Parodi.

Descripción: La composición en horizontal permite al pintor captar la tierra, representada por las rocas, en un primer plano; el mar, en un plano intermedio; y el cielo, que aparece al fondo. Este tipo de composición es característico en la producción pictórica de Avendaño. Es una pintura sencilla, resuelta a base de diagonales, natural, luminosa y vital. Destacan los magníficos efectos de la luz sobre las superficies, reforzados por la pincelada de gran soltura, y la interacción lograda entre la luz y el color.

Historia de la pieza: Estado de conservación: bueno.

Exposiciones:

Serafin Avendaño, 1837-1916, celebrada en Vigo en 1991.

Catálogos:

Serafin Avendaño, 1837-1916, 1991, p. 137.

Bibliografia:

Bruno (1971).

Marini (1986).

Rocchiero (1960). 


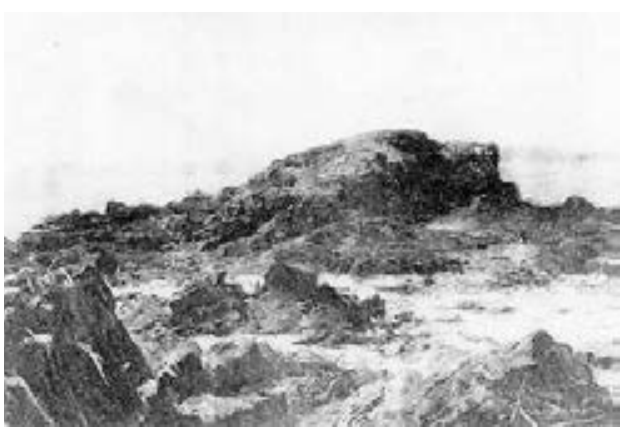

\author{
FICHA CATALOGRÁFICA \\ N. ${ }^{\circ}$ orden: 45 \\ Colección privada, Génova
}

Autor-atribución. Título de la obra: Atribuido a Serafín Avendaño (Vigo, 1837-Valladolid, 1916): Escollera marina.

Estilo-cronología: Fechado en el último cuarto del siglo XIX.

Tipo de obra, material y técnica: Cuadro. Óleo sobre tabla.

Dimensiones: $22,5 \times 35 \mathrm{~cm}$.

Elementos autógrafos: Firmado en el margen inferior derecho: «Avendaño».

Localización y procedencia: Génova, colección privada.

Procede de la colección de Gerolamo Vasallo de Sampierdarena (Génova).

Descripción: La composición tiene como protagonistas a las rocas marinas, tema bastante cultivado por el pintor (fichas n..$^{\circ} 24$ y n. ${ }^{\circ} 33$ ). Se reproducen con fidelidad a la naturaleza. Avendaño se deleita en los detalles, de ahí que saque el mayor provecho a las irregularidades de las rocas, con el fin de conseguir ricos contrastes de luces y sombras. Recurre a una paleta basada en grises y azules, con toques de blanco, que confieren a la obra una luminosidad especial. La pincelada se caracteriza por su gran soltura.

Historia de la pieza: Estado de conservación: bueno.

Exposiciones:

Serafin Avendaño, 1837-1916, celebrada en Vigo en 1991.

Catálogos:

Serafin Avendaño, 1837-1916, 1991, p. 137.

Bibliografia:

Bruno (1971).

Rocchiero (1960). 


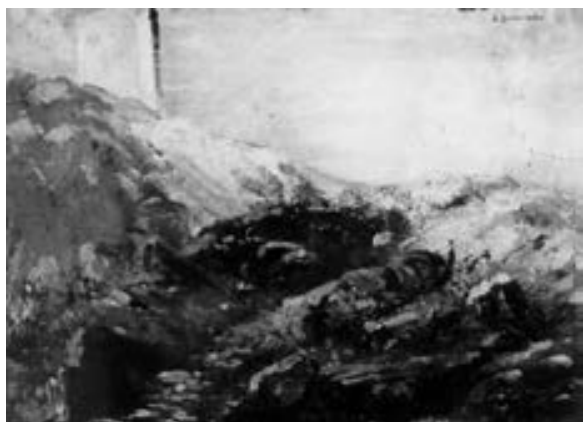

\author{
FICHA CATALOGRÁFICA \\ N. ${ }^{\circ}$ orden: 46 \\ Colección privada, Génova
}

Valle montañés, Serafín Avendaño, colección privada, Génova.

Autor-atribución. Título de la obra: Serafín Avendaño (Vigo, 1837-Valladolid, 1916): Valle montañés.

Estilo-cronología: Datado en el último cuarto del siglo XIX.

Tipo de obra, material y técnica: Cuadro. Óleo sobre papel pegado a cartón.

Dimensiones: $22,5 \times 28,5 \mathrm{~cm}$.

Elementos autógrafos: Firmado en el margen superior izquierdo: «S. Avendaño». Localización y procedencia: Génova, colección privada.

Procede de la colección de Gerolamo Vasallo de Sampierdarena (Génova).

Descripción: Se representa un aspecto de la naturaleza, en concreto una vista bastante cercana de un valle de montańa. Destaca el empleo de una pincelada densa y de gran soltura, aplicada con decisión, consiguiendo cualidades táctiles. Se recurre, como en obras anteriores, a colores locales, como es el caso de los verdes y grises, con toques de blanco, que confieren a la obra una luminosidad especial.

Historia de la pieza: Estado de conservación: bueno.

Exposiciones:

Tessere minori e maggiori del "mosaico" pittorico ligure fra 1850 e 1950, celebrada en el Centro d'Arte la Maddalena de Génova en 1990.

Serafin Avendaño, 1837-1916, celebrada en Vigo en 1991.

Catálogos:

Rocchiero (1990).

Serafin Avendaño, 1837-1916, 1991, p. 138.

Bibliografia:

Bruno (1971).

Rocchiero (1960). 


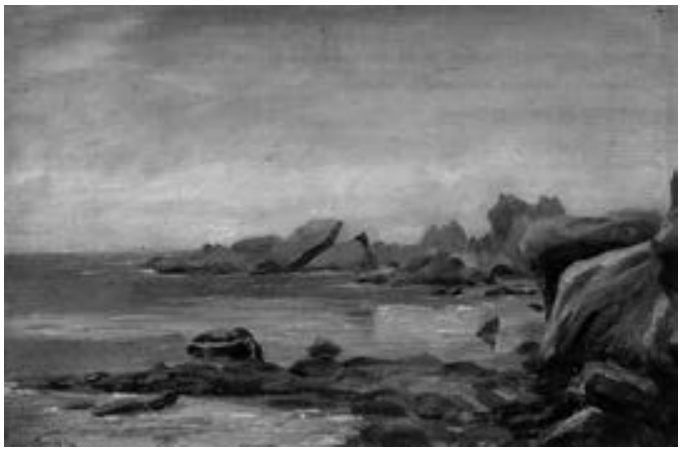

FICHA CATALOGRÁFICA

N. ${ }^{\circ}$ orden: 47

Colección privada,

Génova

Marina con promontorio de escollera, Serafín Avendaño, colección privada, Génova.

Autor-atribución. Título de la obra: Serafín Avendaño (Vigo, 1837-Valladolid, 1916): Marina con promontorio de escollera.

Estilo-cronología: Fechado en el último cuarto del siglo XIX.

Tipo de obra, material y técnica: Cuadro. Óleo sobre tabla.

Dimensiones: $20 \times 30 \mathrm{~cm}$.

Elementos autógrafos: Firmado en el margen inferior izquierdo: «S. Avendaño». Localización y procedencia: Génova, colección privada.

Descripción: Paisaje marino con escollera. Como puede comprobarse, el pintor recurre a la composición en horizontal, permitiéndole ofrecer así una visión de conjunto. De hecho, aparecen la tierra, el mar y el cielo, formando un todo. Los verdes son densos, los grises cálidos y profundos y los azules finos, con algún toque de rojo y de blanco.

El profesor V. Rocchiero opina que este paisaje presenta más semejanzas con el paisaje marino español que con el italiano a causa de su relieve abrupto. De hecho, se aprecia una menor luminosidad que en las composiciones con temática marina ligur.

Historia de la pieza: Estado de conservación: bueno.

Bibliografia:

Bruno (1971).

Rocchiero (1960). 


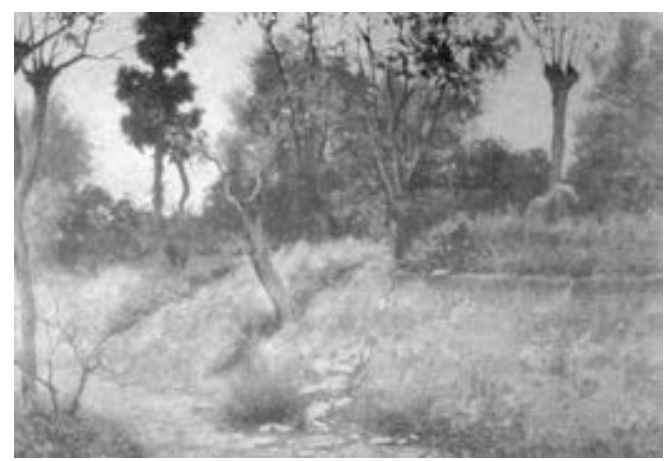

FICHA CATALOGRÁFICA

N. ${ }^{\circ}$ orden: 48

Colección privada, Génova

Colinas piamontesas con figura femenina, Serafín Avendaño,

Autor-atribución. Titulo de la obra: Serafín Avendaño (Vigo, 1837-Valladolid, 1916): Colinas piamontesas con figura femenina.

Estilo-cronología: Datado en el último cuarto del siglo XIX.

Tipo de obra, material y técnica: Cuadro. Óleo sobre lienzo.

Dimensiones: $48 \times 68 \mathrm{~cm}$.

Elementos autógrafos: Firmado en el margen inferior izquierdo.

Localización y procedencia: Génova, colección privada.

Procede de la colección del abogado L. Parodi de Génova.

Descripción: Esta escena está ambientada en el campo. Se trata de una composición en horizontal, captada en perspectiva, reforzada, a su vez, por el camino que se adentra hacia el fondo. En el montículo aparece, esbozada, una figura femenina en descanso. Destaca la luminosidad que emana de la composición, transmitiendo sensación de serenidad.

Historia de la pieza: Estado de conservación: bueno.

Exposiciones:

Una collezione di dipinti dell'Ottocento ligure, celebrada en la Galería Clemente de Génova en 1985.

Catálogos:

Rocchiero (1985).

Serafin Avendaño, 1837-1916, 1991, p. 139.

Bibliografia:

Rocchiero (1960). 


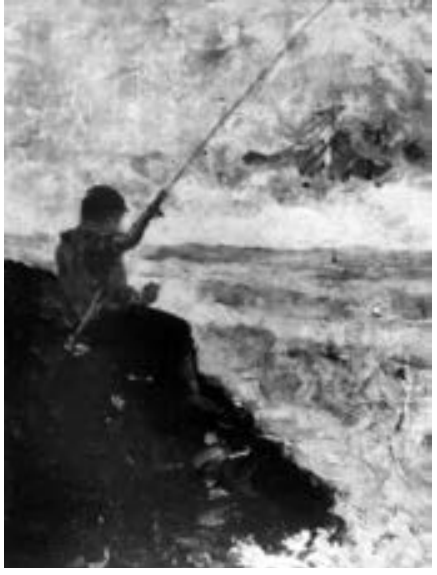

FICHA CATALOGRÁFICA

N. ${ }^{\circ}$ orden: 49

Colección privada, Génova

Pescador con caña sobre el escollo, Serafín Avendaño, colección privada, Génova.

Autor-atribución. Título de la obra: Atribuido a Serafín Avendaño (Vigo, 1837-Valladolid, 1916): Pescador con caña sobre el escollo.

Este cuadro fue atribuido en 1972 por Alessandro Ruta a Serafín Avendaño.

Estilo-cronología: Datado en el último cuarto del siglo XIX.

Tipo de obra, material y técnica: Cuadro. Óleo sobre lienzo.

Dimensiones: $21 \times 17 \mathrm{~cm}$.

Localización y procedencia: Génova, colección privada.

Procede de la colección de Alessandro Ruta de Génova.

Descripción: Paisaje marino con figura. Es una composición en vertical que presenta, a la izquierda, un pescador con cańa sobre un escollo, y, a la derecha, el mar y el cielo. Como puede comprobarse, en esta obra aflora el lenguaje de la macchia, a base de pinceladas cortas y densas, aplicadas con gran soltura. La pincelada actúa como elemento unificador de la composición, es decir, es difícil encontrar un límite entre los diferentes elementos de la naturaleza. Mediante la pincelada picuda y decidida se consigue captar la agitación de las olas, algo inusual en la producción pictórica de Avendaño, que, por lo general, transmite serenidad y sosiego. Se recurre a una paleta luminosa, que acentúa los contrastes de claros y oscuros.

Historia de la pieza: Estado de conservación: bueno.

Bibliografía:

Rocchiero (1960). 


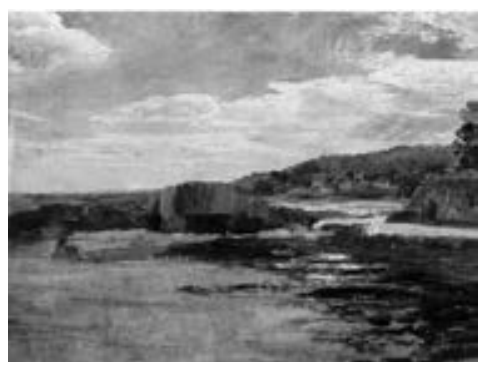

\author{
FiCHA CATALOGRÁFICA \\ N. ${ }^{\circ}$ orden: 50 \\ Colección privada, Génova
}

Costa marítima franco-ibérica, Serafín Avendaño, colección privada, Génova.

Autor-atribución. Título de la obra: Serafín Avendaño (Vigo, 1837-Valladolid, 1916): Costa maritima franco-ibérica.

Estilo-cronología: Datado en 1913.

Tipo de obra, material y técnica: Cuadro. Óleo sobre lienzo aplicado a cartón.

Dimensiones: $29 \times 39 \mathrm{~cm}$.

Elementos autógrafos: Firmado y datado en el margen inferior izquierdo: «S. Avendaño 1913».

Localización y procedencia: Génova, colección privada.

Proviene de una colección privada de Bordighera (Imperia).

Para Vitaliano Rocchiero (1991, p. 139) se trata de una de las últimas obras de Serafín Avendaño. Fue adquirido por un valor de 15000000 de liras.

Descripción: Se representa un paisaje marino. Se ofrece, en horizontal, una amplia visión que integra el mar, la tierra y el cielo. En el mundo marino, Avendaño despliega su más fina paleta de azules, y en la representación de la tierra recurre a la gama de los verdes y marrones. Se aprecian también los toques de blanco, que confieren a la composición una gran fuerza expresiva. De hecho, se emplea una pincelada amplia, densa, que adquiere valores táctiles.

Historia de la pieza: Estado de conservación: bueno.

Exposiciones:

Serafin Avendaño, 1837-1916, celebrada en Vigo en 1991.

Catálogos:

Serafin Avendaño, 1837-1916, 1991, p. 139.

Bibliografia:

Bruno (1971).

Marini (1986).

Rocchiero (1960). 


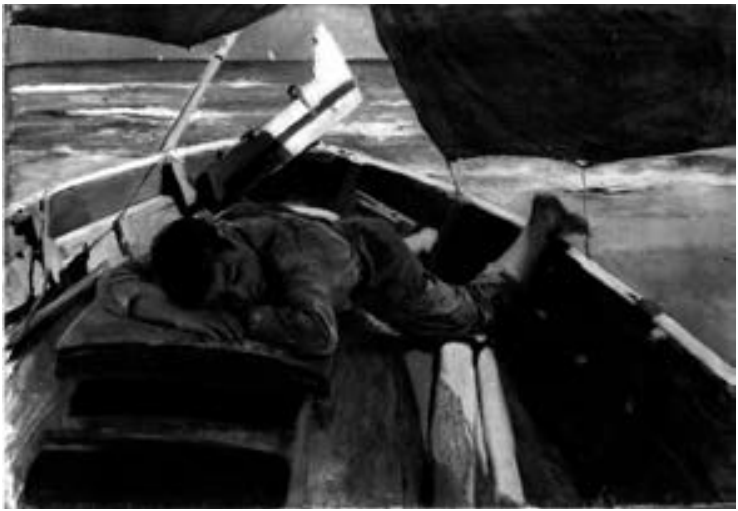

FICHA CATALOGRÁFICA

N. ${ }^{\circ}$ orden: 51

Colección Frugone, Génova-Nervi

Sueñecito en barca, Joaquín Sorolla y Bastida, colección Frugone, Génova-Nervi.

Autor-atribución. Título de la obra: Joaquín Sorolla y Bastida (Valencia, 1863Cercedillo, Madrid, 1923): Sueñecito en barca.

Estilo-cronología: Datado en 1896. Esta obra correspondería al período de formación del pintor.

Tipo de obra, material y técnica: Cuadro. Óleo sobre lienzo.

Dimensiones: $45,5 \times 66,5 \mathrm{~cm}$.

Elementos autógrafos: Firmado y datado en el margen inferior derecho (en la barca): «J. Sorolla y Bastida 1896».

Localización y procedencia: Génova-Nervi, colección Frugone de Villa Grimaldi Fassio, en la sala n. ${ }^{\circ}$ 8, dedicada a la pintura extranjera.

La obra procede de la colección de Luigi Frugone, y, tras su fallecimiento, en 1953, pasa por donación al municipio de Génova.

Descripción: Se representa un paisaje marino, que tiene como motivo principal el sueño sereno de un muchacho en una barca. Se capta, en un primer plano, parte de la barca y al muchacho, y, al fondo, el mar. Esta obra es testimonio tanto de la inclinación del pintor por los temas marinos y la pintura sencilla, natural, directa, fresca y vital, como de la tendencia hacia el realismo y la pintura al aire libre. Se advierte un especial interés por el efecto de la luz, que constituye el leitmotiv de su obra. De este modo, recurre a una paleta luminosa a base de colores amarillos y blancos, aplicados con una pincelada resuelta y segura. Se consigue complementar la luz solar y el color, y plasmar también el aire, ese ambiente que existe entre objeto y espectador. 
Historia de la pieza: Estado de conservación: excelente.

Noticias documentales inéditas: Inv. G. A. M. 1590.

Exposiciones:

Exposición de las colecciones Frugone, celebrada en el Palazzo Bianco de Génova en 1938.

Exposición de la colección Luigi Frugone, celebrada en Villa Grimaldi Fassio de Génova-Nervi en 1984.

Catálogos:

Frabetti (1984).

Bibliografía:

Giubilei (1993).

Grosso (1938a), p. 24.

Pantorba (1953).

Pons-Sorolla (1993).

Santos Torrecilla y Casado (1983).

Somaré (1936). 


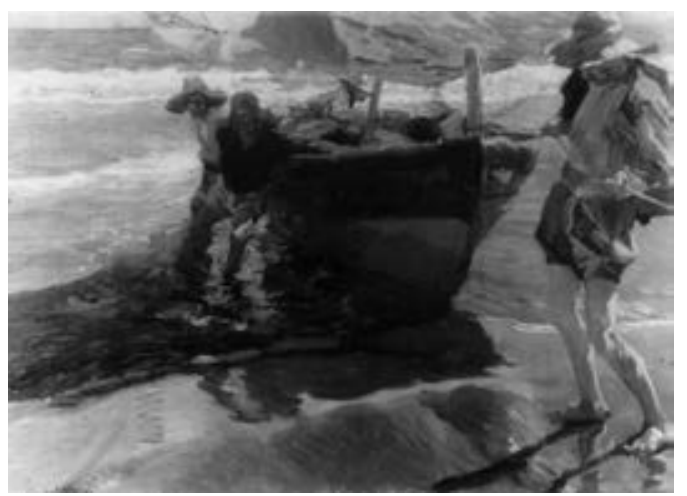

FICHA CATALOGRÁFICA

N. ${ }^{\circ}$ orden: 52

Colección Frugone,

Génova-Nervi
La vuelta de la pesca, Joaquín Sorolla y Bastida, colección Frugone, Génova-Nervi.

Autor-atribución. Título de la obra: Joaquín Sorolla y Bastida (Valencia, 1863Cercedillo, Madrid, 1923): La vuelta de la pesca.

Estilo-cronología: Fechado en 1904. Esta obra pertenecería al período de formación del pintor.

Tipo de obra, material y técnica: Cuadro. Óleo sobre lienzo.

Dimensiones: $75,3 \times 105 \mathrm{~cm}$.

Elementos autógrafos: Firmado y datado en el margen inferior izquierdo: «J. Sorolla y Bastida 1904».

Localización y procedencia: Génova-Nervi, colección Frugone de Villa Grimaldi Fassio, en la sala n. ${ }^{\circ}$ 8, dedicada a la pintura extranjera.

Procede de la colección de Luigi Frugone, y tras su muerte, en 1953, pasa por donación al municipio de Génova.

Descripción: Representa a cuatro pescadores que regresan de su jornada de trabajo, dentro de la predilección del pintor por los temas marinos. El pintor ofrece, con la sensualidad que le caracterizaba, la belleza y la vida del mundo que le rodeaba. Se trata de una magnífica composición en perspectiva, que capta a los pescadores en un primer plano, pues son los verdaderos protagonistas de la obra. Se emplea una paleta luminosa y clara, aplicada con una pincelada segura y densa. Destacan los efectos producidos por la luz sobre los elementos compositivos, dando lugar a ricos contrastes de luces y sombras.

Este tema fue cultivado por Sorolla en otras de sus obras, como es el caso de La vuelta de la pesca de 1894, conservada en el Museo de Luxemburgo, y de Fin de la jornada de 1900. 
Historia de la pieza: Estado de conservación: excelente.

Noticias documentales inéditas: Inv. G. A. M. 1589.

Exposiciones:

Exposición de las colecciones Frugone, celebrada en el Palazzo Bianco de Génova en 1938.

Exposición de la colección Luigi Frugone, celebrada en Villa Grimaldi Fassio de Génova-Nervi en 1984.

Catálogos:

Frabetti (1984).

Bibliografía:

Giubilei (1993).

Grosso (1938a), p. 24.

Pantorba (1953).

Pons-Sorolla (1993), pp. 87-98.

Santos Torrecilla y Casado (1983).

Somaré (1936). 



\section{Catálogo II LA PINTURA ESPAÑOLA EN EL RESTO DE LIGURIA}





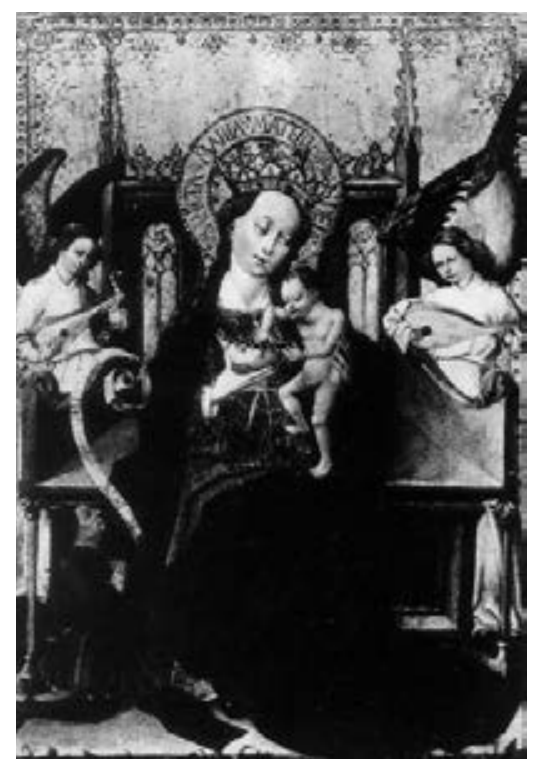

FICHA CATALOGRÁFICA

N. ${ }^{\circ}$ orden: 53

Museo Civico Amedeo Lia, La Spezia

Virgen entronizada con el Niño, ángeles músicos y donante, atribuido a un anónimo español, Museo Civico Amedeo Lia, La Spezia.

Autor-atribución. Titulo de la obra: Atribuido a un anónimo español: Virgen entronizada con el Niño, ángeles músicos y donante.

Federico Zeri (Zeri y De Marchi, 1997, pp. 394-395) considera que podría tratarse de una obra perteneciente a un artista originario de la costa oriental de España, que se instaló en Italia, tomando elementos de la cultura lombarda y piamontesa.

En mi opinión, la tabla Lia se relaciona, desde un punto de vista estilístico, con la pintura alemana de la segunda mitad del siglo XV, en la que se constatan influencias de la pintura flamenca.

Estilo-cronología: Zeri (Zeri y De Marchi, 1997, p. 395) establece su cronología en la segunda mitad del siglo XV, hacia 1450 .

Tipo de obra, material y técnica: Cuadro. Óleo sobre tabla.

Dimensiones: $58 \times 40 \mathrm{~cm}$.

Elementos autógrafos: No está firmada.

Localización y procedencia: La Spezia (Liguria), Museo Civico Amedeo Lia, sala V.

Procede de la colección de Marcello Massarenti de Roma. En 1902 fue adquirida, junto con toda la colección de este coleccionista, por Henry Wal- 
ters, quien la vendió en febrero de 1922. Más tarde, Amedeo Lia, fundador del Museo Amedeo Lia, la adquirió a través de un anticuario italiano, quien la había comprado en Nueva York.

Descripción: La tabla es de gran calidad y representa a la Virgen sentada en un trono ricamente decorado, flanqueado por dos ángeles músicos, que ofrece al Niño una cesta con cerezas, símbolo de la Encarnación de Cristo. A sus pies, en dimensiones más reducidas, está arrodillado el donante, del que parte una inscripción, que se lee de modo fragmentario: "AT... D... E... MEI», es decir, Mater Dei Memento Mei. Presenta un elaborado fondo dorado.

Historia de la pieza: Estado de conservación: excelente.

Noticias documentales inéditas: Inv. 74.

Catálogos:

Catalogue du Musée de peinture, sculpture et archéologie au Palais Accoramboni, 1897, n.o 45.

Zeri y De Marchi (1997), pp. 394-395.

Bibliografia:

Châtelet y Recht (1988).

Walters (¿1909?), n. ${ }^{\circ} 736$. 


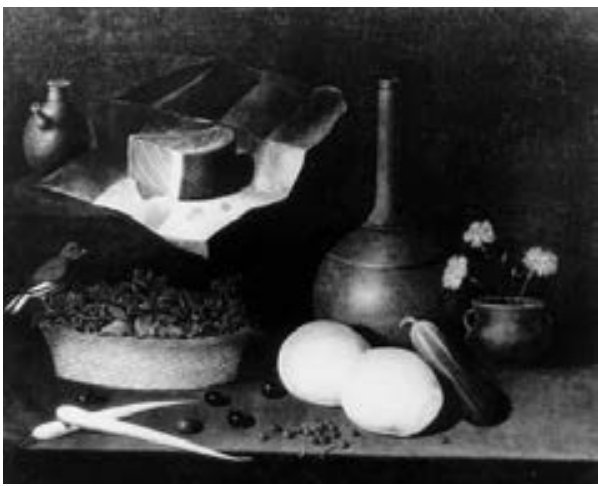

\section{FICHA CATALOGRÁFICA}

N. ${ }^{\circ}$ orden: 54

Museo Civico Amedeo Lia, La Spezia

Naturaleza muerta, atribuido a un anónimo español, Museo Civico Amedeo Lia, La Spezia.

Autor-atribución. Título de la obra: Atribuido a un anónimo español: Naturaleza muerta.

A. G. De Marchi (Zeri y De Marchi, 1997, p. 396) considera que la tipología de esta naturaleza muerta es española. Si bien no es posible dar un nombre concreto, opina que podría estar en relación con la producción de Moriel, y, desde un punto de vista compositivo, con los modelos de Juan van der Hamen. Precisamente a este último fue atribuida cuando se expuso en la muestra Maestros flamencos y holandeses, que tuvo lugar en Milán en 1973.

En mi opinión, esta obra está en la línea de las del pintor madrileño Juan van der Hamen (1596-1631) o de algún seguidor suyo.

Estilo-cronología: Federico Zeri (Zeri y De Marchi, 1997, p. 396) establece su cronología entre el segundo y tercer cuarto del siglo XVII.

Tipo de obra, material y técnica: Cuadro. Óleo sobre lienzo.

Dimensiones: $58 \times 72 \mathrm{~cm}$.

Elementos autógrafos: No está firmado.

Localización y procedencia: La Spezia (Liguria), Museo Civico Amedeo Lia, sala XIII.

Procede de la colección de Amedeo Lia, quien lo donó a la ciudad de La Spezia en 1997.

Descripción: La composición de este cuadro, con los objetos dispuestos en dos planos, está relacionada con los modelos de bodegón español del siglo XVII. Así, se representan hortalizas, tres jarrones, uno de ellos con claveles, y tam- 
bién un pájaro sobre un cesto. Cabe destacar la simplicidad compositiva, la importancia concedida al volumen y el rico contraste de luces y sombras.

Historia de la pieza: Estado de conservación: excelente.

Noticias documentales inéditas: Inv. 233.

Exposiciones:

Maestros flamencos y holandeses, celebrada en una galería de Milán en 1973.

Catálogos:

Maestros flamencos y holandeses, 1973.

Pintura española de bodegones y floreros de 1600 a Goya, 1984.

La belleza de lo real, 1995.

Zeri y De Marchi (1997), p. 396.

Bibliografia:

Angulo Iñíguez (1977), pp. 24-30.

Camón Aznar (1985), pp. 202-218.

Pérez Sánchez (1992). 


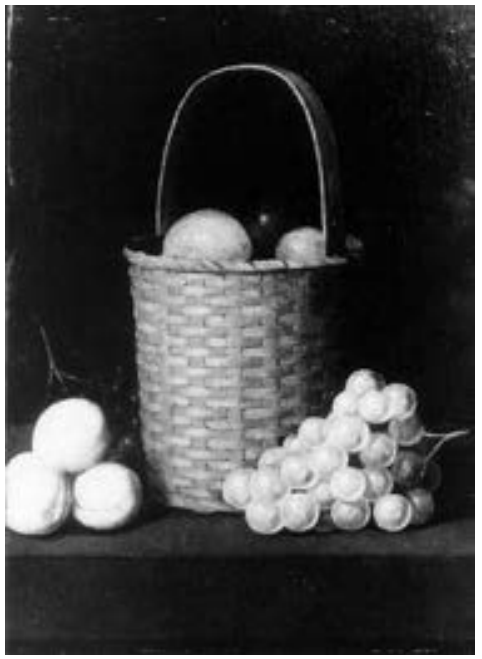

\author{
FICHA CATALOGRÁFICA \\ N. ${ }^{\circ}$ orden: 55 \\ Museo Civico Amedeo Lia, La Spezia
}

Naturaleza muerta con cesto y fruta,

atribuido a un anónimo español,

Museo Civico Amedeo Lia, La Spezia.

Autor-atribución. Título de la obra: Atribuido a un anónimo español: Naturaleza muerta con cesto y fruta.

Federico Zeri (Zeri y De Marchi, 1997, p. 395) atribuye esta obra a un anónimo español, aunque opina que no es posible formular ninguna hipótesis atributiva.

En mi opinión, se encontraría en la misma línea que la obra anterior (ficha n. ${ }^{\circ}$ 54), es decir, recuerda a las producciones de Juan van der Hamen (1596-1631) o de algún bodegonista de su entorno artístico.

Estilo-cronología: Datado en el siglo XVII.

Tipo de obra, material y técnica: Cuadro. Óleo sobre lienzo.

Dimensiones: $38 \times 28 \mathrm{~cm}$.

Elementos autógrafos: No está firmado.

Localización y procedencia: La Spezia (Liguria), Museo Civico Amedeo Lia, sala XIII.

Procede de la colección de Amedeo Lia, quien lo donó a la ciudad de La Spezia en 1997.

Descripción: Se trata de una composición simétrica, que presenta una cesta con fruta, a cuyos lados se disponen más piezas de fruta: melocotones y un racimo de uvas. Es una composición de gran belleza y simplicidad, que podría 
recordar a los bodegones de Juan Bautista de Espinosa. Destacan los ricos contrastes de luces y sombras, que confieren cualidades volumétricas a los elementos compositivos.

Historia de la pieza: Estado de conservación: excelente.

Noticias documentales inéditas: Inv. 289.

Catálogos:

Maestros flamencos y holandeses, 1973.

Pintura española de bodegones y floreros de 1600 a Goya, 1984.

La belleza de lo real, 1995.

Zeri y De Marchi (1997), p. 396.

Bibliografia:

Angulo Iñíguez (1977), pp. 24-30.

Camón Aznar (1985), pp. 202-218.

Pérez Sánchez (1992). 


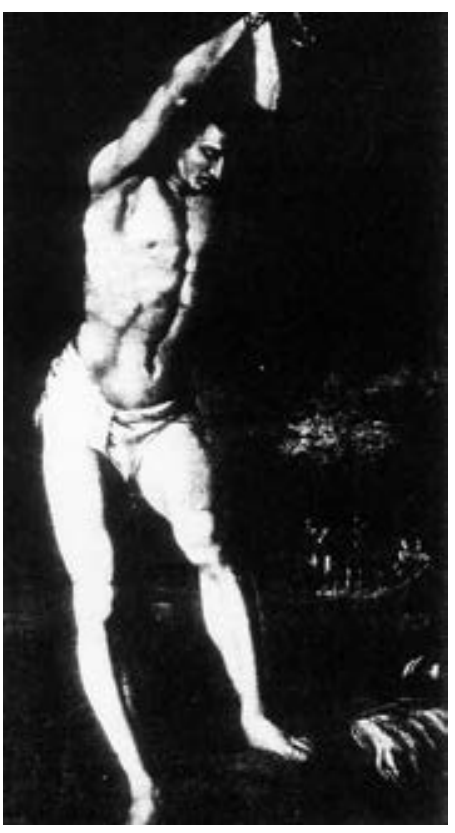

Ficha CATALOGRÁFICA

N. ${ }^{\circ}$ orden: 56

Oratorio dei Rossi, Gavi Ligure
San Sebastián, atribuido a escuela española, Oratorio dei Rossi, Gavi Ligure.

Autor-atribución. Título de la obra: Atribuido a escuela española: San Sebastián.

Giovanni Meriana (Meriana y Manzitti, 1975, p. 80) señala que las condiciones de conservación del cuadro no son buenas, lo que dificulta su correcta lectura e interpretación. A pesar de estos inconvenientes, piensa que se trata de una obra de escuela española.

En mi opinión, el modelo de santo podría recordar las figuras de Cristo de Alonso Cano, como, por ejemplo, Cristo atado a la columna (1646-1650), conservado en el Museo Nacional Rumano de Bucarest. Y el tratamiento del paisaje, los contrastes de luces y sombras, y el realismo crudo nos podrían llevar a colocarlo en la línea de Ribera.

Estilo-cronología: Meriana (Meriana y Manzitti, 1975, p. 80) fija su cronología en la primera mitad del siglo XVII.

Tipo de obra, material y técnica: Cuadro. Óleo sobre lienzo.

Dimensiones: $161 \times 82 \mathrm{~cm}$.

Localización y procedencia: Gavi Ligure, Oratorio dei Rossi, presbiterio.

Procedencia desconocida. 
Descripción: Se representa a san Sebastián después de sufrir el martirio. Sebastián era un joven militar romano que por profesar la fe cristiana fue perseguido y martirizado. Se le representa atado, casi desnudo, con los brazos en alto, y atravesado por flechas. De ahí que las flechas sean el símbolo de su martirio y pasara a convertirse en santo protector, junto a san Roque, contra la peste. Como puede verse, el santo aparece en un primer plano de la composición, y al fondo se abre un paisaje. Destaca la representación natural del cuerpo del santo, el rico contraste de luces y sombras, y el empleo de colores oscuros, con algún toque de blanco.

Historia de la pieza: Estado de conservación: normal.

Bibliografia:

Angulo Iñíguez (1977).

Biblioteca Sanctorum, 1967, vol. XI, pp. 776-801.

Guida d'Italia. Liguria, 1982, p. 297.

Itinerari di Italia Nostra, 1995, p. 30.

Meriana y Manzitti (1975), pp. 80-81.

Wethey ([1955] 1983), p. 116. 


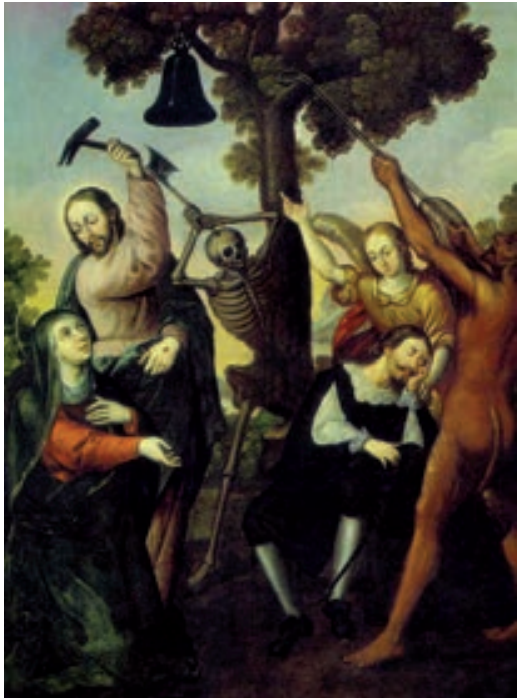

\section{FICHA CATALOGRÁFICA}

N. ${ }^{\circ}$ orden: 57

Iglesia de Santo Stefano, Chiusanico (Imperia)
Alegoría de la muerte, atribuido a un seguidor o al taller de Ignacio de Ries,

iglesia de Santo Stefano, Chiusanico (Imperia).

Autor-atribución. Título de la obra: Atribuido a un seguidor o al taller de Ignacio de Ries: Alegoría de la muerte.

Alessandro Giacobbe (1995, p. 130) atribuye esta obra a un seguidor de Ignacio de Ries por la relación que presenta, desde el punto de vista temático y estilístico, con la Alegoría del árbol de la vida de Ignacio de Ries conservada en la catedral de Segovia.

Respecto a Ries, se cree que debió de ser oriundo del norte de Alemania o flamenco. Se estableció en Espańa y se relacionó con los pintores sevillanos.

Estilo-cronología: Giacobbe (1995, p. 130) establece su cronología a mediados del siglo XVII, en función de la obra de la catedral de Segovia, fechada en 1653 .

Tipo de obra, material y técnica: Cuadro. Óleo sobre lienzo.

Dimensiones: $160 \times 115 \mathrm{~cm}$.

Localización y procedencia: Chiusanico (Imperia), iglesia de Santo Stefano, presbiterio.

Giacobbe (1995, p. 130) considera que forma parte del grupo de cuadros conservados en la iglesia de Santo Stefano de Chiusanico: Virgen de Guadalu- 
pe, Dolorosa, Virgen de Guadalupe e Inmaculada Concepción, de procedencia española, probablemente sevillana.

Se desconocen las vías de llegada, pero es posible que se encontraran en la iglesia antes de la reconstrucción de esta, entre 1824 y 1834. Giacobbe (1995, p. 131), basándose en las relaciones comerciales que existieron entre el sur de España (especialmente, Sevilla y Cádiz) y Liguria durante los siglos XVII y XVIII, indica que posiblemente estos cuadros llegaron desde Sevilla, que era el punto clave del comercio con América.

Descripción: Se trata el tema del árbol de la vida, relacionado con la cultura simbólica de la época, alusiva a la transitoriedad de la vida y a las veleidades de la condición humana, de las que hay que dar cuenta a la hora de la muerte. Se representa el árbol de la vida, en el eje de la composición, que está siendo talado por un esqueleto, que simbolizaría la Muerte. A un lado del árbol aparece un hombre, entre un ángel y un diablo (que tira fuertemente de una soga anudada a la copa del árbol, ayudando así a la caída de este), que se disputan su alma; y, en el otro lado, se encuentra Cristo, que tañe una campana con un martillo, que determinará la salvación eterna, y la Virgen, que actúa como intercesora de los hombres. De este modo, el tronco del árbol se transforma en el eje central de una balanza bien-mal (Cristo y Diablo). Se aprecia la atención al detalle, como se constata en la macabra anatomía de la Muerte o en la puntilla de la camisa del pecador. De hecho, fueron algunos elementos de la vestimenta, como la puntilla que adorna la camisa, los que contribuyeron a la datación de la obra en el siglo XVII. Giacobbe (1995, p. 131) advierte que este realismo difiere del componente nórdico de la cultura del pintor, y que la relación con Ries se advierte al representar tipos humanos muy semejantes, rígidos, pero suavizados en sus rasgos físicos. Asimismo, en esta obra no se han representado algunos de los elementos iconográficos y simbólicos presentes en la de Ries, como es el caso del grupo de personajes en la copa del árbol que parecen celebrar un banquete o las inscripciones situadas en la parte superior de la composición, que sirven de complemento y aclaración a la imagen. Destacan la rica gama cromática y los contrastes de luces y sombras. Por tanto, se trata de una obra alegórica de clara intención moralizante.

Historia de la pieza: Estado de conservación: excelente. Fue restaurado entre 1993 y 1994 por la sociedad Nicola Restauri de Aramengo (Piamonte). El director de los trabajos fue Franco Boggero. 
Bibliografia:

Bauerreis (1938).

Cook (1974).

Dufour-Kowalska (1985).

Giacobbe (1992).

Giacobbe (1995).

Lapostolle (1991).

Levi (1984).

Navarrete Prieto (1998), p. 249.

Rudolf (1957).

Saxl (1942), pp. 96-97.

Sebastián López (1981).

Steingner (1985).

Valdivieso (1986), pp. 191-92.

Veca (1981).

Vertova (1992). 


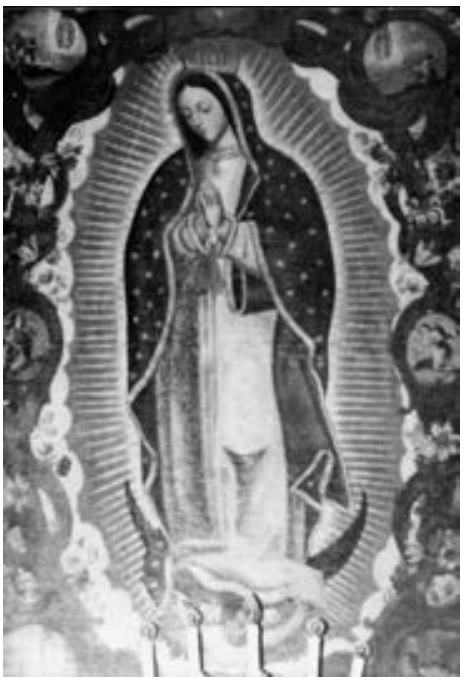

FICHA CATALOGRÁFICA

N. ${ }^{\circ}$ orden: 58

Iglesia de Santo Stefano, Chiusanico (Imperia)
Virgen de Guadalupe, procedencia española, iglesia de Santo Stefano, Chiusanico (Imperia).

Autor-atribución. Titulo de la obra: De procedencia española: Virgen de Guadalupe.

Alessandro Giacobbe (1992, p. 130) señala su procedencia española, probablemente sevillana.

Estilo-cronología: L. L. Calzamiglia (1902, p. 105) establece su cronología entre 1750 y 1777, atendiendo a que en la obra aparece representada la ciudad de México con su nueva basílica de 1709.

Tipo de obra, material y técnica: Cuadro. Óleo sobre lienzo.

Dimensiones: $200,7 \times 132 \mathrm{~cm}$.

Elementos autógrafos: No está firmada.

Localización y procedencia: Chiusanico (Imperia), en la iglesia de Santo Stefano, colocada en la pared izquierda del presbiterio de la iglesia.

Giacobbe (1995, p. 130) considera que esta obra forma parte del grupo de cuadros conservados en la parroquia de Chiusanico: Alegoría de la muerte, Dolorosa, Virgen de Guadalupe e Inmaculada Concepción, considerados de procedencia española.

Se desconocen las vías de llegada de estas telas «mexicanas», como las denomina Calzamiglia, a dicha parroquia. 
Giacobbe (1995, p. 131), basándose en la relaciones comerciales que existieron entre el sur de España (especialmente, Sevilla y Cádiz) y Liguria durante los siglos XVII y XVIII, indica que posiblemente estos cuadros llegaron desde Sevilla.

Según la tradición oral, estos cuadros proceden de España, y fueron donados por la familia Ghersi de Chiusanico (memoria oral transmitida por Mons. Fiorenzo Gerini de Albenga).

Descripción: La imagen de la Virgen de Guadalupe, desde el punto de vista iconográfico, deriva de la del Apocalipsis. De ahí que la Virgen aparezca sobre una media luna, sustentada por un ángel, y rodeada por una aureola luminosa. En los márgenes de la composición se encuentran las escenas relativas a la aparición de la Virgen al indio Juan Diego. Destaca la decoración floral alrededor de la Virgen, que embellece la obra. Se aprecia que la piel de la Virgen es morena, y su vestimenta presenta los colores marianos de la tradición: rosado para la túnica y azul para el manto. Se advierten también las cintas negras sobre su pecho, que simbolizarían, según la costumbre azteca, la próxima maternidad de la Virgen. Asimismo, se representa el Espíritu Santo, en forma de paloma, que refuerza la idea de la maternidad. A los pies de la Virgen se muestra una panorámica de la ciudad de México.

Historia de la pieza: Estado de conservación: bueno.

Bibliografia:

Calzamiglia (1992).

Giacobbe (1992).

Giacobbe (1995), p. 130.

Levi (1984).

Maza (1959), p. 12.

Perfetti (1987).

Sebastián López (1990), pp. 165-166.

Sebastián López, Mesa Figueroa y Gisbert de Mesa (1985), pp. 511-514.

Vargas Ugarte (1956), pp. 163-191. 


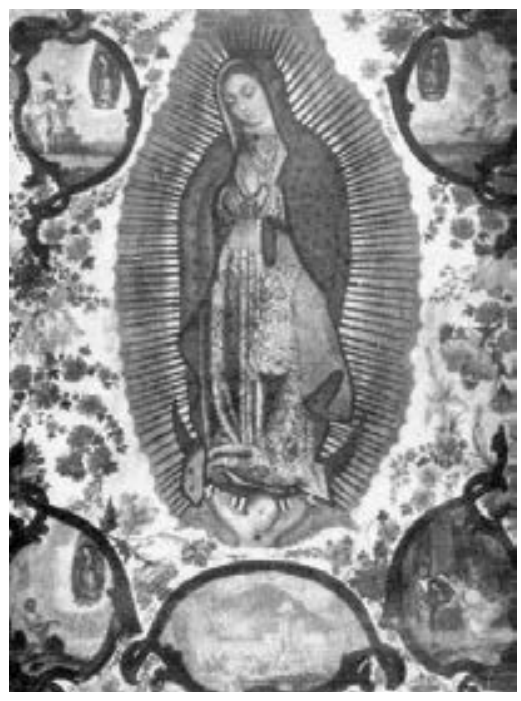

FICHA CATALOGRÁFICA

N. ${ }^{\circ}$ orden: 59

Iglesia de Santo Stefano, Chiusanico (Imperia)
Virgen de Guadalupe, procedencia española, iglesia de Santo Stefano, Chiusanico (Imperia).

Autor-atribución. Título de la obra: De procedencia española: Virgen de Guadalupe.

Alessandro Giacobbe (1995, p. 130) indica su procedencia española, probablemente sevillana.

Es una copia de la Virgen de Guadalupe, de menores dimensiones (ficha n. $\left.{ }^{\circ} 58\right)$.

Estilo-cronología: Datado por Calzamiglia (1992, p. 105) entre 1750 y 1777.

Tipo de obra, material y técnica: Cuadro. Óleo sobre lienzo.

Dimensiones: $104 \times 82 \mathrm{~cm}$.

Elementos autógrafos: No está firmado.

Localización y procedencia: Chiusanico (Imperia), iglesia de Santo Stefano, sacristía de la iglesia.

Giacobbe considera que esta obra forma parte del grupo de cuadros conservados en la iglesia de Santo Stefano de Chiusanico: Alegoria de la muerte, Virgen de Guadalupe, Dolorosa e Inmaculada Concepción.

Se desconocen las vías de llegada de estas telas «mexicanas», como las denomina L. L. Calzamiglia, a la parroquia de Chiusanico. 
La tradición oral indica que los cuadros de la sacristía proceden de Espańa y que fueron donados por la familia Ghersi de Chiusanico a la iglesia (memoria oral transmitida por Mons. Fiorenzo Gerini).

A pesar de las lagunas documentales, lo que no se pone en duda es su procedencia española, probablemente sevillana.

Descripción: Esta obra se encuentra, desde el punto de vista iconográfico, en la línea de la anterior (ficha.$^{\circ}$ 58). Pero, a diferencia de aquella, presenta unas dimensiones más reducidas, e incluye el monograma del nombre de Jesús (IHS), con una cruz, a la altura de las manos de la Virgen. Se advierte, también, una decoración más abundante a base de marcos de rocalla.

Historia de la pieza: Estado de conservación: bueno.

Bibliografía:

Calzamiglia (1992).

Giacobbe (1992).

Giacobbe (1995), p. 130.

Levi (1984).

Maza (1959), p. 12.

Perfetti (1987).

Sebastián López (1990), pp. 165-166.

Sebastián López, Mesa Figueroa y Gisbert de Mesa (1985), pp. 511-514.

Vargas Ugarte (1956), pp. 163-191. 


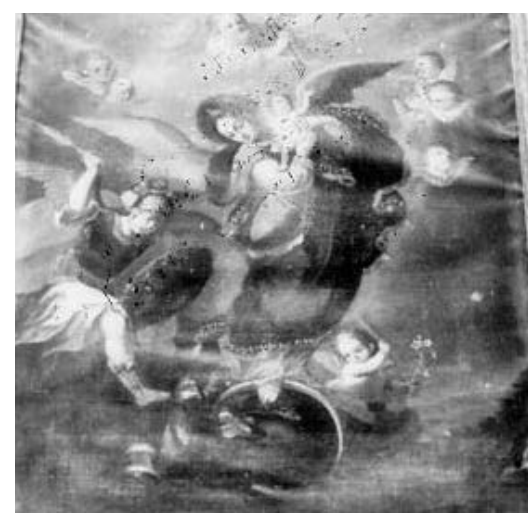

\section{FICHA CATALOGRÁFICA}

N. ${ }^{\circ}$ orden: 60

Iglesia de Santo Stefano, Chiusanico (Imperia)

Inmaculada, Luis Mena, iglesia de Santo Stefano, Chiusanico (Imperia).

Autor-atribución. Titulo de la obra: Luis Mena: Inmaculada.

El estudio llevado a cabo por Nicola Serrato permitió revelar la firma del autor: «Luis Mena». Para Alessandro Giacobbe (1992, p. 124) se trata de un pintor desconocido, pero evidentemente espańol y probablemente sevillano.

Estilo-cronología: Datado entre la segunda mitad del siglo XVII y principios del XVIII.

Tipo de obra, material y técnica: Cuadro. Óleo sobre lienzo.

Dimensiones: $110 \times 120 \mathrm{~cm}$.

Elementos autógrafos: Se aprecia la firma "Luis Mena», en el margen inferior derecho de la composición.

Localización y procedencia: Chiusanico (Imperia), iglesia de Santo Stefano, sacristía de la iglesia.

Para Giacobbe esta obra forma parte del conjunto de cuadros conservados en la iglesia de Chiusanico: Alegoría de la muerte, Virgen de Guadalupe, Dolorosa y Virgen de Guadalupe, de procedencia española.

Se desconoce en qué época y cómo llegó a Chiusanico, y se admite su procedencia española, posiblemente sevillana.

La tradición oral recoge que los cuadros colocados en la sacristía proceden de España, y que fueron donados por la familia Ghersi de Chiusanico a la iglesia (memoria oral transmitida por Mons. Fiorenzo Gerini de Albenga).

Descripción: La obra se titula Inmaculada por la relación que guarda, desde el punto de vista iconográfico, con la Inmaculada Concepción. Se trata de una 
variante iconográfica poco frecuente, que representa, como indica la figura de san Juan Evangelista, en el margen inferior derecho de la composición, el siguiente episodio del Apocalipsis: «apareció en el cielo una mujer vestida de sol, con la luna debajo de sus pies y sobre la cabeza una corona de doce estrellas. Apareció en el cielo otra señal, y vi un gran dragón de color de fuego, que tenía siete cabezas y diez cuernos. Se paró delante de la mujer, que estaba a punto de parir, para tragarse a su hijo. Hubo una batalla en el cielo. Miguel y sus ángeles peleaban con el dragón. Este persiguió a la mujer que había parido un hijo varón. Pero le fueron dadas a la mujer dos alas de águila para que volase al desierto» $(12,1-14)$.

La Virgen asciende al cielo con su hijo en brazos y en alto la espera Dios Padre. La obra es de una extraordinaria calidad y de una gran belleza, pero el mal estado de conservación y la desafortunada ubicación sobre un armario en la sacristía dificultan la merecida apreciación.

Historia de la pieza: Estado de conservación: deteriorado.

Bibliografía:

Giacobbe (1992).

Giacobbe (1995), p. 130.

Levi (1984). 


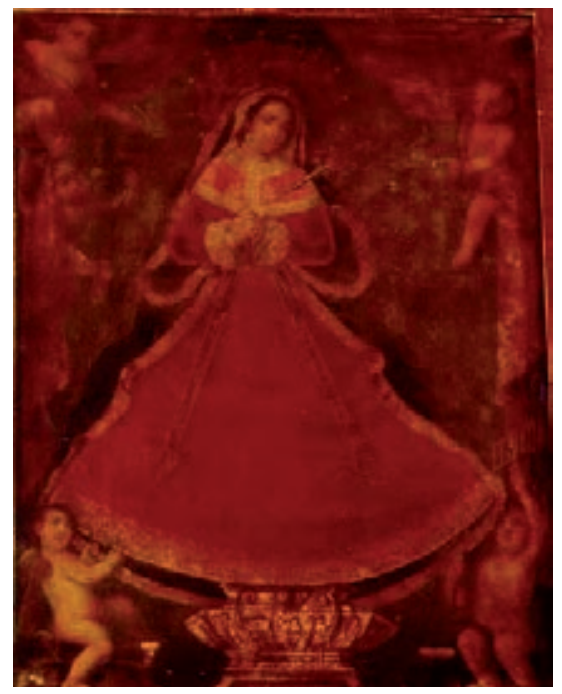

\section{FICHA CATALOGRÁFICA}

N. ${ }^{\circ}$ orden: 61

Iglesia de Santo Stefano, Chiusanico (Imperia)

Dolorosa, procedencia española,

iglesia de Santo Stefano, Chiusanico (Imperia).

Autor-atribución. Título de la obra: De procedencia española: Dolorosa.

Alessandro Giacobbe (1995, p. 130) señala su procedencia española, probablemente sevillana. Este autor considera que se trata de una tipología mariana venerada en el sur de España, posiblemente relacionada con un culto de tipo local (Giacobbe, 1992, p. 125).

Estilo-cronología: Datado entre la segunda mitad del XVII y el siglo XVIII.

Tipo de obra, material y técnica: Cuadro. Óleo sobre lienzo.

Dimensiones: $120 \times 95 \mathrm{~cm}$.

Localización y procedencia: Chiusanico (Imperia), iglesia de Santo Stefano, sacristía de la iglesia.

En opinión de Giacobbe esta obra forma parte del grupo de cuadros existentes en la iglesia de Santo Stefano de Chiusanico: Alegoría de la muerte, Virgen de Guadalupe, Inmaculada y Virgen de Guadalupe.

Se desconoce en qué época y cómo llegó a Chiusanico, pero no se duda acerca de su procedencia espańola, probablemente sevillana.

La tradición oral indica que los cuadros de la sacristía proceden de Espańa y que fueron donados por la familia Ghersi de Chiusanico a la iglesia (memoria oral transmitida por Mons. Fiorenzo Gerini de Albenga). 
Descripción: Representación de la Virgen Dolorosa, con vestido rojo y manto azul. Esta imagen puede ser representada hasta con siete espadas, pero, en este caso, lleva una sola clavada en el pecho, de acuerdo con la profecía de Simeón (Lucas, 11, 35), en señal de los dolores que tendría que padecer.

La Virgen aparece rodeada por ángeles que llevan los instrumentos de la Pasión de Cristo. Y, como puede comprobarse, sus rostros son iguales, y se han resuelto de manera bastante esquemática. En el fondo de la composición hay una cortina roja. En general, predomina el rojo, que tendría una cierta connotación simbólica. Se recurre también al empleo del dorado.

Historia de la pieza: Estado de conservación: deteriorado.

Bibliografia:

Giacobbe (1992).

Giacobbe (1995), p. 130.

Levi (1984).

Sebastián López (1990), p. 165.

Trens (1947). 


\section{FICHA CATALOGRÁFICA \\ N. ${ }^{\circ}$ orden: 62 \\ Pinacoteca Civica, Imperia}

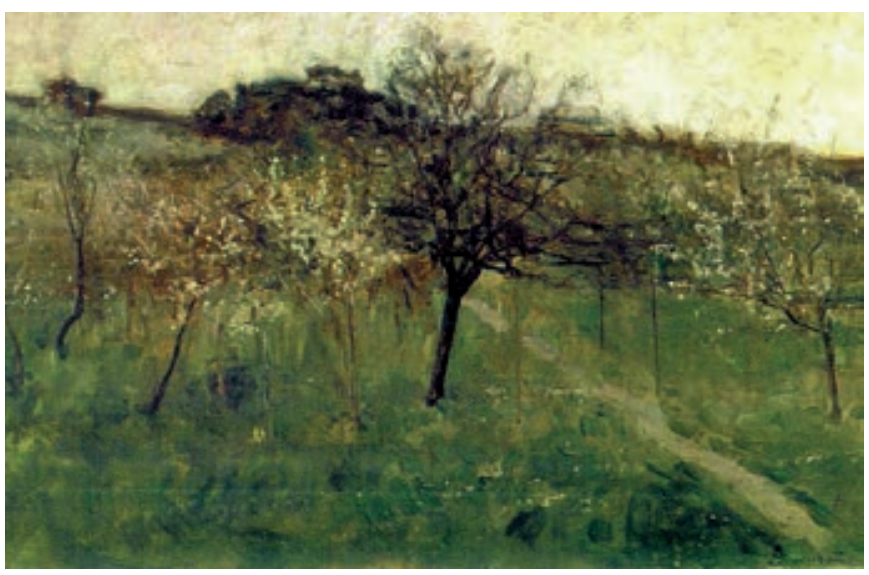

Primavera en Liguria, Serafín Avendaño, Pinacoteca Civica, Imperia.

Autor-atribución. Título de la obra: Serafín Avendaño (Vigo, 1837-Valladolid, 1916): Primavera en Liguria.

Estilo-cronología: Datado hacia 1868.

Tipo de obra, material y técnica: Cuadro. Óleo sobre lienzo.

Dimensiones: $23 \times 35,5 \mathrm{~cm}$.

Elementos autógrafos: Firmado en el margen inferior derecho: «S. Avendaño». Localización y procedencia: Imperia (Liguria), Pinacoteca Civica.

Procede de la colección de S. Rebaudi de Génova-Pegli, quien la donó a la Pinacoteca de Imperia.

Descripción: Se representa la primavera a través de un campo florido. Esta obra recuerda, desde el punto de vista estilístico, otra del pintor titulada Campo con moreras (ficha n. ${ }^{\circ} 30$ ). Avendaño recurre, como en la mayoría de sus obras, a la composición en horizontal. Se ofrece una amplia vista en perspectiva, reforzada por el camino que se adentra hacia el fondo. Responde a la predilección 
del pintor por la gama de los verdes suaves y grises delicados, con algún toque de blanco. Los colores son esmaltados y la pincelada corta y densa, aflorando el lenguaje de la macchia ('mancha'). Es un testimonio ejemplar del mundo poético de Avendaño. De hecho, Gianfranco Bruno (1993, p. 155) llega a denominarlo "Sisley de provincia», un petit maître capaz de superar el inicial naturalismo, todavía con tintes de elementos románticos, en un genuino y moderno sentimiento de la naturaleza.

Historia de la pieza: Estado de conservación: bueno.

Exposiciones:

XXX Exposición de la Società Promotrice di Belle Arti, celebrada en Génova en 1881.

Exposición anual de la Società Promotrice di Belle Arti, celebrada Florencia en 1882.

Exposición celebrada en el Palacio Nacional de Brera, Milán, en 1882.

Serafin Avendaño, 1837-1916, celebrada en Vigo en 1991.

Catálogos:

Serafin Avendaño, 1837-1916, 1991, p. 139.

Bibliografia:

Bruno (1993), p. 155.

F. G. (1985), p. 18.

Rocchiero (1960). 
FICHA CATALOGRÁFICA

N. ${ }^{\circ}$ orden: 63

Colección privada, Albisola (Savona)

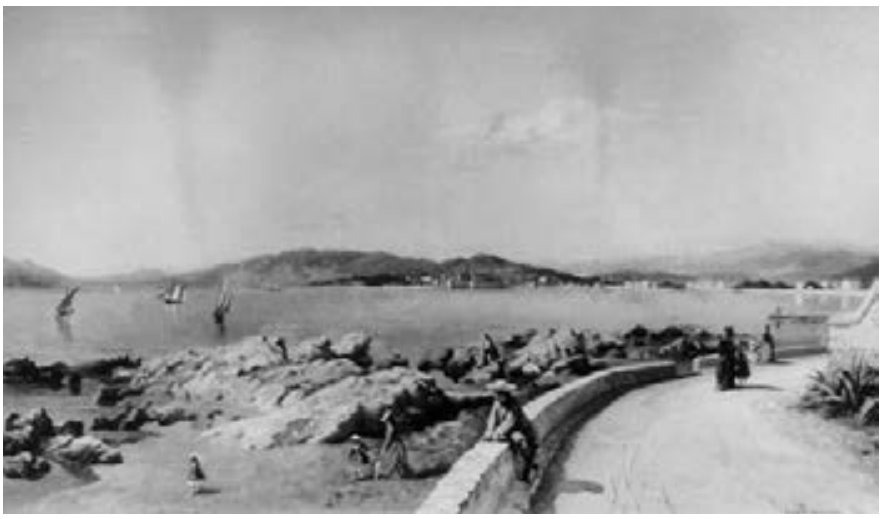

Vista de Cannes, desde el mar, Serafín Avendaño, colección privada, Albisola (Savona).

Autor-atribución. Titulo de la obra: Serafín Avendaño (Vigo, 1837-Valladolid, 1916): Vista de Cannes, desde el mar.

Estilo-cronología: Datado en 1875.

Tipo de obra, material y técnica: Cuadro. Óleo sobre lienzo.

Dimensiones: $33 \times 60 \mathrm{~cm}$.

Elementos autógrafos: Firmado en el margen inferior izquierdo: «S. Avendaño». Localización y procedencia: Albisola (Savona), colección de G. Robaldo y D. Tiscione.

Descripción: Esta obra se encuentra en la línea, desde el punto de vista compositivo, de otra del pintor vigués titulada Puerto de ribera, al norte de Vigo (ficha n. ${ }^{\circ}$ 39). Pero, a diferencia de aquella, esta es más cálida y luminosa. Se trata de una composición en horizontal, que ofrece una amplia panorámica. Es un testimonio de los numerosos viajes que Avendańo realizó por Europa, en este caso a Francia, y de la predilección por los temas marinos. Es sabido que el pintor visitaba los lugares más pintorescos, captando en ellos aquello que le impresionaba con la máxima sencillez, haciendo, eso sí, concesiones al 
dibujo minucioso y no tanto a las elegancias formales. Se representa la tierra, el mar y el cielo, con profunda serenidad, incluyendo figuras que no alteran el equilibrio natural. Se basa en una paleta luminosa que confiere frescura y vitalidad a la obra.

Historia de la pieza: Estado de conservación: bueno.

Exposiciones:

Serafin Avendaño, 1837-1916, celebrada en Vigo en 1991.

Catálogos:

Serafin Avendaño, 1837-1916, 1991, p. 135.

Bibliografia:

Bruno (1971).

Marini (1986).

Rocchiero (1960). 


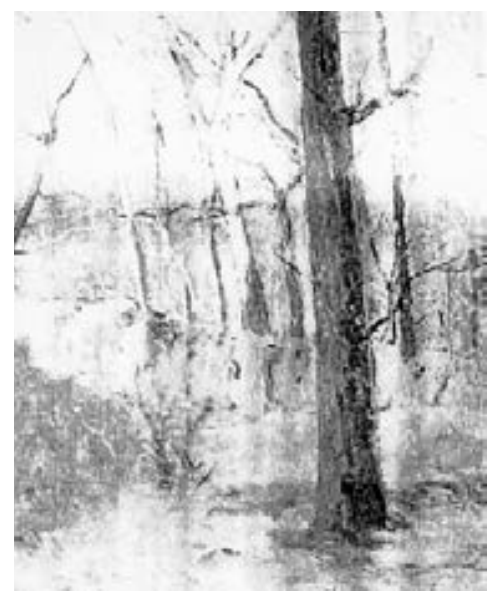

\section{FICHA CATALOGRÁFICA}

N. ${ }^{\circ}$ orden: 64

Colección privada, Albisola (Savona)

Arboleda desnuda en invierno, Serafín Avendaño, colección privada, Savona.

Autor-atribución. Título de la obra: Serafín Avendaño (Vigo, 1837-Valladolid, 1916): Arboleda desnuda en invierno.

Estilo-cronología: Fechado en el último cuarto del siglo XIX.

Tipo de obra, material y técnica: Cuadro. Óleo sobre tabla.

Dimensiones: $36 \times 27,5 \mathrm{~cm}$.

Elementos autógrafos: Firmado en el margen inferior izquierdo: «Avendaño». Localización y procedencia: Savona, colección privada.

Procede de la colección de G. Robaldo y D. Tiscione de Albisola (Savona).

Descripción: Se ofrece un detalle de una arboleda desnuda, que refleja la predilección del pintor por los paisajes sencillos y humildes. Se reproduce la esencia de la naturaleza, de modo bastante esquemático y a base de pocas pinceladas. Es una composición en perspectiva, que recurre a una paleta luminosa y cálida.

Historia de la pieza: Estado de conservación: bueno.

Exposiciones:

Serafin Avendaño, 1837-1916, celebrada en Vigo en 1991.

Catálogos:

Serafin Avendaño, 1837-1916, 1991, p. 137.

Bibliografia:

Bruno (1971).

Rocchiero (1960). 


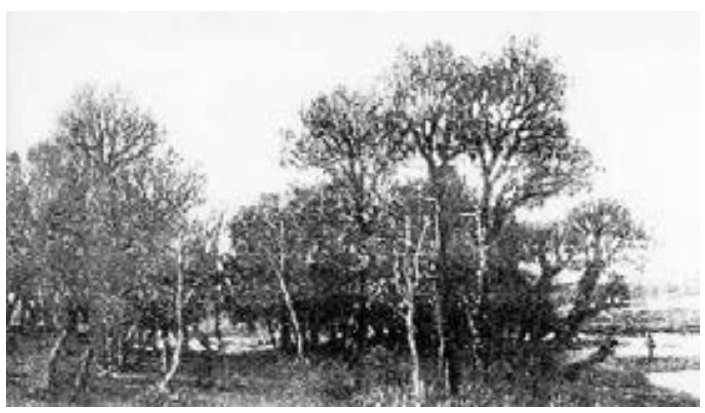

FICHA CATALOGRÁFICA

N. ${ }^{\circ}$ orden: 65

Colección privada, Albisola (Savona)

«Macchia» de árboles y césped, Serafín Avendaño,

colección privada, Savona.

Autor-atribución. Título de la obra: Serafín Avendaño (Vigo, 1837-Valladolid, 1916): "Macchia» de árboles y césped.

Estilo-cronología: Datado en el último cuarto del siglo XIX.

Tipo de obra, material y técnica: Cuadro. Pastel sobre cartulina.

Dimensiones: $15 \times 27 \mathrm{~cm}$.

Elementos autógrafos: Firmado en el margen inferior izquierdo: «S. Avendaño». Localización y procedencia: Savona, colección privada.

Procede de la colección de G. Robaldo y D. Tiscione de Albisola (Savona).

Descripción: Se ofrece una amplia visión de una arboleda frondosa. Se trata de una composición en horizontal, captada en perspectiva. Es un ambiente humilde, sencillo, en el que aflora el lenguaje de la macchia ('mancha'). Se emplean los semitonos verdes, grises del mundo vegetal, con sus luces y sombras. Esta obra trasluce el pequeño y gran mundo «incontaminado», fresco y poético, por el que abogaba el pintor vigués.

Historia de la pieza: Estado de conservación: bueno.

Exposiciones:

Serafin Avendaño, 1837-1916, celebrada en Vigo en 1991.

Catálogos:

Serafin Avendaño, 1837-1916, 1991, p. 138.

Bibliografia:

Bruno (1971).

Rocchiero (1960). 


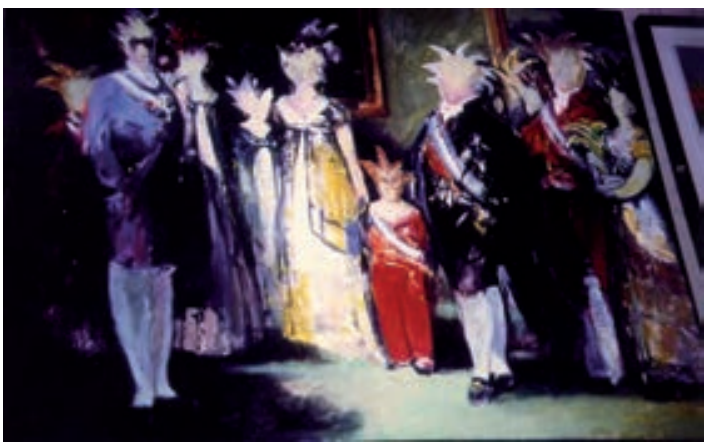

FiCHA CATALOGRÁFICA

N. ${ }^{\circ}$ orden: 66

Colección privada, Savona

Familia Real de Carlos IV, Juan Segura García, colección privada, Savona.

Autor-atribución. Titulo de la obra: Juan Segura García (Palma de Mallorca, 1955): Familia Real de Carlos IV.

Estilo-cronología: Datado en 1985.

Tipo de obra, material y técnica: Cuadro. Óleo sobre lienzo.

Dimensiones: $160 \times 120 \mathrm{~cm}$.

Elementos autógrafos: Firmado y datado en el margen inferior izquierdo: «Familia Real Carlos IV. Segura 1985 Savona».

Localización y procedencia: Savona (Liguria), colección privada de Roberto Debenedetti y Silvia Bottaro.

Este cuadro fue realizado durante la estancia del pintor en Savona. Juan Segura tenía un estudio de pintura en via del Santuario (Savona), junto con el pintor savonés Enzo L’Acqua. Roberto Debenedetti y Silvia Bottaro adquirieron este cuadro en 1985 en dicho estudio.

Descripción: Se representa a la familia real de Carlos IV, recordando la obra del mismo tema pintada por Francisco de Goya. Es decir, en la composición se recurre a la mancha de color; un color vivo e intenso, aplicado con gran soltura. Como puede comprobarse, los personajes carecen de rostro, a excepción del pequeño príncipe. El color predomina en la composición, pero no se abandona la figuración, el carácter narrativo de la imagen. La obra adquiere un cierto tono de parodia e ironía.

Historia de la pieza: Estado de conservación: excelente.

Bibliografia:

Bozal (1992). 


\section{FICHA CATALOGRÁFICA \\ N. ${ }^{\circ}$ orden: 67 \\ Colección privada, Savona}

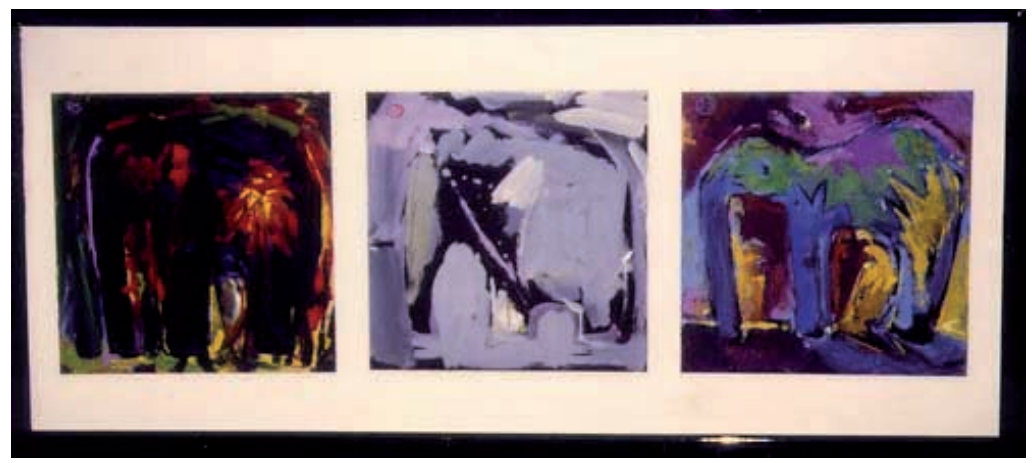

Elefantes, Juan Segura García, colección privada, Savona.

Autor-atribución. Título de la obra: Juan Segura García (Palma de Mallorca, 1955): Elefantes.

La obra está formada por tres pequeńos cuadros, en cada uno de los cuales se representa un elefante.

Estilo-cronología: Fechado en 1985.

Tipo de obra, material y técnica: Cuadro. Pintura al temple.

Dimensiones: $20 \times 20 \mathrm{~cm}$ (cada uno).

Elementos autógrafos: Firmado, cada uno de los cuadros, en el margen superior izquierdo: «J. S.».

Localización y procedencia: Savona (Liguria), colección privada de Roberto Debenedetti y Silvia Bottaro.

Este cuadro fue realizado durante la estancia del pintor en Savona. Roberto Debenedetti y Silvia Bottaro lo adquirieron en 1985, en el estudio que Segura tenía en Savona.

Descripción: Se trata de una obra que comprende tres cuadros, de reducidas dimensiones, que presentan el mismo motivo, un elefante. Como puede verse, el elefante tiene la misma posición en cada uno de los cuadros, aunque es de 
diferente color. Como en la composición anterior (ficha n. ${ }^{\circ}$ 66), el pintor se interesa por el color, por la mancha pictórica, aplicada a base de amplias pinceladas. Es interesante destacar que el elefante es un animal recurrente en la producción pictórica de Juan Segura.

Historia de la pieza: Estado de conservación: excelente.

Bibliografia:

Bozal (1992). 


\section{FICHA CATALOGRÁFICA \\ N. ${ }^{\circ}$ orden: 68 \\ Colección privada, Savona}

Autor-atribución. Título de la obra: Antoni Tàpies (Barcelona, 1923): Composición. Estilo-cronología: Datado en 1959.

Tipo de obra, material y técnica: Cuadro. Pintura al temple.

Dimensiones: $35,5 \times 25 \mathrm{~cm}$.

Elementos autógrafos: Firmado en el margen inferior derecho.

Localización y procedencia: Savona (Liguria), colección privada de Roberto Debenedetti y Silvia Bottaro.

Procede de la Sala Gaspar de Barcelona. En 1961 pasó a una colección privada de Milán, donde permaneció hasta que Roberto Debenedetti lo comprara en la Galería Farsetti de Prato, en 1986, por 3500 millones de liras.

Descripción: La obra corresponde a la etapa en la que Tàpies concebía la "pintura como muro», dotándola así de gran homogeneidad. Composición geométrica, basada en una serie de líneas negras que destacan sobre un fondo grismarrón. Se persigue la materialidad de la obra, que es el medio, no la finalidad, de la creación. La pintura conjuga la expresividad de la materia y la interioridad de la obra.

Historia de la pieza: Estado de conservación: excelente.

Exposiciones:

Galleria d'Arte Moderna Farsetti de Prato, 1986.

Catálogos:

Catálogo de la exposición celebrada en noviembre de 1986, en la Galleria Farsetti de Prato.

Bibliografia:

Bozal (1992).

Cirlot (1983), pp. 69-114.

Combalía Dexeus (1989).

Laclotte (dir.) (1989), pp. 462-463.

Tàpies (1974).

Tàpies (1995).

Tàpies y Valente (2004). 


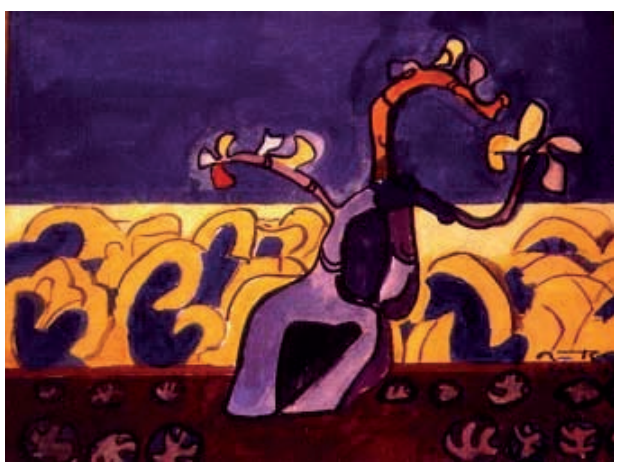

Ficha CATALOGRÁFICA

N. ${ }^{\circ}$ orden: 69

Colección privada, Savona

Ginestas, José Ortega,

colección privada, Savona.

Autor-atribución. Título de la obra: José Ortega (1921, Arroba de Los Montes, Ciudad Real-1991): Ginestas.

Estilo-cronología: Fechado en 1973.

Tipo de obra, material y técnica: Cuadro. Pintura al temple sobre papel.

Dimensiones: $52 \times 65 \mathrm{~cm}$.

Elementos autógrafos: Firmado y datado en 1973.

Localización y procedencia: Savona (Liguria), colección privada de Roberto Debenedetti y Silvia Bottaro.

Roberto Debenedetti compró este cuadro en la Galería Pitti de Florencia el 29 de noviembre de 1991.

Descripción: Antes de pasar al análisis de la obra, es preciso decir que José Ortega ha sido considerado la figura clave del realismo social espańol. Pero este cuadro se aparta de la temática de sus primeras obras, caracterizadas por el expresivo realismo social, y está más bien relacionado con algunas pinturas como Segador y Luna de 1970, en las que la abstracción camina hacia lo concreto, destacando la tensión entre los elementos compositivos y el peso de las manchas o la vivacidad del grafismo.

Se trata de una composición en horizontal, que representa una ginesta, planta mediterránea característica de Liguria. Es una composición sintética, dinámica y atenta a los aspectos plásticos y pictóricos. Destaca la importancia concedida al color; un color cálido e intenso. Se refleja el interés que el pintor sentía por la tierra y por la naturaleza.

Historia de la pieza: Estado de conservación: excelente. 
Exposiciones:

Exposición celebrada en la Galería Pitti de Florencia en 1991.

Catálogos:

Catalogo dell'asta Pitti, 29 de noviembre de 1991, n. ${ }^{o} 128$, p. 42.

Bibliografía:

Bozal (1992), pp. 242-244.

Calvo Serraller (1985).

Lara (1976).

López (1987).

Rodríguez Olivares (1976). 


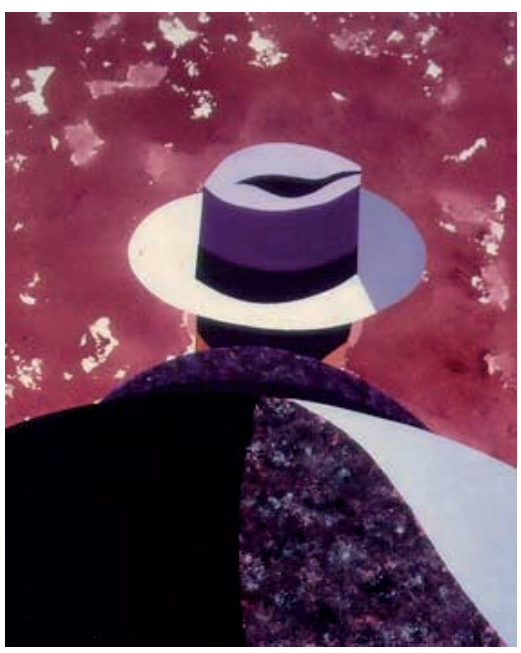

Ficha CATALOGRÁFICA

N. ${ }^{\circ}$ orden: 70

Colección privada, Savona
Personaje, Eduardo Arroyo, colección privada, Savona.

Autor-atribución. Titulo de la obra: Eduardo Arroyo (Madrid, 1937): Personaje. Estilo-cronologia: Datado en 1976.

Tipo de obra, material y técnica: Cuadro. Técnica mixta, collage sobre papel.

Dimensiones: $76 \times 56 \mathrm{~cm}$.

Elementos autógrafos: Está firmado y fechado en el margen inferior derecho.

Localización y procedencia: Savona (Liguria), colección privada de Roberto Debenedetti y Silvia Bottaro.

Procede de una colección privada de Albisola (Savona), donde permaneció hasta que fue adquirido por Roberto Debenedetti en 1982.

Descripción: La obra pictórica de Eduardo Arroyo se caracteriza por su sentido visual, por la afectividad crítica, lúdica y paródica, pero, sobre todo, por su narración figurativa. Su gusto por lo cotidiano, su preocupación por la narratividad y por representar figuras y escenarios tanto cotidianos como universales (el hombre del paraguas, el paseante, etc., todos protagonistas del medio urbano) pueden tener sus precedentes en Jean Hélion y en Adami.

La presente obra se incluiría en este contexto, pues se representa un hombre de espaldas al espectador, captado a la altura, aproximadamente, de los hombros. Va vestido con traje y lleva un sombrero. Se recurre a la gama de los negros, grises y azules, con algún toque de rojo-granate para el fondo de la 
composición. Destaca la pureza de los colores y el carácter volumétrico de la figura masculina. Desde el punto de vista compositivo y temático, podría recordar la pintura de Eduardo Úrculo.

Historia de la pieza: Estado de conservación: excelente.

Bibliografia:

Arroyo (1982).

Bozal (1992), pp. 439-451.

Calvo Serraller (1985).

Durozoi (dir.) (1997), p. 28.

Navarro (comisaria de exposición) (2002). 



\section{BIBLIOGRAFÍA}

"Acquisizioni dai Musei e Gallerie dello Stato», Bolletino d'Arte, 1954.

Actas del Simposium Internacional Zurbarán y su época. Fuente de Cantos, Llerena, Guadalupe. Badajoz, Consejería de Cultura y Patrimonio, 1998.

Alizeri, F. (1846-1847), Guida artistica per la città di Genova. Génova, Grondona, 2 vols.; 2. a edición, 1864 .

- (1875), Guida illustrativa del cittadino e del forastiero per la città di Genova e sue adiacenze. Génova, Sambolino.

Angulo Iñíguez, D. (1977), Pintura del siglo XVII, vol. XV de Ars Hispaniae, Madrid, Plus-Ultra.

- (1981), Murillo. Catálogo crítico. Madrid, Espasa-Calpe.

ARGAN, G. C. (1984), Storia dell'arte italiana. Florencia.

ARroyo, E. (1982), Eduardo Arroyo: 20 años de pintura, 1962-1982. [Catálogo de

la exposición celebrada en Madrid entre mayo y junio de 1982]. Madrid,

Dirección General de Bellas Artes, Archivos y Bibliotecas.

Arslan, E. (1960), I Bassano. Milán, Ceschina, vol. I.

BACCHESChi, E. (ed.) (1983, 1988), Il Museo dell'Accademia Ligustica di Belle

Arti. La Pinacoteca. [Catálogo]. Génova, Sagep. [1. a edición, 1983; 2. a, 1988].

Balestreri, L., y W. Piastra (1973), Storia della chiesa di San Giorgio in Genova. Génova, A Compagna.

BANChERO, G. (1846a), Guida alle belleze di Genova. Génova.

- (1846b), «Il Palazzo Reale di Genova», en Monumenti antichi. Génova, pp.3-11.

BARriLI, A. G. (1885), Amori alla macchia. Milán, Treves.

BARILli, R. (ed.) (1988), Il secondo Ottocento italiano. Le poetiche del vero. Milán, Mazzotta.

Bauerreis, R. (1938), Arbor Vitae. Der "Lebensbaum» und seine Verwendung in Liturgie, Kunst und Brauchtum des Abendlandes. Múnich. 
La belleza de lo real. Floreros y bodegones en el Museo del Prado, 1600-1800. Museo del Prado, del 21 de julio al 29 de octubre. Madrid, Museo del Prado, 1995.

Beringheli, G. (1991), Dizionario degli artisti liguri. Génova, De Ferrari.

Bernardi, M. (1942), Mostra dei Pittori della Scuola di Rivara. [Catálogo de la exposición celebrada en Turín en 1942]. Turín, Salone della Stampa.

Berry, M. (1985), Alla Porta Occidentale d'Italia. Guida Storica e Artistica della Riviera di Ponente. Museo Bicknell-Bordighera, Istituto Internazionale di Studi Liguri.

Biancale, M. (1961), Arte italiana. Ottocento e Novecento. Roma.

Biavati, G. (1977), Nervi: Museo di Villa Luxoro. Génova, Sagep (Guide di Genova, 48).

Biblioteca Sanctorum. Istituto Giovanni XXIII della Pontificia Università Lateranense. Roma, Città Nuova, 1964-1967: vol. v, pp. 154-162 y 1052-1131; vol. VI, pp. 1109-1137; vol. VIII, pp. 107-130; vol. IX, pp. 1251-1268; vol. XI, pp. 776-801.

Boccardo, P. (1987), «Per la storia della quadreria di Palazzo Spinola», en Palazzo Spinola a Pelliceria. Due musei in una dimora storica, Genova, Tormena (Quaderni della Galleria Nazionale di Palazzo Spinola, 10).

- (2004), "Virreyes y financieros. Mercado artístico y colecciones entre Madrid y Génova (siglos XVII-XVIII)", en Boccardo, Colomer y Di Fabio (dirs.) (2004), pp. 189-204.

- y C. Di Fabio (2004), «Pinturas del Siglo de Oro en Génova entre los siglos XVII y XIX», en Boccardo, Colomer y Di Fabio (dirs.) (2004), pp. 233-246.

- J. L. Colomer y C. Di Fabio (dirs.) (2004), España y Génova. Obras, artistas y coleccionistas. Madrid, Fernando Villaverde Ediciones, Centro de Estudios Hispánicos e Iberoamericanos.

Boggero, F. (1979), Chiese di San Giorgio e San Torpete. Génova, Sagep (Guide di Genova, 84).

- (1990), Chiese di Genova. Génova, Sagep.

- y R. Paglieri (1988), La città della Liguria. Imperia. Génova, Sagep.

- y B. Ciliento (eds.) (1995), Restauri in provincia di Imperia, 1986-1993. Génova, Sagep.

BoITO, C. (1877), Scrittori e pittori d'oggi. Turín.

Botto, I. M., y L. Tagliaferro (eds.) (1977a), Galleria di Palazzo Rosso. Génova, Sagep (Guide di Genova, 43).

- y L. Tagliaferro (eds.) (1977b), Galleria di Palazzo Bianco. Génova, Sagep (Guide di Genova, 44).

Bozal, V. (1992), Pintura y escultura españolas del siglo XX (1939-1990), vol. XXXVII de Summa Artis. Historia General del Arte. Madrid, Espasa-Calpe. 
Brasas Egido, J. C. (1988), Las edades del hombre. [Catálogo de la exposición]. Valladolid.

BRUNO, G. (1971), «La pittura tra Ottocento e Novecento», en Torriti y Castelnovi (eds.) (1971), vol. II, pp. 445-487.

- (1978), «I grigi maestri del paesaggio ligure», La Casana (Génova), año XX, n. ${ }^{\circ} 1$.

- (1979), Immagine e paesaggio. Liguria 1850-1970 (catálogo de la exposición). Génova, Galleria Rubinacci.

- (1981a), La pittura in Liguria dal 1850 al Divisionismo. Génova, Stringa.

- (1981b), La pittura in Liguria tra '800 e '900 (catálogo de la exposición). Génova, Cassa di Risparmio di Genova e Imperia.

- (1981c), «La pittura in Liguria tra '800 e '900», La Casana (Génova), año XXIII, n. ${ }^{\circ} 4$.

- (1983), «La pittura in Liguria dal Neoclassicismo al Divisionismo», Catalogo dell'Arte Italiana del Ottocento (Milán, Giorgio Mondadori), n. ${ }^{\circ} 12$.

- (1993), L'alba del vero: Pittura del secondo '800 in Liguria. Génova, Erga.

- y L. PerissinotTi (1989), La Scuola Grigia a Carcare. [Catálogo de la exposición]. Génova, Erga.

Bussolino, P. (1877), Indicatore commerciale. Génova, pp. 260-271, 2. a edición.

CaAmaño Fernández, R. E. (1991), «El paisajista Avendaño», en Serafín Avendaño, 1837-1916, pp. 13-14.

Calderini, M. A. (1901), Antonio Fontanesi, pittore paesista. Turín, Paravia, 1. ${ }^{\mathrm{a}}$ edición.

Calvo Serraller, F. (1985), España, medio siglo de arte de vanguardia, 19391985. Madrid, Fundación Santillana, Ministerio de Cultura, 2 vols.

CAlzamiglia, L. (1992), «Una tradizione colombiana, a posteriori: le tele della Madonna di Guadalupe nella parrocchiale di Chiusanico», en I Colombo di Chiusanico. [Actas del Congreso celebrado en Chiusanico, agosto de 1991]. Imperia, Dominici, pp. 95-106.

Camerana, G. (1872), «Esposizioni di Belle Arti», Arte in Italia, julio.

CAMÓn AZnar, J. (1985), La pintura española del siglo XVII, vol. XXV de Summa Artis. Historia General del Arte. Madrid, Espasa-Calpe.

CAppellini, A. (1942), «Il San Giorgio dei genovesi nella storia e nell'arte», Geno$v a$, julio.

Cataldi Gallo, M. (1990), Gerolamo Grimaldi e la Società Patria. Aspetti della cultura figurativa ligure nell'età dell'Illuminismo. Génova, Sagep.

"Catalogo dei quadri e pitture esistenti nel palazzo di S. E. il sig. marchese Giacomo Filippo Durazzo, 1792: A. D.», Cataloghi, n. ${ }^{\circ} 12$.

Catalogo dell'asta Pitti, 29 de noviembre de 1991. Florencia, 1991. 
Catalogo della Collezione Francesco Donghi di Genova. Génova, Casa de venta Jandolo-Tavazzi, 1912.

Catalogue du Musée de peinture, sculpture et archéologie au Palais Accoramboni. Roma, Imprimerie du Vatican, 1897.

Cattaneo, C., et ál. (1995), Il Palazzo Durazzo Pallavicini. Bolonia, Nuova Alfa. Caturla, M. L. (1994), Francisco de Zurbarán, traducción y adaptación de O. Delenda. París.

CECIONI, A. (1905), Scritti e ricordi. Florencia.

ChÂtelet, A., y R. ReCht (1988), Le monde gothique. Automne et renouveau, 1380-1500. París, Gallimard (L'Univers des formes).

Ciliento, B. (1986), "La visita alla Galleria», en Visita alla Galleria di Palazzo Reale. Génova, Ministero per i Beni Culturali e Ambientali (L'attività didattica della Galleria di Palazzo Reale di Genova, Quaderno, 5), pp. 11-33.

Cirlot, L. (1983), La pintura informal en Cataluña 1951-1970. Barcelona, Anthropos.

Comanducci, A. M. (1934), I pittori italiani dell'Ottocento. Dizionario critico e documentario. Milán.

Combalía Dexeus, V. (1989), Tàpies. Barcelona, Polígrafa.

CoOK, R. (1974), The Tree of Life. Symbol of the Centre. Londres.

De Dominici, B. (1970), Vite dei pittori, scultori e architetti napolitani. Nápoles, EDART. [Edición original, 1742-1743].

De Gaufridy, P. (1928), «La Galleria d'Arte Moderna nel Palazzo Serra a Nervi», La grande Genova, año VIII, n. ${ }^{\circ} 11$, pp. 589-594.

De Simoni, L. (1948), Le chiese di Genova. Génova, Ceretti.

Del Guercio, A. (1982), La pittura dell'Ottocento. Turín, UTET.

Delogu, G. (1928), «Riberismo», L'Arte di Adolfo Venturi (Roma, Industrie Grafiche), año XXXI, fasc. IV, pp. 1-8.

Di FabIo, C. (1992), La Galleria di Palazzo Bianco-Genova. Milán, Garolla.

Domenech, R. (1910), Sorolla: su vida y su arte. Madrid, Leoncio Miguel.

Dragone, A. (1986), Da Bagetti a Reycend. [Catálogo de la exposición]. Turín.

- (1988), «Paesaggisti a raccolta nel verde Canavese», Antiquariato (Milán).

- (1992), «Arte: La rivolta in grigio. Tonalismo e chiaroscuro nei paesaggisti liguri di metà '800", AD/Architectural Digest (Milán), n.o 133, junio.

- y J. Dragone Conti (1947), I paesisti piemontesi dell'Ottocento. Milán, Bertieri.

Dufour-Kowalska, G. (1985), L'arbre de vie et la croix. Essai su l'inspiration visionnaire. Génova.

DurozoI, G. (dir.) (1997), Diccionario Akal de Arte del siglo XX. Madrid, Akal. EsCuDERO, José Antonio (1985), «La reconstrucción de la Administración central en el siglo XVIII», en Ramón Menéndez Pidal (dir.), Historia de España. Volu- 
men XXIX: La época de los primeros Borbones. T. I: La nueva monarquia y su posición en Europa (1700-1759). Madrid, Espasa-Calpe, pp. 79-175.

F. G. (1985), «La Civica Pinacoteca di Imperia», La Casana (Génova), año XXVII, n. ${ }^{\circ}$, pp. $18-22$.

Felton, C. (1971), Jusepe de Ribera. A Catalogue Raisonné. Pittsburgh, University of Pittsburgh.

Ferrari, O. (1986), «L'iconografia dei filosofi antichi nella pittura del secolo XVII in Italia», Storia dell'Arte (Florencia, Nuova Italia), n. ${ }^{\circ} 57$, pp. 103-183.

Fitz DarbY, D. (1962), «Ribera and the Wise Man», Art Bulletin, diciembre.

Frabetti, G. (1980), Nervi: Galleria d'Arte Moderna e Parco Serra, Génova, Sagep (Guide di Genova, 97).

- (1984), La raccolta Frugone. [Catálogo de la exposición celebrada en la Villa Grimaldi Fassio de Génova-Nervi, del 1 de abril al 29 de octubre de 1984]. Génova.

Gaya NuÑo, J. A. (1958), La pintura española fuera de España. Madrid, EspasaCalpe.

- (presentación) (1978), L'opera completa di Murillo. Milán, Rizzoli (Classici dell'Arte, 93).

Genaille, J. (1964), «Portraits inédits du collectionneur Aguado, de Madame Aguado et de leurs enfants», Gazette des Beaux-Arts, n. ${ }^{\circ}$ 68, pp. 25-36.

GiacobBe, A. (1992), «La parrocchiale di Santo Stefano, centro aggregante del borgo, e la sua quadreria spagnola», en I Colombo di Chiusanico. [Actas del Congreso celebrado en Chiusanico, agosto de 1991]. Imperia, Dominici, pp. 124-127.

- (1995), "Seguace di Ignacio de Ries, Allegoria della Morte, Chiusanico, sec. XVII», en Boggero y Ciliento (eds.) (1995), pp. 130-133.

Giffi PonZI, E. (1990), "Due dipinti di Gerrit van Honthorst a Genova», Bolletino d'Arte, n. ${ }^{\circ}$ 60, pp. 95-98.

GiUbilei, M. ${ }^{a}$ F. (1990), La Pittura di paesaggio in Liguria tra Ottocento e Novecento. Collezionismo pubblico e privato nelle raccolte della Galleria d'Arte Moderna di Genova. Génova, Costa-Nolan.

- (1993), La raccolta Frugone. Génova, Nuova Alfa.

- (1994), «Ferruccio Stefani, un collezionista-mercante di buon gusto e di buona volontà al servizio dei fratelli Frugone», Bolletino dei Musei Civici Genovesi, año XVI, n. ${ }^{\circ}$ 47-48-49, enero-diciembre.

- (1999), "Artisti di Genova e delle Riviere alle mostre milanesi tra Otto e Novecento", en G. Ginex y S. Rebora (eds.), Scoperta del mare. Pittori lombardi in Liguria tra '800 e '900. [Catálogo de la exposición]. Milán, Mazzotta, pp. 64-71. 
Giubilei, M.a F. (2004), «Serafín Avendaño (1837-1916). Un español en Génova», en Boccardo, Colomer y Di Fabio (dirs.) (2004), pp. 259-266.

Gregori, M. (presentación) (1973), L’opera completa di Zurbarán. Milán, Rizzoli (Classici dell'Arte, 69).

Grosso, O. (1910), Catalogo descrittivo ed illustrato dei quadri antichi e moderni delle Gallerie di Palazzo Bianco e Palazzo Rosso. Génova.

- (1920), «L'arte spagnuola a Genova», Vell i Nou (Barcelona, Bayets), época II, vol. I, n. ${ }^{\circ}$ IX, pp. 301-307.

- (1932), Le Gallerie d'Arte del Comune di Genova. Génova, M. U. Masini.

- (1938a), "Le collezioni d'arte moderna Luigi e Lazzaro G. B. Frugone», Genova, año XVIII, n. ${ }^{\circ}$ 2, febrero-XVI, pp. 1-25.

- (1938b), Mostra di Pittori ligure del Ottocento. [Catálogo de la muestra celebrada en el Palazzo Rosso de Génova]. Génova, Bozzo-Coccarello.

- (1963), "La Scuola Pittorica Genovese Grigia», Liguria, año XXX, n. ${ }^{\circ}$ 12, diciembre, pp. 25-28.

Gudiol, J. (1982), El Greco. 1541-1614. Barcelona, Polígrafa.

Guida d'Italia. Liguria. Milán, Touring Club Italiano, 1982.

Guinard, P. (1960), Zurbaran et les peintres espagnols de la vie monastique. París, Temps.

- (1964), «Aportaciones críticas de obras zurbarescas», Archivo Español de Arte, n. ${ }^{\circ}$ 146-147, abril-septiembre, pp. 115-128.

Haskell, F. (1982), Riscoperte nell'arte. Aspetti del gusto, della moda e del collezionismo. Milán, Comunità.

- (ed.) (1981), Saloni, gallerie, musei e loro influenza sullo sviluppo dell'arte dei secoli XIX e XX. [Actas del XXIX Congreso Internacional de Historia del Arte]. Bolonia, CLUEB.

Inventario dei Beni Artistici del Palazzo Reale di Genova. Génova, Palazzo Reale, 1950. Itinerari di Italia Nostra, Gavi e le colline del Cortese. Génova, Sagep, 1995.

JORDAN, William B. (2005), Juan van der Hamen y León y la Corte de Madrid. Madrid, Patrimonio Nacional.

Labó, M. (1926), Mostra di Pittura ligure dell'Ottocento. [Catálogo de la LXXV Exposición de la Società Promotrice di Belle Arti]. Génova.

- (1971), «Il Palazzo Reale di Genova», L'Illustrazione Italiana (Génova), año XLVII, n. ${ }^{\circ} 14,9$ de mayo.

- (1976), «La Pittura ligure dell'Ottocento», L'Illustrazione Italiana (Génova), año LIII, n. ${ }^{\circ} 23,6$ de junio.

Laclotte, M. (dir.) (1989), Dizionario della pittura e dei pittori. Turín, Einaudi. LAPOSTOLLE, C. (1991), «Albero», en Enciclopedia dell'Arte Medievale, Roma, Istituto della Enciclopedia Italiana, vol. I, pp. 302-307. 
Lara, F. (1976), Pepe Ortega, un grito entre dos mundos. Triunfo. [Catálogo de la exposición]. Madrid.

LE BRUn, J.-B. P. (1809), Choix des tableaux fait en Espagne. París, 2 vols.

LeOncini, L. (1996), Galleria di Palazzo Reale. Génova, Tormena.

- (1997), Palazzo Reale di Genova. Studi e Restauri. Génova, Tormena.

LeVI, G. (1984), "Famiglie contadine della Liguria del Settecento», en Centro e periferia di uno stato assoluto. Tre saggi su Piemonte e Liguria in età moderna. Turín, Rosenberg e Sellier, pp. 89-96.

Llueca Úbeda, E. (1988), Alonso Sánchez Coello (1531-1588). Benifaró de les Valls, Ayuntamiento.

LODI, L. (1991), La Galleria di Palazzo Reale a Genova. Guida. Génova, Brigati Glauco.

LongHI, R. (1984), Scritti sull'Ottocento e Novecento. Florencia.

LÓPEZ, J. M.a (1987), Ortega. [Catálogo de la exposición celebrada en la Sala Luzán, Caja de Ahorros de la Inmaculada de Zaragoza]. Zaragoza, CAI.

López SÁNCHEZ, F. (2004), Nueva información sobre Alonso Cano. Madrid, CSIC,

Departamento de Historia del Arte Diego Velázquez.

López Vázquez, J. M., y L. Seara Morales (1995), Galicia. Arte. Tomo XV: Arte Contemporáneo. A Coruña, Hércules.

Maestros flamencos y holandeses. [Catálogo de la exposición]. Milán, 1973.

MallÉ, L. (1976), La pittura dell'Ottocento piemontese. Turín, Impronta.

MALTESE, C. (1954), «Il momento unitario nella pittura italiana dell'Ottocento», Bolletino d'Arte, año XXXIX, fasc. I, enero-marzo.

- (1960), Storia dell'arte italiana (1785-1943). Turín.

ManzINI, G. (presentación) (1969), L'opera completa di El Greco. Milán, Rizzoli (Classici dell'Arte, 35).

Marcenaro, C. (1964), Dipinti genovesi del XVII e XVIII secolo. Turín, ERI.

- (ed.) (1969), Pittori genovesi a Genova nel '600 e nel '700. [Catálogo de la exposición celebrada en el Palazzo Bianco de Génova, del 6 de septiembre al 9 de noviembre de 1969]. Milán.

Marías, F. (1997), El Greco. Madrid, Nerea.

Marini, G. L. (1986), Il valore dei dipinti dell '800. Turín.

Martelli, D. (1952), Scritti d'arte, reunidos por Antonio Boschetto, Florencia, G. C. Sansoni.

Martinoni, R. (1983), Medioevo e Umanesimo. Gian Vicenzo Imperiale politico, letterato e collezionista genovese del Seicento. Padua, Antenore.

MAYER, A. L. (1923a), Jusepe de Ribera, "Lo Spagnoletto». Leipzig, K. W. Hiersemann. - (1923b), Murillo. Berlín, Deutsche Verlags-Anstalt.

MAZA, F. de la (1959), El guadalupanismo mexicano. México. 
Meriana, G., y C. Manzitti (1975), Le valli del Lemme dello Stura e dell'Olba. Génova, Sagep.

Morassi, A. (1946), Mostra della pittura antica in Liguria dal Trecento al Cinquecento. [Catálogo de la exposición]. Milán, Alfieri.

- (1951), Capolavori della pittura a Genova. Milán y Florencia, Electa.

X Mostra maestri liguri tra il secolo XIX e XX. Génova, 1989.

Navarrete Prieto, B. (1998), La pintura andaluza del siglo XVII y sus fuentes grabadas. Madrid, Fundación de Apoyo a la Historia del Arte Hispánico.

- (2001), Ignacio de Ries. Madrid, Fundación de Apoyo a la Historia del Arte Hispánico.

NAvARro, E. (comisaria de exposición) (2002), Eduardo Arroyo. Madrid, Dirección General de Relaciones Culturales y Científicas. Sociedad Estatal para la Acción Cultural Exterior (SEACEX).

Novella, P. (1898), «La Chiesa di San Giorgio», La Settimana Religiosa, año XXVIII, n. ${ }^{\circ} 18,1$ de mayo, p. 212.

Ottocento. Catalogo dell'Arte Italiana dell'Ottocento (Milán, Mondadori), n. ${ }^{\circ}$ 15, 1986.

Pallucchini, R. (1947), Veneti alla mostra di Brescia e di Genova. Arte Veneta [Catálogo de la exposición]. Brescia y Génova.

- (1962), "Commento alla mostra di Jacopo Bassano», Arte Veneta, XI, pp. 97-119.

Pantorba, B. (1953), La vida y la obra de Joaquín Sorolla. Madrid, Mayfe.

PAPONE, E. (1991), Il passato e il presente. I Musei del Comune di Genova. Génova, Colombo.

Pérez SÁnchez, A. E. (1992), Pintura barroca en España 1600-1750. Madrid, Cátedra.

- (1995), La pintura en Europa. La pintura en España. Milán, Electa, t. II.

- (presentación) (1978), L’opera completa del Ribera. Milán, Rizzoli (Classici dell'Arte, 97).

- y N. SPINOSA (dirs.) (1992), Ribera, 1591-1652. [Catálogo de la exposición celebrada en el Museo del Prado, del 2 de junio al 16 de agosto de 1992]. Madrid, 1994.

Perfetti, C. (1987), Guadalupe. La tilma de la Morenita. Cinisello Balsamo, Edizioni Paoline.

Pesenti, F. R. (1971), «L'Illuminismo e l'età neoclassica», en Torriti y Castelnovi (eds.) (1971), vol. II.

PeSSA, L. (1990), «Un illuminista in Liguria: Gerolamo Grimaldi», en L. Pessa (a cura di), Gerolamo Grimaldi e la Società Patria. Génova, Sagep, pp. 10-24.

Pettorelli, A. (1912), «Il Palazzo Reale di Genova», Rassegna d'Arte, año XII, n. ${ }^{\circ} 819$, agosto-septiembre. 
PiAstra, W. (1973), «La chiesa sotto il clero secolare nel secolo XIX», en Balestreri y Piastra (1973).

PICA, F. (1905), Stefani Esposizioni.

PiCENI, E. (1974), Catalogo Bolaffi della pittura italiana dell'800. Turín.

Pintura española de bodegones y floreros de 1600 a Goya. [Catálogo de la exposición celebrada entre noviembre de 1983 y enero de 1984]. Madrid, Ministerio de Cultura, 1984.

Pittori dell'800. [Catálogo de la exposición]. Turín, 1982.

Pleguezuelo Hernández, A. (1990), «Nuevos datos biográficos sobre el pintor Ignacio de Ries», Archivo Hispalense. Revista histórica, literaria y artística, t. 73, n. ${ }^{\circ} 222$, pp. 207-212.

Poggi, P. (1938), Catalogo della Pinacoteca Civica di Savona. Savona.

Poleggi, E. (1968), Strada Nuova, una lottizzazione del Cinquecento a Genova. Génova.

- (1969), Descrizione della città di Genova da un anonimo del 1818, ricerca iconografica e note. Génova, Sagep, $1 .^{a}$ edición.

POns-Sorolla, B. (1993), «Sorolla, su pintura y su familia», en Sorolla, pintor de la luz, pp. 8-98.

Puncuh, D. (1979), «L'archivio Durazzo-Giustiniani di Genova», Atti della Società Ligure di Storia Patria, serie XIX, fasc. I, enero-junio, pp. 335-341.

- (1984), «Collezionismo e commercio di quadri nella Genova sei-settecentesca», Rassegna degli Archivi di Stato (Roma), año XLIV/1, n. ${ }^{o}$ 1, enero-abril, pp. 164-219.

RatTI, C. G. (1779), Epilogo della vita del cavalier Antonio Raffaelo Mengs. Génova.

- (1780), Istruzione di quanto può vedersi di più bello in Genova in Pittura, Scultura ed Architettura. Génova, Gravier, 1780, 2. ${ }^{\text {a }}$ edición. [1. ${ }^{a}$ edición, Génova, Scionico, 1766].

Ravaschio, G. (1964), Fortune dell'Ottocento pittorico. [Catálogo de la exposición]. Génova.

Riva, G. (1938), «La mostra dei pittori liguri dell'Ottocento», Genova, n. ${ }^{\circ}$ 10, octubre.

Rocchiero, V. (1959-1963), «Ottocento ligure, Galleria dei Pittori», Voce di Genova.

- (1960), "Ottocento pittorico genovese. Serafino De Avendańo», Liguria (Génova), ańo XXVII, n. ${ }^{\circ}$ 8, agosto, pp. 17-20.

- (1963), Scuola Grigia genovese ed altri valori ottocenteschi. Scuola Pittorica Novatrice 1863-1963. Génova.

- (1968), «Maestri della Pittura ligure del secondo '800 e del primo '900», Liguria (Génova). 
Rocchiero, V. (1981), Scuole, gruppi, pittori dell'Ottocento ligure. Roma [etc.], Sabatelli.

- (1985), Una collezione di dipinti dell'Ottocento ligure. [Catálogo de la exposición]. Génova, c. 7/1, VII, p. 10.

- (1990), Tessere minori e maggiori del «mosaico» pittorico ligure fra $1850 e$ 1950. [Catálogo de la exposición celebrada en el Centro d'Arte la Maddalena de Génova]. Génova.

- (1991), «Un investigador del natural», en Serafin Avendaño, 1837-1916, pp. 15-17.

Rodríguez Olivares, L. (1976), «Pintores españoles de hoy: Ortega», Gaceta del Arte (Madrid), 14 de marzo.

Rotondi, P. (1967), La Galleria Nazionale di Palazzo Spinola a Genova. Milán, Arte Grafiche Ricordi.

Rotondi Terminiello, G. (1976), Palazzo Reale. Génova, Sagep (Guide di Genova, 17).

- G. Rosato y F. Simonetti (1994), Palazzo Spinola a Pelliceria. Due musei in una dimora storica. Un progetto realizzato, Génova, Tormena (Quaderni della Galleria Nazionale di Palazzo Spinola, 14).

Rudolf, R. (1957), Ars Moriendi. Colonia-Graz.

SAlerno, L. (1963), «Musei e collezioni», en Enciclopedia Universale dell'Arte. Venecia-Roma, IX, C.

Salvago RagGi, C. (2001), «Un'amica e un confessore per Giuseppina Strepponi», en R. Iovino y S. Verdino, Giuseppe Verdi, genovese. Génova-Lucca, Comitato Organizzatore delle Celebrazione Verdiane, pp. 75-79.

Santos Torrecilla, R., y M. ${ }^{a}$ J. CaSAdo (1983), Joaquin Sorolla, Madrid, Sarpe (Los genios de la pintura española, 5).

SAXL, F. (1942), "A Spiritual Enciclopedia of the later Middle Ages», Journal of the Warburg and Courtauld Institutes, 5, pp. 82-134.

SBorgi, F. (1971a), Pittura e cultura artistica nell'Accademia Ligustica a Genova 1751-1920, Génova, s. e. (Quaderni dell'Istituto di Storia dell'Arte dell'Università di Genova, 7).

- (1971b), «L'Ottocento: ritardi di un'esperienza», en Torriti y Castelnovi (eds.) (1971).

- (1975), Pittura neoclassica e romantica in Liguria. [Catálogo de la exposición celebrada en el Museo de la Accademia Ligustica de Génova]. Génova.

- (1990), "La pittura dell'Ottocento in Liguria», en La Pittura in Italia. L'Ottocento. Milán, Electa.

Sebastián López, S. (1981), Contrarreforma y Barroco. Lecturas iconográficas e iconológicas. Madrid, Alianza Forma. 
SebASTIÁn LÓpez, S. (1990), El barroco iberoamericano: mensaje iconográfico. Madrid, Encuentro.

- J. de Mesa Figueroa y T. Gisbert de Mesa (1985), Arte iberoamericano desde la colonización a la independencia, vol. XXVIII de Summa Artis. Historia General del Arte. Madrid, Espasa-Calpe.

Serafín Avendaño, 1837-1916. [Catálogo de la exposición]. Vigo, Caixavigo, 1991.

Signorini, T. (1870), «Rivista artistica. Del congresso e dell'esposizione di Parma», La Rivista Europea, fasc. I, diciembre.

Società Promotrice di Belle arti (1876), XXXV Esposizione. Turín.

Società Promotrice di Belle arti In Genova (1882), XXXI Esposizione, Génova.

- (1883), Rendiconto dell'esercizio 1882. Génova.

SOMARÉ, E. (1928), Storia dei pittori italiani dell'Ottocento. Milán, L'Esame, vol. I.

- (1936), La raccolta Luigi Frugone. Bérgamo.

- (1944), La pittura italiana dell'Ottocento, Novara, Istituto Geografico De Agostini.

SORIA, M. (1953), The Painting of Zurbaran. Londres, Phaidon Press.

- (1954), "Greco's Italian Period», Arte Veneta (Venecia), año VIII, pp. 213-221. Sorolla, el pintor de la luz. [Catálogo de la exposición celebrada en el Museo de San Carlos de Ciudad de México, entre diciembre de 1992 y febrero de 1993]. México, 1993.

Sinosa, N. (1994), Museo Nazionale di Capodimonte. Nápoles, Electa.

- (1995a), «La Sala del Van Dyck», en Cattaneo et ál. (1995), pp. 230-233.

- (1995b), «Sala del Reni», en Cattaneo et ál. (1995), pp. 122-123.

Staglieno, M. (1862-1867), Memorie e documenti sulla Accademia Ligustica di Belle Arti. Parte Primera 1751-1797, Génova, 1862. Parte segunda 17971863, Génova, 1864. Parte tercera. Ilustraciones y catálogos, Génova, 1867.

STEINGNER, B. (1985), «Paradisiebaum und Kreuz. Der Baum in der christlichen Bildtradition», en H. Gercke (ed.), Der Baum. Heidelberg, Braus, pp. 86-101. Stella, A. (1893), Pittura e Scultura in Piemonte 1842-1891. [Catálogo de la exposición retrospectiva celebrada en Turín en 1892]. Turín.

SUIDA, W. (1906), Genua. Leipzig.

Sullivan, E. J. (1989), Claudio Coello y la pintura barroca madrileña. Madrid, Nerea.

Tagliaferro, L. (1991a), Galleria di Palazzo Rosso. Génova, Sagep.

- (1991b), «I musei della Duchessa», en I Duchi di Galliera. Génova, Marietti, pp. 879-903.

- (1995), La magnificenza privata. Génova, Marietti. 
Tagliaferro, L., y C. Di Fabio (1991), Galleria di Palazzo Bianco. Guida. Génova, Comune di Genova.

TÀPIES, A. (1974), L'Art contra l'Estètica. Espluges de Llobregat, Ariel.

- (1995), Tàpies. Barcelona, Globos.

- y J. Á. VAlEnTE (2004), Comunicación sobre el muro. Barcelona, Ediciones de la Rosa Cúbica.

ThIEMe, U., y F. BECKer (1907-1954), Allgemeines Lexicon der bildenden Künstler. Leipzig.

TomÁs FerRÉ, F. (2006), Joaquín Sorolla. Madrid, TF Editores.

Torriti, P. (1963a), Il Palazzo Reale di Genova e la sua quadreria. Génova, Grifone.

- (1963b), La quadreria dell'Accademia Ligustica di Belle Arti in Genova. Génova, Sagep.

- (1967), La Galleria del Palazzo Durazzo Pallavicini a Genova. Génova, Sigla Effe.

- (1970), Tesori di Strada Nuova, la Via Aurea dei genovesi. Génova, Sagep.

- (1971), «Apporti toscani e lombardi», en Torriti y Castelnovi (eds.) (1971), vol. II, pp. 13-21.

- y G. V. Castelnovi (eds.) (1971), La pittura a Genova e in Liguria dal Seicento al primo Novecento. Génova, Sagep, 1971.

Trapier, E. Du Gué (1967), «Zurbaran's Processions of Virgin Martyrs», Apollo, mayo, pp. 414-419.

Trens, M. (1947), "La Virgen de los Dolores», Iconografía de la Virgen en el arte español. Madrid, Plus Ultra, pp. 223-232.

VAldivieso, E. (1986), Historia de la pintura sevillana. Sevilla, Guadalquivir.

Vargas Ugarte, R. (1956), Historia de culto de María, Madrid, vol. I, pp. 163191, 3. a edición.

VeCA, A. (1981), Vanitas. Il Simbolismo del tempo. Bérgamo.

Venturi, A. (1929), Note ad alcuni quadri del Museo Nazionale di Capodimonte, p. 209.

Vertova, L. (1992), «La Morte Secca», Mitteilungen des Kunsthistorische Institutes in Florenz, XXXVI, 1-2, pp. 103-128.

Viardot, L. (1839), Galerie Aguado. Choix des principaux tableaux de M. le Marquis de las Marismas del Guadalquivir. París, Gavard.

Vita e cultura cappuccina. Chiesa della SS. Concenzione a Genova. Génova, Sagep (Quaderni del Catalogo dei Beni Culturali, 1), 1984.

Walters, H. (¿1909?), The Walters Collection. Baltimore, n.o 736.

Wethey, H. E. (1955), Alonso Cano. Painter. Sculptor. Architect. Princeton (New Jersey), Princeton University Press. [Edición española: Alonso Cano. Pintor, escultor y arquitecto. Madrid, Alianza Forma, 1983]. 
Wethey, H. E. (1962), El Greco and his School. Princeton (New Jersey), Princeton University Press, 2 vols.

Zampetti, P. (1957), Jacopo Bassano. [Catálogo de la exposición celebrada en Venecia, del 29 de junio al 27 de octubre de 1957]. Venecia, Alfieri.

Zeri, F., y A. G. De Marchi (1997), La Spezia. Museo Civico Amadeo Lia. Dipinti. La Spezia. La Spezia, Amilcare Pizzi. 



\section{ÍNDICE}

Preámbulo ....................................................................................

Introducción. Estado de la cuestión ................................................ 15

\section{PARTE I. LA PINTURA ESPAÑOLA EN GÉNOVA}

1. La pintura española del siglo XVII en Génova ........................... 27

1.1. Valoración de la pintura española del Siglo de Oro y su dispersión ....................................................................

1.2. Estudio de las obras de pintura española del siglo XVII en

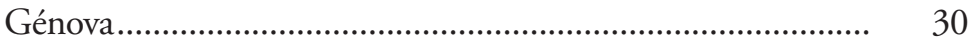

2. La pintura española del siglo XVIII en Génova .......................... 59

2.1. Consideraciones sobre la cultura artística de la segunda mitad del siglo XVIII en Liguria ........................................ 59

2.2. Un ilustrado en Liguria: Gerolamo Grimaldi .................... $\quad 60$

2.3. Estudio de las obras de pintura española del siglo XVIII en

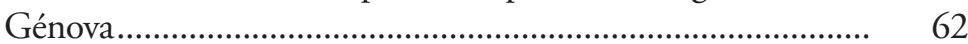

3. La pintura española del siglo XIX en Génova ............................. 65

3.1. Serafín Avendaño (Vigo, 1837-Valladolid, 1916) y el ambiente artístico ligur

3.2. Estudio de las obras de Serafín Avendaño ......................... 74

3.2.1. Estudio de las obras de Serafín Avendaño conservadas en museos genoveses

3.2.2. Estudio de las obras de Serafín Avendaño existentes en colecciones privadas genovesas 
3.3. Otro representante de la pintura española entre finales del siglo XIX e inicios del XX: Joaquín Sorolla y Bastida (Valencia, 1863-Cercedillo, Madrid, 1923).................................. 84

PARTE II. LA PINTURA ESPAÑOLA EN EL RESTO DE LIGURIA

1. La pintura española de los siglos XV-XVIII en el resto de Liguria 89

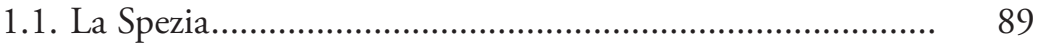

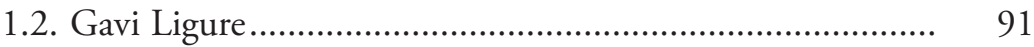

1.3. Chiusanico (Imperia) ....................................................... 91

2. La pintura española del siglo XIX en el resto de Liguria ............. 99

2.1. La producción pictórica de Serafín Avendaño en el resto de Liguria

2.1.1. Estudio de las obras de Serafín Avendaño conservadas en museos

2.1.2. Estudio de las obras de Serafín Avendaño existentes en colecciones privadas de Savona ......................... 100

3. La pintura española del siglo XX en el resto de Liguria .............. 103

3.1. Savona ........................................................................... 103

Conclusión ............................................................................. 105

CATÁlOGO I. LA PINTURA ESPAÑOLA EN GÉNOVA ........ 113

CATÁLOGO II. LA PINTURA ESPAÑOLA EN EL RESTO DE LIGURIA …......................................................................... 219

Bibliografía........................................................................... 255 
Este libro se terminó de imprimir en los talleres gráficos de INO Reproducciones, S. A. de Zaragoza, en diciembre de 2008 $\mathrm{BOCOS}$ 



\section{Títulos de la colección Humanidades}

1 Joaquín Lomba Fuentes, El oráculo de Narciso. (Lectura del Poema de Parménides) 2. ed. (1992).

2 Luis Fernández Cifuentes, Garcia Lorca en el Teatro: La norma y la diferencia (1986).

3 Ignacio Izuzquiza Otero, Henri Bergson: La arquitectura del deseo (1986).

4 Gabriel Sopeña Genzor, Dioses, ética y ritos. Aproximación para una comprensión de la religiosidad entre los pueblos celtibéricos (1987).

5 José Riquelme Otálora, Estudio semántico de purgare en los textos latinos antiguos (1987).

6 José Luis Rodríguez García, Friedrich Hölderlin. El exiliado en la tierra (1987).

7 José María Bardavío García, Fantasías uterinas en la literatura norteamericana (1988).

8 Patricio Hernández Pérez, Emilio Prados. La memoria del olvido (1988).

9 Fernando Romo Feito, Miguel Labordeta. Una lectura global (1988).

10 José Luis Calvo Carilla, Introducción a la poesía de Manuel Pinillos. Estudio y antología (1989).

11 Alberto Montaner Frutos, Política, historia y drama en el cerco de Zamora. La Comedia segunda de las mocedades del Cid de Guillén de Castro (1989).

12 Antonio Duplá Ansuategui, Videant consules. Las medidas de excepción en la crisis de la República Romana (1990).

13 Enrique Aletá Alcubierra, Estudios sobre las oraciones de relativo (1990).

14 Ignacio Izuzquiza Otero, Hegel o la rebelión contra el límite. Un ensayo de interpretación (1990).

15 Ramón Acín Fanlo, Narrativa o consumo literario (1975-1987) (1990).

16 Michael Shepherd, Sherlock Holmes y el caso del Dr. Freud (1990).

17 Francisco Collado Rodríguez (ed.), Del mito a la ciencia: la novela norteamericana contemporánea (1990).

18 Gonzalo Corona Marzol, Realidad vital y realidad poética. (Poesía y poética de José Hierro) (1991).

19 José Ángel García Landa, Samuel Beckett y la narración reflexiva (1992).

20 Ángeles Ezama Gil, El cuento de la prensa y otros cuentos. Aproximación al estudio del relato breve entre 1890 y 1900 (1992).

21 Santiago Echandi, La fábula de Aquiles y Quelone. Ensayos sobre Zenón de Elea (1993).

22 Elvira Burgos Díaz, Dioniso en la filosofía del joven Nietzsche (1993).

23 Francisco Carrasquer Launed, La integral de ambos mundos: Sender (1994).

24 Antonio Pérez Lasheras, Fustigat mores. Hacia el concepto de la sátira en el siglo XVII (1994).

25 M. ${ }^{a}$ Carmen López Sáenz, Investigaciones fenomenológicas sobre el origen del mundo social (1994).

26 Alfredo Saldaña Sagredo, Con esa oscura intuición. Ensayo sobre la poesía de Julio Antonio Gómez (1994).

27 Juan Carlos Ara Torralba, Del modernismo castizo. Fama y alcance de Ricardo León (1996).

28 Diego Aísa Moreu, El razonamiento inductivo en la ciencia y en la prueba judicial (1997). 
29 Guillermo Carnero, Estudios sobre teatro español del siglo XVIII (1997).

30 Concepción Salinas Espinosa, Poesía y prosa didáctica en el siglo XV: La obra del bachiller Alfonso de la Torre (1997).

31 Manuel José Pedraza Gracia, Lectores y lecturas en Zaragoza (1501-1521) (1998).

32 Ignacio Izuzquiza, Armonía y razón. La filosofía de Friedrich D. E. Schleiermacher (1998).

33 Ignacio Iñarrea Las Heras, Poesía y predicación en la literatura francesa medieval. El dit moral en los albores del siglo XIV (1998).

34 José Luis Mendivil Giró, Las palabras disgregadas. Sintaxis de las expresiones idiomáticas y los predicados complejos (1999).

35 Antonio Armisén, Jugar y leer. El Verbo hecho tango de Jaime Gil de Biedma (1999).

36 Abū ț-Tāhir, el Zaragozano, Las sesiones del Zaragocí. Relatos picarescos (maqāmāt) del siglo XII, estudio preliminar, traducción y notas de Ignacio Ferrando (1999).

37 Antonio Pérez Lasheras y José Luis Rodríguez (eds.), Inventario de ausencias del tiempo despoblado. Actas de las Jornadas en Homenaje a José Antonio Rey del Corral, celebradas en Zaragoza del 11 al 14 de noviembre de 1996 (1999).

38 J. Fidel Corcuera Manso y Antonio Gaspar Galán, La lengua francesa en España en el siglo XVI. Estudio y edición del Vocabulario de los vocablos de Jacques de Liaño (Alcalá de Henares, 1565) (1999).

39 José Solana Dueso, El camino del ágora. Filosofia política de Protágoras de Abdera (2000).

40 Daniel Eisenberg y M. ${ }^{a}$ Carmen Marín Pina, Bibliografia de los libros de caballerías castellanos (2000).

41 Enrique Serrano Asenjo, Vidas oblicuas. Aspectos históricos de la nueva biografía en España (192-1936) (2002).

42 Daniel Mesa Gancedo, Extraños semejantes. El personaje artificial y el artefacto narrativo en la literatura hispanoamericana (2002).

43 María Soledad Catalán Marín, La escenografía de los dramas románticos españoles (1834-1850) (2003).

44 Diego Navarro Bonilla, Escritura, poder y archivo. La organización documental de la Diputación del reino de Aragón (siglos XV-XVIII) (2004).

45 Ángel Longás Miguel, El lenguaje de la diversidad (2004).

46 Niall Binns, ¿Callejón sin salida? La crisis ecológica en la poesía hispanoamericana (2004).

47 Leonardo Romero Tobar (ed.), Historia literaria / Historia de la literatura (2004).

48 Luisa Paz Rodríguez Suárez, Sentido y ser en Heidegger. Una aproximación al problema del lenguaje (2004).

49 Evanghélos Moutsopoulos, Filosofía de la cultura griega, traducción de Carlos A. Salguero-Talavera (2004).

50 Isabel Santaolalla, Los «Otros». Etnicidady «raza» en el cine español contemporáneo (2005).

51 René Andioc, Del siglo XVIII al XIX. Estudios histórico-literarios (2005).

52 María Isabel Sepúlveda Sauras, Tradición y modernidad: Arte en Zaragoza en la década de los años cincuenta (2005).

53 Rosa Tabernero Sala, Nuevas y viejas formas de contar. El discurso narrativo infantil en los umbrales del siglo XXI (2005). 
54 Manuel Sánchez Oms, L'Écrevisse écrit: la obra plástica (2006).

55 Agustín Faro Forteza, Películas de libros (2006).

56 Rosa Tabernero Sala, José D. Dueñas Lorente y José Luis Jiménez Cerezo (coords.), Contar en Aragón. Palabra e imagen en el discurso literario infantil y juvenil (2006).

57 Chantal Cornut-Gentille, El cine británico de la era Thatcher. ¿Cine nacional o «nacionalista»? (2006).

58 Fernando Alvira Banzo, Martín Coronas, pintor (2006).

59 Iván Almeida y Cristina Parodi (eds.), El fragmento infinito. Estudios sobre "Tlön, Uqbar, Orbis Tertius" de J. L. Borges (2007).

60 Pedro Benítez Martín, La formación de un francotirador solitario. Lecturas filosóficas de Louis Althusser (1945-1965) (2007).

61 Juan Manuel Cacho Blecua (coord.), De la literatura caballeresca al Quijote (2007).

62 José Julio Martín Romero, Entre el Renacimiento y el Barroco: Pedro de la Sierra y su obra (2007).

63 M. a del Rosario Álvarez Rubio, Las historias de la literatura española en la Francia del siglo XIX (2007).

64 César Moreno, Rafael Lorenzo y Alicia M. a de Mingo (eds.), Filosofía y realidad virtual (2007).

65 Luis Beltrán Almería y José Luis Rodríguez Garcia (coords.), Simbolismo y hermetismo. Aproximación a la modernidad estética (2008).

66 Juan Antonio Tello, La mirada de Quirón. Literatura, mito y pensamiento en la novela de Félix de Azúa (2008).

67 Manuela Aguado Catalán, El Romanticismo en Aragón (1838-1854). Literatura, prensa y sociedad (2008).

68 Gonzalo Navajas, La utopía en las narrativas contemporáneas (Novela/Cine/Arquitectura) (2008).

69 Leonardo Romero Tobar (ed.), Literatura y nación. La emergencia de las literaturas nacionales (2008). 
n las cuatro provincias que constituyen la región italiana de Liguria (Imperia, Savona, Génova y La Spezia) se conservan numerosas obras de pintores españoles o atribuidas. En este libro se lleva a cabo un examen pormenorizado de dichas obras, que se sitúan cronológicamente entre los siglos xv y xx y que corresponden a artistas como Ribera, Zurbarán, Murillo, el Greco, Serafín Avendaño, Sorolla, Tàpies, José Ortega o Eduardo Arroyo, entre otros. En la primera parte se analizan las vías de llegada y se valoran en el contexto general de la pintura española y en el más específico de su influencia en la pintura ligur. El estudio se realiza distinguiendo las obras conservadas en museos de las existentes en colecciones particulares, tanto de la ciudad de Génova como del resto de Liguria. En la segunda parte se catalogan un total de 70 obras, de cada una de las cuales se ofrece una completa ficha técnica acompañada de la ilustración respectiva.

El presente libro pretende dar a conocer este rico patrimonio artistico, que por diferentes motivos se encuentra disperso fuera de España, y dejar constancia de las intensas relaciones culturales y artisticas que desde época medieval han existido entre Liguria y nuestro país. 